\title{
Prediction of External Corrosion for Steel Cylinders-2007 Report
}

November 2007

Rick Schmoyer

Oak Ridge National Laboratory 
This report has been reproduced directly from the best available copy.

Available to DOE and DOE contractors from the Office of Scientific and Technical Information, P.O. Box 62, Oak Ridge, TN 37831; prices available from 845-576-8401, FTS 626-8401.

Available to the public from the National Technical Information Service, U.S. Department of Commerce, 5285 Port Royal Rd., Springfield, VA 22161.

This report was prepared as an account of work sponsored by an agency of the United States Government. Neither the United States Government nor any agency thereof, nor any of their employees, makes any warranty, express or implied, or assumes any legal liability or responsibility for the accuracy, completeness, or usefulness of any information, apparatus, product, or process disclosed, or represents that its use would not infringe privately owned rights. Reference herein to any specific commercial product, process, or service by trade name, trademark, manufacturer, or otherwise, does not necessarily constitute or imply its endorsement, recommendation, or favoring by the United States Government or any agency thereof. The views and opinions of authors expressed herein do not necessarily state or reflect those of the United States Government or any agency thereof. 


\title{
PREDICTION OF EXTERNAL CORROSION \\ FOR STEEL CYLINDERS-2007 REPORT
}

Rick Schmoyer

Oak Ridge National Laboratory

November 2007

\author{
Prepared for \\ U.S. Department of Energy \\ Office of Environmental Restoration and Waste Management \\ under budget and reporting code EW 20
}

Prepared by

OAK RIDGE NATIONAL LABORATORY

P.O. Box 2008

Oak Ridge, Tennessee 37831-6054

managed by

UT-Battelle, LLC

for the

U.S. DEPARTMENT OF ENERGY

under contract DE-AC05-00OR22725 

TABLE OF CONTENTS

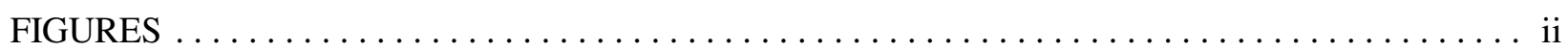

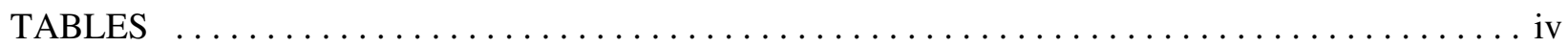

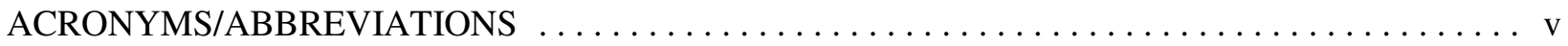

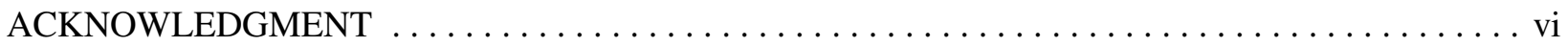

EXECUTIVE SUMMARY $\ldots \ldots \ldots \ldots \ldots \ldots \ldots \ldots \ldots \ldots \ldots \ldots \ldots \ldots \ldots \ldots$ vii

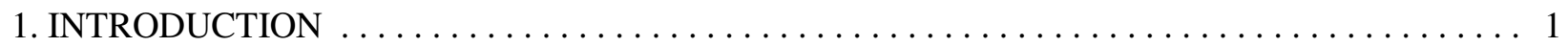

2. APPROACHES TO MODELING CYLINDER WALL THICKNESS $\ldots \ldots \ldots \ldots \ldots \ldots \ldots \ldots \ldots$

2.1. The Basic Problem and Approaches $\ldots \ldots \ldots \ldots \ldots \ldots \ldots \ldots \ldots \ldots \ldots \ldots \ldots$

2.2. Maximum Pit Depth (Indirect) Model $\ldots \ldots \ldots \ldots \ldots \ldots \ldots \ldots \ldots \ldots \ldots \ldots \ldots \ldots \ldots \ldots \ldots$

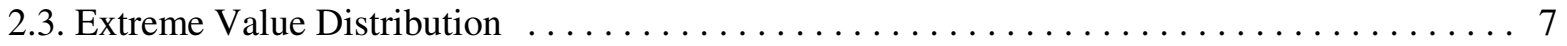

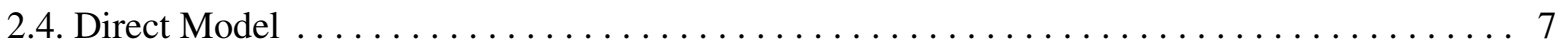

2.5. Rare Events and Small Sample Sizes $\ldots \ldots \ldots \ldots \ldots \ldots \ldots \ldots \ldots \ldots \ldots \ldots$

3. ULTRASONIC THICKNESS DATA AND CID DATA $\ldots \ldots \ldots \ldots \ldots \ldots \ldots \ldots \ldots \ldots \ldots$

3.1. Data Sources, Types, and Collection Procedures $\ldots \ldots \ldots \ldots \ldots \ldots \ldots \ldots \ldots \ldots \ldots$

3.3. Data Inventory by Functional Group $\ldots \ldots \ldots \ldots \ldots \ldots \ldots \ldots \ldots \ldots \ldots \ldots \ldots \ldots \ldots \ldots$

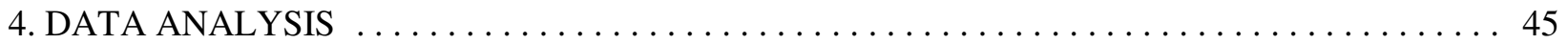

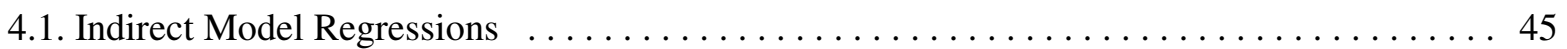

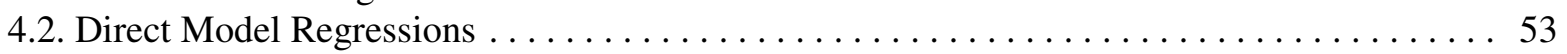

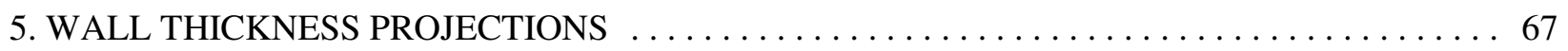

6. MODEL CHECKS AND VALIDATION $\ldots \ldots \ldots \ldots \ldots \ldots \ldots \ldots \ldots \ldots \ldots \ldots \ldots \ldots \ldots$

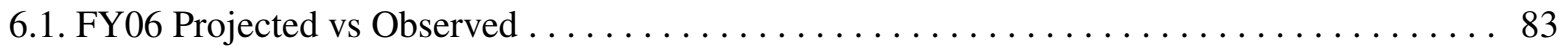

6.3. Statistical Assessment of the Choice of Functional Groups . . . . . . . . . . . . . . 87

7. CONCLUSIONS, LIMITATIONS, RECOMMENDATIONS $\ldots \ldots \ldots \ldots \ldots \ldots \ldots \ldots \ldots$

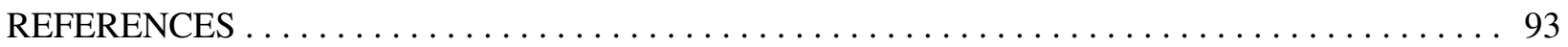




\section{FIGURES}

Figure 1. Age and unpainted age distributions for ETTP thin K-yard bottom cylinders $\ldots \ldots \ldots \ldots$

Figure 2. Age and unpainted age distributions for ETTP thin cylinders except K-yard bottom . . . . . 15

Figure 3. Age and unpainted age distributions for PGDP thin bottom former G-yard cylinders . . . . 16

Figure 4. Age and unpainted age distributions for PGDP thin bottom cylinders except former G-yard . 16

Figure 5. Age and unpainted age distributions for PGDP thin top cylinders $\ldots \ldots \ldots \ldots \ldots \ldots$

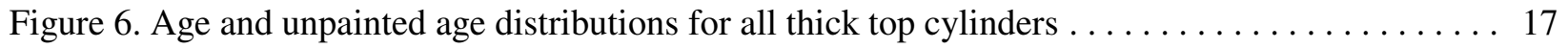

Figure 7. Age and unpainted age distributions for all thick bottom cylinders $\ldots \ldots \ldots \ldots \ldots \ldots$

Figure 8. Age and unpainted age distributions for all thin top cylinders, head/skirt interface $\ldots \ldots \ldots 18$

Figure 9. Age and unpainted age distributions for all thin bottom cylinders, head/skirt interface . . . 19

Figure 10. Age and unpainted age distributions for all thick cylinders, head/skirt interface . . . . . 19

Figure 11. Age and unpainted age distributions for Portsmouth thin top cylinders $\ldots \ldots \ldots \ldots \ldots$

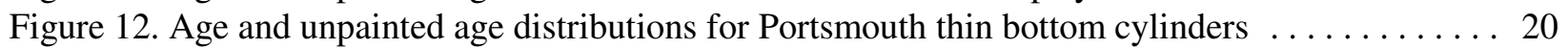

Figure 13. Age and unpainted age distributions for all 30A top cylinders $\ldots \ldots \ldots \ldots \ldots \ldots \ldots 21$

Figure 14. Age and unpainted age distributions for all 30A bottom cylinders $\ldots \ldots \ldots \ldots \ldots \ldots 21$

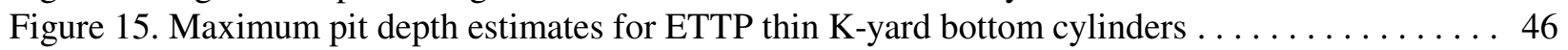

Figure 16. Maximum pit depth estimates for ETTP thin cylinders except K-yard bottom . . . . . . . 46

Figure 17. Maximum pit depth estimates for PGDP thin bottom former G-yard cylinders . . . . . . 47

Figure 18. Maximum pit depth estimates for PGDP thin bottom cylinders except former G-yard . . . . 47

Figure 19. Maximum pit depth estimates for PGDP thin top cylinders $\ldots \ldots \ldots \ldots \ldots \ldots \ldots \ldots 48$

Figure 20. Maximum pit depth estimates for all thick top cylinders $\ldots \ldots \ldots \ldots \ldots \ldots \ldots \ldots \ldots 48$

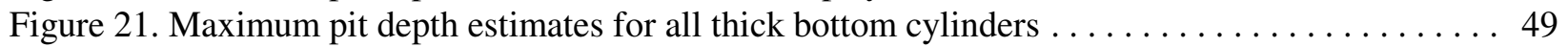

Figure 22. Maximum pit depth estimates for all thin top cylinders, head/skirt interface . . . . . . . 49

Figure 23. Maximum pit depth estimates for all thin bottom cylinders, head/skirt interface . . . . . 50

Figure 24. Maximum pit depth estimates for all thick cylinders, head/skirt interface $\ldots \ldots \ldots \ldots .50$

Figure 25. Maximum pit depth estimates for Portsmouth thin top cylinders $\ldots \ldots \ldots \ldots \ldots \ldots \ldots 1$

Figure 26. Maximum pit depth estimates for Portsmouth thin bottom cylinders $\ldots \ldots \ldots \ldots \ldots \ldots 1$

Figure 27. Maximum pit depth estimates for all 30A top cylinders $\ldots \ldots \ldots \ldots \ldots \ldots \ldots \ldots \ldots 52$

Figure 28. Maximum pit depth estimates for all 30A bottom cylinders $\ldots \ldots \ldots \ldots \ldots \ldots \ldots \ldots 2$

Figure 29. The direct-model regression residuals $\ldots \ldots \ldots \ldots \ldots \ldots \ldots \ldots \ldots \ldots \ldots \ldots \ldots$

Figure 30 . The distribution of the regression residuals with the nine outliers removed ....... 58

Figure 31. Direct-model predicted and observed (UT-measured) minimum wall thicknesses for ETTP thin

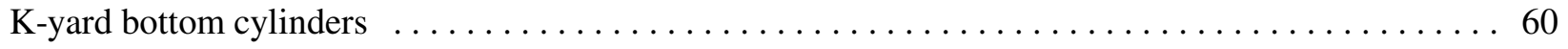

Figure 32. Direct-model predicted and observed (UT-measured) minimum wall thicknesses for ETTP thin

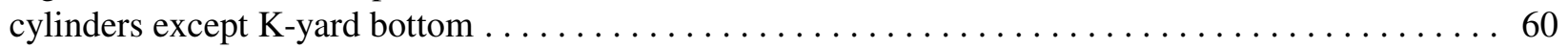

Figure 33. Direct-model predicted and observed (UT-measured) minimum wall thicknesses for PGDP thin

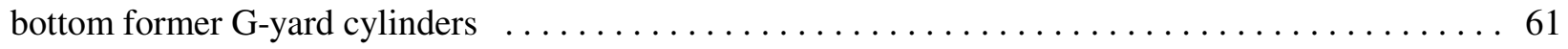
Figure 34. Direct-model predicted and observed (UT-measured) minimum wall thicknesses for PGDP thin

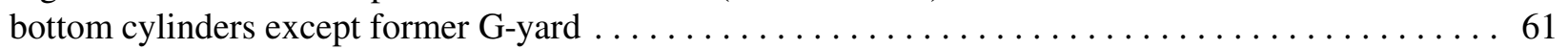
Figure 35. Direct-model predicted and observed (UT-measured) minimum wall thicknesses for PGDP thin

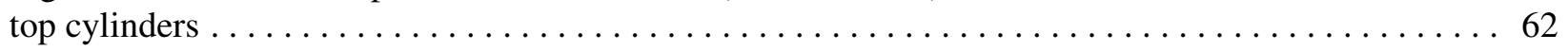
Figure 36. Direct-model predicted and observed (UT-measured) minimum wall thicknesses for all thick top

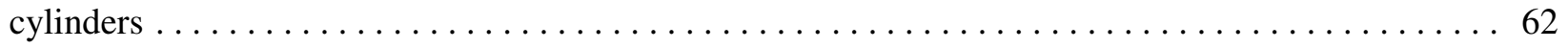
Figure 37. Direct-model predicted and observed (UT-measured) minimum wall thicknesses for all thick

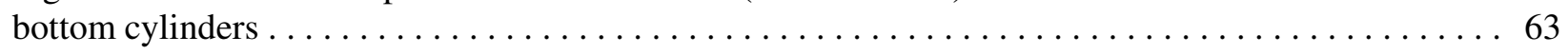
Figure 38. Direct-model predicted and observed (UT-measured) minimum wall thicknesses for all thin top

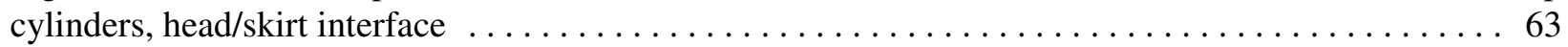
Figure 39. Direct-model predicted and observed (UT-measured) minimum wall thicknesses for all thin

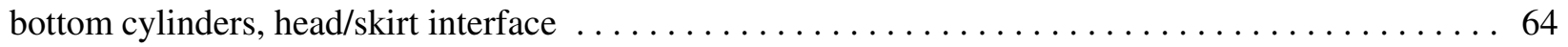
Figure 40. Direct-model predicted and observed (UT-measured) minimum wall thicknesses for all thick

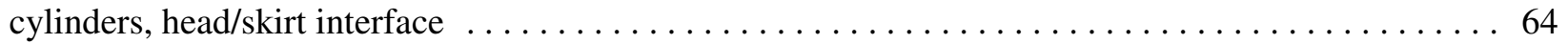
Figure 41. Direct-model predicted and observed (UT-measured) minimum wall thicknesses for Portsmouth 


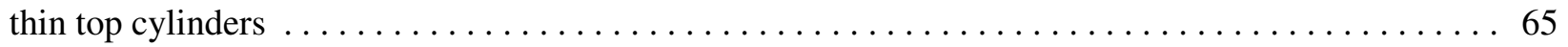
Figure 42. Direct-model predicted and observed (UT-measured) minimum wall thicknesses for Portsmouth

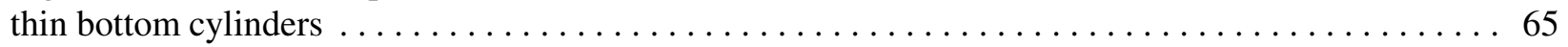
Figure 43. Direct-model predicted and observed (UT-measured) minimum wall thicknesses for all 30A top

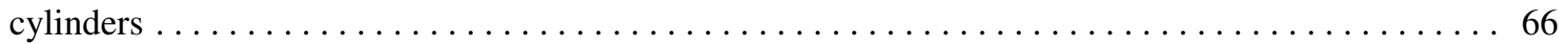
Figure 44. Direct-model predicted and observed (UT-measured) minimum wall thicknesses for all 30A

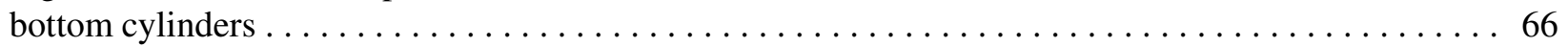
Figure $45.95 \%$ confidence intervals for the $B G$ parameter estimates for the 12 functional groups . . . 88 


\section{TABLES}

Table E1. Numbers of Cylinders with UT Measurements Made After FY03 (New for This Report)* . viii Table 1. CID Counts by Site and Cylinder Thickness Type (Cylinders of Known Age) . . . . . . . 12

Table 2A. Cylinder Functional Groups for Main Body UT Measurements . . . . . . . . . . 13

Table 2B. Cylinder Functional Groups for Head/Skirt Interface UT Measurements . . . . . . . . 13 Table 3A. Manual UT Main-Body Minimum Thickness Measurements By Fiscal Year and Site of

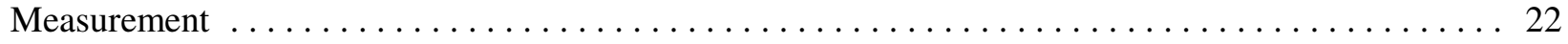

Table 3B. Manual UT Head/Skirt Interface Minimum Thickness Measurements (At Portsmouth) By Fiscal

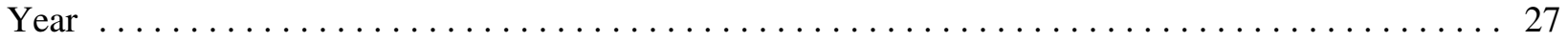
Table 3C. P-Scan Main-Body Minimum Thickness Measurements By Fiscal Year and Site of Measurement

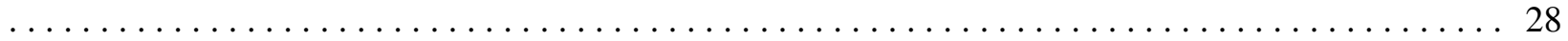
Table 4A. Manual UT Main-Body Minimum Thickness Measurements By Site-Specific Functional Group

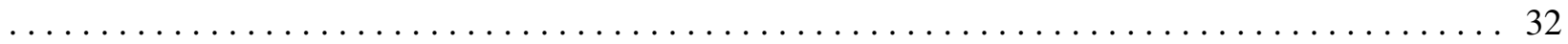
Table 4B. Manual UT Head/Skirt Interface Minimum Thickness Measurements By Site-Specific Functional

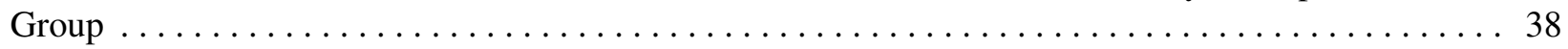
Table 4C. P-Scan Main-Body Minimum Thickness Measurements By Site-Specific Functional Group ...

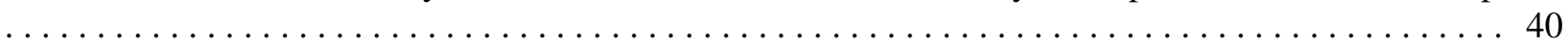

Table 4D. Site-Specific Functional Groups Having No UT Measurement Data . . . . . . . . . . . 42

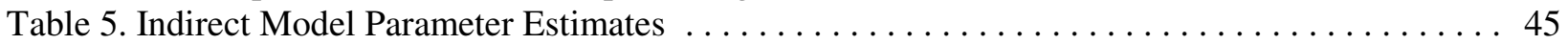

Table 6. Standard Deviations of Direct-Model Weighted Residuals $\ldots \ldots \ldots \ldots \ldots \ldots \ldots \ldots \ldots 5$

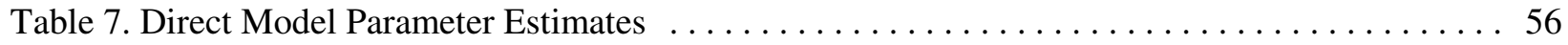

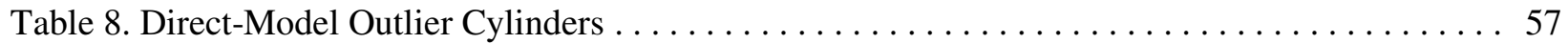

Table 9. Direct Model Parameter Estimates After Excluding Outliers . . . . . . . . . . . . . . . . . 59 Table 10. Direct-Model Projections for Various Target Years and Thickness Specs, Outlier Cylinders

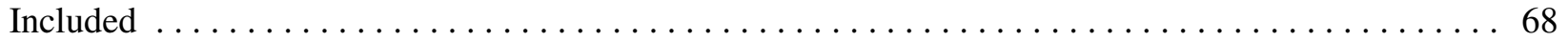
Table 11. Direct-Model Projections for Various Target Years and Thickness Specs, Outlier Cylinders

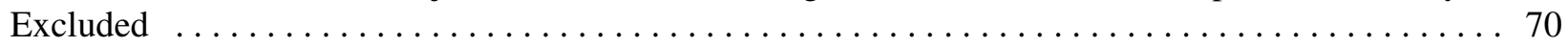

Table 12. Direct-Model Failure Rate Estimates for Target Years and Thickness Specs, Outlier Cylinders

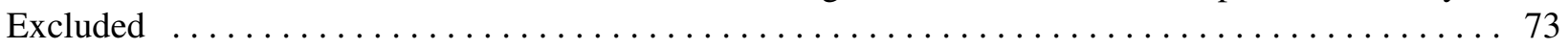
Table 13. Projections by Age and Functional Group of the 2010 Risk of Failing the 62.5 Mil Thickness Spec,

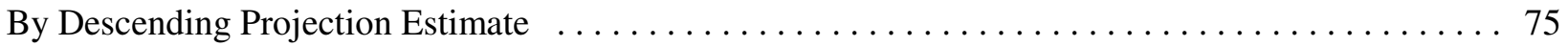
Table 14. Projections for FY06 Based Only on UT Measurements Made Before FY06, Outliers Excluded*

Table 15. Original Thickness Estimates and Corresponding Direct Model Estimates (All Values in Mils)

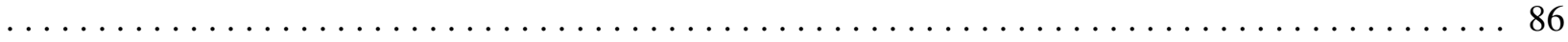

Table16. Functional Group and "Supergroup" Comparison Tests . . . . . . . . . . . . . . . . 89 


\section{ACRONYMS/ABBREVIATIONS}

$\begin{array}{ll}\text { ANSI } & \text { American National Standards Institute } \\ \text { BJC } & \text { Bechtel Jacobs Company, LLC } \\ \text { CID } & \text { Cylinder Inventory Database } \\ \text { DOE } & \text { Department of Energy } \\ \text { DUF }_{6} & \text { Depleted uranium hexafluoride } \\ \text { ETTP } & \text { East Tennessee Technology Park } \\ \text { FY } & \text { Fiscal Year } \\ \text { LCL } & \text { Lower confidence limit } \\ \text { mil } & \text { 0.001 inch } \\ \text { ORNL } & \text { Oak Ridge National Laboratory } \\ \text { PGDP } & \text { Paducah Gaseous Diffusion Plant } \\ \text { PORTS } & \text { Portsmouth Gaseous Diffusion Plant } \\ \text { SEMP } & \text { System Engineering Management Plan } \\ \text { SRD } & \text { System Requirements Document } \\ \text { UDS } & \text { Uranium Disposition Services, LLC } \\ \text { UF } & \text { Uranium hexafluoride } \\ \text { UCL } & \text { Upper confidence limit } \\ \text { UT } & \text { Ultrasonic thickness }\end{array}$




\section{ACKNOWLEDGMENT}

The author would like to thank Dr. Steven J. Pawel, Materials Science \& Technology Division, Oak Ridge National Laboratory, and Dr. C. Phillip McGinnis, Nuclear Science \& Technology Division, Oak Ridge National Laboratory, for carefully reviewing this report and for many helpful suggestions. 


\section{EXECUTIVE SUMMARY}

Depleted uranium hexafluoride $\left(\mathrm{DUF}_{6}\right)$ is stored in over 62,000 containment cylinders at the Paducah Gaseous Diffusion Plant (PGDP) in Paducah, Kentucky, and at the Portsmouth Gaseous Diffusion Plant (PORTS) in Portsmouth, Ohio. Over 4,800 of the cylinders at Portsmouth were recently moved there from the East Tennessee Technology Park (ETTP) in Oak Ridge, Tennessee. The cylinders range in age up to 56 years and come in various models, but most are 48-inch diameter "thin-wall"(312.5 mil) and "thick-wall" (625 mil) cylinders and 30-inch diameter "30A" (including "30B") cylinders with 1/2" (500 mil) walls. Most of the cylinders are carbon steel, and they are subject to corrosion.

The United States Department of Energy (DOE) manages the cylinders to maintain them and the DUF 6 they contain. Cylinder management requirements are specified in the System Requirements Document (LMES 1997a), and the activities to fulfill them are specified in the System Engineering Management Plan (LMES 1997b). This report documents activities that address DUF $_{6}$ cylinder management requirements involving measuring and forecasting cylinder wall thicknesses.

As part of these activities, ultrasonic thickness (UT) measurements are made on samples of cylinders. For each sampled cylinder, multiple measurements are made in an attempt to find, approximately, the minimum wall thickness. Some cylinders have a skirt, which is an extension of the cylinder wall to protect the head (end) and valve. The head/skirt interface crevice is thought to be particularly vulnerable to corrosion, and for some skirted cylinders, in addition to the main body UT measurements, a separate suite of measurements is also made at the head/skirt interface. The main-body and head/skirt minimum thickness data are used to fit models relating minimum thickness to cylinder age, nominal thicknesses, and cylinder functional groups defined in terms of plant site, storage yard, top or bottom row storage positions, etc. These models are then used to compute projections of numbers of cylinders expected to fail various minimum wall thickness criteria.

The minimum wall thickness criteria are as follows. For thin-wall cylinders: 0 (breach), 62.5, and 250 mils. For thick-wall cylinders: 0, 62.5, and 500 mils. For 30A cylinders: 0, 62.5, and 100 mils. Each of these criteria triplets are based respectively on (1) loss of $\mathrm{DUF}_{6}$ (breaching), (2) safe handling and stacking operations, and (3) ANSI N14.1 standards for off-site transport and contents transfer.

This report complements and extends previous editions of the cylinder corrosion report by Lyon (1995, 1996, 1997, 1998, 2000), by Schmoyer and Lyon (2001, 2002, 2003), and by Schmoyer (2004). These reports are based on UT data collected in FY03 and before. In this report UT data collected after FY03 but before FY07 is combined with the earlier data, and all of the UT data is inventoried chronologically and by the various functional groups. The UT data is then used to fit models of maximum pit depth and minimum wall thickness, statistical outliers are investigated, and the fitted models are used to extrapolate minimum thickness estimates into the future and in turn to compute projections of numbers of cylinders expected to fail various thickness criteria. A model evaluation is performed comparing UT measurements made after FY05 with model-fitted projections based only on data collected in FY05 and before. As in previous reports, the projections depend on the treatment of outliers.

Because cylinders are selected for UT measurement by random or approximately random methods, the projections based on the UT data apply to the entire target population of DOE DUF6 cylinders now stored at PGDP and Portsmouth-with several exceptions: According to the cylinder inventory database (CID), as of November 12, 2007, there were 63,589 cylinders at the two sites. Of the 63,589, however, 946 cylinders are nickel or monel and not subject to external corrosion, 32 cylinders are of unknown material type, 170 are model $10 \mathrm{~A}, 8 \mathrm{H}$, or $8 \mathrm{~S}$ cylinders, for which no UT measurements have ever been taken, and 3 cylinders were delivered after FY06. These cylinders are excluded from the target population, leaving a population of 62,438 cylinders. 
Of the 62,438 cylinders in the target population, $92.7 \%$ are thin-wall cylinders, $3.2 \%$ are thick-wall cylinders, and $4.1 \%$ are $30 \mathrm{~A}$ cylinders. Except for the $30 \mathrm{~A}$ cylinders, the ages of the cylinders are known at least approximately for all but 24 cylinders (23 thick-wall and one thin-wall). Delivery dates of all but a few of the 30A cylinders are unknown and are taken by assumption to be 1954 . The other 24 cylinders with unknown delivery dates are assumed to have been delivered in 1951 (and thus to be as old as any in the target population). As none of the 24 were ever among cylinders sampled for UT measurement, they are used for population projections but not for model fitting. Because there are only 24 of these (of which 23 are thick-wall cylinders), the assumption that they are essentially as old as possible is only very slightly conservative (pessimistic).

UT measurements were made after FY03 (new for this report) on 1,108 thin-wall, thick-wall, and 30A cylinders. Table E1 gives counts of these cylinder by fiscal year and site. Most of the ETTP UT measurements were made in preparation for the transfer of cylinders from ETTP to Portsmouth but are nevertheless similar to other UT measurements made earlier at ETTP and at the other sites. Cylinders measured at both ETTP and PGDP were mostly thin-wall models with relatively fewer 30A models. Cylinders measured at Portsmouth were thin-wall and relatively fewer thick-wall models. In addition to the main-body measurement, minimum thicknesses at the head-skirt interface were estimated for 180 cylinders at Portsmouth.

\section{Table E1. Numbers of Cylinders with UT Measurements Made After FY03 (New for This Report)*}

\begin{tabular}{|c|c|c|c|c|c|}
\hline Fiscal Year & ETTP & PGPD & PORTS & All Sites & $\begin{array}{c}\text { Head/Skirt } \\
\text { Interface } \\
\text { (PORTS only) }\end{array}$ \\
\hline $\mathbf{2 0 0 4}$ & 199 & 94 & 152 & $\mathbf{4 4 5}$ & 113 \\
\hline $\mathbf{2 0 0 5}$ & 140 & 69 & 155 & $\mathbf{3 6 4}$ & 38 \\
\hline $\mathbf{2 0 0 6}$ & 47 & $100 * *$ & 152 & $\mathbf{2 9 9}$ & 29 \\
\hline $\mathbf{2 0 0 4 - 0 6}$ & $\mathbf{3 8 6}$ & $\mathbf{2 6 3}$ & $\mathbf{4 5 9}$ & $\mathbf{1 , 1 0 8}$ & $\mathbf{1 8 0}$ \\
\hline
\end{tabular}

*Excludes measurements made on 33 "CV" model cylinders, which are nickel.

***Measurements included with FY06 data but actually made between October 23 and November 3, 2006.

In addition to incorporating this substantial amount of new UT data, this edition of the cylinder corrosion report differs from previous editions in the treatment of painted cylinders. In previous editions of the report, cylinders identified as painted were simply excluded from functional groups considered at-risk of failing minimum thickness criteria. For this report, cylinders ages are adjusted to "unpainted ages," that is, the times the cylinders existed in an unpainted condition, where a painted condition is assumed to last ten years after painting. Although still an approximation, this treatment is better than excluding them.

This edition of the cylinder corrosion report also differs from previous editions in that two simplifications have been made in the analysis. Both simplifications are consistent with recommendations made in the 2004 edition and allow for a clearer (though somewhat shorter) exposition. In previous editions of the report, automatic P-scan data (collected before FY98) was included but, because of unresolved bias issues, was essentially disregarded in the analysis. In this edition, the P-scan data is handled simply by referring to the previous editions. 
The other simplification is in the modeling process. In previous editions of the report, two corrosion models have been considered in parallel: a direct model, in which minimum wall thickness is modeled directly as a function of cylinder age and grouping characteristics (i.e., site, cylinder model, etc.), and an indirect model in which estimated maximum pit depth is modeled as a function of the same predictors. However, the indirect model has given generally unsatisfactory results in that estimates of model parameters have been outside admissible ranges (suggesting, for example, that wall thickness might increase with age). In this edition of the report the indirect model is still fit, but only to establish that its estimates are once again unreasonable. The indirect model is pursued no further in the report. Projections of cylinder thickness in the future are based on the direct model, as in previous editions.

Also new for this report is that nominal thicknesses rather than original thickness estimates are used as predictors in the direct regression model. Nominal thicknesses are preferable to original thickness estimates because regression predictors are assumed to be fixed (not random) and independent of the regression dependent variable (minimum thickness). This condition holds for the nominal thicknesses but not original thickness estimates. However, as a validation check, the original thickness estimates as previously computed are now compared to corresponding estimates based on the fitted model. The two sets of estimates do tend to agree.

In addition to the validation checks based on original thickness, other validations checks on the fitted corrosion model include a comparison of FY06 UT measurement results with FY06 forecasts based only on UT data collected before FY06. Yet another validation check is an investigation of cylinder functional group differences, which supports the cylinder grouping system used in the analysis.

As in previous editions of the report, statistical outliers are identified in the analysis, and the modelbased projections differ depending on whether outliers are included in the analysis. Nine outliers are identified in the analysis. As in previous editions, projections with the outliers included in the analysis seem too conservative. Furthermore, remeasurements in FY03 of several thin-wall cylinders with outlier minimum thicknesses (as identified in the 2003 corrosion report) did not confirm their original measurements. This suggests that the nine outlier cylinders should be remeasured (or investigated and explained on a case by case basis). Projections in this report are computed both with and again without these nine outliers.

According to the direct-model rate projections, the cylinders most likely to fail either the breach or 62.5 mil criteria are the 30A cylinders, both top and bottom rows. Because of both lower (i.e., more negative) log-age coefficient estimates for the 30As and greater variability of the 30A cylinder minimum UT measurements, the risk estimates for the 30A functional groups are higher than for the thin-wall cylinders. The functional groups with the next highest risk estimates are the thin-wall cylinders from ETTP K-yard bottom rows followed by the other ETTP thin-wall cylinders.

When the nine outliers are included in the analysis, the direct model predicts a few failures of the breach and 62.5 mil thickness criteria. After the outliers are excluded, the direct model projections are at the model's limit of resolution, which (in a sense discussed in the report) is the smallest number of thickness failures the direct model can predict. Thus, the direct-model projections are consistent with the hypothesis of zero breaches for all of the years 2005-2025 with the exception of 2025 for the 30A cylinders (either top or bottom rows), for which, according to the model, one breach (on average) is expected. For the 62.5 mil criteria, the projections are consistent with no failures for all years and all groups except the 30As. Note also that because of the resolution limit, however, failures are not ruled out.

In addition to functional grouping, cylinder age has an important and statistically significant effect on the corrosion process. Older cylinders are of greater concern. Therefore risk estimate tables are presented in the report that at are both age and functional-group specific. These tables should also be considered in cylinder management. 
The following limitations should be kept in mind when considering this report: (1) UT minimum thicknesses are only estimates of actual minimum thicknesses because the thinnest points on each cylinder are not necessarily found in the measurement process. (2) Storage (e.g., ground contact) conditions have changed over the years for many cylinders. (3) Implicit in the modeling approach is an assumption of age invariance- that newer or older cylinders alike tend to have similar corrosion when they are the same age. This assumption could fail because of generally improved cylinder storage conditions and could thus lead to overestimation of the effect of age on corrosion. (4) Environmental changes such as increased acid rain are not accounted for in the model. (5) Cylinder sampling was not always random. Inspection is one reason for making the cylinder UT measurements, and inspection sampling tends to focus on cylinders with poorer conditions. This would lead to a more pessimistic assessment of overall conditions of cylinders than random sampling for the express purpose of characterization. (6) Literature about the atmospheric corrosion of steel might not directly apply to cylinder corrosion modeling, for example because of the thermal inertia of the cylinders.

Corrosion projections made in this report are based on analyses that account for cylinder functional groups, ages, and nominal thicknesses. However, a myriad of other variables are not accounted for. Examples include how many use cycles the cylinders went through, how many nicks and scrapes they suffered, and the nature of surface coatings, now perhaps long gone. There are variations in how the UT measurements were made over the years of data collection. Functional group membership is sometimes only known approximately and in a some cases (e.g., 30As) even cylinder ages are approximations. Because of these extraneous sources of variation and other approximations, corrosion physics is blurred in the statistical noise. Thickness measurements vary widely about their model-based predictions. In this context, because there is not a definitive corrosion model based on chemistry and physics, it does not make sense to try to resolve fine differences between either the deterministic or stochastic components of plausible candidate models. Rather, it is better to focus on general model behavior and on data quality and quantity, so that laws-of-large numbers will allow a general corrosion signal to be resolved from the statistical noise.

The main recommendations of this report are as follows:

- The projections in this report are based on the assumption that historical trends will continue. However, cylinder maintenance is not static. Storage yards have been improved. Cylinders have been moved and restacked. Cylinders have been painted. Although the statistical assessment in this report does not point to a need for redefining the cylinder functional grouping, an engineering assessment might. Particularly in view of the imminent conversion processing, the functional grouping used to classify cylinders should be reconsidered, in addition, from an operational perspective.

- Nine cylinders with UT measurements identified in this report as direct-model outliers substantially influence the corrosion projections. Those cylinders should be remeasured (or explained) to confirm or correct their thickness measurements.

- With the nine outlier cylinders excluded from the analysis, projections are consistent with the hypothesis of zero breaches for all of the years 2005-2025 with the exception of 2025 for the 30A cylinders (either top or bottom rows), for which one breach (on average) is expected. For the 62.5 mil criteria, the projections are consistent with no failures for all years and all groups except the 30As. When the nine outliers are included in the analysis, the model predicts a few failures of the breach and 62.5 mil thickness criteria.

- Cylinder maintenance, sampling, and conversion/disposition schedules should be prioritized in terms of the risk estimates in this report. Both cylinder age and functional group differences affect projections about risk or, equivalently, years of service life. Oldest cylinders from the riskiest functional groups should be processed first. 
- Similarly, because of the dual objectives of inspection and characterization in cylinder sampling, sampling for future UT measurements should be weighted toward riskier cylinders. In the past, sampling has tended to focus more heavily on riskier functional groups, though not necessarily on older cylinders within the riskier groups. Particularly now with a clearer cylinder disposition schedule, the service lives of most cylinders need only extend for a few more years. Sampling plans can now focus on characterizing percentages of cylinders that are acceptable, rather than on determining the relationship between minimum thickness and functional group and age. Through the use of sampling weights, plans can be designed to preferentially sample riskier cylinders while still admitting (through the weights) unbiased estimates with valid confidence intervals. The analysis in this report can be used as a basis for sampling weights. 


\section{INTRODUCTION}

Depleted uranium hexafluoride $\left(\mathrm{DUF}_{6}\right)$ is stored in over 62,000 containment cylinders at the Paducah Gaseous Diffusion Plant (PGDP) in Paducah, Kentucky, and at the Portsmouth Gaseous Diffusion Plant (PORTS) in Portsmouth, Ohio. Over 4,800 of the cylinders at Portsmouth were recently moved there from the East Tennessee Technology Park (ETTP) in Oak Ridge, Tennessee. The cylinders range in age up to 56 years and come in various models, but most are 48-inch diameter "thin-wall"(312.5 mil) and "thick-wall" (625 mil) cylinders and 30-inch diameter "30A" (including "30B") cylinders with 1/2" (500 mil) walls. Most of the cylinders are carbon steel, and they are subject to corrosion.

The United States Department of Energy (DOE) manages the cylinders to maintain them and the DUF 6 they contain. Cylinder management requirements are specified in the System Requirements Document (SRD, LMES 1997a), and the activities to fulfill them are specified in the System Engineering Management Plan (SEMP, LMES 1997b). This cylinder corrosion report documents activities that address specific requirements and actions stated in the SRD and SEMP with respect to forecasting cylinder wall thicknesses. SEMP Action 2.1.2 is to "model corrosion to project cylinder integrity" and the corresponding System Requirement 1.2.2 is that "performance shall be monitored and evaluated to identify potential risks within the Project." This report documents the methods for projecting cylinder wall thicknesses and numbers of cylinders expected to fail various thickness criteria.

SEMP Action 3.1.2 is to "statistically determine the baseline condition of cylinder populations by obtaining quantitative data," and the corresponding System Requirement 4.1.2 calls for monitoring cylinder conditions. This report documents statistical methods used to characterize cylinder populations on the basis of ultrasonic thickness (UT) measurements. Wall thickness data has been collected annually since FY94 at the three DOE sites. UT data is collected by sampling cylinders and by making UT measurements at various locations on each sampled cylinder. By assumption, for each cylinder sampled, the minimum UT measurement approximates the actual minimum thickness of the cylinder. This report describes corrosion models fit to the UT data, which have been updated and refined along with the annual installments of data.

System Requirement 4.2.1 states that "cylinders shall be categorized to ensure that risks are identified," and SEMP Action 2.2 is to define and describe categories in terms of cylinder functional criteria and/or factors that could adversely impact cylinder integrity. The analyses in this report are based on cylinder populations defined in terms of cylinder types (e.g., thick-wall, thin-wall) and historical storage locations (site, storage yard, and top/bottom row position). Wall thickness projections are computed from corrosion models relating minimum wall thickness to cylinder age, functional group, and nominal thickness.

System Requirement 4.2.2 states that "cylinder conditions shall be forecast to direct surveillance and maintenance resources," and SEMP Action 2.4 is to "define procedures for forecasting cylinder conditions." System Requirement 4.2.2a is to "identify which collected data will be used for forecasting" (SEMP Action 2.2.) and to "integrate forecasting with modeling efforts" (SEMP Action 2.3). System Requirement 4.2.b (SEMP Action 2.3.1) is to "forecast cylinder conditions using the parameters identified." Cylinder wall thickness, the subject of this report, is one parameter identified in the project for forecasting cylinder conditions. SEMP Action 3.1.1 is to "project the number of noncompliant cylinders."

These projections are the primary purpose of this report, which complements and extends previous editions by Lyon (1995, 1996, 1997, 1998, 2000), by Schmoyer and Lyon (2001, 2002, 2003), and by Schmoyer (2004). Each annual installment of UT measurement data has led to refinements in both the functional forms used for corrosion modeling and in the fitted parameters that describe the forms. Section 2 of this report introduces two approaches for modeling and forecast cylinder wall thicknesses, a 
"direct" approach, in which wall thickness is modeled directly, and an "indirect" approach based on separate models of pit depth and original thickness. Although both models can be used to project cylinder minimum thicknesses on the basis of observed UT measurements, the projections are different functions of the observed measurements, and they have different statistical errors. Because of substantial statistical variation in the measurements themselves, the statistical error of the projections can be as important in the corrosion modeling as the physical relationship between corrosion and age.

Section 3 is an inventory of the cylinders with UT measurements made at ETTP, Paducah, and Portsmouth in FY06 and before. Section 4 is about regression model fitting with the models introduced in Section 2 and the data discussed in Section 3. Because, as in previous editions of this report, the indirect model leads to parameter estimates outside admissible ranges, the indirect model is not considered further for making projections about future wall thicknesses.

As prescribed by SEMP Action 3.1.1, Section 5 contains projections, based on the models fit in Section 4 , of numbers of cylinders expected to fail various thickness criteria. Projections are also expressed as proportions (rates) expected to fail the criteria. Projections are given by age and by cylinder functional group, and both with and without statistical outliers in the analysis. Differences between the with and without-outlier analyses suggest that the cylinders identified as outliers be remeasured (or explained). Model validation is considered in Section 6, where the direct model is evaluated by comparing actual FY06 observations with projections based on fitting the models with UT measurement data only from before FY06. Original thickness estimates and functional group definitions are also assesses as part of the model validation. Limitations, conclusions, and recommendations are considered in Section 7.

To make projections about a cylinder's minimum thickness it is necessary to estimate minimum thicknesses of the cylinder at least two points in time. Although UT measurements have been made on some cylinders more than one time over the years, the great majority of UT'd cylinders were measured only once. (This is consistent with UT measurement as an inspection procedure.) However, in addition to the single UT measurements, information about (though not measurements of) initial thicknesses is available. This information includes nominal thicknesses as well as UT maximums.

Essentially all of the UT measurements were made after 1993, and most cylinders were delivered well before 1993. Design sheets cite nominal thickness specifications, but (as discussed in Section 6) actual initial thicknesses and nominal thicknesses apparently tend to differ somewhat, at least for cylinders that are forty or fifty years old. However, no initial thickness measurements were ever documented for these cylinders. Therefore initial thicknesses are estimated for each cylinder group from both nominal thicknesses and maximum thickness measurements. Nominal thicknesses rather than original thickness estimates are ultimately used as predictors in the regression models (Section 4), however. In Section 6, the original thickness estimates based on UT maximums are compared to the model-based estimates as a model validation exercise.

The disposition of any particular cylinder for storage, handling, and transfer should depend on the condition of the cylinder. In this report "condition" is taken to be the minimum wall thickness of the cylinder. Wall thickness criteria are 0, 62.5, and 250 mils for thin-wall cylinders, 0, 62.5, and 500 mils for thick-wall cylinders, and 0, 62.5, and 100 mils for 30A cylinders. Each of these criteria triplets are based respectively on (1) loss of $\mathrm{UF}_{6}$ (breach), (2) safe handling and stacking operations, and (3) ANSI N14.1 (ANSI 1995) standards for off-site transport and contents transfer.

In early editions of this report, projections of the numbers of cylinders expected to fail the various thickness criteria seemed too conservative-more cylinders were projected to fail the criteria than seemed likely to people familiar with the cylinders and storage yards. Previous editions focused on model formulation as a way to improve the projections. The 2003 edition of the report also focused on data issues, particularly on statistical outliers. A conclusion of the 2003 report was that cylinders with anomalous thickness measurements should be remeasured to either confirm or refute the prior 
measurements. Remeasurements of five thin-wall and ten 30A "outlier"cylinders were made at Paducah in FY03. These remeasurements were analyzed in the 2004 report (see Section 4 of that report). The remeasurements supported the idea of excluding at least some of the outlier cylinder data from the projection calculations. With three years-worth of additional data since the last edition of this report, new outliers have cropped up. Again wall thickness projections depend critically on whether or not they are included in the calculations. Again, a recommendation of this report is that these outlier cylinders be reexamined.

The analyses in this report takes into account differences in cylinder types (thin-wall, thick-wall, 30A), storage histories (site, yard, top/bottom row), as well as the UT measurement positions (head/skirt interface or main-body. Some cylinders have a skirt, which is an extension of the cylinder wall to protect the head (end) and valve. The head/skirt interface crevice is thought to be particularly vulnerable to corrosion. Differences among cylinders types are accounted for by classifying cylinders into functional groups. The functional grouping system used for the analyses in this report was developed over the years on the basis of engineering judgment about cylinder storage location histories and cylinder management operations and statistical considerations about data availability. The groups are defined in Section 3. The exact choice of groupings is not critical to the analysis or the projections, however, because, as long as cylinder sampling is approximately random, valid statistical inferences can be made about the cylinders in the groups, regardless of the exact group definitions. Also, as time goes by, differences between the groups are tending to diminish. For example, all cylinders classified in ETTP grous are now actually at Portsmouth. Their storage conditions, though different in the past, are now similar to cylinders that have been at Portsmouth for a long time. As part of the validation analysis in Section 6, an analysis of the functional grouping system is made by comparing the various groups on the basis of a final fitted regression model, which accounts for age as well as group differences. 


\section{APPROACHES TO MODELING CYLINDER WALL THICKNESS}

\subsection{The Basic Problem and Approaches}

The basic problem addressed in this report is to project numbers of noncompliant cylinders- to predict how many cylinders, in cylinder functional groups defined by age, location, storage position (top or bottom row), etc. will have minimum wall thickness below a specified thickness at a specified time. For a cylinder randomly selected from a functional group, let $M(t)$ denote the minimum wall thickness at time $t$. $M(t)$ is random because of the sampling and because of cylinder-to-cylinder variations in initial thickness (manufacturing variability), steel substrate, storage conditions, and the corrosion process. Consider $\operatorname{Prob}(M(t)<z)$, the probability that $M(t)$ is less than $z$. For a group of $N$ cylinders, the expected number of cylinders with minimum thickness below $z$ at time $t$ is $N \times \operatorname{Prob}(M(t)<z)$. For a group of cylinders having various ages,

Expected number of cylinders with minimum thickness below $z$ at time $t=$

$$
\sum_{\mathrm{a}}(\text { Number of cylinders of age a at time } \mathrm{t}) \times \operatorname{Prob}(M(t)<z \text {; for cylinders of age a }),
$$

where the range of the summation (a) is over all cylinder ages. Equation (2.1) describes the effect of age. The number of cylinders of age a at time $t$ is known, but the individual probabilities (for each age a) are unknown and must be estimated.

Note that (2.1) is the expected number of noncompliant cylinders. The actual number of noncompliant cylinders - what we would most like to predict — tends to differ from (2.1) because of statistical variation in the actual numbers about their expectation. Furthermore, (2.1), which describes the effect of cylinder age, is itself unknown, though it can be estimated by estimating the individual probabilities $\operatorname{Prob}(M(t)<z$; for cylinder of age a) for the various ages a for which there are cylinders. However, the actual number of noncompliant compliant cylinders then departs from the estimate of (2.1) because of two error components: statistical variability about (2.1) in the numbers of noncompliant cylinders and error in estimating (2.1) itself. Even if the expected number of cylinders in (2.1) is known exactly, the actual number still varies about that expectation. The error in estimating (2.1) becomes negligible for very large sample sizes, but the statistical variation between the actual and expected numbers of cylinders can be appreciable regardless of the sample size.

Methods of accounting for estimation error and error due to variation in the actual number of noncompliant cylinders are discussed below. For a specified confidence level 1- $\alpha$ and time t, we would like to compute a bound $\mathrm{U}$ for the actual number $\mathrm{N}$ of noncompliant cylinders, such that $\operatorname{Prob}(\mathrm{N}<\mathrm{U})=$ $1-\alpha$. Such a bound would then simultaneously account for both error in estimating (2.1) and for statistical variation in actual numbers about (2.1). None of the methods discussed in this report completely achieve this goal, however.

An approach to the problem of estimating (2.1) is to make UT measurements of cylinder wall thicknesses, deliberately trying to locate the actual thickness minima. By doing this for cylinders of various ages and from various functional groups, data so collected can be used to model the minimum thicknesses as a function of age, functional group, and estimates of initial or nominal thicknesses. Initial thickness estimates can be computed from nominal thicknesses (in CID, from design sheet data), as well as UT maximum measurements, and judgment. In this report, this approach is called "direct" because minimum thicknesses are modeled directly and because the objective is to make projections about minimum thicknesses. An approximation is incurred in the direct approach because actual minimum thicknesses may not be discovered because of insufficient searching. For example, if a cylinder's initial thickness is not uniform (e.g., because of variations introduced in forming), then measurements made 
where pitting is worst (the superficially worst case) may not be where the minimum thickness actually occurs.

Another approach is to model maximum pit (i.e., corrosion) depths. As discussed below, pit depth models are more common in the literature than minimum thickness models. Given a pit depth model, projections about minimum thicknesses can be computed as differences between initial thickness estimates and maximum pit depth estimates computed from the pit depth model. As in the direct approach, initial thickness estimates can be based on nominal specifications as well as maximum thickness measurements.

Besides the initial thickness approximation, an approach based on maximum pit depths is approximate because minimum thicknesses need not occur either where initial thicknesses are minimum or where pit depths are maximum. More specifically, for a particular cylinder, let $C_{0}(x)$ denote the initial wall thickness at a location $x$, and let $D(t, x)$ denote the pit depth at location $x$ at time $t$. Then the thickness at point $x$ is $C_{0}(x)-D(t, x)$, and the minimum thickness at time $t$ is

$$
M(t)=\min _{x}\left\{C_{0}(x)-D(t, x)\right\}
$$

where the min is over all points $x$ on the cylinder surface. For time $t$, let $x^{*}(t)$ denote the point $x$ at which the thickness is minimized. Then $M(t)=C_{0}\left(x^{*}(t)\right)-D\left(t, x^{*}(t)\right)$. Note that $D\left(t, x^{*}(t)\right)$ is the pit depth at the point of minimum thickness, which is not necessarily the maximum pit depth. Similarly $C_{0}\left(x^{*}(t)\right)$ is not necessarily the minimum initial thickness.

If $x^{*}(t)$ is estimated through UT scanning, and if UT thickness measurements are made at $x^{*}(t)$ (approximately) and at relatively uncorroded areas in the vicinity of $x^{*}(t)$, then $D\left(t, x^{*}(t)\right)$ and $C_{0}\left(x^{*}(t)\right)$ can be estimated. Those estimates could be used to develop models for pit depths and initial thicknesses at $x^{*}(t)$, which in turn can be combined to produce minimum thickness estimates and projections. Note, however, that this approach would not really be based on maximum pit depths. Furthermore, the approach would be very heavily dependent on proper thickness measurements being made at relatively uncorroded areas near $x^{*}(t)$. Uncorroded areas might not exist. A common notation on cylinder reports is "uniform corrosion," which suggests that for those cylinders an assessment of initial thickness based on thickness measurements is not possible.

Lyon (2000) developed a method based on a maximum pit depth model and a conservative approximation based on the following inequality:

$$
\begin{aligned}
M(t) & \geq \min _{x}\left\{C_{0}(x)\right\}-\max _{x}\{D(t, x)\} \\
& =C_{0}-\max _{x}\{D(t, x)\} \\
& =C_{0}-D(t)
\end{aligned}
$$

where $C_{0}$ is the initial minimum thickness, and $D(t)$ is the maximum pit depth at age $t$. By this inequality, $C_{0}-D(t)$ is a lower bound for $M(t)$, and conclusions about $C_{0}-D(t)$ are conservative conclusions about $M(t)$. 
In Lyon's approach, the $C_{0}$ are estimated either with thickness measurements made at uncorroded areas near the area of minimum wall thickness, or else with estimates of original thickness made from measurements at areas of approximate maximum thickness. The $D(t)$ are estimated by subtracting thickness measurements made either where the worst pitting occurs or where the wall thickness is minimum. In this report, because the minimum thicknesses are modeled indirectly through separate models of maximum pit depth and initial thickness, this approach is referred to as "indirect." To make estimates and projections about minimum thicknesses, the statistical distributions of the $C_{0}$ and $D(t)$ are combined (see Lyon 2000) in a way that assumes the two distributions are statistically independent. The statistical independence is an assumption that could fail, however, for example if steel quality and initial thickness are correlated.

\subsection{Maximum Pit Depth (Indirect) Model}

The particular indirect model considered in this report is based on the power law, which has been used in many previous applications of corrosion modeling (e.g., Felieu et al. 1993a; Felieu et al. 1993b; Legault and Preban 1975; Pourbaix 1982; Mughabghab and Sullivan 1989; Romanoff 1957). The power law is $D=A \times(\text { age })^{b}$, where $D$ denotes pit depth, and $A$ and $b$ are constants. For $b<1$ the power law allows for "leveling off" in corrosion, which is commonly seen in the atmospheric corrosion of steel because of the semi-protective qualities of iron oxides. According to Pourbaix (1982), Passano (1934) was the first to use the power law relationship in corrosion prediction. This law is considered to be valid for different types of atmospheres (rural, marine, industrial) and a number of materials. The parameter $A$ can be interpreted as the corrosion in the first year, and the parameter $b$ represents the attenuation of the corrosion because of the passivation of the material in the atmosphere (Pourbaix, p.115).

The model parameters $A$ and $b$ can be estimated using the log-linear regression model ${ }^{1}$

$$
\log (D)=\log (A)+b \log (\text { age })+\text { random error, }
$$

which is the indirect model considered in this report. The random errors are assumed to be statistically independent and independent of the cylinder initial thickness. In Section 4, separate regression models are fit for each of fourteen cylinder functional groups. For the regressions, maximum pit depth measurements for each cylinder are estimated from minimum thickness measurements and estimates of initial thickness, which are based on maximum wall thickness measurements made for each cylinder.

From model (2.2) it follows that for a cylinder of given age, the mean corrosion rate is $D /$ age $=$ $A \times(\text { age })^{b-1}$. If $b=1$, this implies that the age-averaged corrosion rate is constant, while if $b<1$ (which is typical), the corrosion rate decreases with time. Mechanistic interpretations of $b$ have also been made (Horton 1964). If $b=0.5$, then the relationship is said to be parabolic, with the corrosion rate controlled by diffusion through the rust layer. If $b<0.5$, the rust layer is showing protective properties, while if $b>$ 0.5 , the rust layer is not fully protective because of factors that may be preventing the homogeneous thickening of the layer. A value of $b$ that exceeds 1 is inadmissible according to the passivation theory.

Because estimates of the leveling off $(b<1)$ pattern usually expected for pit depths can be sensitive to narrow data ranges, outliers, and other data anomalies, the power law approach should be used with caution. In fact, it will be shown in Section 4 of this report that the fitted parameters fail the increasing corrosion $(b>0)$ condition in six of the fourteen functional groups, and they fail the leveling off $(b<1)$ condition in one group. The failure of the indirect model fitted parameter to satisfy these conditions lead in previous editions of this report to the investigation of the direct model.

After fitting the maximum pit depth model, it can be used to project maximum pit depths in the future. To project minimum wall thicknesses and numbers of cylinders falling specified thresholds, the

\footnotetext{
${ }^{1}$ All logarithms in this report are natural logarithms.
} 
maximum pit depth projections have to be combined with estimates of the original thickness of the cylinders. A method for combining the pit depth projections and original thickness estimates is discussed in earlier editions of this report. As discussed in those reports, however, even in cases where the model parameters are within admissible ranges, this approach has lead to projections and confidence bounds that have been in general too conservative to be useful. Because the direct model seems to give more satisfactory results, it is the primary modeling approach in this report.

\subsection{Extreme Value Distribution}

Given that the data consists of either maximum pit depth estimates or minimum thickness estimates, it would seem natural to apply extreme-value statistics to this problem. Application of the extreme value distribution (without confidence limits) is discussed in several papers and has also been suggested for DUF $_{6}$ cylinder corrosion modeling by Rosen and Glaser (1996). The basic idea is that using largesample statistical theory (see, for example, David 1981), it can be shown that for D, the maximum pit depth in $\mathrm{m}$ pit depth measurements made on a randomly selected cylinder, there is a standardization $\mathrm{a}_{\mathrm{m}}$ and $\mathrm{c}_{\mathrm{m}}$ (depending only on $\mathrm{m}$ ) such that as $\mathrm{m}$ increases (i.e., as $\mathrm{m}$ approaches infinity), the statistical distribution of $\mathrm{a}_{\mathrm{m}}+\mathrm{c}_{\mathrm{m}} \times \mathrm{D}$ converges to a particular parametric form known as an extreme value distribution. The similar standardization holds for $\mathrm{M}$, the minimum thickness in $\mathrm{m}$ thickness measurements. Such a standardization, along with estimates of its unknown parameters, would seem like a good choice for projecting pit depths or minimum thicknesses forward in time.

In fact, however, the number of measurements $m$ on any individual cylinder never actually gets very large. The number of UT measurements made on each cylinder is generally in the range of 5-15. The discretion of UT measurement technicians in locating areas of cylinders most likely to be worst in terms of thickness or corrosion might tend to increase the effective sample size, but not in any way that can be reasonably quantified.

It is actually the number of cylinders with UT measurements that is large (in the thousands), not the number of UT measurements per cylinder. Thus large-sample statistical theory suggests that the distribution of the minimum over all cylinders of the per-cylinder minimum thicknesses converges to an extreme value distribution, but the theory does not tell us much about the distribution of per-cylinder minimum thicknesses. Although it would be of interest to project the smallest minimum thickness, estimating the number of noncompliant cylinders requires estimating the per-cylinder minimum thickness distribution. This, together with statistical issues about data quality, outliers, and the basic corrosion-age relationship motivated the direct model as an alternative to the indirect model, rather than development an extreme value approach. The direct model (see below) is nonparametric (not based on any parametric distribution) and does not require choosing any form of parametric statistical distribution.

\subsection{Direct Model}

The direct model was first investigated as an alternative to the indirect approach because of anomalous results based on the indirect approach, due in part to the high variability that has been seen in the minimum thickness and maximum pit depth data. While indirect model projections were computed since the 1997 edition of the this report, thickness projections based on the direct model were first computed in the 2002 edition (Schmoyer and Lyon 2002). Modeling results for both the direct and indirect approaches are discussed in Section 4.

There are other reasons, besides data variability, for exploring alternatives to the indirect approach. For example, pits or other surface relief developed in fabrication or handling hold moisture differently than a uniform surface and therefore corrode at different rates. It may be that the myriad possible variations in 
the statistical "nick and cut" distribution cannot all be described by a simple power law. The power law also might fail because of thermal inertia ${ }^{2}$ of cylinders. ${ }^{3}$

The direct model considered in this report is

$$
M=\theta_{\mathrm{S}}(\text { Nominal Thickness })+\beta_{\mathrm{G}} \log (\text { age })+\text { random error, for age in years }>1
$$

where $M$ is the observed UT-measured minimal thickness, $\theta_{\mathrm{S}}$ is a model parameter depending on whether the measurement is on the main body of head/skirt interface, and $\beta_{\mathrm{G}}$ are model parameters, one for each cylinder group.

Because the variance of minimum thicknesses tends to increase with age, the model (2.3) needs to be weighted when it is fit. This is discussed in Section 4. The variance of pit depths also increases with age, but the log transformation of the pit depths stabilizes the variance of the logs. ${ }^{4}$ The use of nominal thickness as a predictor variable is new for this report. In previous editions an original thickness estimate was used instead. However, the original thickness estimates violates two fundamental assumptions of linear regression, because they are random and statistically dependent on the minimum thicknesses themselves. Nominal thicknesses on the other hand are fixed (non-random) and as such are statistically independent of the minimum thickness measurements.

Another difference between the indirect and direct models is that the direct model has fewer parameters, and some parameters are common to multiple groups. For example, a single $\theta$ parameter is used to model the one-year thickness as a proportion of the nominal thickness for all main-body measurements. All main-body measurements contribute to the estimate of this $\theta$ parameter. Similarly, a different $\theta$ parameter is common to all cylinder head/skirt interface measurements and all head/skirt measurements contribute to its estimate. With more data contributing to them, the estimates of these parameters are statistically more stable. And because the $\theta$ estimates effect the $\beta$ estimates, the $\beta$ estimates are also more stable.

Each of the indirect model parameters is specific to one functional group, and the parameters are estimated on a group-by-group basis. Initial thicknesses are estimated in a separate step and combined with the maximum pit depth estimates. It would be reasonable to combine some of the indirect-model initial thickness parameters over groups (e.g., all thin-wall, main-body initial thicknesses might be assumed the same). However the indirect model's estimates fail the sanity checks at the pit-depth modeling step, before initial thicknesses enter the model. There does not seem to be a reasonable way to associate the pit depth model $\mathrm{A}$ or $\mathrm{b}$ parameters to achieve a more stable fit.

The age $>1$ condition is necessary in the direct model (2.3) because $\log ($ age $)$ is unbounded and negative for age $<1$, and the model could not hold for arbitrarily small ages. Another physical model might hold for age $<1$, but that point is moot for this report because there are no thickness measurements for cylinders of age less than one year.

In the indirect model, the corrosion rate is $d D($ age $) / d($ age $)=b D($ age $) /$ age, with a different parameter $b$ for each cylinder group. Thus the corrosion rate depends on the pit depth. For $0<b<1$, the rate is a concave increasing function of age. This is how the passivation effect is modeled. In the direct model, the passivation effect is also modeled through the corrosion rate, $-d M($ age $) / d($ age $)=-\beta /$ age, which for

\footnotetext{
${ }^{2}$ The tendency of objects of large mass to temporarily differ in temperature from their environment.

${ }^{3}$ Steve Pawel, ORNL Corrosion Science \& Technology Group, personal communication.

${ }^{4}$ By Taylor's formula, the variance of the logs of the pit depths is approximately the variance of the pit depths divided by the mean squared. As the mean pit depth increases with age, the variance adjustment increases with age.
} 
$\beta<0$ decreases with age, but which does not depend explicitly on pit depth. Other differences between the direct and indirect models are discussed in previous editions of this report.

\subsection{Rare Events and Small Sample Sizes}

In fitting the direct model, cylinder groups are combined. In fitting the indirect model, they have generally been kept separate. In addition to possibly affecting the admissibility of parameter estimates this also bears on the statistical properties of model-based projections of the numbers of cylinders failing the various criteria. Failures of the various criteria are generally rare events, and only a few are likely to occur. Without extensive assumptions it is very difficult to get statistical confidence in predictions that rare events won't occur in the future, particularly with small sample sizes. Thus it is advantageous to combine groups in the data analysis.

Consider, for example, a random sample of $n$ independent trials $X_{1}, \ldots, X_{n}$, and a future trial $X^{*}$. The probability that $X^{*}$ is less than $X_{(1)}$, the smallest of $X_{1}, \ldots, X_{n}$ is $1 /(n+1)$. Without strong assumptions about the statistical distribution of the Xs, there is not much stronger that can be said about how high $\mathrm{X}^{*}$ might be. If $n=200$, then $X^{*}>X_{(1)}$ with confidence $1-1 /(200+1)=.995$. If $n=3,000$ then the confidence level is $1 /(n+1)=.9997$. The corresponding expected number of items below $X_{(1)}$ in a population of say 10,000 items is 50 in the first cast, but only 3 in the second. Forecasts about maximum pit depths or minimum wall thickness also entail error in estimating the relationship between the wall thickness or pit depths and age. However, if that relationship is known exactly (i.e., that component of error is ignored), then the statistical distribution of the minimum thicknesses (or maximum pit depths) behaves like the $\mathrm{X}_{1}$, $\ldots, X_{n}$ in the example. 


\section{ULTRASONIC THICKNESS DATA AND CID DATA}

The purpose of this report is to project numbers of cylinders (possibly zero) that will fail certain wall thickness specifications by certain specified years. These projections are based on regressions with UT measurement data that relate minimum thicknesses to cylinder age, functional group, and original thickness. This section inventories the data sources used for making theses projections. The regressions are used to estimate failure rates, but the absolute numbers likely to fail also depend on the numbers of cylinders at risk. Counts of cylinders at risk, as well as nominal wall thicknesses, location histories, and other general information about the cylinders are obtained from the Cylinder Inventory Database (CID, Bechtel Jacobs, 1998). The CID and the UT data are described generally and functional groups are defined in Section 3.1. The previous edition of this report (Schmoyer 2004) was based on wall thickness data that had been collected through FY03. This report incorporates additional UT data collected in FY04-06. The UT data collection is chronicled by fiscal year in Section 3.2. In Section 3.3 the data is inventoried by functional groups.

\subsection{Data Sources, Types, and Collection Procedures}

P-Scan and Manual UT Data. For this report, a manual UT probe (Lykins and Pawel 1997) was used for all wall thickness data collected in FY98 and later. Except for head/skirt interface data, UT measurements from before FY98 were made with an automated P-scan system (see Schmidt et al 1996 for a description of the equipment). P-scan measurements were made during FY94 at K-1066-K yard at ETTP, in the fall of 1995 at PGDP, between March and September 1996 at both Portsmouth and PGDP, and during FY97 primarily at Portsmouth. The P-scan wall thickness data consists of a grid of measurements, each for a region about 0.1 inches square. Initial thicknesses were estimated with measurements near the maximum-depth pit made either with the P-scanner or with a hand-held probe.

Manual UT measurements for six cylinders made in FY98 are significantly different from P-scan measurements of the same cylinders made in FY94 (see Schmoyer and Lyon 2003, Table 5). The manually collected data shows a larger minimum thickness (mean difference: 49.8 mils; standard error: 8.8 mils; significance level of difference: $\mathrm{p}=.002$ ). Similarly, Schmidt et al (1996) found that P-scan measurements under-predicted minimum wall thickness by an average of 10-20 mils. Although these studies establish that there is an important difference between the two UT methods, they are too small to serve as basis for calibrating one method with the other. In fact no definitive calibration study has ever been conducted with $\mathrm{DUF}_{6}$ cylinders to relate the two methods. Without a calibration correction, combining the P-scan and manual UT data into a single (uncorrected) analysis would skew corrosion rate estimates because the P-scan method predates the manual UT measurements and the P-scanned cylinders tend therefore to have lower ages. For this reason, in previous editions of this report, the P-scan data was analyzed but generally disregarded in the conclusions of the analysis. In this edition of the report the Pscan data is handled simply by referring to the previous editions.

Statistical Sampling Model. For the corrosion modeling in this report, cylinder sampling is assumed to emulate random sampling. This is an approximation. Cylinders with difficult physical access have been excluded from UT measurements. Cylinders have sometimes been sampled as a matter of convenience, for example, when they were moved. This is the case for the ETTP cylinders recently moved to Portsmouth. Several other cylinders (e.g., FY03 outlier remeasurements) were resampled. When cylinders are measured multiple times, only the most recent measurements are used to fit the corrosion models because independent observations is a requirement in the regressions.

Independence is violated slightly in the direct-model regression in that head/skirt observations are treated as statistically independent of main body measurements, even when two sets of measurements are from the same cylinder. This approximation could be avoided by analyzing head/skirt and main body data in separate models. However, as discussed in Section 2.5, because the direct model approach is based on a nonparametric approximation, the lowest probabilities direct-model projections can represent are limited 
by the underlying sample size. Pooling observations minimizes the resolution limit by keeping the sample size as large as possible.

With the exception of the sampling at Portsmouth, the sampling design is cross-sectional-each year, new samples of cylinders are selected for scanning. An alternative to cross-sectional sampling is longitudinal sampling, as at Portsmouth, with the same cylinders measured multiple times over the years. A randomly selected sample of cylinders measured repeatedly over the years can serve as bellwethers for all of the cylinders. Because each cylinder in such a sample can serve as its own control, changes in the sample can be measured on a cylinder to cylinder basis. Measuring the same cylinders compensates for measurement bias.

However, there are disadvantages to the longitudinal approach: (1) Although longitudinal sampling compensates for biases in the measurements that are consistent from year to year, it does not compensate for biases due to changes in the measurement method such as changes in instrument calibration or the change from P-scanning to manual UT scanning. (2) Because the atmospheric corrosion of steel is a very slow process, it takes a very long time to acquire enough longitudinal data to model corrosion effectively. The majority of UT data already collected has been sampled on a cross-sectional basis and is needed to support near-term decisions about cylinder movements and dispositions. (3) Perhaps most important, though an express objective in the cylinder monitoring is characterization, inspection is also a goal. Because year-to-year changes are so small, there is little point, from the perspective of inspection, in remeasuring the same cylinders. Measuring the same cylinders year after year diverts resources that could be used to scan cylinders that were not scanned previously. In a cross-sectional approach, new cylinders are scanned (and thus inspected) each year.

Breached cylinders. Two breached cylinders were discovered by visual inspection in FY92 in K-1066$\mathrm{K}$ yard at ETTP. Mechanical damage may have been a factor, but the strength of the evidence points to external corrosion as the principal cause of those breaches (Barber et al, 1991). In early editions of this report, the data for those two breaches has been used in the corrosion modeling.

Two other breaches were discovered at ETTP in FY92, and two breaches were discovered at Portsmouth in FY90. It was concluded, however, that those breaches were caused by mechanical damage rather than external corrosion (Barber et al, 1991; Barber et al, 1994). Three other breaches, all due to handling damage, are also mentioned in DOE (2003, Chapter 2). As the intent of this report is to model and project effects of corrosion, the implicit zero minimum thicknesses of these mechanically breached cylinders are excluded from the corrosion modeling.

A reviewer of the 2002 report expressed another reason for excluding even the two corrosion-induced breaches - that the breaches "represent a corrosion situation that simply no longer exists (e.g., corr rate $\approx$ $30 \mathrm{mils} / \mathrm{yr}$ ), and using data skewed by that to project future conditions is technically inappropriate." $\mathrm{In}$ practice a breached cylinder is either repaired or replaced, so it can be inappropriate to use a zero minimum thickness in characterizing a functional group of cylinders. A similar argument could also be made, however, for other cylinders besides those that have breached. Much of the cylinder thickness data used for this report is for cylinders that have spent at least part of their lifetimes in conditions similar to the situation for the breached cylinders.

In practice the zero minimum thicknesses for the two corrosion-induced breaches are excluded more or less by default as follows: As discussed above, in fitting the direct model, for cylinders with multiple sets of UT measurements, only the most recent set is used. This is done for several reasons. In corrosion modeling, the UT date (and cylinder age) are critically associated with the measurements. Using only one set of measurements avoids dealing with multiple dates and the possibly intractable problem of

${ }^{5}$ Steve Pawel, ORNL Corrosion Science \& Technology Group, personal communication.. 
accounting for correlations between UT measurements repeated over time. The most recent set of UT measurements is used because it is assumed to be most accurate and because it minimizes the extent of extrapolations into the future. Since the two breached cylinders were remeasured in FY01, the FY01 data is supercedes the old FY92 breach (zero minimum thickness) data.

Cylinder Inventory Database (CID) and UT Raw Data Sheets. CID data is used to classify cylinders into functional groups and to count the cylinders in each group. The CID, as of November 12, 2007, contains records for 63,589 cylinders. Of the 63,589, however, 946 cylinders are not subject to external corrosion because they are either nickel (694 cylinders) or Monel (252 cylinders), and 32 cylinders are of unknown material type. These cylinders are excluded from the target populations of this report. Of the remaining $62,611(=63,589-946-32)$ cylinders, 170 are model $10 \mathrm{~A}, 8 \mathrm{H}$, or $8 \mathrm{~S}$ cylinders. These cylinders are excluded from the target populations because no UT measurements have been made on cylinders of these model types. This leaves 62,441 cylinders in the target population. Finally, cylinder ages, which are necessary for corrosion modeling, are determined from cylinder delivery dates. Three cylinders delivered after FY06 (9/30/06) are excluded from the target population because they are essentially out of the scope of the present study. This leaves 62,438 cylinders.

Table 1 shows cylinder counts of the thin-wall, thick-wall, and 30A cylinders at the two current storage sites. Of the total of 62,348 cylinders, 57,892 (92.7\%) are thin-wall, 1,972 (3.2\%) are thick-wall, and $2,574(4.1 \%)$ are $30 \mathrm{~A}$ cylinders.

Table 1. CID Counts by Site and Cylinder Thickness Type (Cylinders of Known Age)

\begin{tabular}{|c|c|c|c|c|}
\hline & $\begin{array}{c}\text { Thin-wall } \\
\text { Site }\end{array}$ & $\begin{array}{c}\text { Thick-wall } \\
(\mathbf{6 1 2 . 5} \text { mils })\end{array}$ & $\begin{array}{c}\text { 30A (and } \\
\mathbf{3 0 B})\end{array}$ & \\
\hline PGPils $)$ & $\mathbf{( 5 0 0}$ mils) & Total \\
\hline PORTS & 35,906 & 315 & 1,825 & 38,046 \\
\hline Total & 21,986 & 1,657 & 749 & 24,392 \\
\hline
\end{tabular}

The CID contains a UT summary table with fields for cylinder ID, model, UT data, nominal wall thickness, UT minimum wall thickness, and UT measurement site. However, the minimum thickness is an overall minimum, and there are not separate minimums for main-body measurements and head/skirt measurements (when taken). The CID also does not have UT maximums, which are used in estimating original thicknesses and in the indirect model pit depth estimates. Therefore, for the analyses in this report, UT raw data sheets were also examined to obtain the UT measurement maximums and separate minimum and maximums for main-body and head/skirt interface measurements.

Functional Groups. Tables 2A and 2B show cylinder counts by cylinder functional groups for mainbody and head/skirt interface measurements. The functional group definitions are clear from the names of the groups (e.g., "PORTS thin top row," "All thin bottom row, head/skirt"), with two exceptions: Any thin-wall cylinder that was stored for more than one year in a bottom row of the unrefurbished PGDP C-745-G yard is so classified. Similarly, any thin-wall cylinder that was stored for more than one year in a bottom row of the ETTP K-1066-K yard is so classified. Also, if the top/bottom row status of a cylinder during its longest unpainted residency period is unknown, then the longest top/bottom status that is known was substituted. Because the historical record of some cylinders is incomplete, the functional groups are sometimes an approximation. Nevertheless, they are an attempt to classify cylinders according to either where they spent the greatest number of days, or, in the case of particularly 
unfavorable locations, where they spent significant time. Of course, this may differ from where a cylinder is currently being stored or where it was stored when UT measurements were made on it.

\section{Table 2A. Cylinder Functional Groups for Main Body UT Measurements}

\begin{tabular}{|r|r|r|}
\hline Functional Group & $\begin{array}{c}\text { Cylinders in } \\
\text { Population } \\
\text { (CID) }\end{array}$ & $\begin{array}{c}\text { Cylinders } \\
\text { With UT } \\
\text { Measurements }\end{array}$ \\
\hline ETTP thin K bottom & 1,491 & 232 \\
\hline ETTP thin except K bottom & 3,262 & 366 \\
\hline PGDP thin bottom former G & 9,106 & 344 \\
\hline PGDP thin bottom except former G & 13,567 & 327 \\
\hline PGDP thin top & 13,231 & 245 \\
\hline All thick top & 983 & 84 \\
\hline All thick bottom & 989 & 75 \\
\hline PORTS thin top & 8,470 & 402 \\
\hline PORTS thin bottom & 8,765 & 353 \\
\hline All 30As top & 1,493 & 205 \\
\hline All 30As bottom & 1,081 & 164 \\
\hline & $\mathbf{6 2 , 4 3 8}$ & $\mathbf{2 , 7 9 7}$ \\
\hline
\end{tabular}

Figures 1-14 show the age distributions of the cylinders for each of the functional groups. The distributions for both actual ages and "unpainted" ages are shown in the figures. The unpainted age of a cylinder is defined as the age less time spent painted, where, as an approximation, a painted state of cylinder is assumed to last exactly ten years after it is painted. Only cylinders with paint dates documented in the CID are treated as painted. According to the CID, 4,733 cylinders have paint dates. The dates range from June 18, 1996 to August 30, 2002. ${ }^{6}$

\section{Table 2B. Cylinder Functional Groups for Head/Skirt Interface UT Measurements}

\begin{tabular}{|r|r|r|}
\hline Functional Group & $\begin{array}{c}\text { Skirted } \\
\text { Cylinders in } \\
\text { Population } \\
\text { (CID) }\end{array}$ & $\begin{array}{c}\text { Cylinders } \\
\text { With UT } \\
\text { Head/Skirt } \\
\text { Measurements }\end{array}$ \\
\hline All thin top, head/skirt & 2,632 & 140 \\
\hline All thin bottom, head/skirt & 2,818 & 139 \\
\hline All thick, head/skirt & 1,972 & 158 \\
\hline & $\mathbf{7 , 4 2 2}$ & $\mathbf{4 3 7}$ \\
\hline
\end{tabular}

${ }^{6}$ This is obviously an approximation. Initial factory surface coatings are ignored, however, because little is known about them and because they were likely destroyed by autoclaving. Any other painting is ignored because there is no record of it. 
The age of cylinder is assumed to begin with "birth" at the delivery date. The delivery dates of the 30As are assumed to be 1954. The ages for the other cylinders are known at least approximately for all but 24 cylinders (23 thick-wall and one thin-wall). These 24 cylinders are assumed delivered in 1951 and thus as old as any in the target population. As none of the 24 were ever among cylinders sampled for UT measurement, they are used for population projections but not for model fitting. As there are only 24 of these (of which 23 are thick-wall cylinders), the assumption that they are essentially as old as possible is only slightly conservative.

\subsection{Data Inventory by Fiscal Year}

In this section the UT measurement inventory is discussed in order of the fiscal year the measurements were made and by functional group. Table $3 \mathrm{~A}$ shows this inventory for manual UT measurements made on the main cylinder body. Table 3B shows the inventory for head/skirt interface UT measurements. Table $3 \mathrm{C}$ shows the inventory for main-body P-scan measurements.

FY92. The data for FY92 is for the two breached cylinders discussed above. The breaches were discovered in FY92 in K-1066-K yard, and external corrosion is considered to have caused the breaches. This data is not used in the corrosion modeling.

FY94. Between December 1993 and May 1994, wall thickness measurements were made on 136 cylinders in K-1066-K yard (Philpot 1995) using an automated P-scanner. It was intended that the cylinders selected for measurement should be chosen at random, though there were limitations imposed by the P-scanner (length of power cord, clearance between adjacent cylinders). Because of accuracy limits in the equipment used to collect this data, thickness measurements were recorded only to the nearest 5 mils. There were questions about the accuracy of the wall thickness measurements of the first 21 of these cylinders, and only minimum wall thickness data was recorded for the first 21. Maximum thicknesses were also recorded for the remaining 115 cylinders. Since maximum thickness data was not recorded for the first 21 cylinders, maximum pit depths could not be used for these cylinders, and because they are P-scan measurements, they are not included in either the direct or indirect-model analyses in this report. Only the last 115 cylinders are indicated in Table 3C.

FY95. During FY95, data was collected for 100 thin-wall cylinders at PGDP using the automated Pscanner (Blue 1994). The primary purpose of this effort was to assess "the condition of the more vulnerable portion" of the cylinder population at PGDP (Blue 1995). The cylinders were selected from various yards on the basis of judgement and thus do not constitute a random sample, though they may emulate one.

FY96. During FY96, wall thicknesses of over 600 cylinders were measured at Portsmouth, and almost 250 cylinders were measured at PGDP. Measurements at both sites were by P-scanning. The X-745-E yard at Portsmouth, which had been a compacted gravel area, was reconstructed during FY95-96 to a reinforced concrete yard. In FY96, 5,708 cylinders were relocated to meet new storage requirements. At Portsmouth, $10 \%$ of the cylinders that were being relocated were selected (using a random number generator). The $10 \%$ evaluation criterion was required by a Consent Decree with the Ohio Environmental Protection Agency. Most of the cylinders measured at PGDP were from the old C-745-G yard and had been set aside as part of relocation efforts performed during FY95 and FY96. These cylinders compose a systematic sample from the first 3,900 cylinders moved out of the C-745-G yard. (They were selected from approximately 390 cylinders that had been set aside from the first 3,900 cylinders moved out of the C-745-G yard.) An additional 14 cylinders from C-745-F and C-745-K yards were also evaluated. For C-745-F yard, single stacked cylinders from the north end were selected, while the C-745-K yard cylinders were selected on the basis of ease of accessibility with the equipment. 


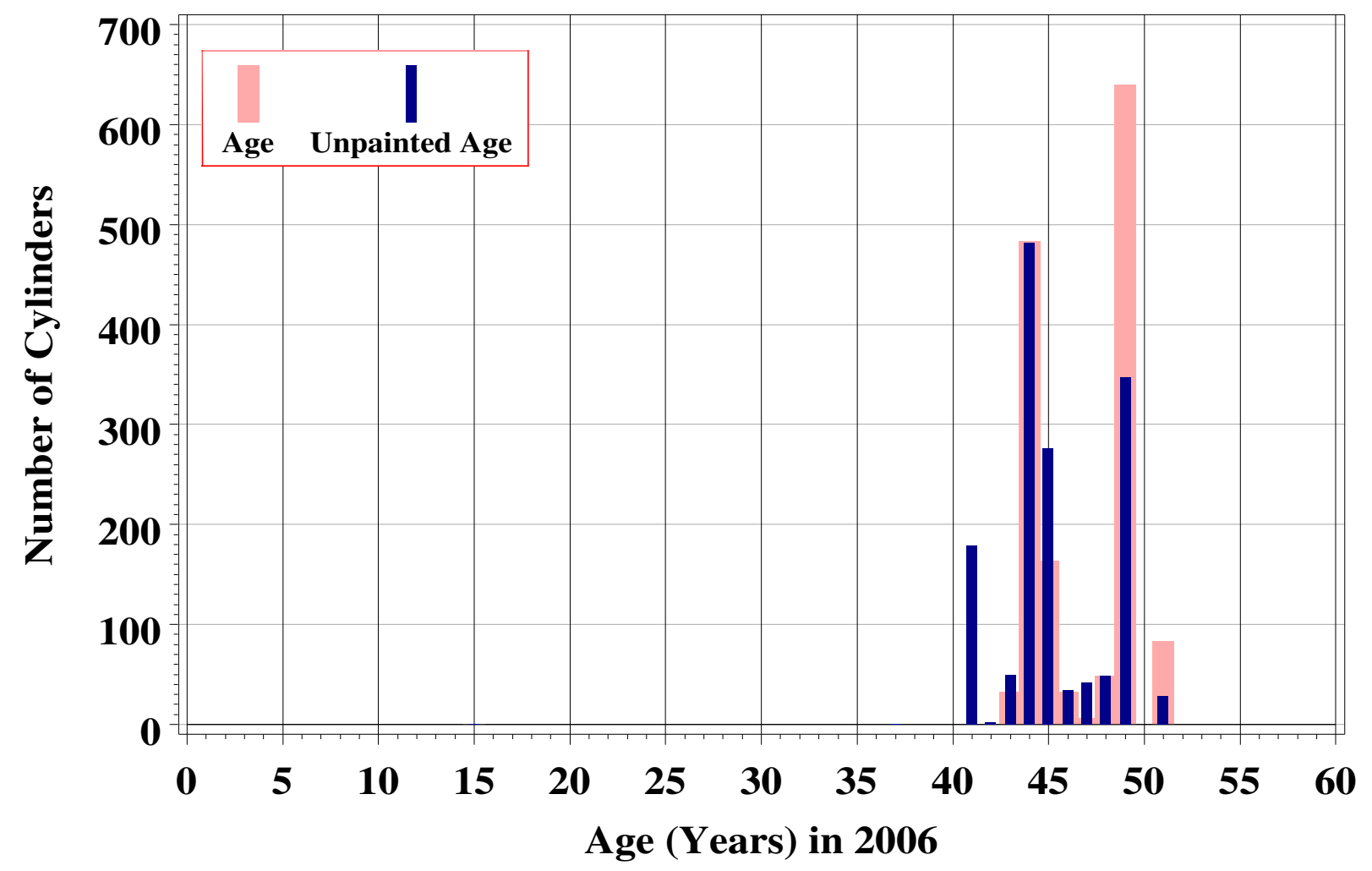

Figure 1. Age and unpainted age distributions for ETTP thin K-yard bottom cylinders.

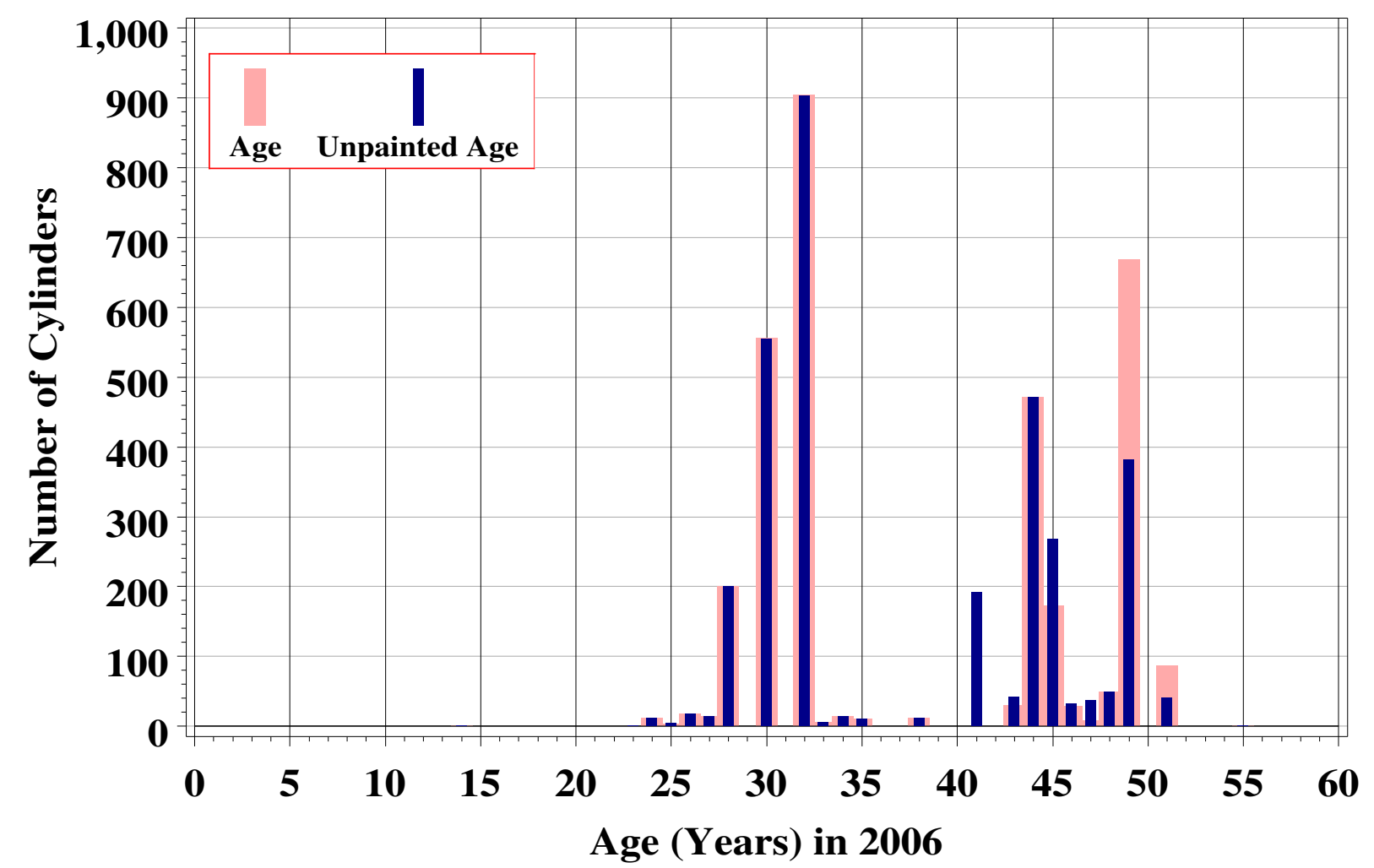

Figure 2. Age and unpainted age distributions for ETTP thin cylinders except K-yard bottom. 


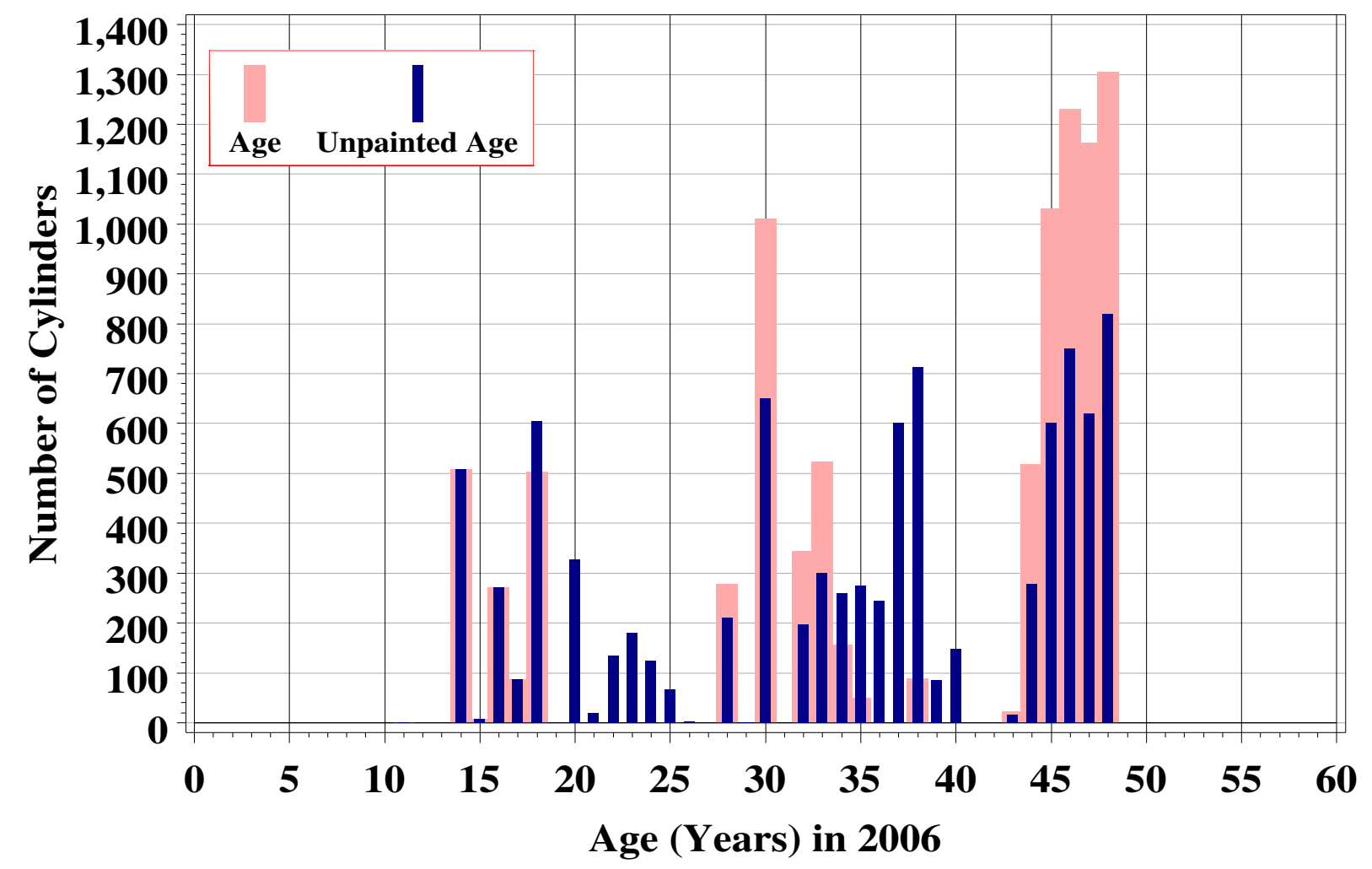

Figure 3. Age and unpainted age distributions for PGDP thin bottom former G-yard cylinders.

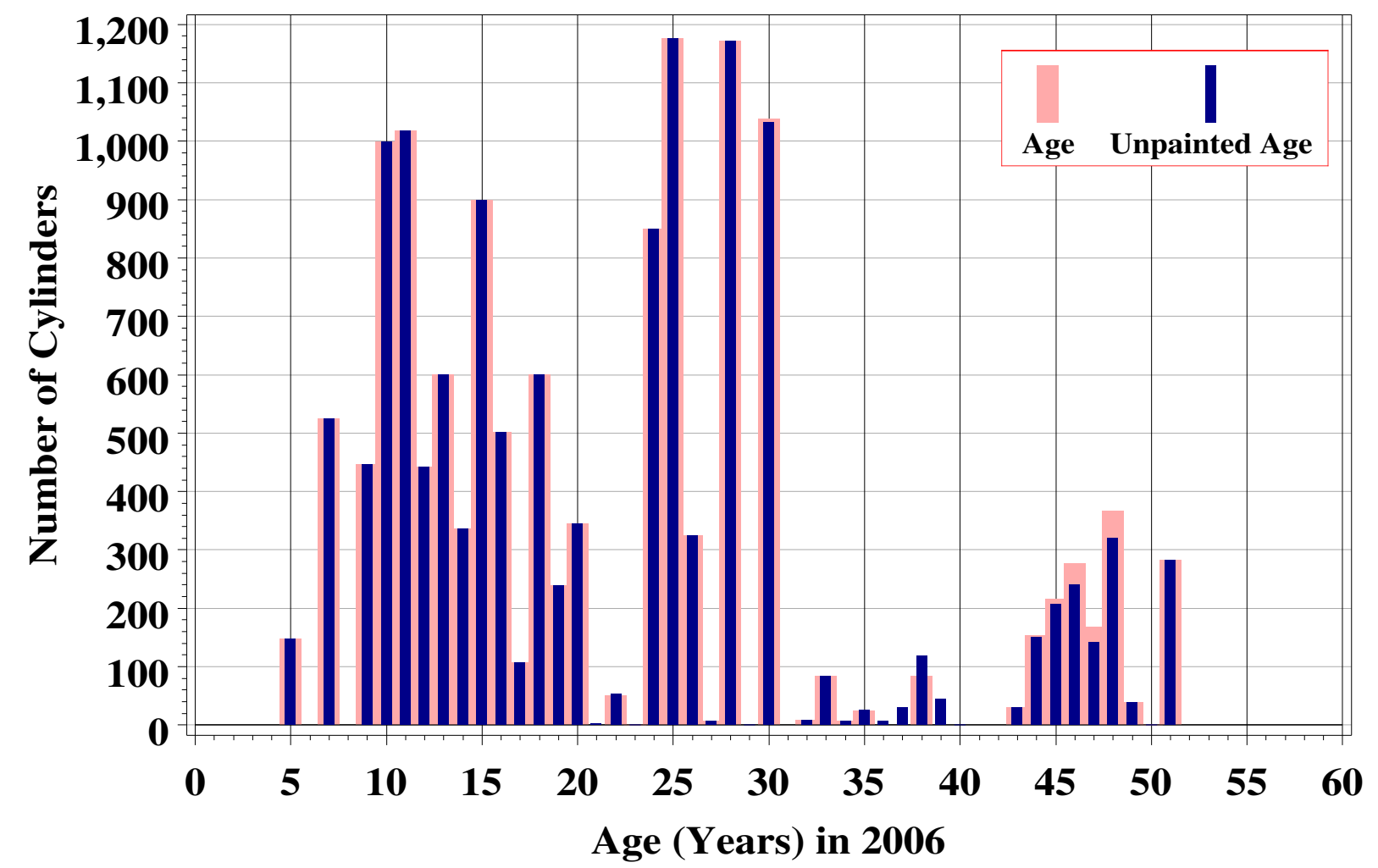

Figure 4. Age and unpainted age distributions for PGDP thin bottom cylinders except former G-yard. 


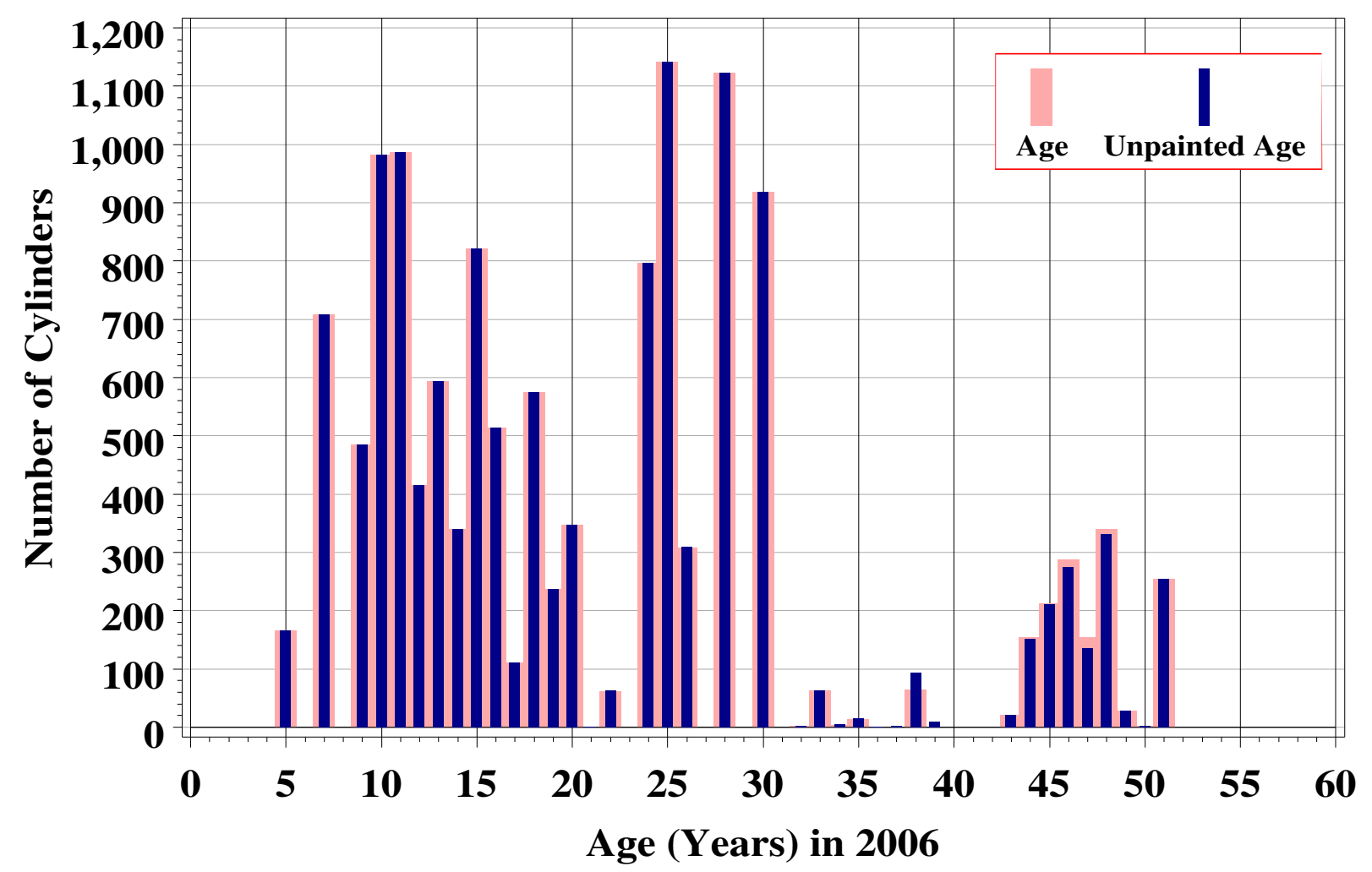

Figure 5. Age and unpainted age distributions for PGDP thin top cylinders.

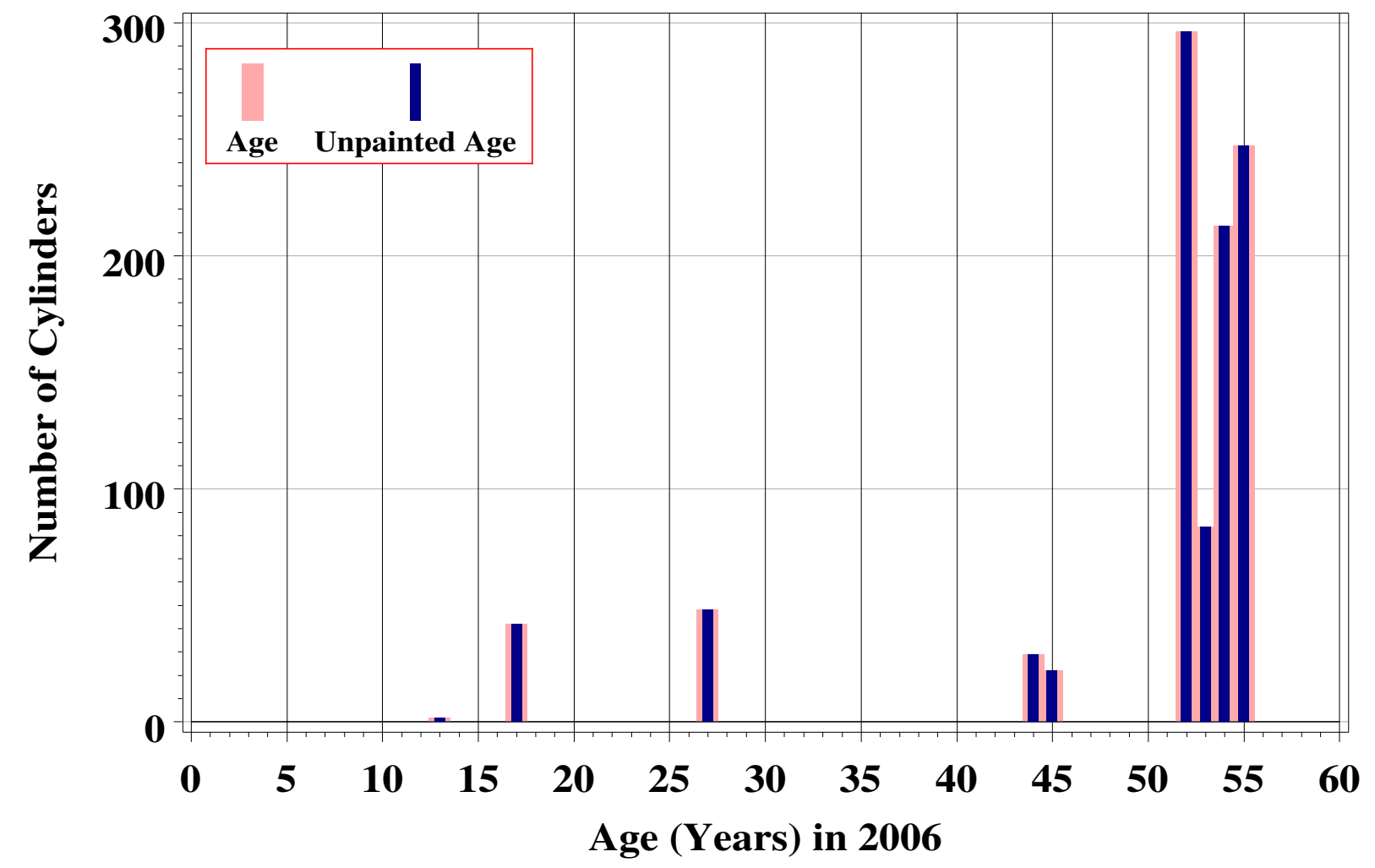

Figure 6. Age and unpainted age distributions for all thick top cylinders. 


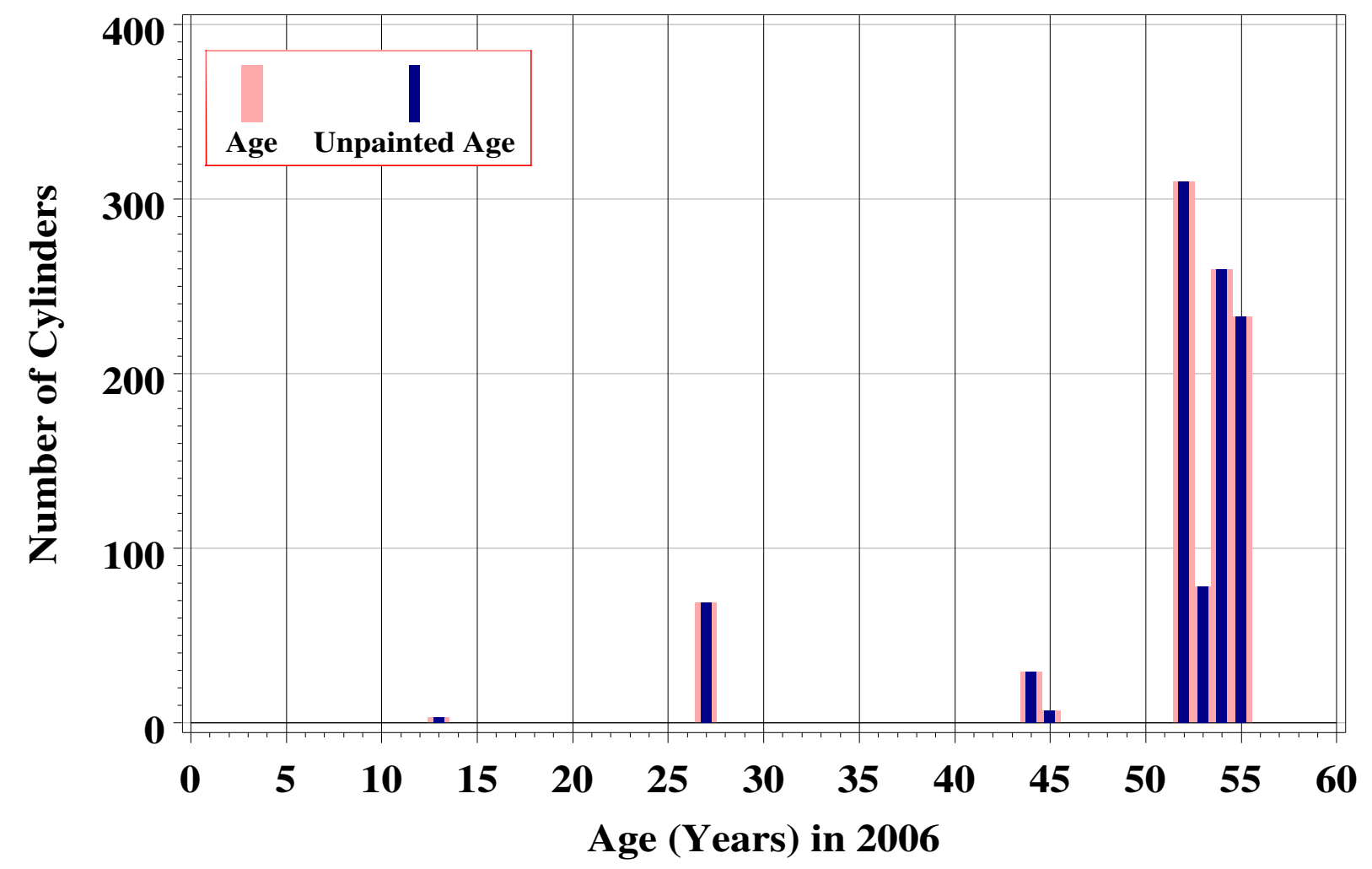

Figure 7. Age and unpainted age distributions for all thick bottom cylinders.

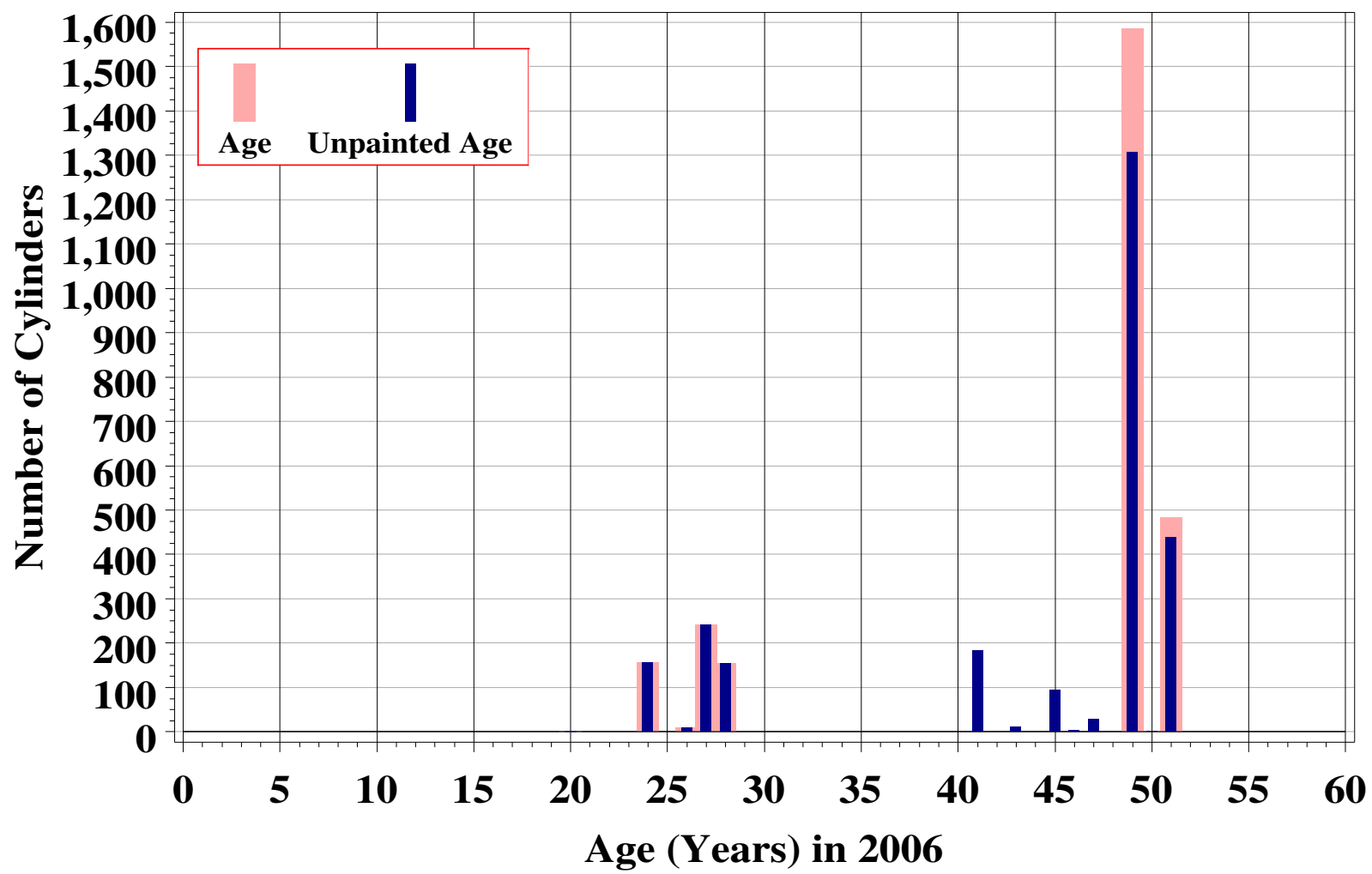

Figure 8. Age and unpainted age distributions for all thin top cylinders, head/skirt interface. 


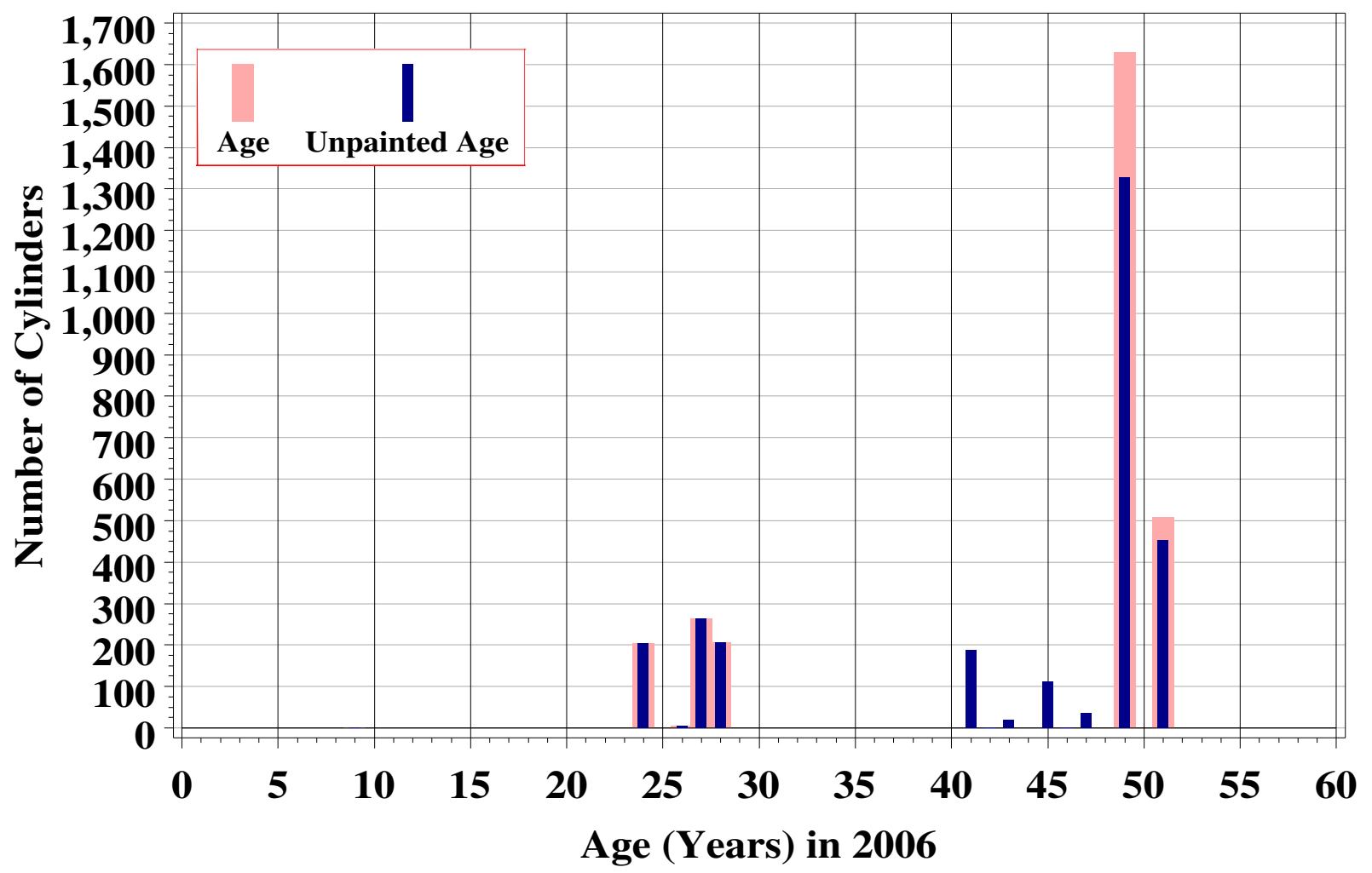

Figure 9. Age and unpainted age distributions for all thin bottom cylinders, head/skirt interface.

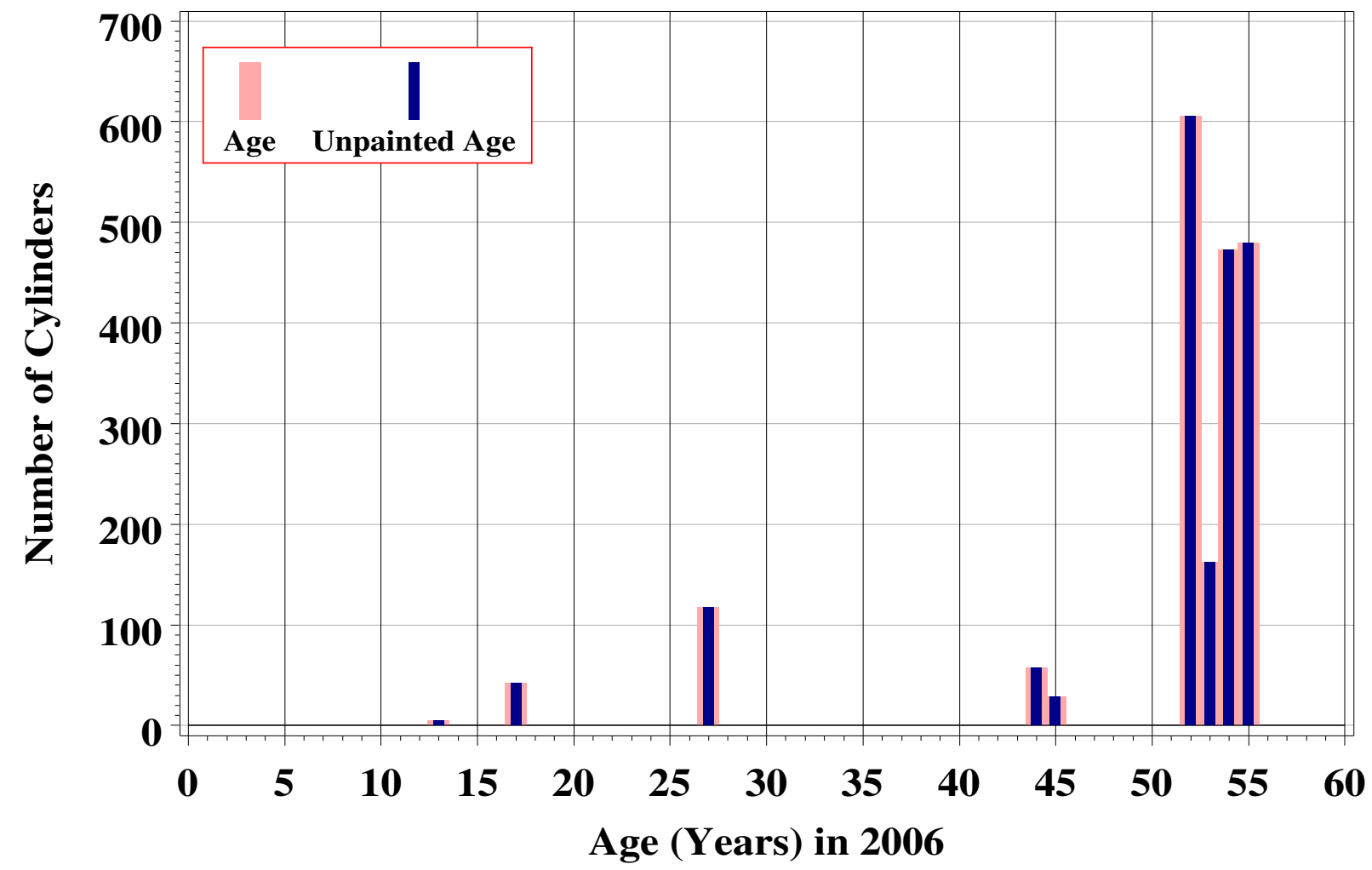

Figure 10. Age and unpainted age distributions for all thick cylinders, head/skirt interface. 


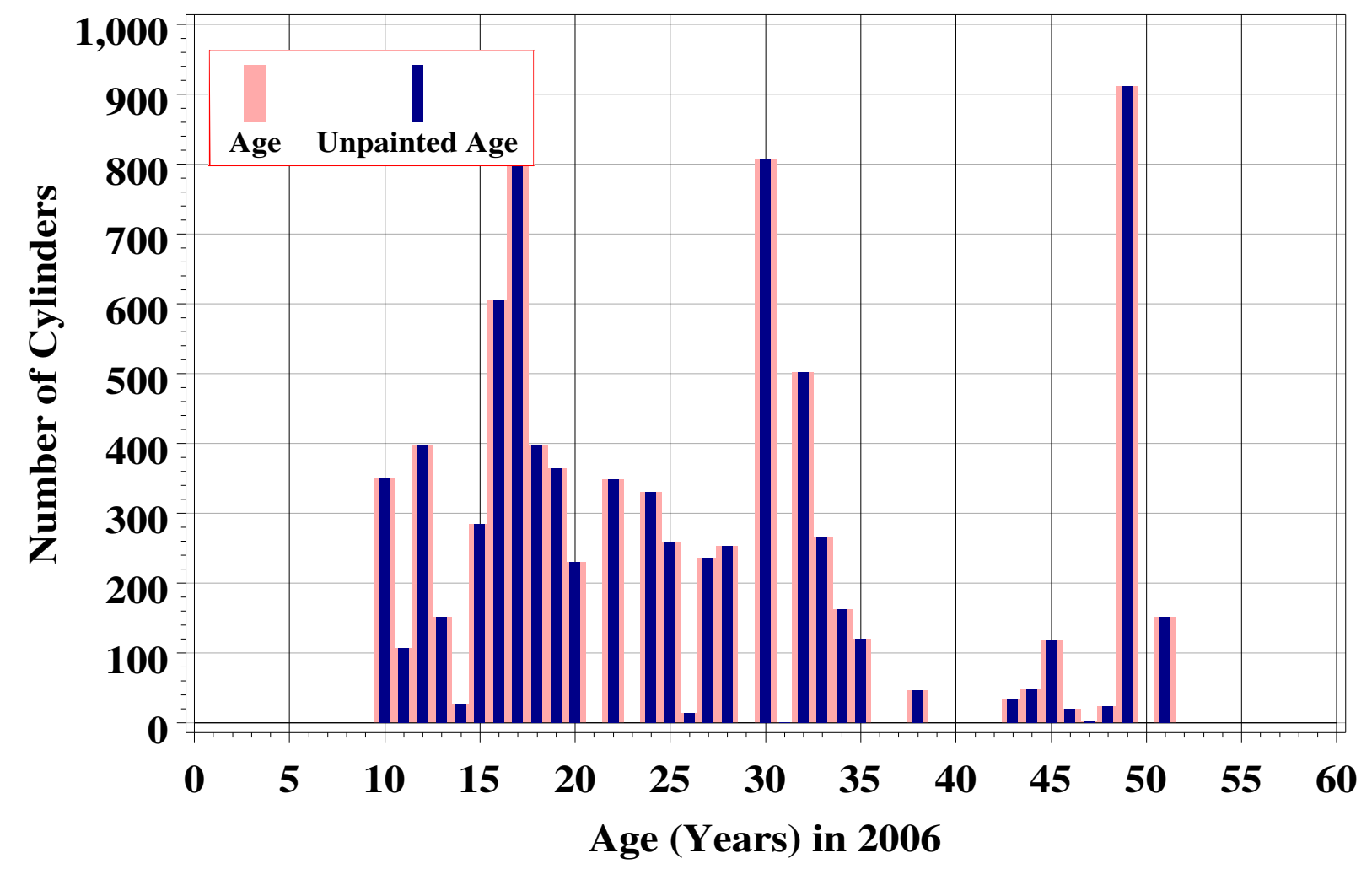

Figure 11. Age and unpainted age distributions for Portsmouth thin top cylinders.

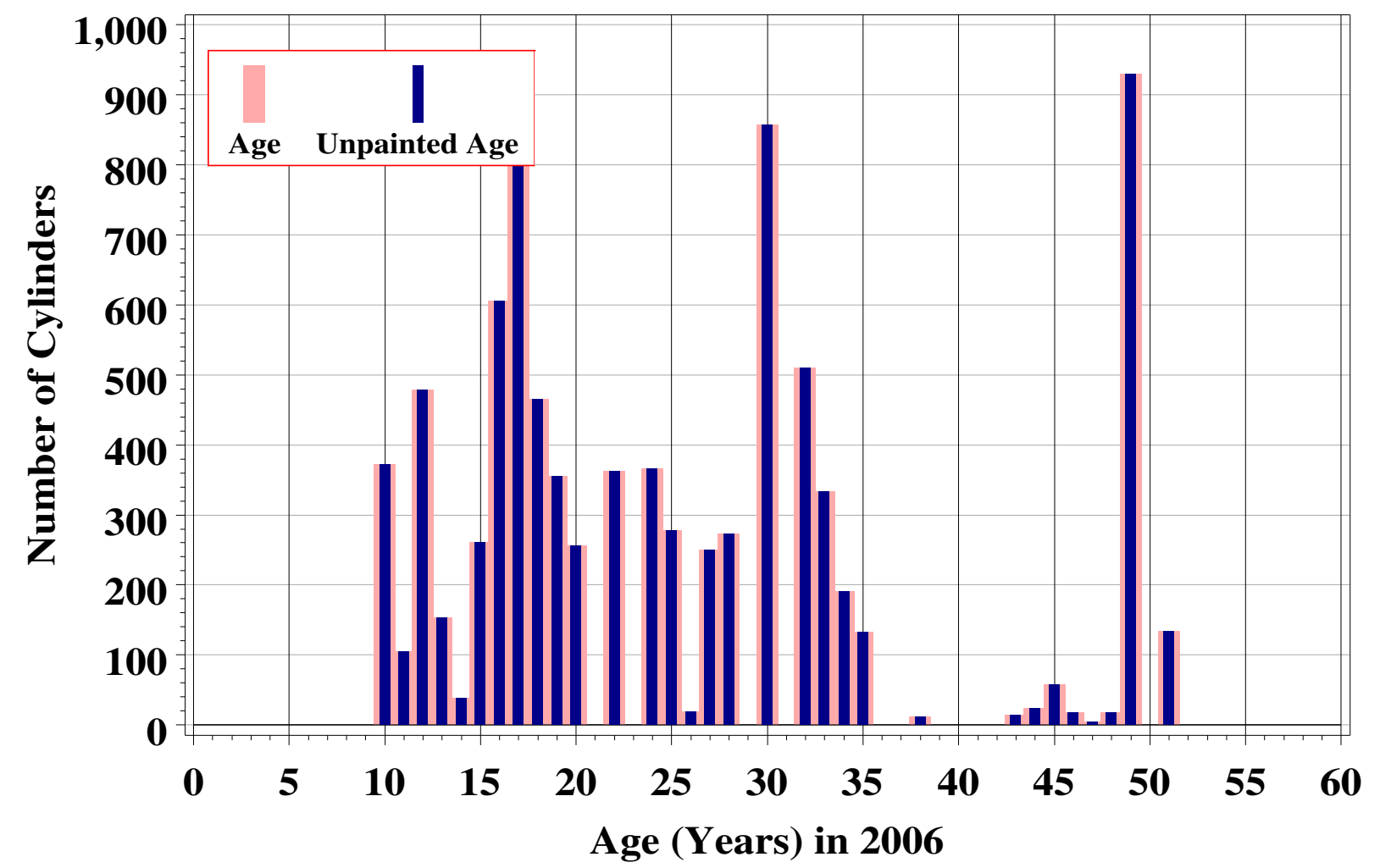

Figure 12. Age and unpainted age distributions for Portsmouth thin bottom cylinders. 


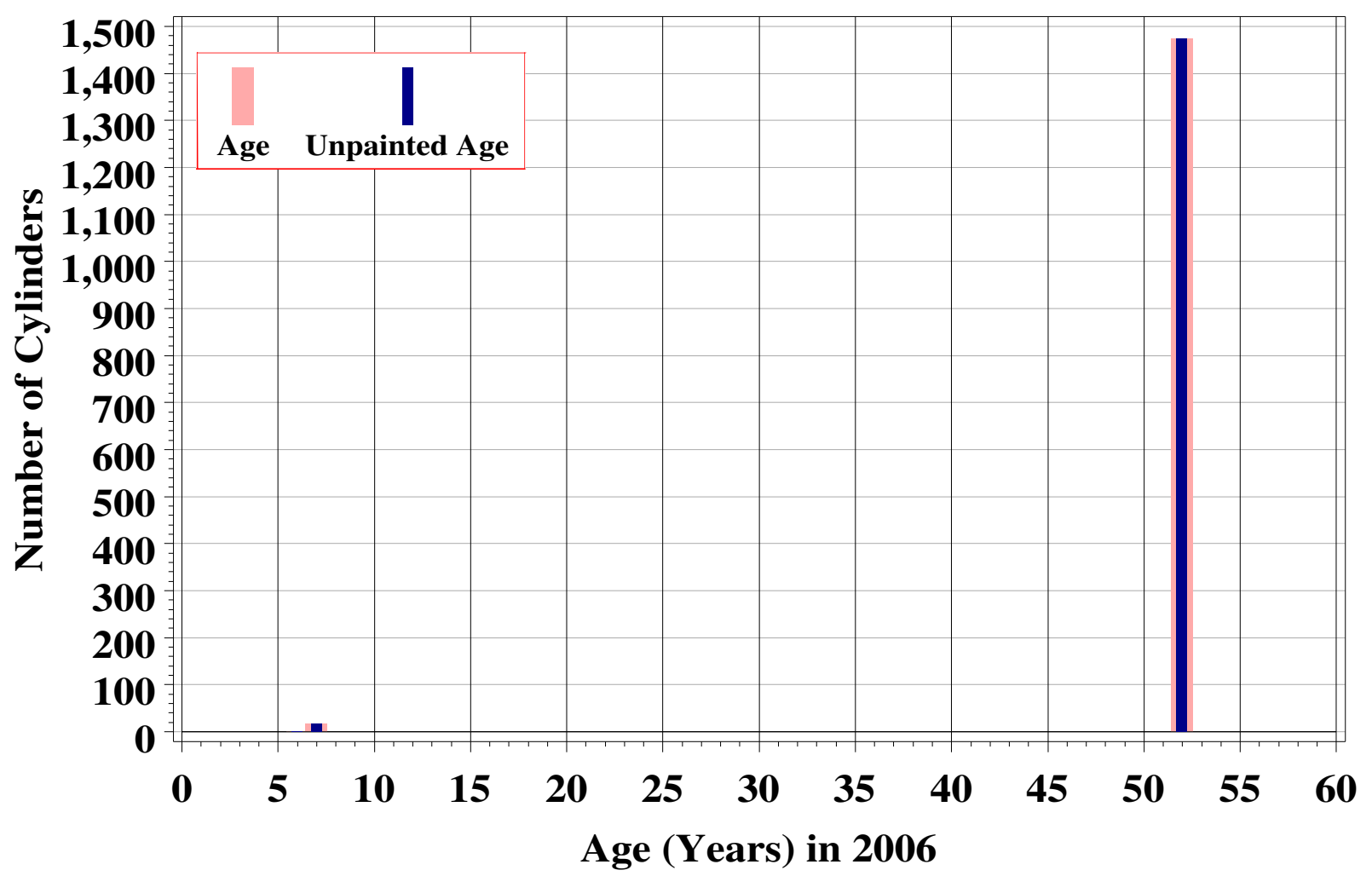

Figure 13. Age and unpainted age distributions for all 30A top cylinders.

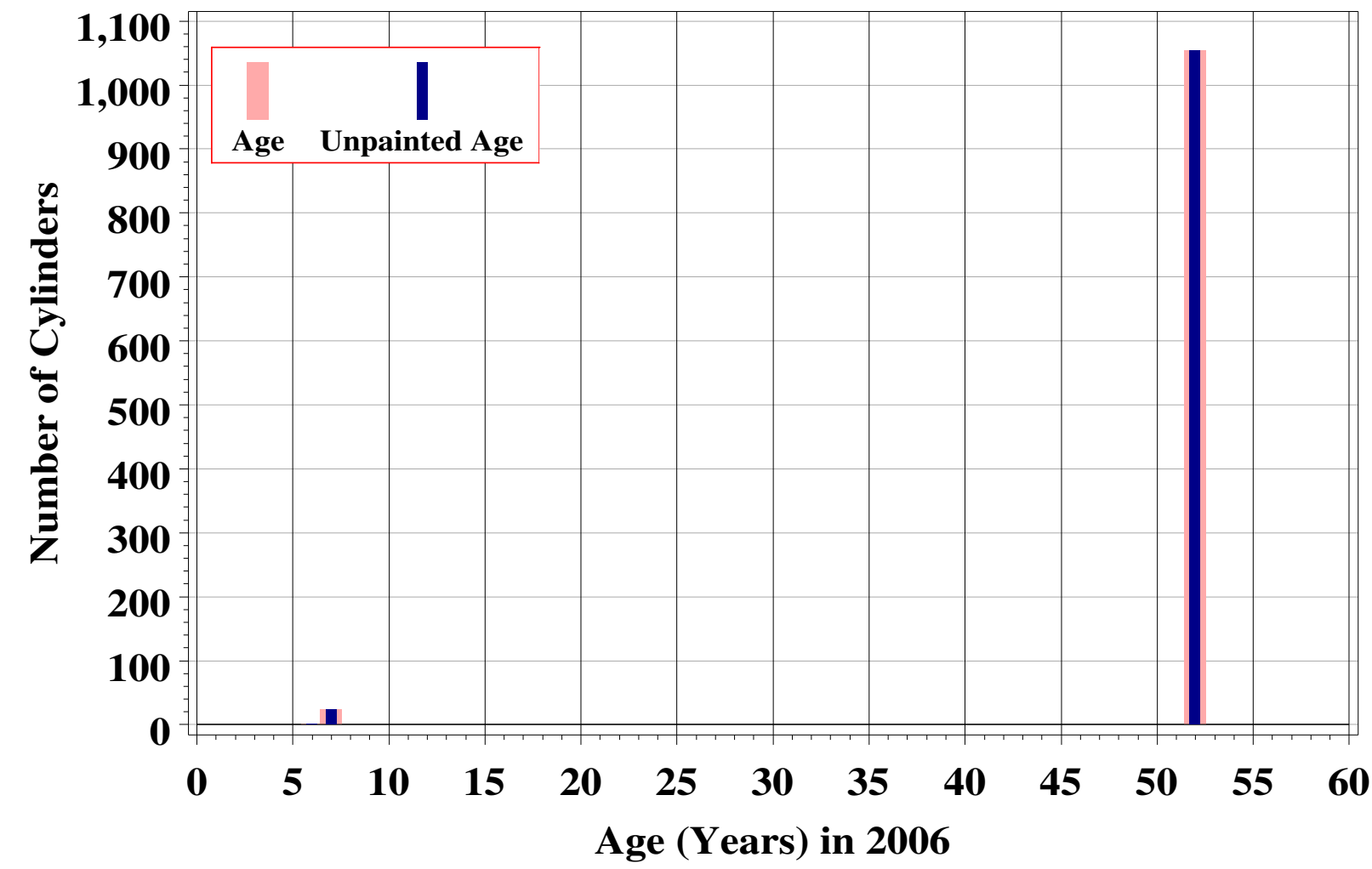

Figure 14. Age and unpainted age distributions for all $30 \mathrm{~A}$ bottom cylinders. 
Table 3A. Manual UT Main-Body Minimum Thickness Measurements By Fiscal Year and Site of Measurement

\begin{tabular}{|c|c|c|c|c|}
\hline $\begin{array}{l}\text { Fiscal } \\
\text { Year }\end{array}$ & $\begin{array}{c}\text { Site of } \\
\text { Measurement }\end{array}$ & Functional Group & $\begin{array}{l}\text { Number of } \\
\text { Cylinders } \\
\text { Measured }\end{array}$ & $\begin{array}{l}\text { Number not } \\
\text { Measured } \\
\text { Again Later }\end{array}$ \\
\hline \multirow[t]{2}{*}{1998} & ETTP & ETTP thin $\mathrm{K}$ btm & 19 & 18 \\
\hline & & ETTP thin except $\mathrm{K}$ btm & 21 & 17 \\
\hline 1998 & ETTP & & 40 & 35 \\
\hline \multirow[t]{6}{*}{1998} & Portsmouth & All thick top & 1 & 1 \\
\hline & & All thick btm & 1 & 1 \\
\hline & & PORTS thin top & 68 & 57 \\
\hline & & PORTS thin btm & 61 & 53 \\
\hline & & All 30A top & 4 & 4 \\
\hline & & All 30A btm & 9 & 9 \\
\hline 1998 & Portsmouth & & 144 & 125 \\
\hline 1998 & & & 184 & 160 \\
\hline \multirow[t]{2}{*}{1999} & ETTP & ETTP thin $\mathrm{K}$ btm & 17 & 16 \\
\hline & & ETTP thin except $\mathrm{K}$ btm & 13 & 12 \\
\hline 1999 & ETTP & & 30 & 28 \\
\hline \multirow[t]{5}{*}{1999} & PGDP & PGDP thin btm former $G$ & 102 & 100 \\
\hline & & PGDP thin btm except former G & 54 & 52 \\
\hline & & PGDP thin top & 40 & 40 \\
\hline & & All 30A top & 54 & 45 \\
\hline & & All $30 \mathrm{~A} \mathrm{btm}$ & 46 & 44 \\
\hline 1999 & PGDP & & 296 & 281 \\
\hline \multirow[t]{3}{*}{1999} & Portsmouth & All thick top & 12 & 4 \\
\hline & & PORTS thin top & 89 & 34 \\
\hline & & PORTS thin btm & 53 & 15 \\
\hline 1999 & Portsmouth & & 154 & 53 \\
\hline 1999 & & & 480 & 362 \\
\hline \multirow[t]{3}{*}{2000} & ETTP & ETTP thin $\mathrm{K}$ btm & 28 & 28 \\
\hline & & ETTP thin except $\mathrm{K}$ btm & 30 & 30 \\
\hline & & PGDP thin btm former $G$ & 1 & 1 \\
\hline 2000 & ETTP & & 59 & 59 \\
\hline \multirow[t]{3}{*}{2000} & PGDP & PGDP thin btm former $\mathrm{G}$ & 60 & 58 \\
\hline & & PGDP thin btm except former G & 24 & 24 \\
\hline & & PGDP thin top & 16 & 16 \\
\hline
\end{tabular}


Table 3A. Manual UT Main-Body Minimum Thickness Measurements By Fiscal Year and Site of Measurement

\begin{tabular}{|c|c|c|c|c|}
\hline $\begin{array}{l}\text { Fiscal } \\
\text { Year }\end{array}$ & $\begin{array}{c}\text { Site of } \\
\text { Measurement }\end{array}$ & Functional Group & $\begin{array}{l}\text { Number of } \\
\text { Cylinders } \\
\text { Measured }\end{array}$ & $\begin{array}{l}\text { Number not } \\
\text { Measured } \\
\text { Again Later }\end{array}$ \\
\hline 2000 & PGDP & & 100 & 98 \\
\hline \multirow[t]{4}{*}{2000} & Portsmouth & All thick top & 16 & 7 \\
\hline & & All thick btm & 7 & 6 \\
\hline & & PORTS thin top & 71 & 36 \\
\hline & & PORTS thin btm & 58 & 32 \\
\hline 2000 & Portsmouth & & 152 & 81 \\
\hline 2000 & & & 311 & 238 \\
\hline \multirow[t]{2}{*}{2001} & ETTP & ETTP thin $\mathrm{K}$ btm & 54 & 50 \\
\hline & & ETTP thin except $\mathrm{K}$ btm & 46 & 41 \\
\hline 2001 & ETTP & & 100 & 91 \\
\hline \multirow[t]{4}{*}{2001} & PGDP & PGDP thin btm except former $\mathrm{G}$ & 147 & 143 \\
\hline & & PGDP thin top & 93 & 92 \\
\hline & & All 30A top & 61 & 58 \\
\hline & & All 30A btm & 38 & 35 \\
\hline 2001 & PGDP & & 339 & 328 \\
\hline \multirow[t]{4}{*}{2001} & Portsmouth & All thick top & 9 & 3 \\
\hline & & All thick btm & 5 & 5 \\
\hline & & PORTS thin top & 81 & 45 \\
\hline & & PORTS thin btm & 58 & 32 \\
\hline 2001 & Portsmouth & & 153 & 85 \\
\hline 2001 & & & 592 & 504 \\
\hline \multirow[t]{2}{*}{2002} & ETTP & ETTP thin $\mathrm{K}$ btm & 50 & 47 \\
\hline & & ETTP thin except $\mathrm{K}$ btm & 53 & 49 \\
\hline 2002 & ETTP & & 103 & 96 \\
\hline \multirow[t]{5}{*}{2002} & PGDP & PGDP thin btm former $\mathrm{G}$ & 42 & 42 \\
\hline & & PGDP thin btm except former G & 17 & 17 \\
\hline & & PGDP thin top & 18 & 18 \\
\hline & & All 30A top & 20 & 20 \\
\hline & & All 30A btm & 5 & 5 \\
\hline 2002 & PGDP & & 102 & 102 \\
\hline \multirow[t]{2}{*}{2002} & Portsmouth & All thick top & 19 & 13 \\
\hline & & All thick btm & 17 & 17 \\
\hline
\end{tabular}


Table 3A. Manual UT Main-Body Minimum Thickness Measurements By Fiscal Year and Site of Measurement

\begin{tabular}{|c|c|c|c|c|}
\hline $\begin{array}{l}\text { Fiscal } \\
\text { Year }\end{array}$ & $\begin{array}{c}\text { Site of } \\
\text { Measurement }\end{array}$ & Functional Group & $\begin{array}{l}\text { Number of } \\
\text { Cylinders } \\
\text { Measured }\end{array}$ & $\begin{array}{l}\text { Number not } \\
\text { Measured } \\
\text { Again Later }\end{array}$ \\
\hline & & PORTS thin top & 63 & 23 \\
\hline & & PORTS thin btm & 54 & 27 \\
\hline 2002 & Portsmouth & & 153 & 80 \\
\hline 2002 & & & 358 & 278 \\
\hline \multirow[t]{5}{*}{2003} & PGDP & PGDP thin btm former $\mathrm{G}$ & 28 & 28 \\
\hline & & PGDP thin btm except former $G$ & 30 & 30 \\
\hline & & PGDP thin top & 22 & 22 \\
\hline & & All 30A top & 10 & 10 \\
\hline & & All $30 \mathrm{~A} \mathrm{btm}$ & 10 & 10 \\
\hline 2003 & PGDP & & 100 & 100 \\
\hline \multirow[t]{4}{*}{2003} & Portsmouth & All thick top & 27 & 18 \\
\hline & & All thick btm & 19 & 14 \\
\hline & & PORTS thin top & 63 & 32 \\
\hline & & PORTS thin btm & 46 & 30 \\
\hline 2003 & Portsmouth & & 155 & 94 \\
\hline 2003 & & & 255 & 194 \\
\hline \multirow[t]{4}{*}{2004} & ETTP & ETTP thin $\mathrm{K}$ btm & 32 & 32 \\
\hline & & ETTP thin except $\mathrm{K}$ btm & 128 & 126 \\
\hline & & All 30A top & 18 & 18 \\
\hline & & All 30A btm & 21 & 21 \\
\hline 2004 & ETTP & & 199 & 197 \\
\hline \multirow[t]{5}{*}{2004} & PGDP & PGDP thin btm former $\mathrm{G}$ & 38 & 38 \\
\hline & & PGDP thin btm except former G & 27 & 27 \\
\hline & & PGDP thin top & 27 & 27 \\
\hline & & All 30A top & 1 & 1 \\
\hline & & All $30 \mathrm{~A} \mathrm{btm}$ & 1 & 1 \\
\hline 2004 & PGDP & & 94 & 94 \\
\hline \multirow[t]{4}{*}{2004} & Portsmouth & All thick top & 18 & 12 \\
\hline & & All thick btm & 14 & 14 \\
\hline & & PORTS thin top & 76 & 53 \\
\hline & & PORTS thin btm & 44 & 32 \\
\hline 2004 & Portsmouth & & 152 & 111 \\
\hline
\end{tabular}


Table 3A. Manual UT Main-Body Minimum Thickness Measurements By Fiscal Year and Site of Measurement

\begin{tabular}{|c|c|c|c|c|}
\hline $\begin{array}{l}\text { Fiscal } \\
\text { Year }\end{array}$ & $\begin{array}{c}\text { Site of } \\
\text { Measurement }\end{array}$ & Functional Group & $\begin{array}{l}\text { Number of } \\
\text { Cylinders } \\
\text { Measured }\end{array}$ & $\begin{array}{l}\text { Number not } \\
\text { Measured } \\
\text { Again Later }\end{array}$ \\
\hline 2004 & & & 445 & 402 \\
\hline \multirow[t]{4}{*}{2005} & ETTP & ETTP thin $\mathrm{K}$ btm & 30 & 30 \\
\hline & & ETTP thin except $\mathrm{K}$ btm & 50 & 50 \\
\hline & & All 30A top & 28 & 28 \\
\hline & & All $30 \mathrm{~A} \mathrm{btm}$ & 32 & 32 \\
\hline 2005 & ETTP & & 140 & 140 \\
\hline \multirow[t]{5}{*}{2005} & PGDP & PGDP thin btm former $G$ & 19 & 19 \\
\hline & & PGDP thin btm except former G & 11 & 11 \\
\hline & & PGDP thin top & 11 & 11 \\
\hline & & All 30A top & 21 & 21 \\
\hline & & All 30A btm & 7 & 7 \\
\hline 2005 & PGDP & & 69 & 69 \\
\hline \multirow[t]{5}{*}{2005} & Portsmouth & ETTP thin $\mathrm{K}$ btm & 4 & 2 \\
\hline & & ETTP thin except $\mathrm{K}$ btm & 13 & 11 \\
\hline & & All thick top & 7 & 7 \\
\hline & & PORTS thin top & 61 & 61 \\
\hline & & PORTS thin btm & 70 & 70 \\
\hline 2005 & Portsmouth & & 155 & 151 \\
\hline 2005 & & & 364 & 360 \\
\hline \multirow[t]{3}{*}{2006} & ETTP & ETTP thin except $\mathrm{K}$ btm & 10 & 10 \\
\hline & & All thick top & 19 & 19 \\
\hline & & All thick btm & 18 & 18 \\
\hline 2006 & ETTP & & 47 & 47 \\
\hline \multirow[t]{4}{*}{2006} & Portsmouth & ETTP thin $\mathrm{K}$ btm & 9 & 9 \\
\hline & & ETTP thin except $\mathrm{K}$ btm & 20 & 20 \\
\hline & & PORTS thin top & 61 & 61 \\
\hline & & PORTS thin btm & 62 & 62 \\
\hline 2006 & Portsmouth & & 152 & 152 \\
\hline 2006 & & & 199 & 199 \\
\hline \multirow[t]{3}{*}{2007} & PGDP & PGDP thin btm former G & 58 & 58 \\
\hline & & PGDP thin btm except former G & 23 & 23 \\
\hline & & PGDP thin top & 19 & 19 \\
\hline
\end{tabular}


Table 3A. Manual UT Main-Body Minimum Thickness Measurements By Fiscal Year and Site of Measurement

\begin{tabular}{|r|l|l|r|r|}
\hline $\begin{array}{c}\text { Fiscal } \\
\text { Year }\end{array}$ & $\begin{array}{c}\text { Site of } \\
\text { Measurement }\end{array}$ & Functional Group & $\begin{array}{c}\text { Number of } \\
\text { Cylinders } \\
\text { Measured }\end{array}$ & $\begin{array}{c}\text { Number not } \\
\text { Measured } \\
\text { Again Later }\end{array}$ \\
\hline 2007 & PGDP & & 100 & 100 \\
\hline 2007 & & & 100 & 100 \\
\hline & & & 3,288 & 2,797 \\
\hline
\end{tabular}


Table 3B. Manual UT Head/Skirt Interface Minimum Thickness Measurements (At Portsmouth) By Fiscal Year

\begin{tabular}{|c|c|c|c|}
\hline $\begin{array}{l}\text { Fiscal } \\
\text { Year }\end{array}$ & Functional Group & $\begin{array}{l}\text { Number of } \\
\text { Cylinders } \\
\text { Measured }\end{array}$ & $\begin{array}{l}\text { Number not } \\
\text { Measured } \\
\text { Again Later }\end{array}$ \\
\hline \multirow[t]{3}{*}{1997} & All thin top, head/skirt & 118 & 2 \\
\hline & All thin btm, head/skirt & 114 & 2 \\
\hline & All thick, head/skirt & 115 & 42 \\
\hline 1997 & & 347 & 46 \\
\hline \multirow[t]{3}{*}{2000} & All thin top, head/skirt & 48 & 22 \\
\hline & All thin btm, head/skirt & 39 & 19 \\
\hline & All thick, head/skirt & 23 & 13 \\
\hline 2000 & & 110 & 54 \\
\hline \multirow[t]{3}{*}{2001} & All thin top, head/skirt & 50 & 25 \\
\hline & All thin btm, head/skirt & 49 & 29 \\
\hline & All thick, head/skirt & 14 & 8 \\
\hline 2001 & & 113 & 62 \\
\hline \multirow[t]{3}{*}{2002} & All thin top, head/skirt & 42 & 11 \\
\hline & All thin btm, head/skirt & 33 & 14 \\
\hline & All thick, head/skirt & 36 & 30 \\
\hline 2002 & & 111 & 55 \\
\hline \multirow[t]{3}{*}{2003} & All thin top, head/skirt & 42 & 19 \\
\hline & All thin btm, head/skirt & 26 & 16 \\
\hline & All thick, head/skirt & 46 & 32 \\
\hline 2003 & & 114 & 67 \\
\hline \multirow[t]{3}{*}{2004} & All thin top, head/skirt & 44 & 28 \\
\hline & All thin btm, head/skirt & 37 & 31 \\
\hline & All thick, head/skirt & 32 & 27 \\
\hline 2004 & & 113 & 86 \\
\hline \multirow[t]{3}{*}{2005} & All thin top, head/skirt & 20 & 20 \\
\hline & All thin btm, head/skirt & 12 & 12 \\
\hline & All thick, head/skirt & 6 & 6 \\
\hline 2005 & & 38 & 38 \\
\hline \multirow[t]{2}{*}{2006} & All thin top, head/skirt & 13 & 13 \\
\hline & All thin btm, head/skirt & 16 & 16 \\
\hline \multirow[t]{2}{*}{2006} & & 29 & 29 \\
\hline & & 975 & 437 \\
\hline
\end{tabular}


Table 3C. P-Scan Main-Body Minimum Thickness Measurements By Fiscal Year and Site of Measurement

\begin{tabular}{|c|c|c|c|c|}
\hline $\begin{array}{l}\text { Fiscal } \\
\text { Year }\end{array}$ & $\begin{array}{c}\text { Site of } \\
\text { Measurement }\end{array}$ & Functional Group & $\begin{array}{l}\text { Number of } \\
\text { Cylinders } \\
\text { Measured }\end{array}$ & $\begin{array}{c}\text { Number not } \\
\text { Measured } \\
\text { Again }\end{array}$ \\
\hline 1992 & ETTP & ETTP thin $\mathrm{K}$ btm & 2 & 0 \\
\hline \multirow[t]{2}{*}{1994} & ETTP & ETTP thin $\mathrm{K}$ btm & 48 & 38 \\
\hline & & ETTP thin except $\mathrm{K}$ btm & 67 & 61 \\
\hline 1994 & ETTP & & 115 & 99 \\
\hline 1994 & & & 115 & 99 \\
\hline \multirow[t]{3}{*}{1995} & PGDP & PGDP thin btm former $G$ & 32 & 29 \\
\hline & & PGDP thin btm except former G & 36 & 28 \\
\hline & & PGDP thin top & 32 & 27 \\
\hline 1995 & PGDP & & 100 & 84 \\
\hline 1995 & & & 100 & 84 \\
\hline \multirow[t]{4}{*}{1996} & PGDP & PGDP thin btm former $G$ & 234 & 216 \\
\hline & & PGDP thin btm except former G & 8 & 7 \\
\hline & & PGDP thin top & 6 & 5 \\
\hline & & All thick btm & 1 & 1 \\
\hline 1996 & PGDP & & 249 & 229 \\
\hline \multirow[t]{5}{*}{1996} & Portsmouth & PGDP thin btm former $G$ & 1 & 1 \\
\hline & & All thick top & 65 & 8 \\
\hline & & All thick btm & 70 & 15 \\
\hline & & PORTS thin top & 233 & 32 \\
\hline & & PORTS thin btm & 239 & 73 \\
\hline 1996 & Portsmouth & & 608 & 129 \\
\hline 1996 & & & 857 & 358 \\
\hline \multirow[t]{2}{*}{1997} & PGDP & PGDP thin btm former $\mathrm{G}$ & 2 & 1 \\
\hline & & PGDP thin btm except former G & 1 & 1 \\
\hline 1997 & PGDP & & 3 & 2 \\
\hline \multirow[t]{2}{*}{1997} & Portsmouth & PORTS thin top & 44 & 21 \\
\hline & & PORTS thin btm & 43 & 42 \\
\hline 1997 & Portsmouth & & 87 & 63 \\
\hline \multirow[t]{2}{*}{1997} & & & 90 & 65 \\
\hline & & & 1,164 & 606 \\
\hline
\end{tabular}


FY97. During FY97, both head/skirt interface and overall minimum wall UT measurements were made, nearly all at Portsmouth, mostly for the head/skirt interface. Head/skirt measurements were made for 115 thick-wall and 232 thin-wall cylinders. The head/skirt measurements were made using a manual UT probe; the overall cylinder body measurements were by P-scanning. The cylinders measured at Portsmouth, which had originally been systematically set aside as part of the $10 \%$ criterion, were randomly selected from those cylinders moved during the year. Originally, it was suggested that approximately 250 cylinders should be measured (Lyon and Lykins 1996). However, budget constraints allowed for only $87 \mathrm{P}$-scan evaluations. Three P-scan evaluations of thin-wall cylinders were also made at Paducah. These cylinders were located in the north end of the C-745-F yard when they were measured.

\section{FY97 marks the end of the P-scan UT cylinder data.}

FY98. Four cylinder populations were sampled in FY98, though the data for only three of the samples is used for this report. The first sample consisted of 40 thin-wall cylinders randomly selected from cylinders then in K-1066-K yard at ETTP. These cylinders were chosen from a population of 400 cylinders that were moved to K-1066-E yard during FY98. The second sample-the one that is not used for modeling in this report—consisted of 200 thin-wall cylinders randomly selected from Paducah yards. The Paducah data was representative only of relatively uncorroded locations on each cylinder and therefore is not used for determining either minimum wall thickness or wall loss and is not indicated in Table 3A. The Paducah cylinders were remeasured in FY99 to estimate minimum wall thicknesses for each cylinder. The third sample consisted of 129 thin-wall, 2 thick-wall, and 13 30A cylinders at Portsmouth X-745-C and E yards. Some of the Portsmouth cylinders were also measured in FY96. All of these UT measurements were made with a manual probe.

FY99. There were four sampling efforts in FY99. One effort consisted of 30 thin-wall cylinders randomly selected from ETTP K-1066-K yard. The cylinders were from a functional group of 155 cylinders that could be measured without cylinder movement. All but one of these cylinders was chosen randomly, with the additional one selected by field personnel because of its history of ground/water contact. The second effort was an evaluation of 196 thin-wall cylinders at Paducah (originally slated for measurement in FY98). In the third effort, which was conducted at Portsmouth, measurements were made on 12 thick-wall and 138 thin-wall 48" cylinders. The fourth effort consisted of measurements of 100 model 30 A cylinders from the population of 1,825 at Paducah.

FY2000. UT measurements in FY2000 included 59 thin-wall cylinders from K-1066-K yard at ETTP, 100 thin-wall cylinders at Paducah, and 129 thin-wall and 23 thick-wall cylinders at Portsmouth. At ETTP, the UT procedure involved making nine measurements along the bottom and top (six and twelve o'clock) lines of the cylinders. At PGDP nine measurements were made at various locations. At Portsmouth twelve measurements were made at approximately equally spaced points on the cylinder ends and bodies, and five additional measurements were made in the areas considered to have the worst corrosion. UT measurements at the head/skirt interface crevice were also made at Portsmouth for all 23 of the thick-wall cylinders and for 87 of the thin-wall and cylinders. On each of these cylinders, five measurements were made at the head/skirt interface. Some of the Portsmouth cylinders had been measured previously and many would be measured again subsequently.

FY01. FY01 UT measurements were made for 100 thin-wall ETTP cylinders, mostly from bottom rows of K-1066-K yard. At Paducah, 240 48" thin-wall cylinders were measured from (present or former B, C, $\mathrm{F}$, and $\mathrm{K}$ yards), and 99 30A cylinders (from A and D yards) were measured. At Portsmouth, 139 thinwall cylinders and 14 thick-wall cylinders were measured, all from X-745-E yard. Head-skirt measurements were also made at Portsmouth for 14 thick-wall cylinders and for 99 thin-wall cylinders. At ETTP, the UT procedure involved making four measurements considered to be of the original thickness and five or six additional measurements. The PGDP cylinders were sampled using a random number generator, and the locations of the measurements on the cylinders were as for ETTP. Locations 
on the cylinders of the Portsmouth measurements were as in FY2000. Some of the Portsmouth cylinders had been measured before, and many would be measured again.

FY02. FY02 UT measurements at ETTP were made on a sample of 10348 " thin-wall cylinders. At PGDP, 77 thin-wall cylinders and 25 30A cylinders were sampled and measured. At Portsmouth, 117 thin-wall and 36 thick-wall were measured. The ETTP and PGDP measurements were located on the cylinders as in FY01. Head-skirt measurements were also made at Portsmouth for the 36 thick-wall cylinders and for 75 of the thin-wall cylinders. Locations on the cylinders of the Portsmouth measurements were as in FY2000. Many of the Portsmouth cylinders had been measured before, and many would be measured again.

FY03. FY03 UT measurements were made for 80 thin-wall and $2030 \mathrm{~A}$ cylinders. Ten of the $30 \mathrm{~A}$ measurements and five of the thin-wall measurements were remeasurements of cylinders identified as outliers in the corrosion model analysis for the 2002 edition of this report. The remaining 85 cylinders (75 thin-wall and $1030 \mathrm{~A}$ cylinders) were sampled randomly from unpainted PGDP cylinders that were ten or more years old. At Portsmouth, 109 thin-wall and 46 thick-wall cylinders were measured. These cylinders were sampled as in previous years, and most had been sampled before. The pattern of UT measurements (and the UT data sheets) were the same as in FY2000. Head/skirt interface measurements were made at Portsmouth for 68 of the thin-wall cylinders and for all 46 of the thick-wall cylinders.

FY04. UT measurements were made on 160 thin-wall and 39 30A cylinders at ETTP in FY04. A random sample 100 thin-wall cylinders were measured in early FY04 (before December 4, 2003, mostly from K-1066-E yard). The remaining ETTP cylinders (60 thin-wall and $3930 \mathrm{As})^{7}$ were measured in late FY04 as part of preparations for transferring cylinders to Portsmouth. The cylinders measured in preparation for transfer were not randomly sampled, but the same nine-measurement UT protocol used for the cylinders measured at ETTP earlier in FY04 was also used for the remaining cylinders. At PGDP 92 thin-wall and two 30A cylinders were measured. Several of these were remeasurements of outliers identified in the 2003 cylinder report. Finally 32 thick-wall and 120 thin-wall cylinders were measured at Portsmouth. Head/skirt interface measurements were made on 81 of the thin-wall and all 32 of the thick-wall cylinders. Most of the Portsmouth cylinders had been measured previously and many would be measured again.

FY05. At ETTP in early FY05 80 thin-wall and 60 30A cylinders were measured as a continuation of the UT measurements made in conjunction with the transfer of cylinders to Portsmouth. ${ }^{8}$ At PGDP, 41 thinwall and 28 30A cylinders were measured. At Portsmouth, 7 thick-wall and 141 thin-wall plus 17 additional thin-wall cylinders from ETTP were measured. Head/skirt interface measurements were made for 32 of the thin-wall and 6 of the thick-wall cylinders. Many of the Portsmouth cylinders had been measured before. Four of them would be measured again in FY06. Measurement protocols at each site were as described above for FY04 or before.

FY06. In FY06, at ETTP, 47 thick-wall cylinders were measured as part of preparations for the final cylinder transfers to Portsmouth. At Portsmouth 152 thin-wall cylinders were measured, 20 of which were ETTP transfers. Head/skirt interface measurement were made on 29 of the cylinders. Measurement protocols at each site were as described above.

FY07. 100 thin-wall cylinders were measured at Paducah between October 23 and November 3, 2006. These UT measurements are included, sometimes as FY06 entries, in the analyses performed for this report.

${ }^{7}$ Data kindly provided by Helen Henson, Henson Technical Projects, LLC.

${ }^{8}$ Ibid. 


\subsection{Data Inventory by Functional Group}

In this section the UT data is inventoried by functional group, site within functional group, and fiscal year the measurements were made. Here "site within functional group" refers to the site that leads to the functional group (i.e., where the cylinder was stored for the longest time). Some functional groups, such as the "ETTP thin, K-yard bottom row" group, have cylinders associated with only one site, but others, such as the "All thick top"group, have cylinders associated with multiple sites. Table 4A shows this inventory for manual UT main cylinder body measurements. Table 4B shows the inventory for head/skirt interface UT measurements. Table 4C shows the inventory for main-body P-scan measurements. Finally, Table 4D shows the site-specific functional groups for which no UT measurements have yet been made. Along with the numbers of UT-measured cylinders, total cylinder population counts, and average and maximum cylinder ages are also listed in the tables. All cylinder ages referred to in this subsection are as of the end of 9/30/2006 and are not adjusted for painting. Note that the cylinders in the skirted groups are treated as separate functional groups (the skirted ends) as far as UT measurements are concerned. For main-body measurements, those cylinders themselves are also in other thick-wall or thinwall functional groups.

ETTP thin-wall K-1066-K-yard bottom-row cylinders. The bottom rows of ETTP K-1066-K yard were considered to represent worst-case storage conditions at ETTP. A large portion of these K-yard cylinders were at one time stored in ground contact at K-1066-G yard, starting about 1966. They were relocated to K-yard in 1983 (Barber et al. 1994), where they were stored either in top or bottom rows. According to CID records there are 1,491 cylinders that were stored in ETTP K-yard for more than one year. Of course, all of these cylinders have now been moved to Portsmouth. Nevertheless, for corrosion modeling they are classified as ETTP K-yard bottom-row cylinders. Of the 1,491 cylinders so classified, 349 are listed in the CID as having been painted (since 1996). Their average age is 46.8 and their maximum age is 51 years. UT measurements have been made on 232 of these cylinders.

ETTP thin-wall cylinders except K-1066-K yard bottom-row cylinders. This functional group consists of 3,262 thin-wall cylinders whose longest unpainted residency period was at ETTP, other than the cylinders in the K-yard bottom group discussed above. Their average age is 38.3 years, and the oldest is 55 years old. The CID lists 335 of these cylinders as having been painted. UT measurements have been made for 366 if these cylinders.

PGDP thin-wall bottom-row unrefurbished C-745-G-yard cylinders. This group consists of 9,106 cylinders that were in the unrefurbished PGDP G-yard for more than one year. The PGDP G-yard was refurbished in June of 1995. These cylinders have average age 37.7 and maximum age 48 years. A painting program was initiated for cylinders moved from C-745-G to C-745-S yard in FY96. Of the 9,106 cylinders in this group, 3,188 have been painted (since 1996). UT measurements have been made on 344 .

PGDP thin-wall bottom-row cylinders except unrefurbished C-745-G-yard cylinders. This functional group consists of 13,567 cylinders of ages ranging up to 51 years. Their average age is 22.3 years. 127 of these cylinders have paint dates listed in the CID. UT measurements have been made on 327.

PGDP thin-wall top-row cylinders. This functional group has 13,231 cylinders of ages up to 51 years, averaging 21.9 years. UT measurements have been made on 245 of them. 53 of the cylinders have paint dates listed in the CID 


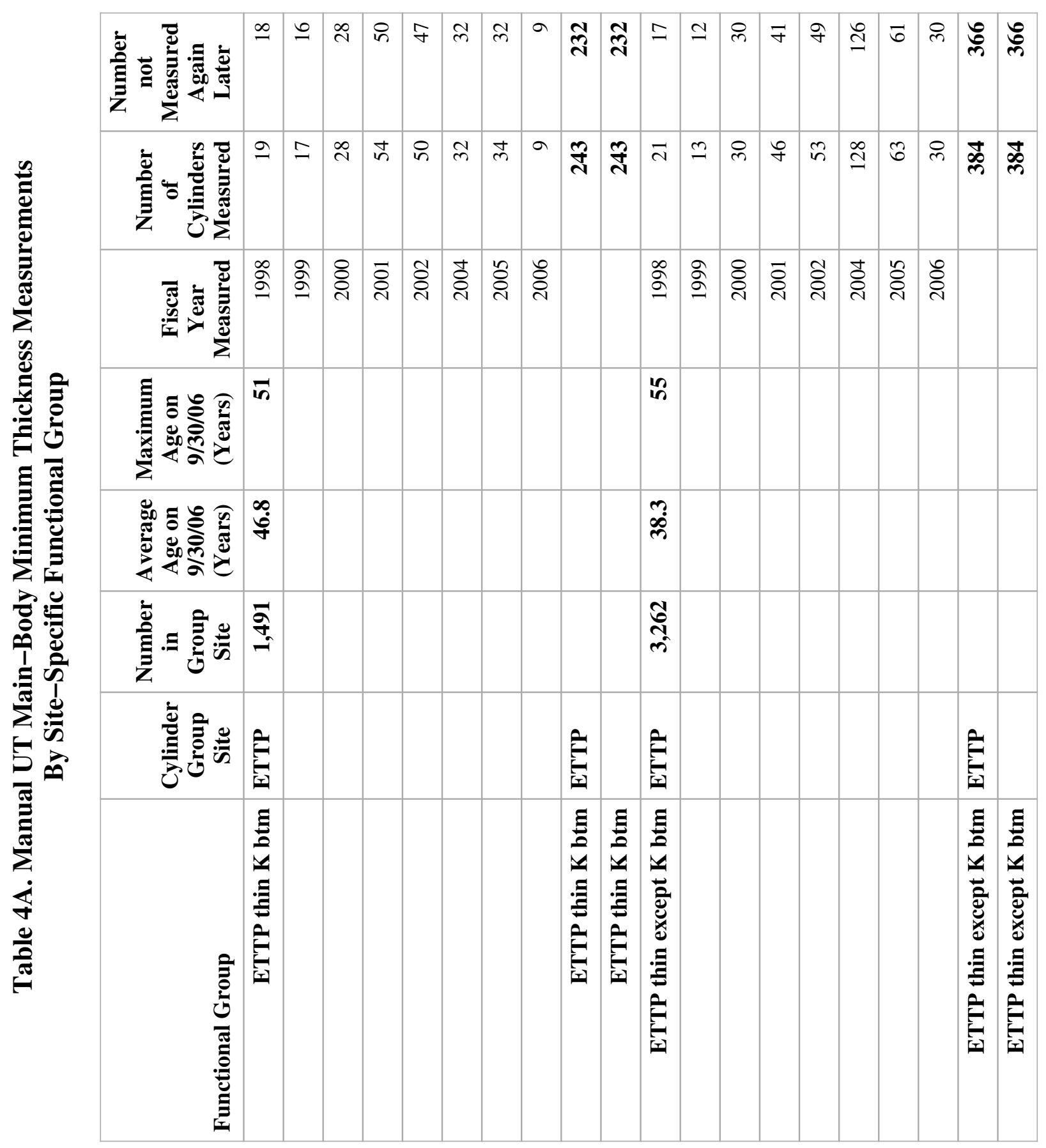




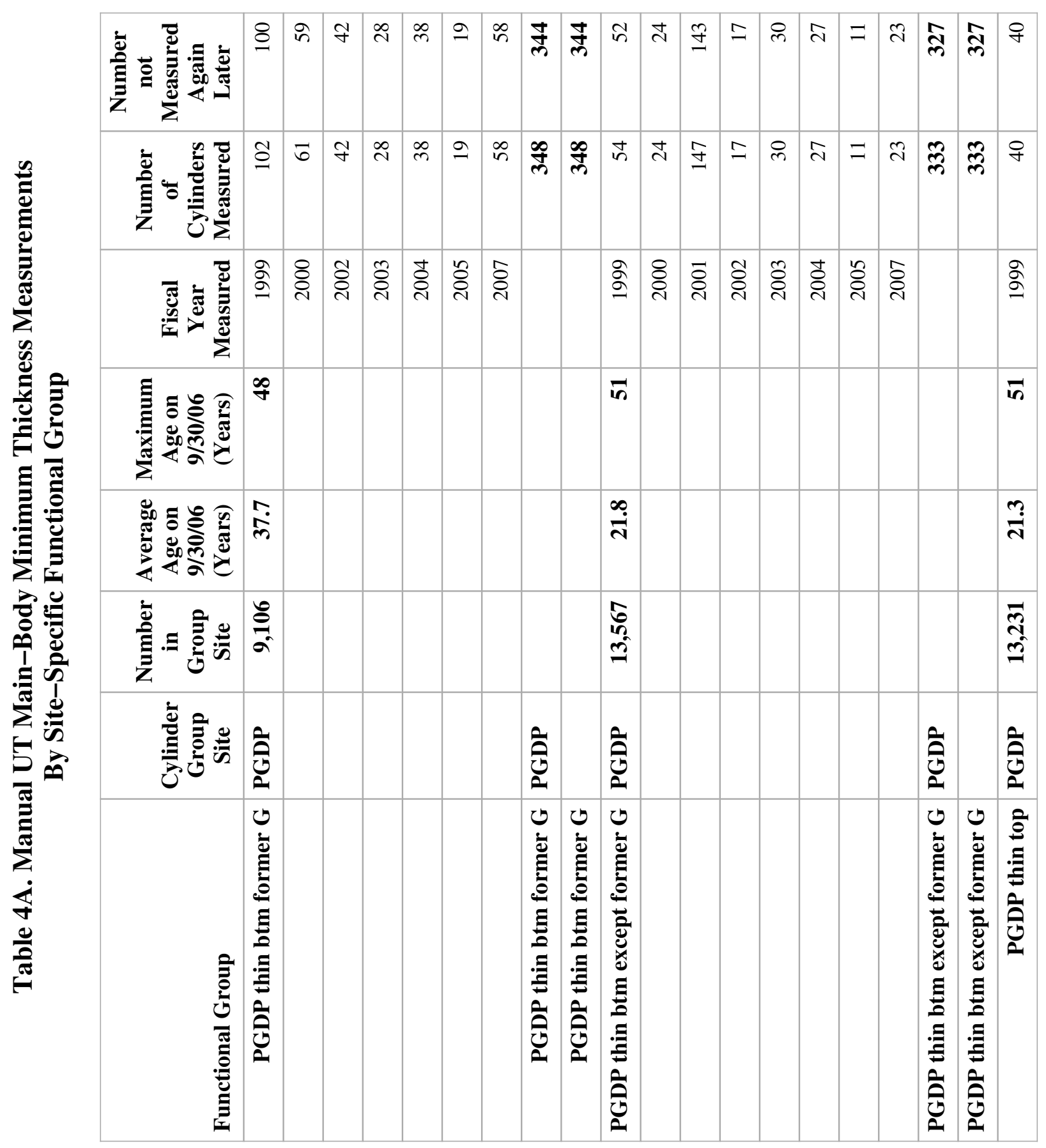




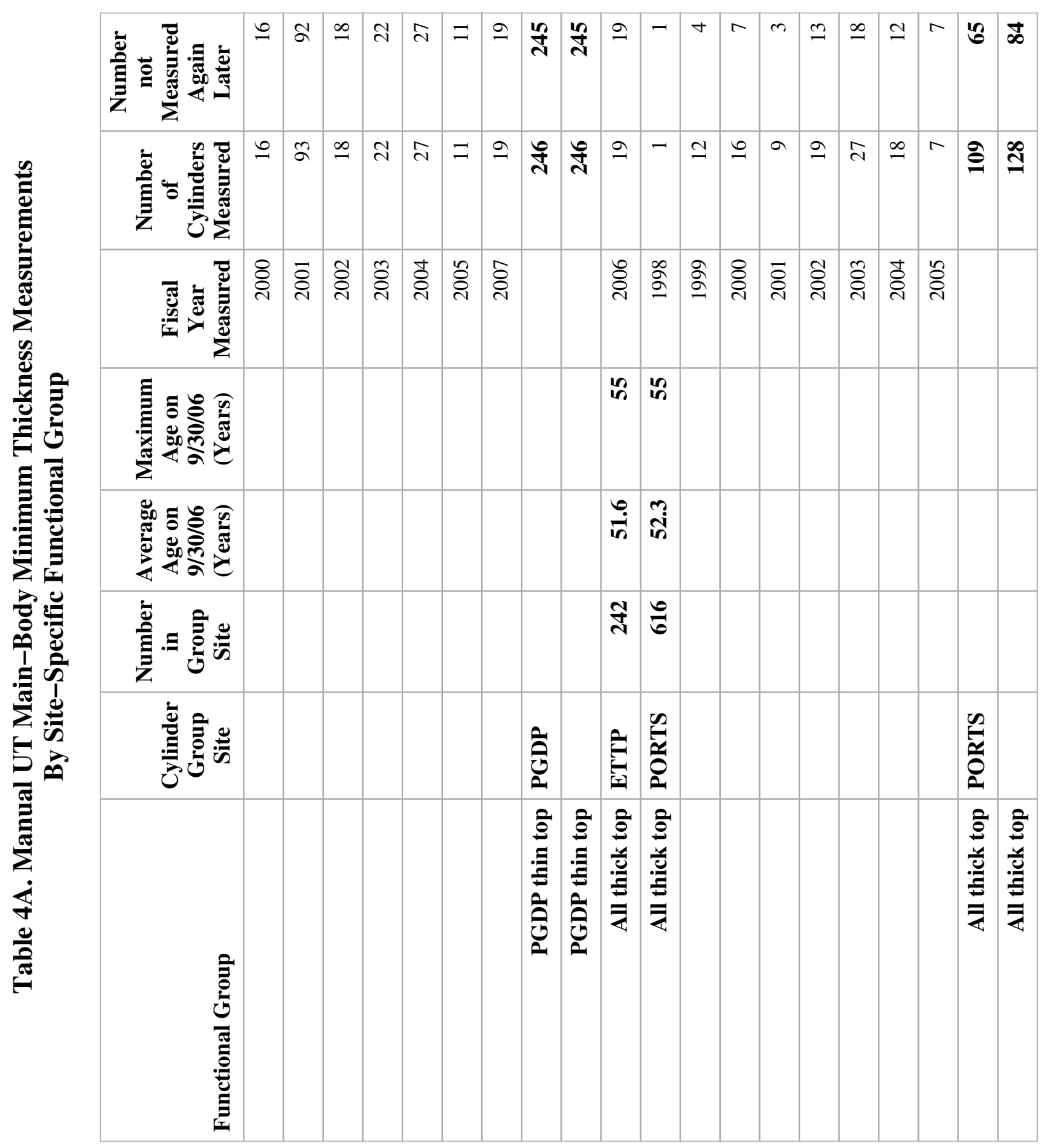




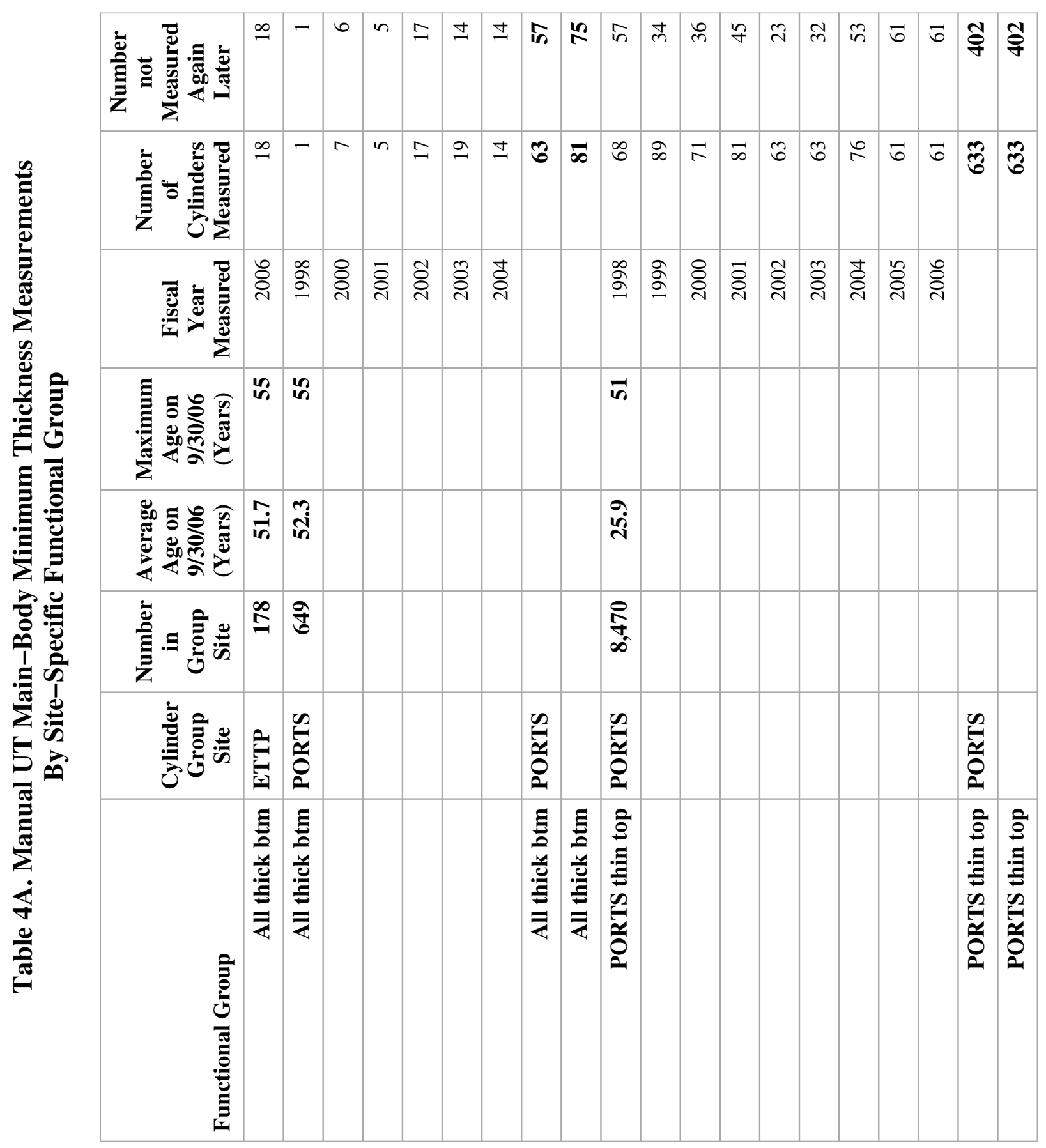




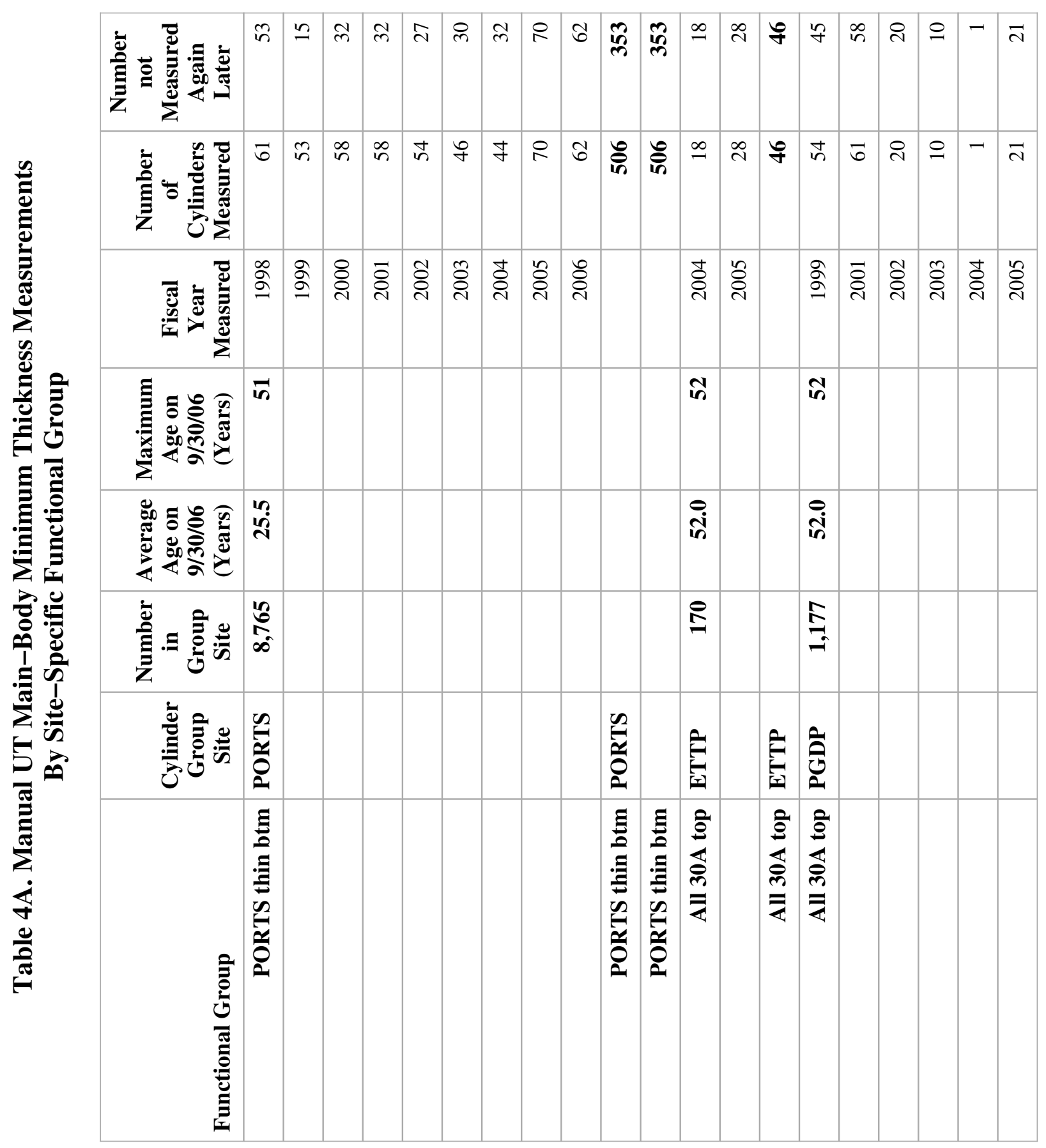




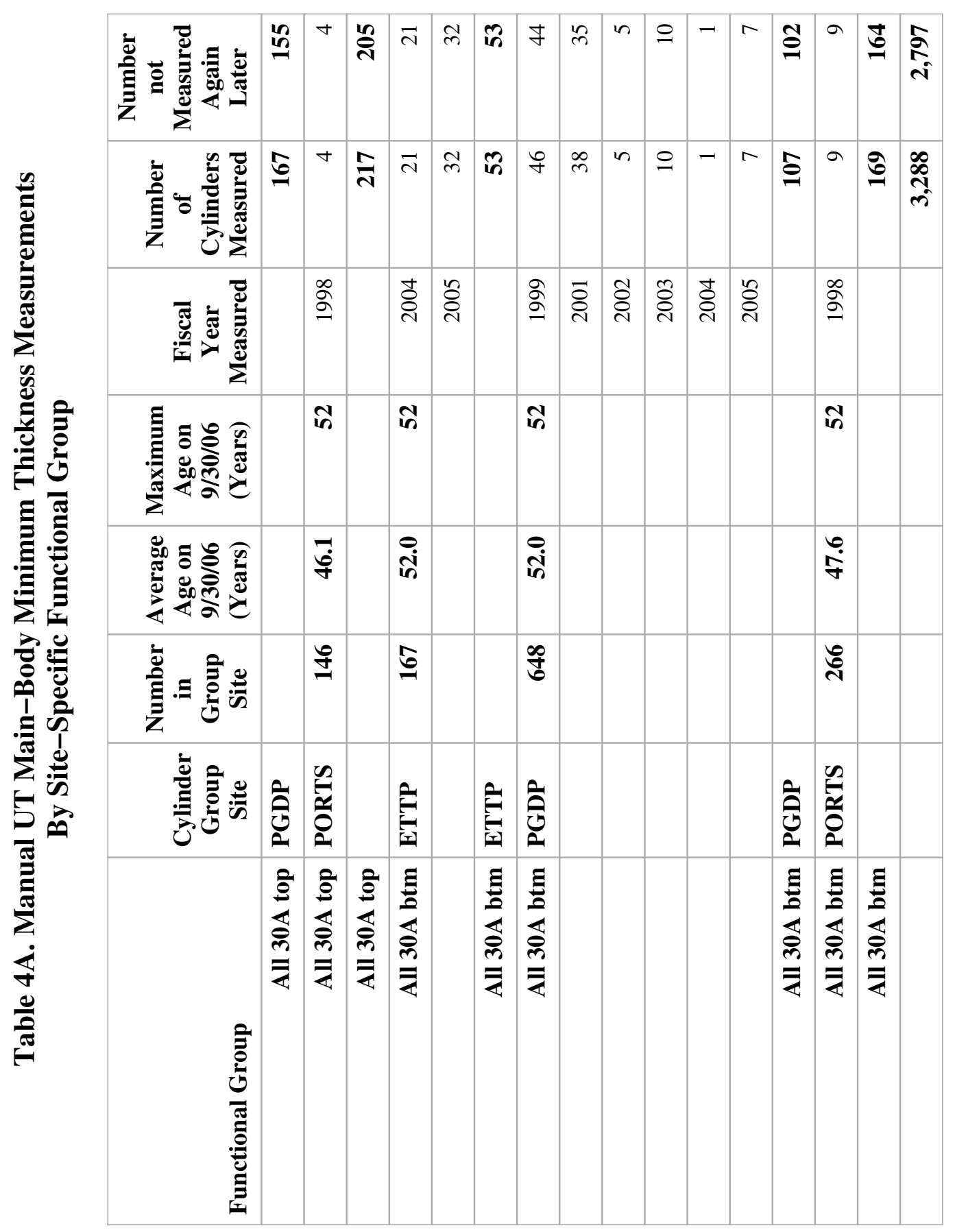




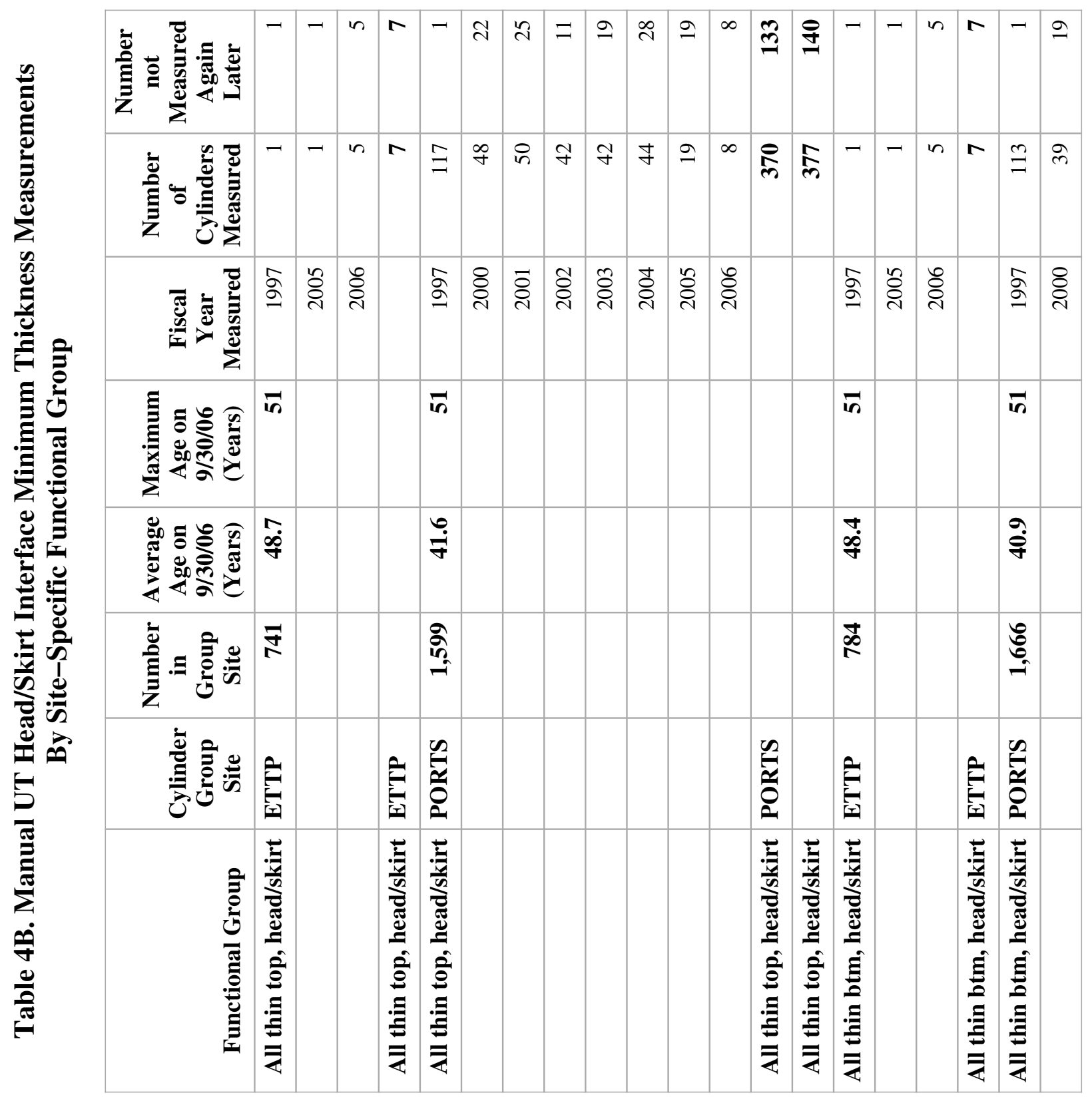




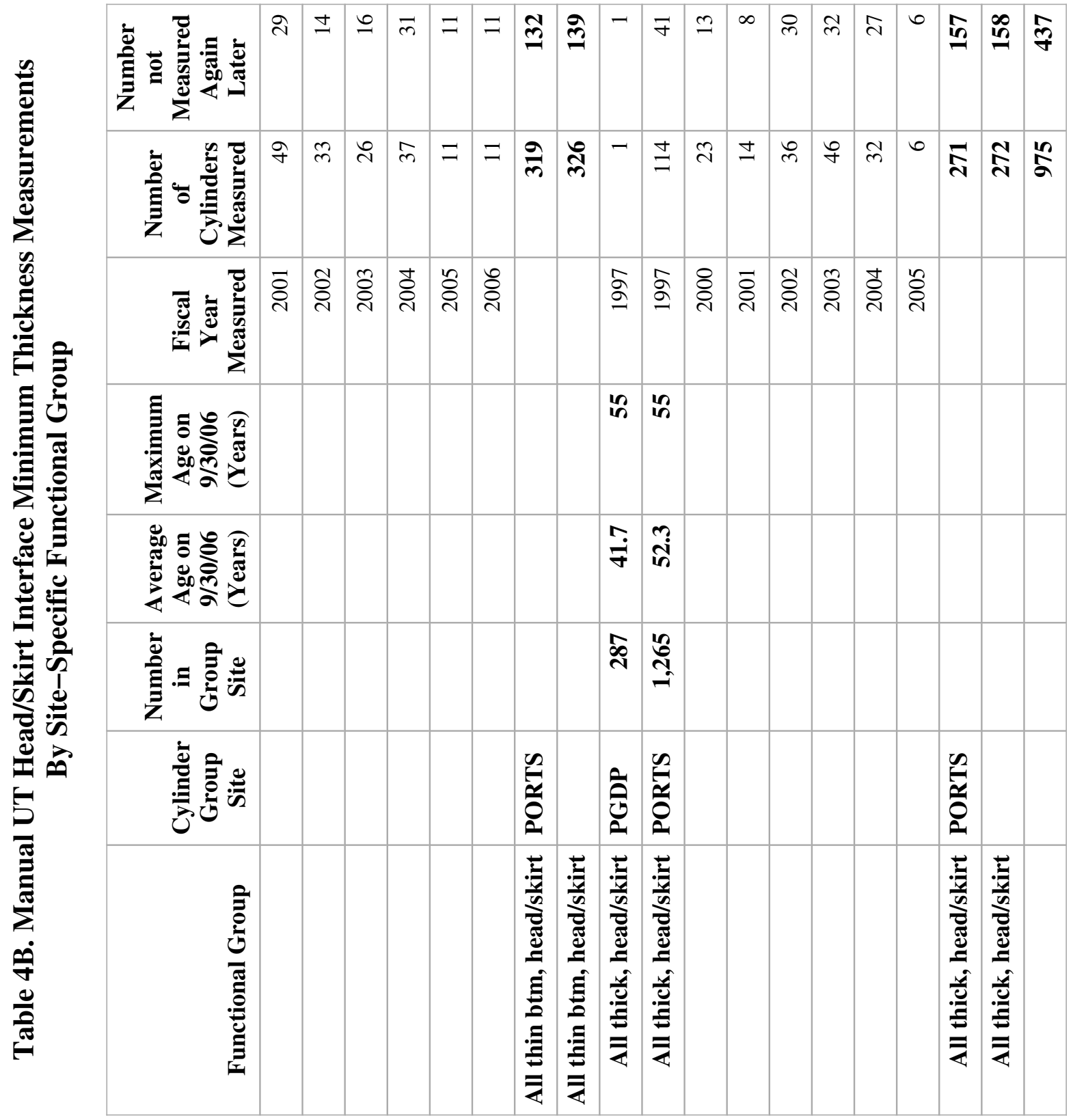




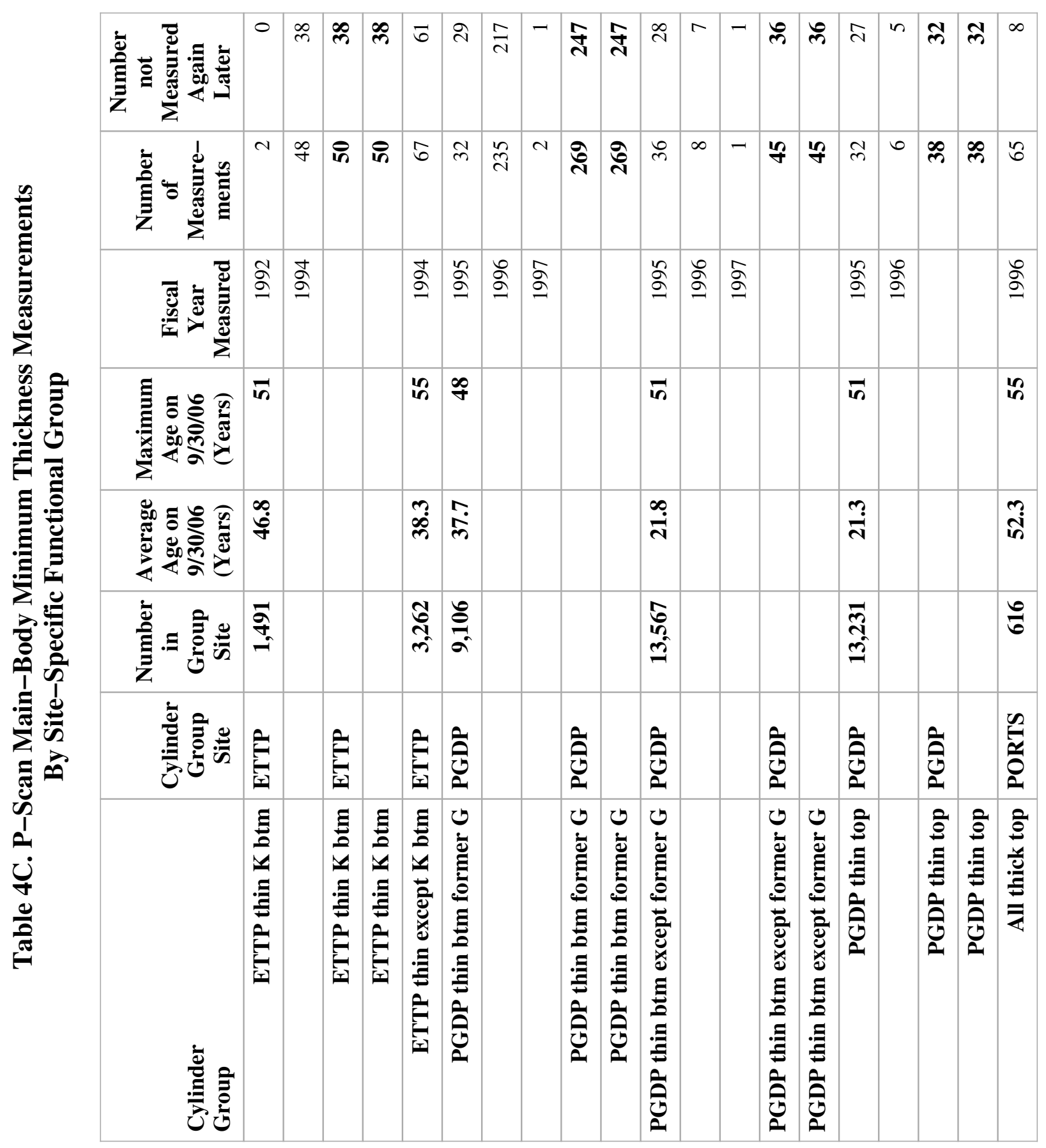




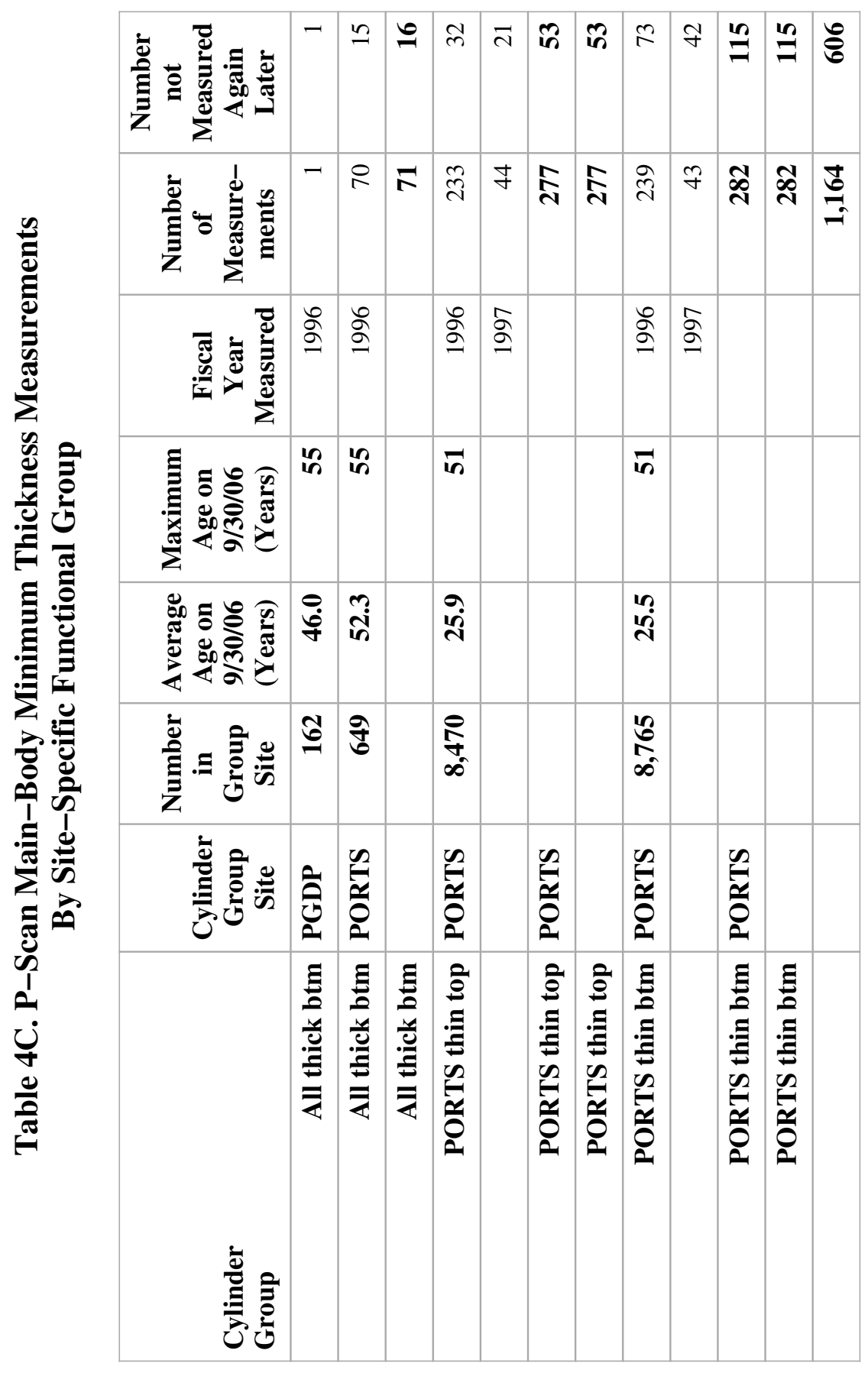




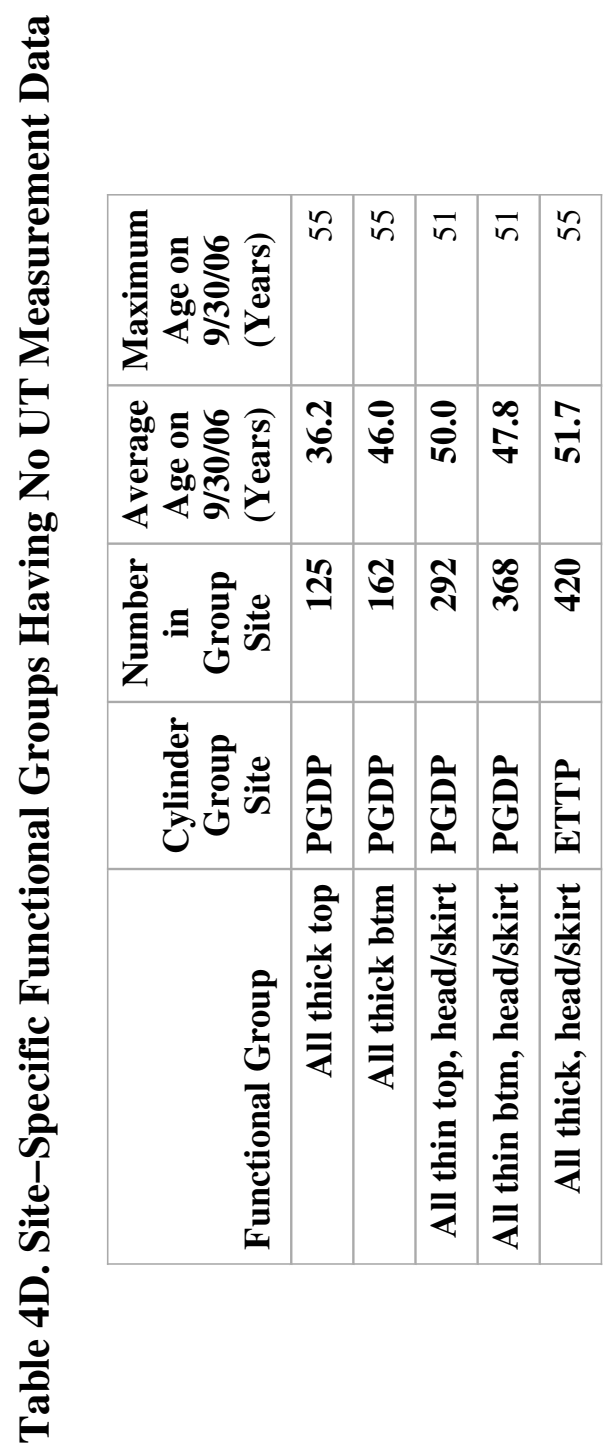


All thick-wall top-row cylinders. This group consists of thick-wall cylinders primarily stored in a top row of cylinders at any site. There are 983 of these cylinders, of which 858 are at Portsmouth and 125 are at Paducah. Of the 858 at Portsmouth, 242 were originally at ETTP. The cylinders range in age up to 55 years, with average ages of 52 years at Portsmouth and 36 years at Paducah. No UT measurements have been made on any of the 125 at Paducah, though UT measurements have been made on 84 of the cylinders now at Portsmouth. None of the 983 cylinders are listed as having been painted in the CID.

All thick-wall bottom-row cylinders. This group consists of thick-wall cylinders primarily stored in a bottom row of cylinders at any site. There are 989 of these cylinders, of which 827 are at Portsmouth and 162 are at Paducah. Of the 827 at Portsmouth, 178 were originally at ETTP. The cylinders range in age up to 55 years, with average ages of 52 years at Portsmouth and 46 years at Paducah. No UT measurements have been made on any of the 162 cylinders at Paducah, though UT measurements have been made on 57 of cylinders now at Portsmouth. None of the 989 cylinders are listed as having been painted in the CID.

All thin-wall top-row cylinders, head/skirt interface. This functional group consists of thin-wall skirted cylinders. These cylinders are also included in other thin-wall, top-row, main-body measurement groups. There are 2,632 thin-wall top-row skirted cylinders, of which 292 are at Paducah and 2,340 are at Portsmouth. Of the 2,340 cylinders at Portsmouth, 741 were originally at ETTP. Most of the PGDP cylinders are about 50 years old, though a few are less than 26 years old. The cylinders from ETTP range up to 51 years old with an average of 49 . The remaining Portsmouth cylinders range up to 51 years with an average of 42 . Among all of these cylinders, 323 have paint dates listed in the CID. No UT measurements have been made on the head/skirt interfaces of any of the 292 of these cylinders at Paducah, but head/skirt measurements have been made on 140 of the others.

All thin-wall bottom-row cylinders, head/skirt interface. This functional group consists of thin-wall skirted cylinders. These cylinders are also included in other thin-wall, bottom-row, main-body measurement groups. There are 2,818 thin-wall bottom-row skirted cylinders, of which of which 368 are at Paducah and 2,450 are at Portsmouth. Of the 2,450 cylinders at Portsmouth, 784 were originally at ETTP. Most of the PGDP cylinders are about 48 years old, though a few are less than 26 years old. The cylinders from ETTP range up to 51 years old with an average of 48 . The remaining Portsmouth cylinders range up to 51 years with an average of 41 . Among all of these cylinders, 358 have paint dates listed in the CID. No UT measurements have been made on the head/skirt interfaces of any of the 368 of these cylinders at Paducah, but head/skirt measurements have been made on 139 of the others.

All thick-wall cylinders, head/skirt interface. This functional group consists of thick-wall skirted cylinders. These cylinders are also included in other thick-wall, main-body measurement groups (top or bottom rows). There are 1,972 thick-wall skirted cylinders. None are listed as having been painted in the CID. 287 of these cylinders are at PGDP, and 1,685 are at Portsmouth, of which 420 were originally at ETTP. The (formerly) ETTP and Portsmouth cylinders at Portsmouth range in age up to 55 years, with an average of 52. The PGDP cylinders range in age up to 55 years with an average of 42 . Head/skirt UT measurements have been made on 158 of these cylinders, of which 157 were at Portsmouth, and 1 was at PGDP. No head/skirt measurements were mode on any of the 420 thick-wall cylinders originally at ETTP.

Portsmouth thin-wall top-row cylinders. There 8,470 thin-wall top-row cylinders that have been stored primarily at Portsmouth. They range in age up to 51 years with an average age of 25.9 years. None of these cylinders are listed as having been painted in the CID. UT measurements have been made on 420 of these cylinders. Many of these cylinders have been measured multiple times over the years. For the corrosion modeling only the most recent UT measurements are used. Cylinders at Portsmouth were moved from single row storage to a two-tiered arrangement around 1976. Prior to that, there were no top row cylinders at Portsmouth. Thus, the "top row"cylinders at Portsmouth have actually been in a top row for at most about $30(=2006-1976)$ years. 
Portsmouth thin-wall bottom-row cylinders. There 8,765 thin-wall bottom-row cylinders that have been stored primarily at Portsmouth. They range in age up to 51 years with an average age of 25.5 years. None of these cylinders are listed as having been painted in the CID. UT measurements have been made on 323 of these cylinders. For the corrosion modeling only the most recent UT measurements are used.

All 30A top-row cylinders. There 1,493 primarily top-row 30A cylinders, of which 1,177 are at PGDP, and 316 are at Portsmouth, of which 170 were originally at ETTP. Very few delivery dates for these cylinders are recorded in the CID, and for most of them, their delivery date is approximated as 1954 and their age in 2006 is thus approximated at 52 years. UT measurements have been made on 155 of the PGDP cylinders, on 46 of the cylinders originally from ETTP, and on 4 of the other Portsmouth cylinders. None have paint dates listed in the CID.

All 30A bottom-row cylinders. 1,081 in pop. There 1,081 primarily bottom-row 30A cylinders, of which 648 are at PGDP and 433 are at Portsmouth, of which 167 were originally at ETTP. Very few delivery dates for these cylinders are recorded in the CID, and for most of them, their age in 2006 is approximated at 52 years. UT measurements have been made on 102 of the PGDP cylinders, on 53 of the cylinders originally from ETTP, and on 9 of the other Portsmouth cylinders. None of these cylinders have paint dates listed in the CID. 


\section{DATA ANALYSIS}

This section describes regression modeling with the corrosion models discussed in Section 2 and the UT data discussed in Section 3. The indirect model, which has been considered in all previous editions of this report, is considered in Section 4.1. As in the past, however, this model leads to inadmissable parameter estimates and is therefore not pursued past simply fitting it. The direct model, which is considered in Section 4.2, provides a better fit. The direct model is used in Section 5 as a basis for projections about cylinder corrosion in the years 2010 and beyond. Model validation checks of the direct model are considered in Section 6. After adjusting for age differences using the direct model, differences between the cylinder functional groups are considered in Section 6.3.

Fitting the direct model points to a number of UT measurement minimums as statistical outliers and raises questions about the validity of these points. Although there are only a few such points, whether or not they are included in the analysis substantially affects the model-based projections. However, whether or not the outliers are included does not seem to have much effect on the admissibility of either the indirect or direct model parameter estimates.

\subsection{Indirect Model Regressions}

The indirect model (2.2) was fit to the available UT maximum pit depth data for each of the cylinder functional groups. The model intercept and slope estimates are shown in Table 5, and the raw data and fitted maximum pit depth prediction curves are shown in Figures 15-28.

\section{Table 5. Indirect Model Parameter Estimates}

\begin{tabular}{|r|r|r|r|r|r|}
\hline Functional Group & $\begin{array}{c}\text { Number } \\
\text { of } \\
\text { Cylinders }\end{array}$ & $\begin{array}{c}\text { Intercept } \\
\text { Estimate }\end{array}$ & $\begin{array}{c}\text { Slope } \\
\text { Estimate }\end{array}$ & $\begin{array}{c}\text { Signif. } \\
\text { Level } \\
\text { Slope > }>\end{array}$ & $\begin{array}{c}\text { Signif. } \\
\text { Level } \\
\text { Slope }<1\end{array}$ \\
\hline ETTP thin K btm & 231 & 9.25 & -1.62 & 0.0112 & 0.9999 \\
\hline PGDP thin btm former G & 343 & 0.89 & 0.46 & 1.0000 & 1.0000 \\
\hline PGDP thin btm except former G & 325 & 0.26 & 0.69 & 1.0000 & 0.9995 \\
\hline PGDP thin top & 244 & 0.91 & 0.43 & 1.0000 & 1.0000 \\
\hline All thick top & 80 & 4.31 & -0.24 & 0.4006 & 0.9031 \\
\hline All thick btm & 75 & -18.2 & 5.55 & 1.0000 & 0.0002 \\
\hline All thin top, head/skirt & 139 & 6.42 & -0.98 & 0.1378 & 0.9855 \\
\hline All thin btm, head/skirt & 139 & 1.86 & 0.16 & 0.5714 & 0.8345 \\
\hline All thick, head/skirt & 157 & 12.45 & -2.31 & 0.0007 & 1.0000 \\
\hline PORTS thin top & 347 & 2.28 & 0.29 & 1.0000 & 1.0000 \\
\hline PORTS thin btm & 310 & 2.74 & 0.17 & 0.9876 & 1.0000 \\
\hline All 30A top & 205 & 18.91 & -3.98 & 0.0009 & 1.0000 \\
\hline All 30A btm & 164 & 21.63 & -4.64 & $<.0001$ & 1.0000 \\
\hline
\end{tabular}




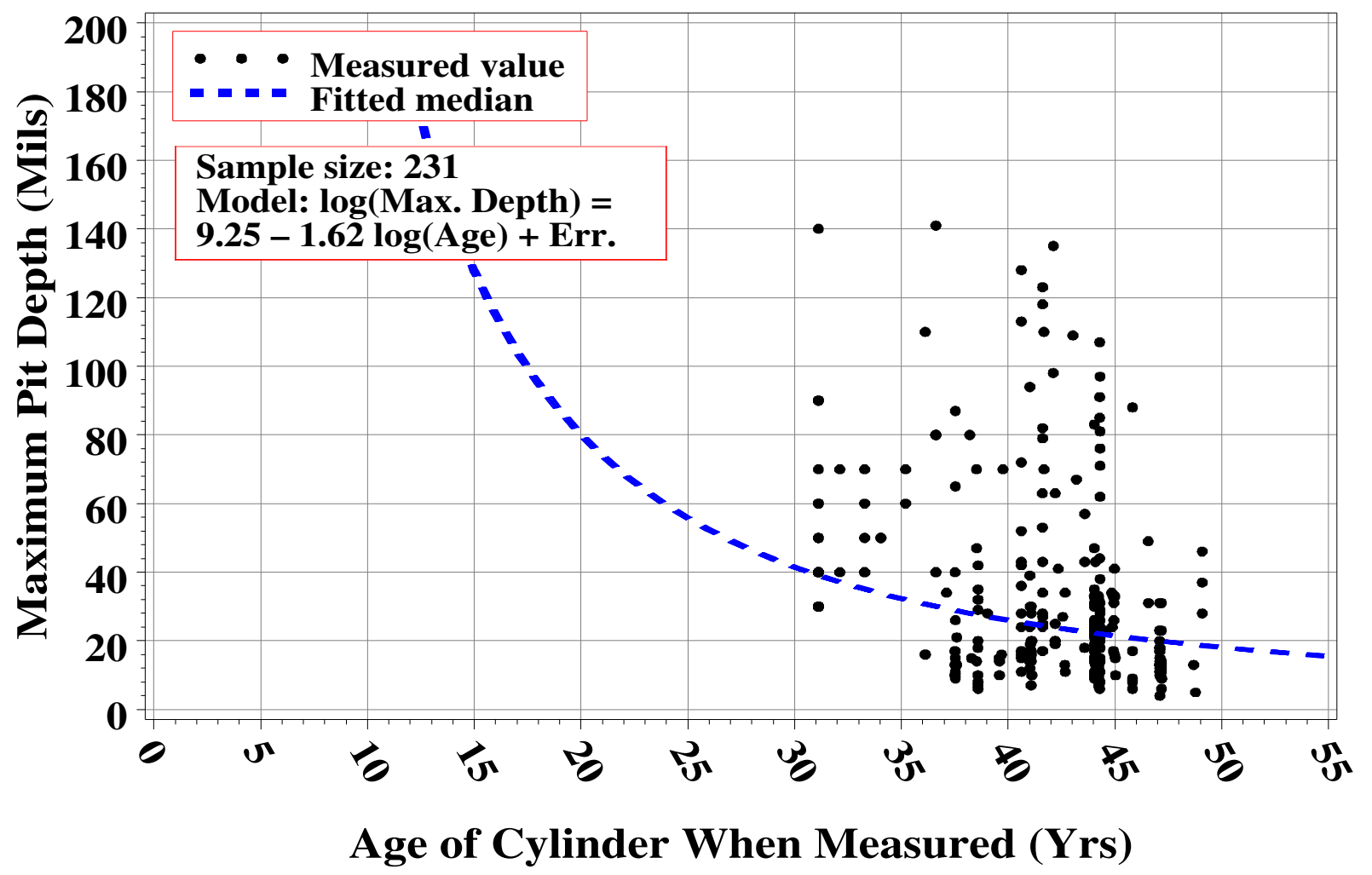

Figure 15. Maximum pit depth estimates for ETTP thin K-yard bottom cylinders cylinders.

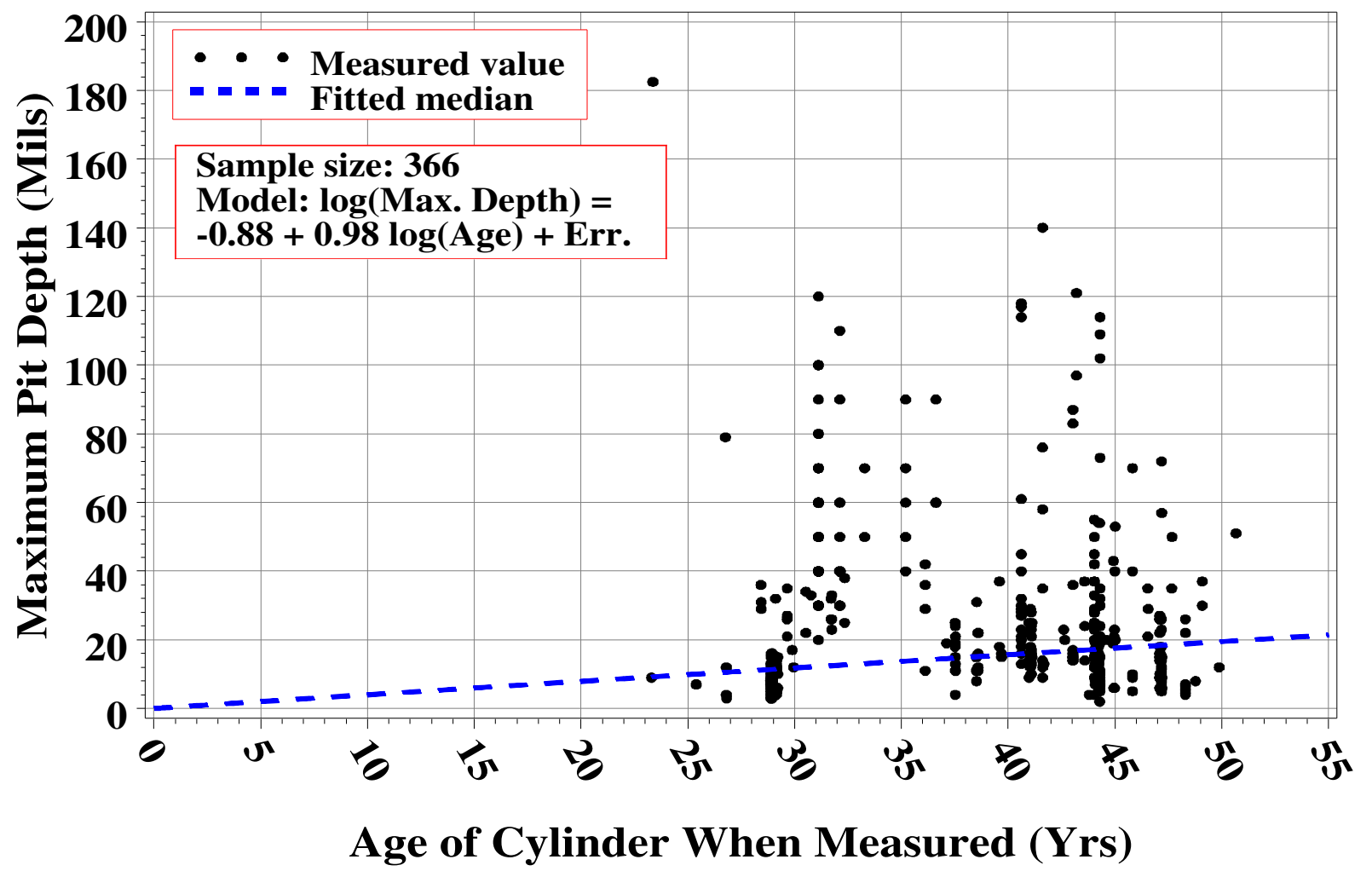

Figure 16. Maximum pit depth estimates for ETTP thin cylinders except K-yard bottom cylinders. 


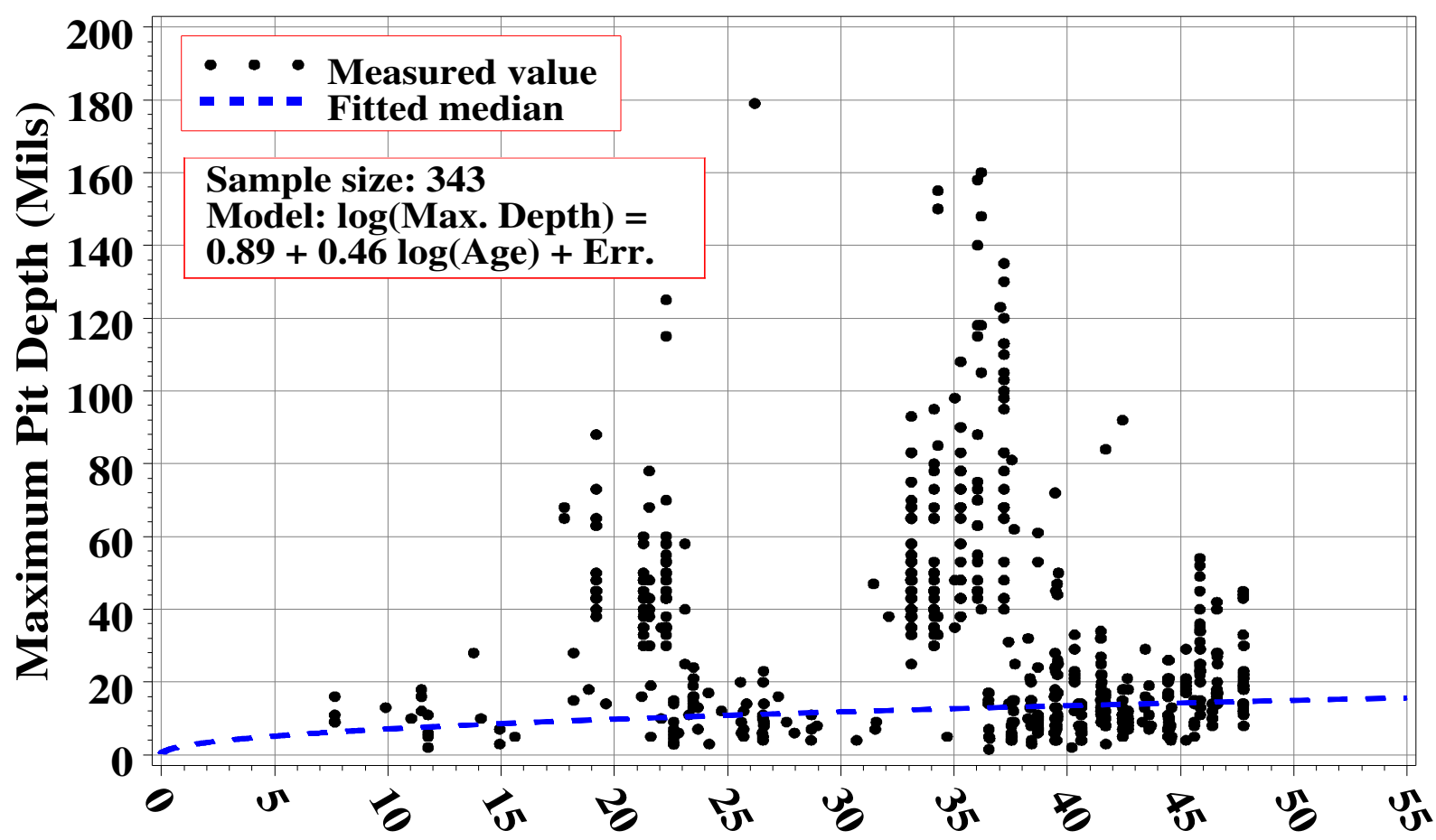

Age of Cylinder When Measured (Yrs)

Figure 17. Maximum pit depth estimates for PGDP thin bottom former G-yard cylinders cylinders.

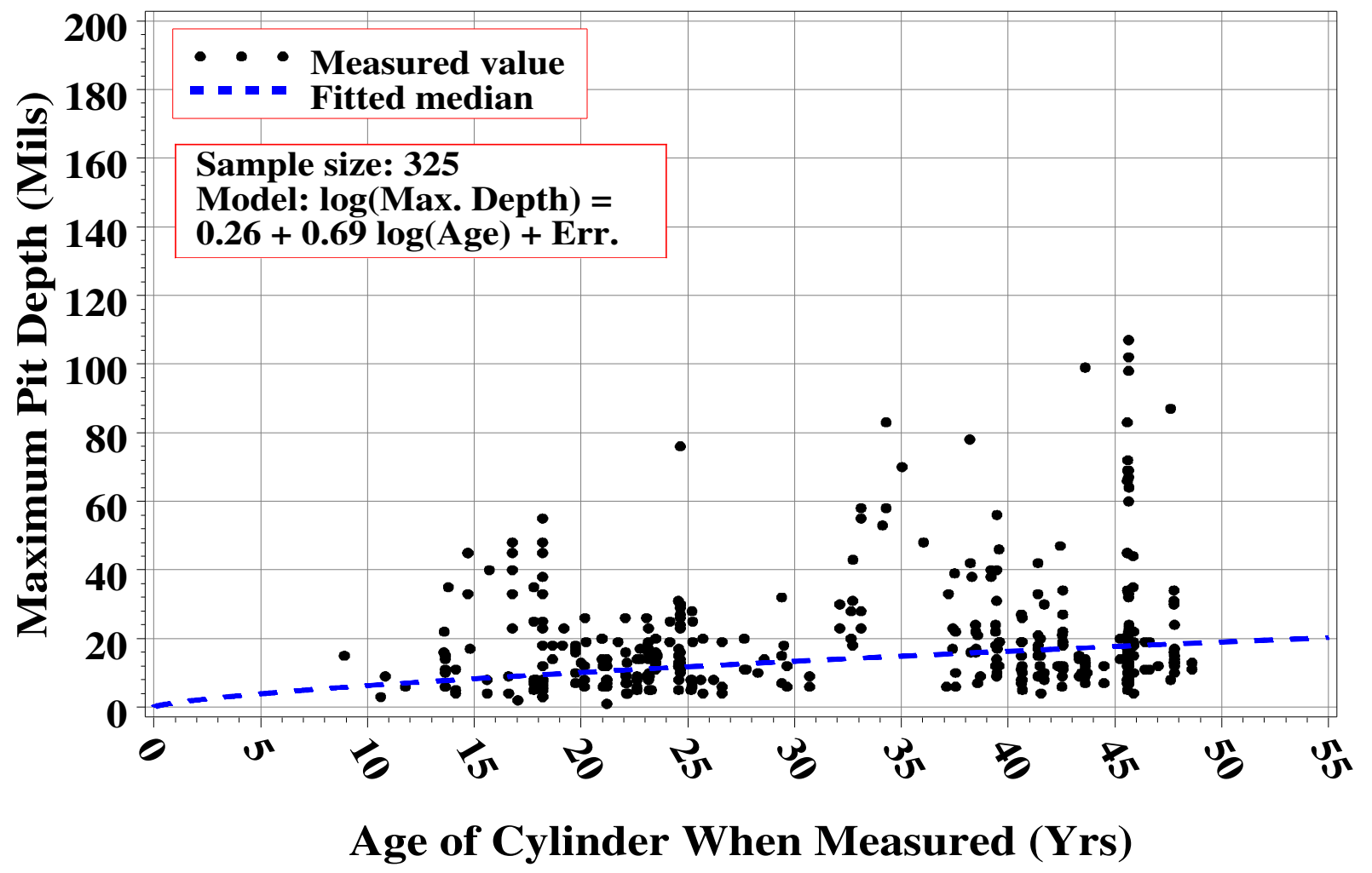

Figure 18. Maximum pit depth estimates for PGDP thin bottom cylinders except former G-yard cylinders. 


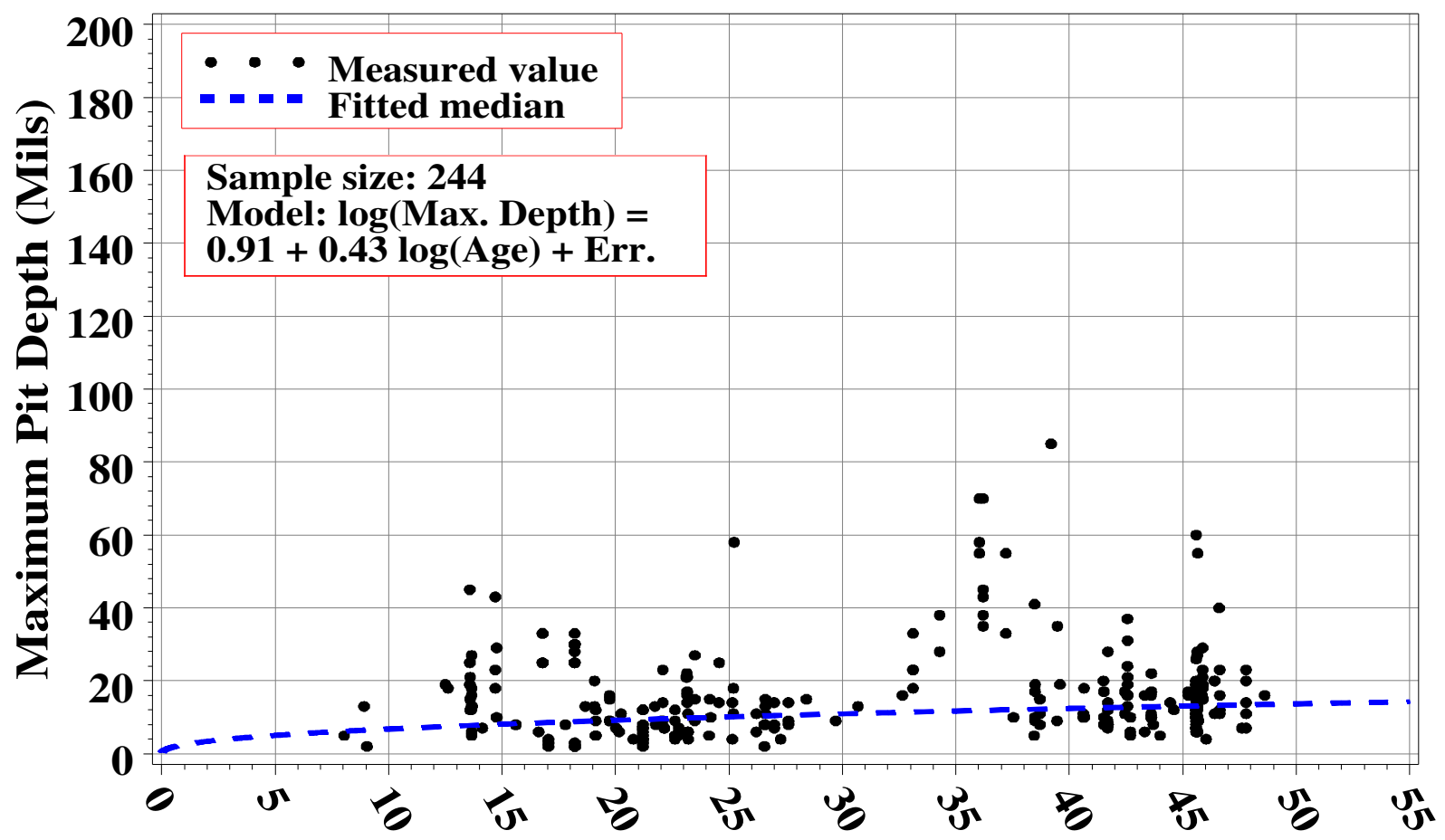

Age of Cylinder When Measured (Yrs)

Figure 19. Maximum pit depth estimates for PGDP thin top cylinders cylinders.

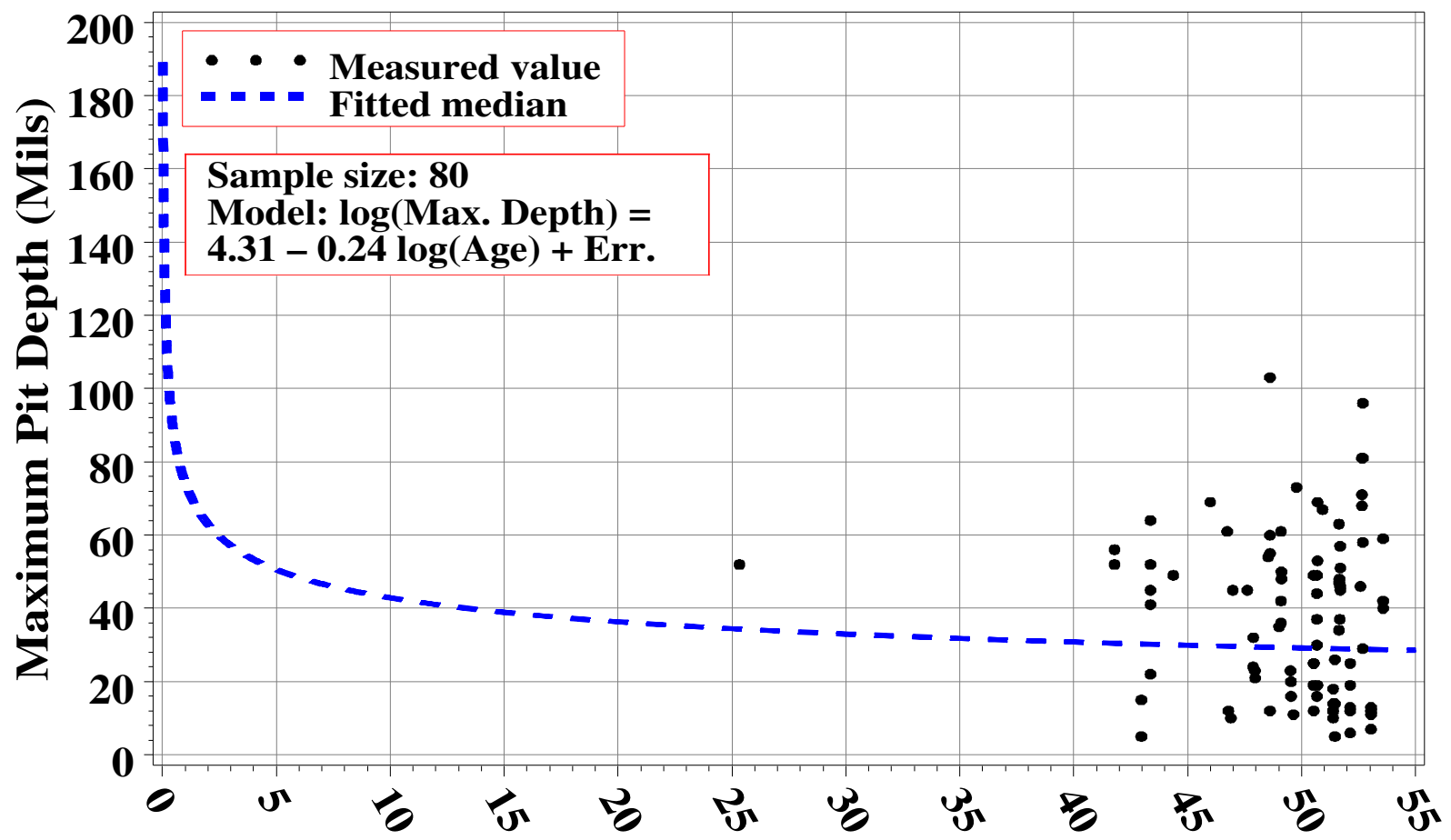

Age of Cylinder When Measured (Yrs)

Figure 20. Maximum pit depth estimates for all thick top cylinders cylinders.

48 


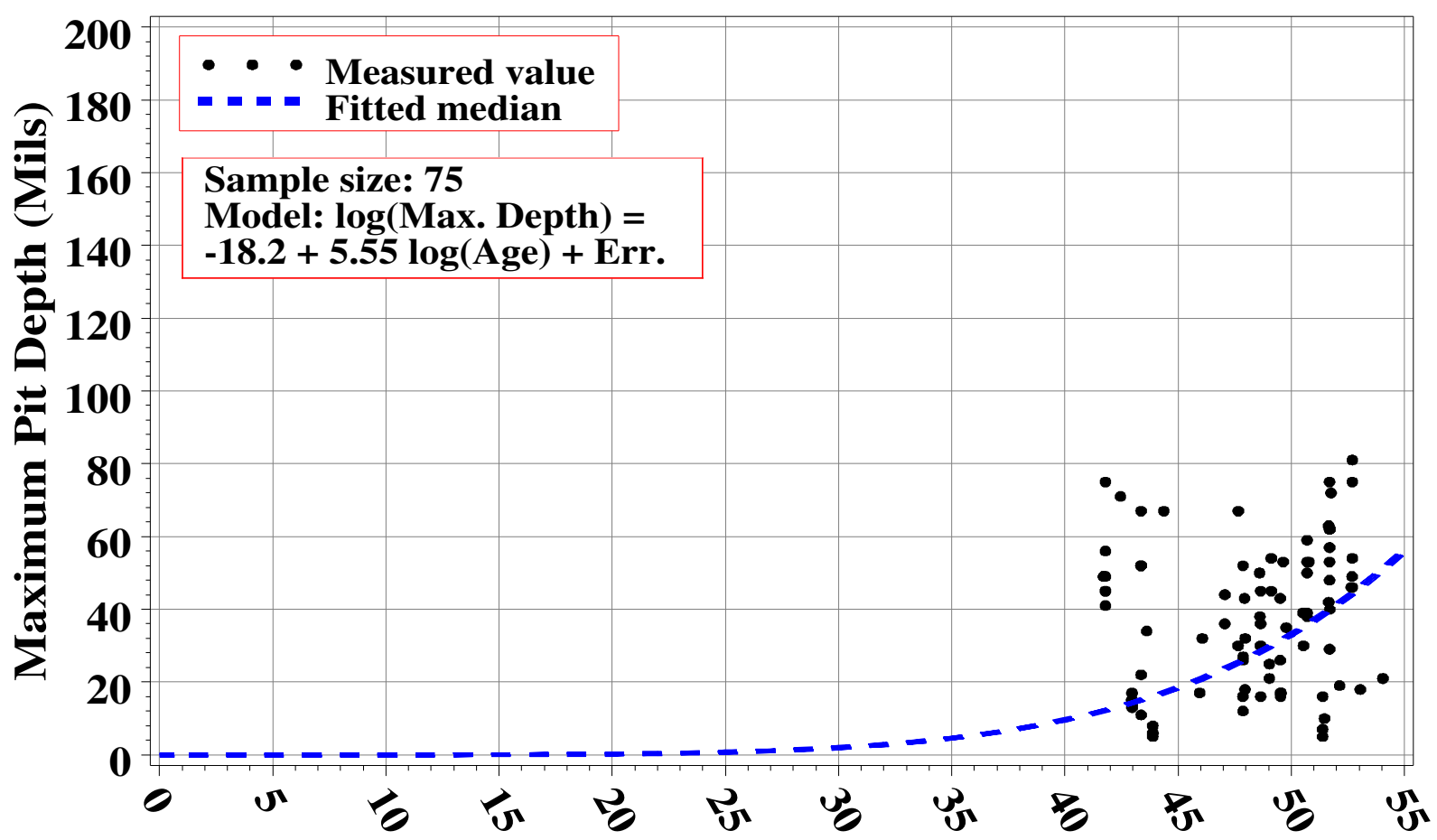

Age of Cylinder When Measured (Yrs)

Figure 21. Maximum pit depth estimates for all thick bottom cylinders cylinders.

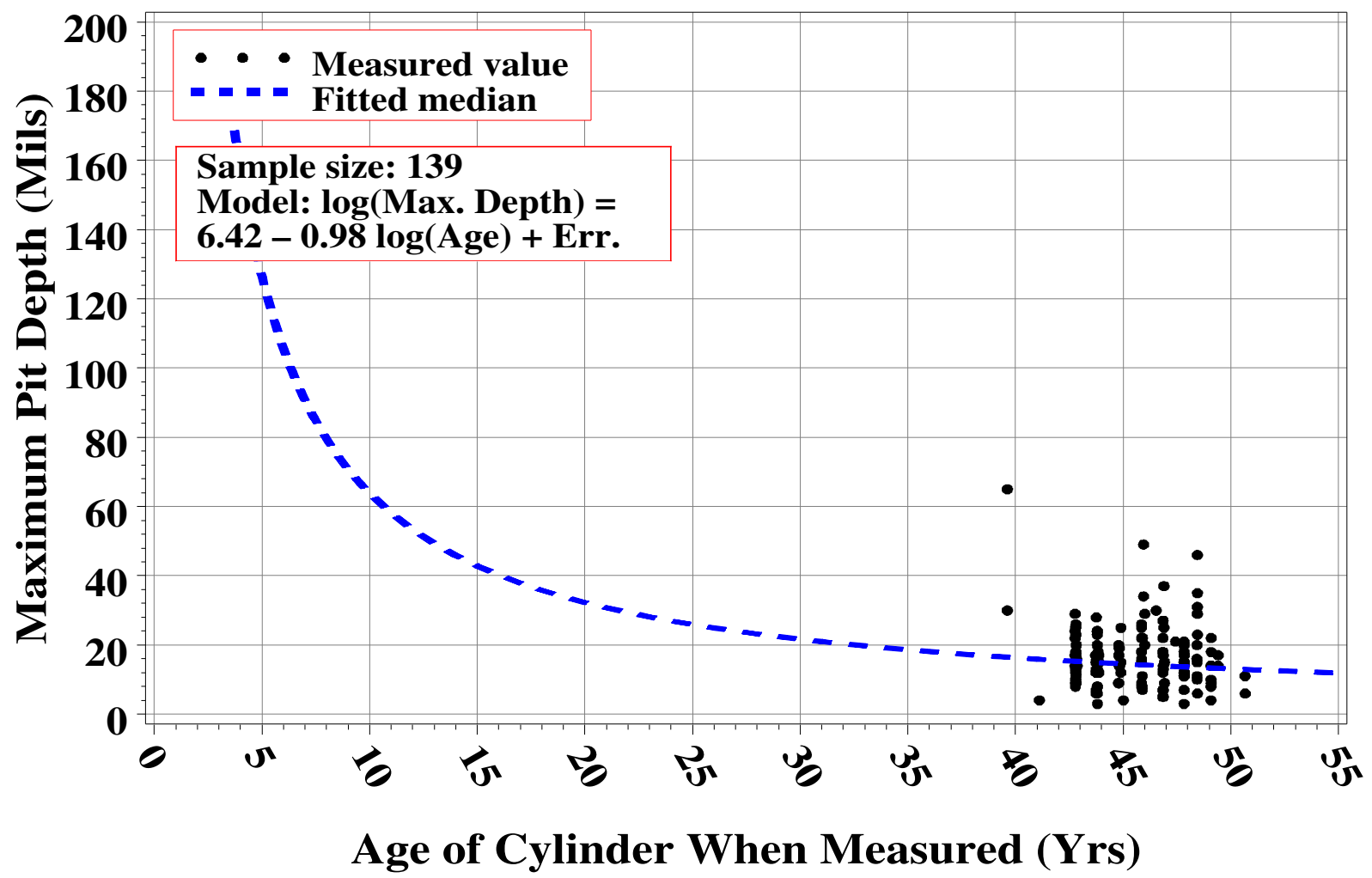

Figure 22. Maximum pit depth estimates for all thin top cylinders, head/skirt interface cylinders. 


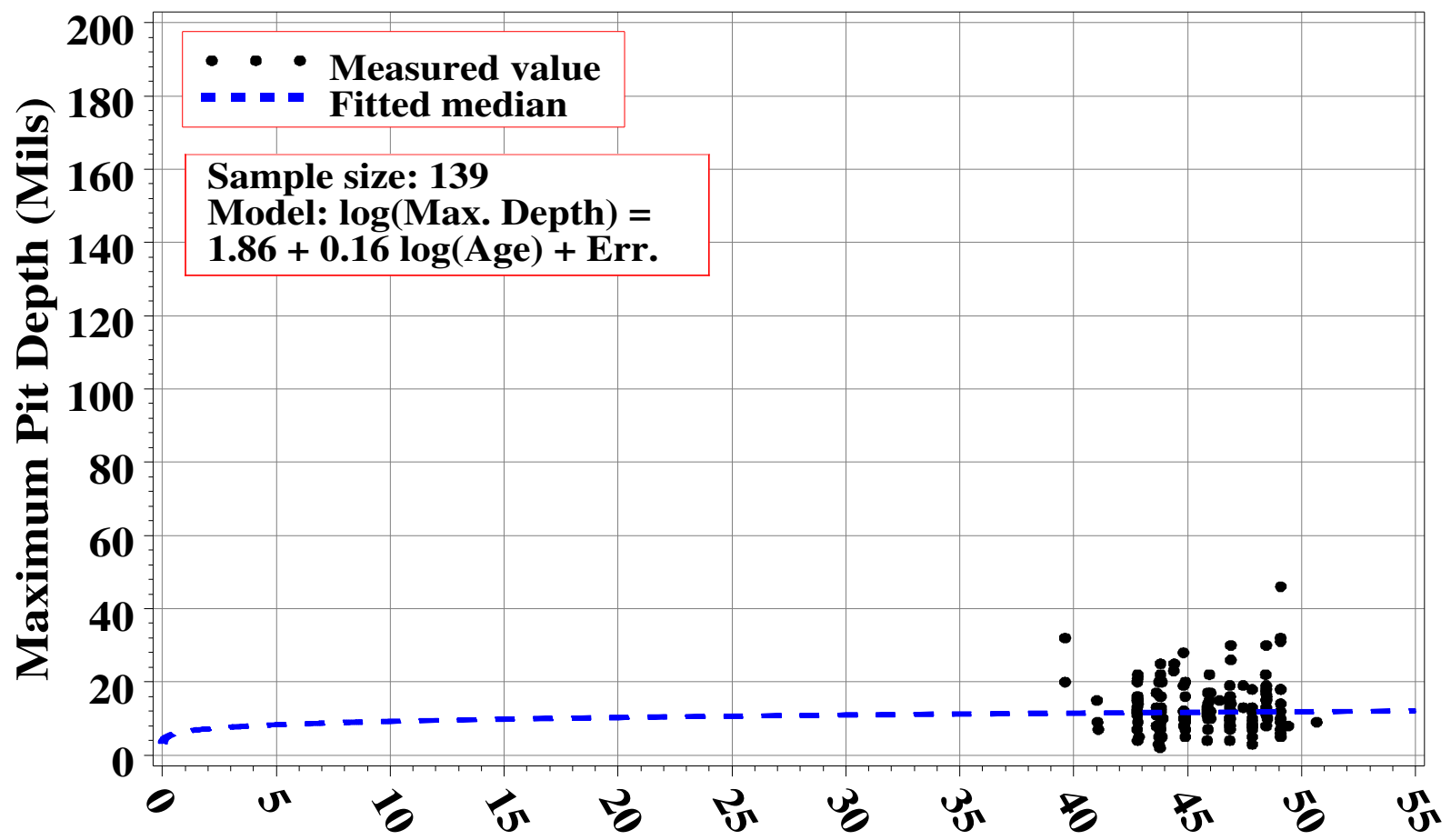

Age of Cylinder When Measured (Yrs)

Figure 23. Maximum pit depth estimates for all thin bottom cylinders, head/skirt interface cylinders.

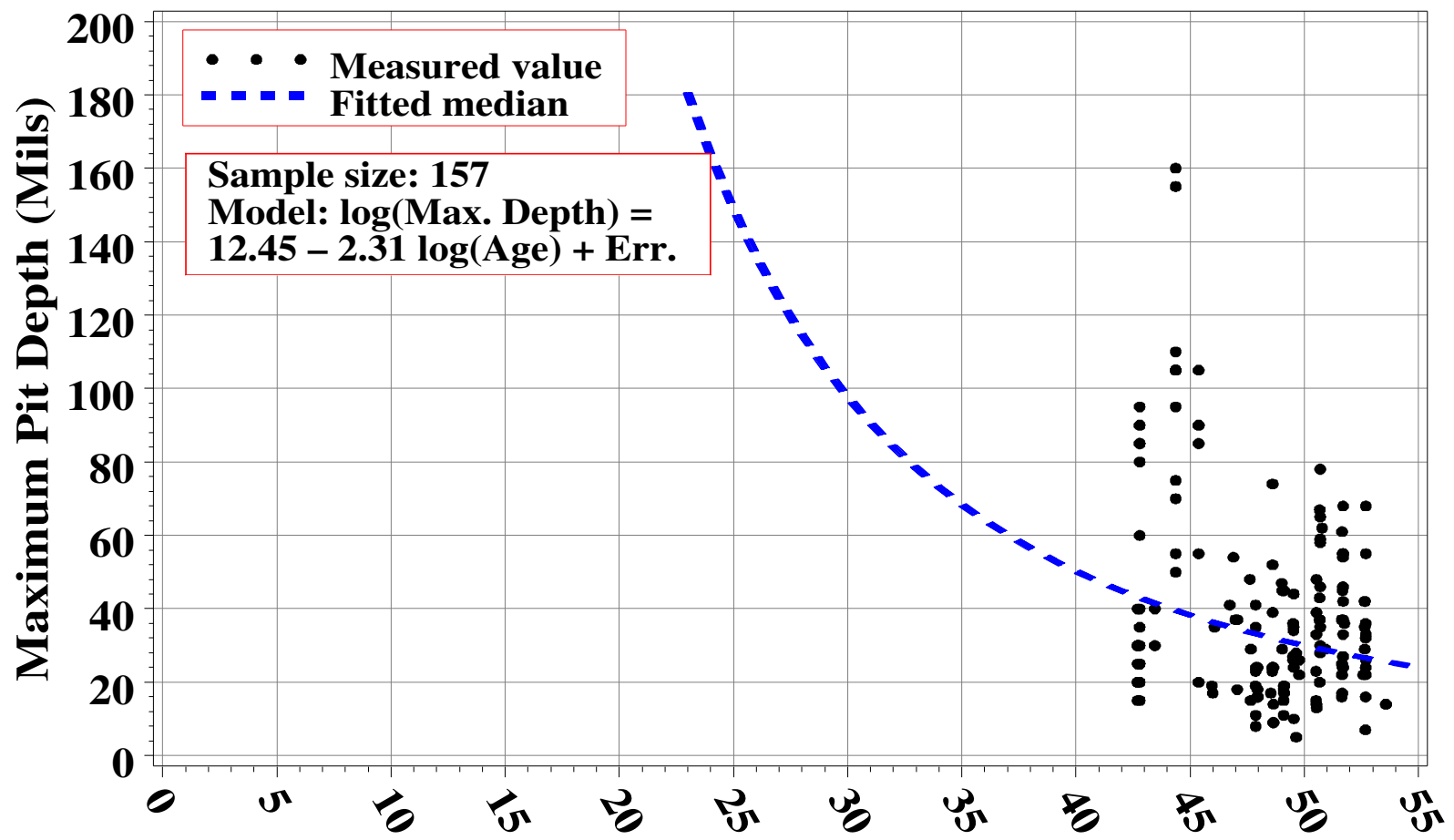

Age of Cylinder When Measured (Yrs)

Figure 24. Maximum pit depth estimates for all thick cylinders, head/skirt interface cylinders.

50 


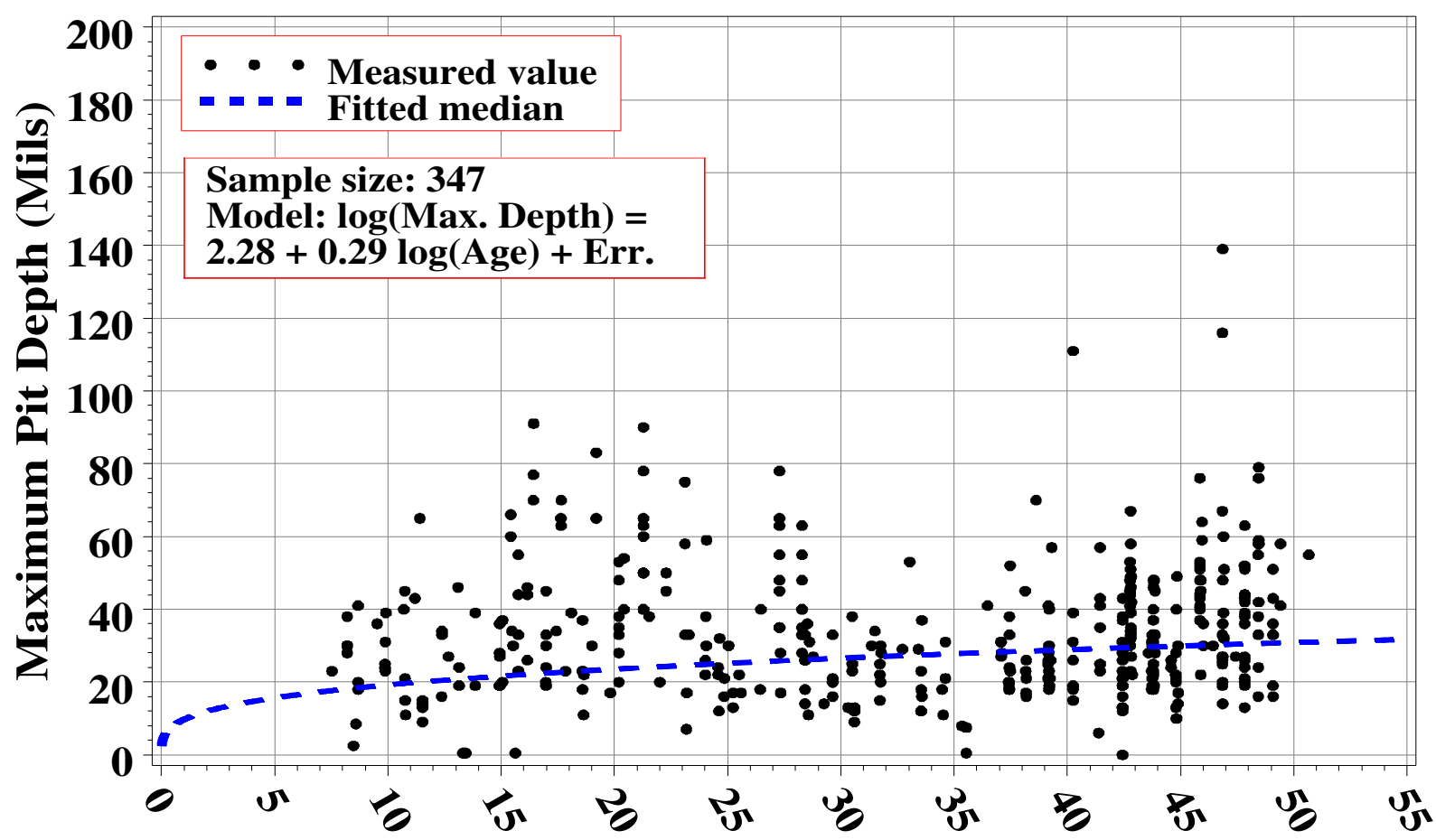

Age of Cylinder When Measured (Yrs)

Figure 25. Maximum pit depth estimates for Portsmouth thin top cylinders cylinders.

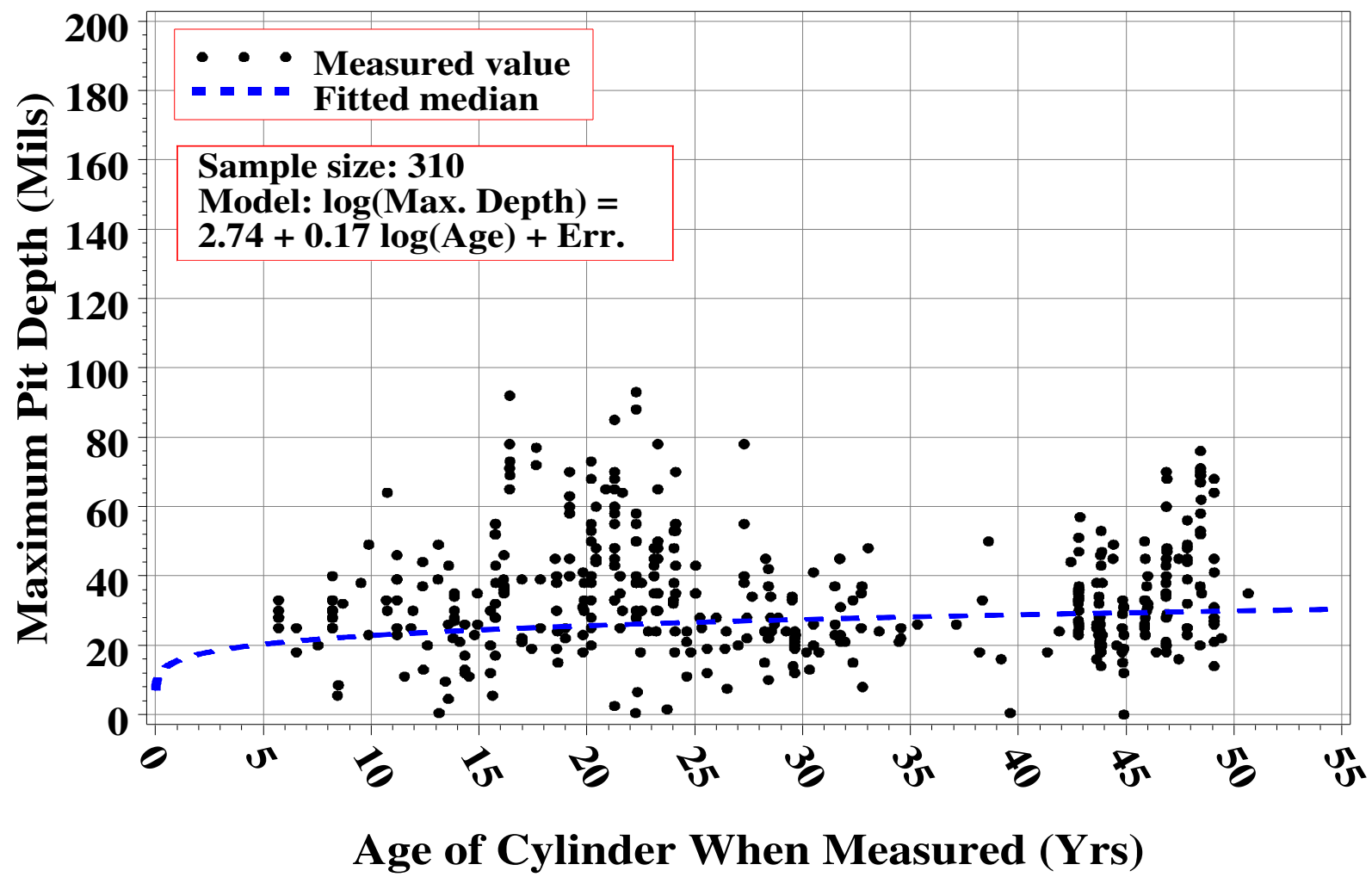

Figure 26. Maximum pit depth estimates for Portsmouth thin bottom cylinders cylinders. 


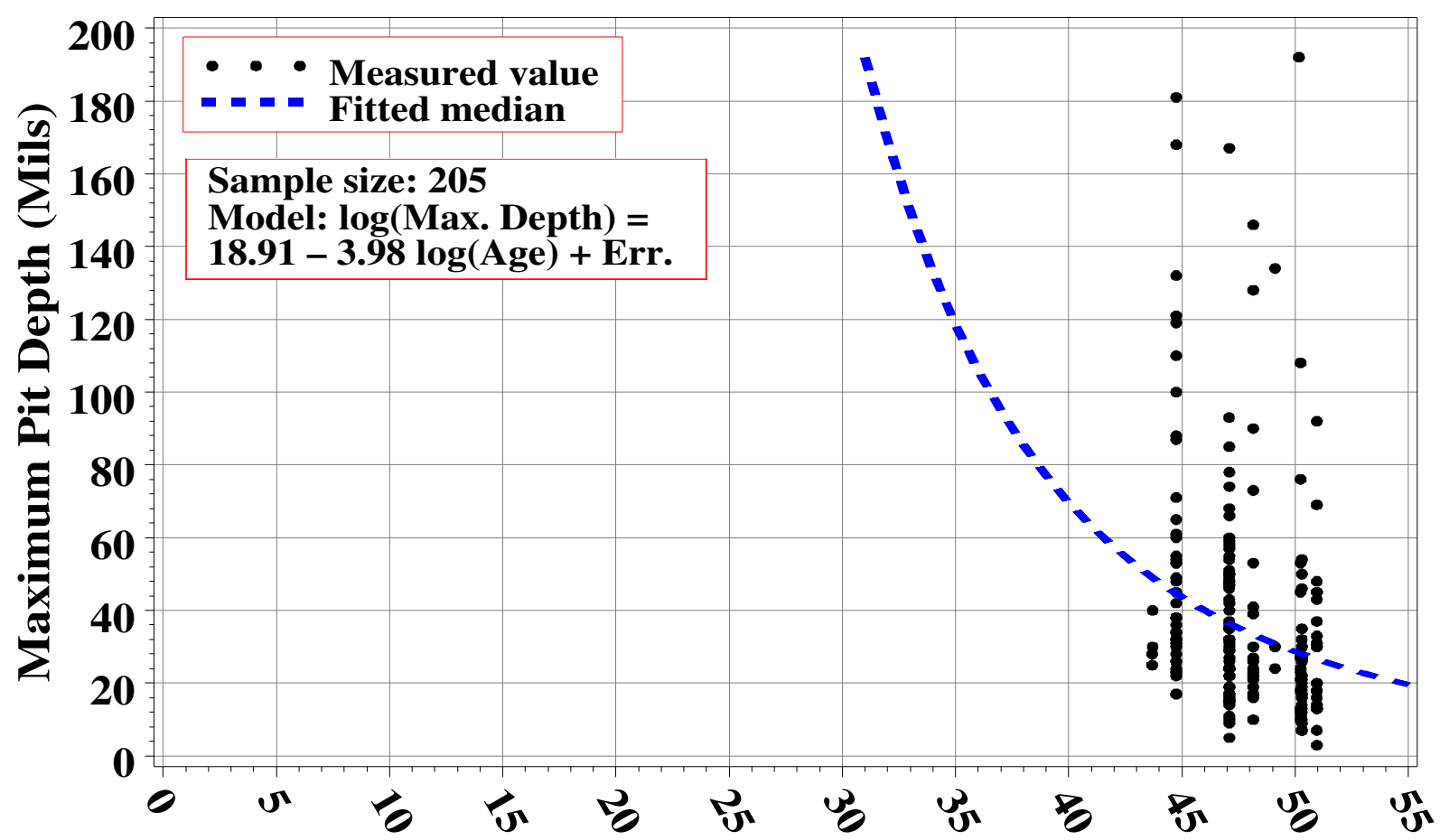

\section{Age of Cylinder When Measured (Yrs)}

Figure 27. Maximum pit depth estimates for all 30A top cylinders cylinders.

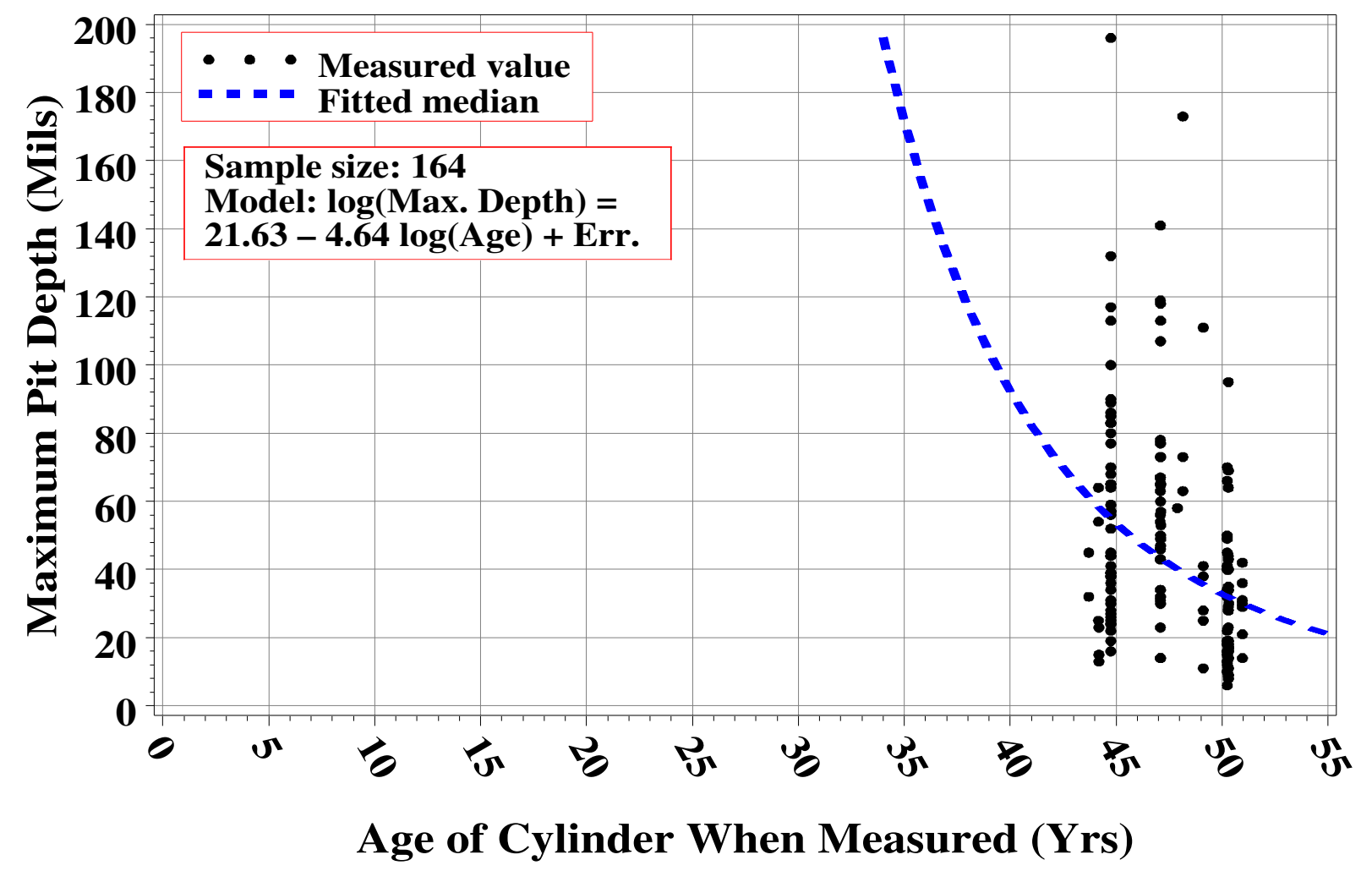

Figure 28. Maximum pit depth estimates for all 30A bottom cylinders cylinders. 
Two data points could not be used in the indirect-model analysis because their maximum pit depths were recorded as 0 (and logs are thus undefined). Table 5 also shows two t-test significance levels, one for the hypothesis test that the slope is greater than or equal to zero, and that the other for the test that the slope is less than or equal to 1 . For four of the fourteen functional groups, the slope estimate is significantly less than 0 , and it is less than 0 (though not significantly) in two other cases. For one functional group (the "all thick bottom row" group) the slope is significantly greater than 1 . A slope less than 0 implies that the pit depth would tend to decrease with age. A slope appreciably in excess of 1 is inconsistent with corrosion passivation theory and generally implies that pit depth estimates increase with age so fast that the estimates would not be useful even as bounds. The positive slopes are also indicated in the decreasing pit depth trend curves in Figures 15, 20, 22, 24, 27, and 28. The slope greater than one is indicated in Figure 21 in the rapid increase of the trend curve for ages greater than 50. Thus the indirect model fails these sanity checks and does not provide useful output for seven of the fourteen functional groups.

The inadmissability of so many of the indirect model parameter estimates might be because the maximum pit depth estimates computed from maximum thickness measurements as a proxy for initial thickness are so variable and sometimes inconsistent. The failure could also be because the logs of the maximum pit depths might not be normally distributed. In particular, there are outliers. However, examination of Figures 15-19 shows that there are not a lot of outliers. In fact, a reanalysis with the outliers discarded (if the log-scale residual exceeds 2) does not change the inadmissability of any of the estimates. The indirect model also might not fit because of changed maintenance and storage conditions or because corrosion physics that might apply to small objects such as metal coupons under ideal conditions, but not necessarily to thermally massive storage cylinders that are abraded, nicked and cut, and autoclaved during one or more use cycles. Of course any reasonable model should hold up under varying conditions. In any case, the failure of the indirect model to provide useful results is consistent with the behavior of this model in the past, and the model not pursued further in this report.

\subsection{Direct Model Regressions}

The failure of the fitted-slope power law model for seven of the fourteen functional groups suggests trying an alternative approach. The direct modeling approach has been used to fit UT data since the 2002 corrosion report and has generally been more satisfactory than the indirect model in the sense of not leading to inadmissable parameter estimates. In addition, as discussed in previous editions of this report, confidence bounds for projections based on the direct model seem to be less conservative than confidence bounds computed with the indirect model.

Weighting. As discussed in Section 2, the variance of the random error term in the direct model (2.3) increases with age. The fitted parameter estimates should account for this by weighting the fit. That is, when the model is fit (by least squares), the left and right sides of (2.3) are divided by a weight adjustment (WA):

$$
\frac{M}{\text { WA }}=\theta_{S}\left[\frac{\text { Nominal Thickness }}{\text { WA }}\right]+\beta_{\mathrm{G}}\left[\frac{\log (\text { age })}{\text { WA }}\right]+\frac{\text { random error }}{\text { WA }}
$$

so that the minimal thickness $M$ divided by WA is actually regressed on the nominal thickness divided by the WA and the log of age divided by the WA. (The "weight" is usually taken to be (WA) ${ }^{-2}$.) The WAs are specific to each UT observation and should be chosen so that the variance of the random error divided by the WA is approximately the same for all observations. 
The adequacy of any given set of WAs can be assessed by fitting the model (4.1) with them, and then by considering the regression residuals:

$$
\text { residual }=\frac{M}{\mathrm{WA}}-\left(\hat{\theta}_{S}\left[\frac{\text { Nominal Thickness }}{\mathrm{WA}}\right]+\hat{\beta}_{\mathrm{G}}\left[\frac{\log (\text { age })}{\mathrm{WA}}\right]\right) \text {, }
$$

where the $\hat{\theta}_{\mathrm{S}}$ and $\hat{\beta}_{\mathrm{G}}$ terms are the fitted parameter estimates. Figure 29 is a residual plot for the model with $\mathrm{WA}=\mathrm{w}(\mathrm{age})^{1 / 2}$ where $\mathrm{w}=3.067$ for $30 \mathrm{~A}$ cylinders and $\mathrm{w}=1$ otherwise. The quantity 3.067 is the ratio of the regression root mean squared error (RMSE) for the model with 30A cylinders only to the RMSE for the model with other (i.e., thick-wall and thin-wall) cylinders only and WA $=(\text { age })^{1 / 2}$ in either case. This weighting system was also used in previous editions of this report. ${ }^{9}$

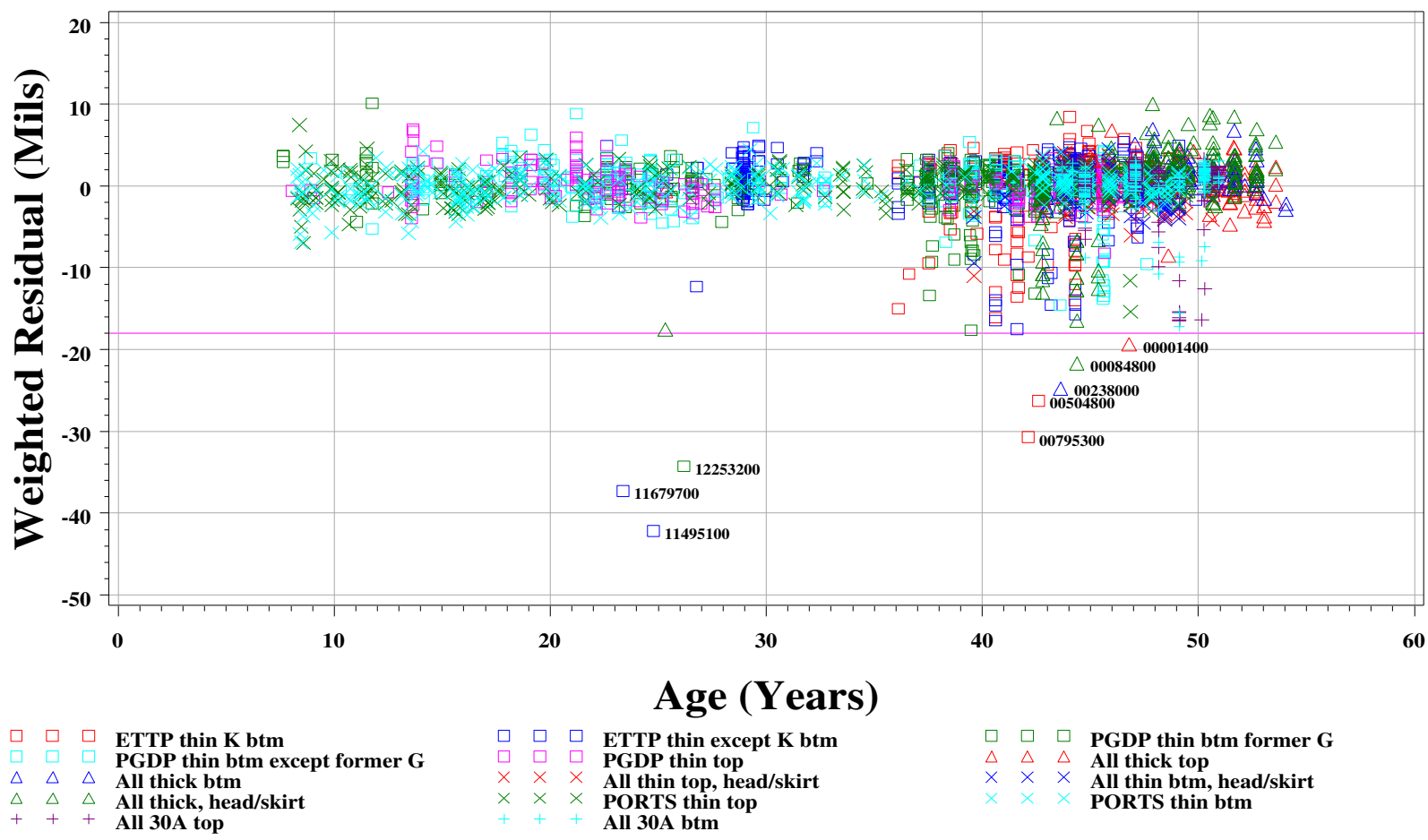

Figure 29. The direct-model regression residuals. One residual of $\mathbf{- 6 8 . 5}$ mils is not shown on the plot: Cylinder $=00105200$, all thick bottom group, measured in FY06. The cylinders IDs of other cylinders with residuals less than $\mathbf{- 1 8}$ mils are shown on the plot.

The functional form of a model, how it is weighted, and whether or not statistical outliers are included in fitting it all affect each other. Residuals in Figure 29 that are less than -18 mils (magenta reference line) are flagged with the fiscal year of their UT measurements. These cylinders are discussed further below. However, they are included in calculating the weights (e.g., in the factor $w=3.067$ ). Also, the functional form of the model considered in this discussion of weight is the final model. In the final model, only one $\beta_{\mathrm{G}}$ parameter is fit for all three head/skirt interface functional groups. This was necessary because

${ }^{9}$ The greater variability of minimum thicknesses for $30 \mathrm{~A}$ cylinders is not understood but might be due to internal corrosion from agents other than $\mathrm{DUF}_{6}$ possibly stored in the $30 \mathrm{~A}$ cylinders prior to the $\mathrm{DUF}_{6}$. 
separate $\beta_{\mathrm{G}}$ terms lead for the skirted cylinders to estimates $\hat{\beta}_{\mathrm{G}}>0$ and $\hat{\theta}_{\mathrm{S}}$ too small. However, this condition does not seem to be related by the choice of weights.

There are more cylinders in the 35-55 year age range than in the 5-35 range. This might make the variance of the residuals appear greater in the more densely populated 35-55 year range. However, the standard deviations of the regression residuals for various groups and age ranges of cylinders are shown in Table 6. Evidently the standard deviation (and thus the variance) of the residuals is approximately constant across these groups and ages. The models without weight adjustments for the 30As or age, or with the alternative and more severe age adjustment $\mathrm{WA} \propto$ age (rather than $(\text { age })^{1 / 2}$ ) do not give residual plots and residual standard deviations this homogenous.

\section{Table 6. Standard Deviations of Direct-Model Weighted Residuals}

\begin{tabular}{|c|c|c|c|c|}
\hline $\begin{array}{l}\text { Thickness } \\
\text { Class }\end{array}$ & $\begin{array}{l}\text { Measurement } \\
\text { Position }\end{array}$ & $\begin{array}{c}\text { Age } \\
\text { Range } \\
\text { (Years) }\end{array}$ & $\begin{array}{c}\text { Number } \\
\text { of } \\
\text { Cylinders }\end{array}$ & $\begin{array}{l}\text { Std. Dev. } \\
\text { of Weighted } \\
\text { Regression } \\
\text { Residuals } \\
\text { (mils) }\end{array}$ \\
\hline \multirow[t]{2}{*}{ 30As } & Main body & $40-49$ & 240 & 3.85 \\
\hline & & $50-69$ & 129 & 2.55 \\
\hline \multirow[t]{2}{*}{ Thick-wall } & Main body & $40-49$ & 73 & 4.53 \\
\hline & & $50-69$ & 85 & 7.73 \\
\hline \multirow[t]{2}{*}{ Thick-wall } & Head/Skirt & $40-49$ & 98 & 6.21 \\
\hline & & $50-69$ & 59 & 2.54 \\
\hline \multirow[t]{6}{*}{ Thin-wall } & Main body & $0-9$ & 51 & 2.95 \\
\hline & & $10-19$ & 283 & 2.20 \\
\hline & & 20-29 & 463 & 3.63 \\
\hline & & $30-39$ & 323 & 2.89 \\
\hline & & $40-49$ & 1146 & 3.23 \\
\hline & & $50-69$ & 3 & 2.49 \\
\hline \multirow[t]{3}{*}{ Thin-wall } & Head/Skirt & $30-39$ & 4 & 3.96 \\
\hline & & $40-49$ & 272 & 1.87 \\
\hline & & $50-69$ & 3 & 1.47 \\
\hline
\end{tabular}

Direct-Model Regression Results. Table 7 shows the $\theta_{S}$ and $\beta_{\mathrm{G}}$ regression parameter estimates for fitting the direct model (4.1) with the 3,234 UT minimum thickness measurements from the fourteen functional groups. The three head skirt groups are treated as one group (with different nominal thicknesses) for fitting the $\beta_{\mathrm{G}}$ 's because, without this adjustment, the head/skirt $\hat{\beta}_{\mathrm{G}}$ estimates turn out to be positive, and $\hat{\theta}_{S}$ estimate for the head/skirt groups is too small. The $\mathrm{R}^{2}$ value for the regression is 
$97.5 \% .^{10}$ The estimates of the $\theta_{S}$ coefficient of the nominal thickness are $1.035 \pm .008$ (standard error) for the main-body measurements and $1.254 \pm .008$ for the head/skirt interface measurements. These are reasonable factors to relate nominal thicknesses to year-one thicknesses. The $\theta_{S}$ factor is considerably larger for the head/skirt measurements, which is consistent with substantially larger UT measurements at the head/skirt interface.

Table 7. Direct Model Parameter Estimates

\begin{tabular}{|r|r|r|}
\hline Model Parameter & Estimate & $\begin{array}{c}\text { Standard } \\
\text { Error }\end{array}$ \\
\hline Nominal thickness (main body) & 1.035 & 0.008 \\
\hline Nominal thickness (H/S interface) & 1.254 & 0.008 \\
\hline Log Age for ETTP thin K btm & -5.677 & 0.802 \\
\hline Log Age for ETTP thin except K btm & -4.224 & 0.786 \\
\hline Log Age for PGDP thin btm former G & -3.738 & 0.815 \\
\hline Age for PGDP thin btm except former G & -3.034 & 0.845 \\
\hline Log Age for PGDP thin top & -2.315 & 0.874 \\
\hline Log Age for All thick top & -3.333 & 1.504 \\
\hline Log Age for All thick btm & -5.231 & 1.525 \\
\hline Log Age for Thick/thin head/skirt & -11.641 & 0.908 \\
\hline Log Age for PORTS thin top & 0.403 & 0.877 \\
\hline Log Age for PORTS thin bottom & 0.216 & 0.900 \\
\hline Log Age for All 30As top & -13.755 & 1.723 \\
\hline Log Age for All 30As btm & -13.991 & 1.849 \\
\hline
\end{tabular}

The three $\beta_{\mathrm{G}}$ coefficient estimates for the head/skirt measurement groups have been combined for this analysis because, when not combined, they turned out to be positive (inadmissable) with a commensurate reduction in the $\theta_{S}$ estimate for the head/skirt measurements. Except for the Portsmouth thin-wall groups, the $\beta_{\mathrm{G}}$ estimates are all negative. The coefficient estimates for the two Portsmouth thin-wall groups are positive, but not significantly ( $\mathrm{p}=.64$ and .81 for the thin top and thin bottom-row groups respectively). Also, as discussed next, the $\beta_{\mathrm{G}}$ estimates for these two groups do turn out to be negative if a few outliers are excluded from the analysis.

As Figure 29 shows, among the 3,234 regression residuals from this model, nine $(0.28 \%)$ are clearly statistical outliers. Whether these outliers are included affects some of the conclusions of this analysis, particularly regarding projections of the number of cylinders failing various thickness criteria (Section 5). The nine outlier cylinders are shown in Table 8. Five are thin-wall and four are thick-wall cylinders. One of the thick-wall cylinder measurements is at the head/skirt interface. Fifteen outlier cylinders from a similar analysis for the 2003 corrosion report were remeasured in FY04. Five of the cylinders were thin-

\footnotetext{
${ }^{10} \mathrm{R}^{2}$ is the squared multiple correlation coefficient or proportion of explained variance (see Draper and Smith, 1981). Because $R^{2}$ is defined only form models with overall intercept term, for calculating $R^{2}$ only, an overall intercept was included in fitting the model. The overall intercept was not statistically significant $(\mathrm{p}=.16)$. With outliers excluded $\mathrm{R}^{2}$ turns out to be $98.3 \%$ and the intercept is not significant $(\mathrm{p}=.65)$.
} 
wall cylinders and ten were 30As. Upon remeasurement, none of the thin-wall cylinder outlier measurements were confirmed, though all but two of the 30As were confirmed (see page 45 of 2004 report). This suggests that the outliers in Table 8 should also be remeasured (or explained), and that some of them may represent bad data points rather than legitimate measurements. For this reason. most of the analyses in this report are performed both with and without the nine outliers.

Table 8. Direct-Model Outlier Cylinders

\begin{tabular}{|c|c|c|c|c|c|c|c|}
\hline $\begin{array}{l}\text { Cylinder } \\
\text { ID }\end{array}$ & $\begin{array}{c}\text { Fiscal } \\
\text { Year } \\
\text { Measured }\end{array}$ & $\begin{array}{c}\text { Site of } \\
\text { UT } \\
\text { Measurement }\end{array}$ & $\begin{array}{c}\text { UT } \\
\text { Measurement } \\
\text { Position }\end{array}$ & $\begin{array}{l}\text { Minimum } \\
\text { Wall } \\
\text { Thickness } \\
\text { (mils) }\end{array}$ & $\begin{array}{c}\text { Age } \\
\text { on } \\
\text { 9/30/06 } \\
\text { (Years) }\end{array}$ & $\begin{array}{c}\text { Paint } \\
\text { Date }\end{array}$ & $\begin{array}{l}\text { Functional } \\
\text { Group }\end{array}$ \\
\hline 00001400 & 1998 & Portsmouth & Main body & 502 & 54.9 & & All thick top \\
\hline 00084800 & 1997 & Portsmouth & Head/Skirt & 595 & 53.9 & & All thick, head/skir \\
\hline 00105200 & 2006 & ETTP & Main body & 132 & 53.0 & & All thick btm \\
\hline 00238000 & 1998 & Portsmouth & Main body & 464 & 52.2 & & All thick btm \\
\hline 00504800 & 2004 & ETTP & Main body & 131 & 50.7 & 24AUG98 & ETTP thin $\mathrm{K}$ btm \\
\hline 00795300 & 2001 & ETTP & Main body & 103 & 49.1 & 29SEP99 & ETTP thin $\mathrm{K}$ btm \\
\hline 11495100 & 2001 & ETTP & Main body & 100 & 31.8 & 28SEP99 & ETTP thin except $\mathrm{K}$ btm \\
\hline 11679700 & 2004 & ETTP & Main body & 130 & 30.4 & 28SEP99 & ETTP thin except $\mathrm{K}$ btm \\
\hline 12253200 & 2004 & PGDP & Main body & 136 & 28.3 & & PGDP thin btm former $\mathrm{G}$ \\
\hline
\end{tabular}

The distribution of regression residuals without the outliers is shown in Figure 30. Without the outliers the distribution is still slightly left skewed, but not nearly so as when the nine outliers are included.

Table 9 shows the $\theta_{S}$ and $\beta_{\mathrm{G}}$ regression parameter estimates for fitting the direct model (4.1) to the 3,225 data points with the nine outliers excluded. With the outliers excluded, all of the $\beta_{\mathrm{G}}$ estimates are negative. However, the parameter estimates are essentially the same as the estimates in Table 8 with the outliers included. (The two negative parameter estimates in Table 8 are not statistically significant.) As will be seen in the next section, it is the model-based predictions, not the parameter estimates that the outliers substantially effect.

Figures 31-44 show the observed minimum thicknesses and direct-model age-weighted fitted regression curves for the fourteen functional groups. In addition, the figures also show two sets of $99 \%$ lower confidence limits (LCLs) for minimum thicknesses for individual cylinders over the age ranges in the plots. The LCL curves are approximations:

Probability ( Actual Minimum Thickness at age $\mathrm{t} \geq \mathrm{LCL}$ at $\mathrm{t}$ ) $\approx .99$

for any particular age t. One set of LCL curves is based on a large-sample approximation that does not assume any particular underlying distribution (e.g., normal) for the regression errors. Schmoyer (1992) has shown that the error in this approximation goes to zero, so that (4.2) holds exactly, as the sample size increases. The large sample size of over 3,200 unique cylinders with minimum thickness measurements supports the large-sample approximation. 


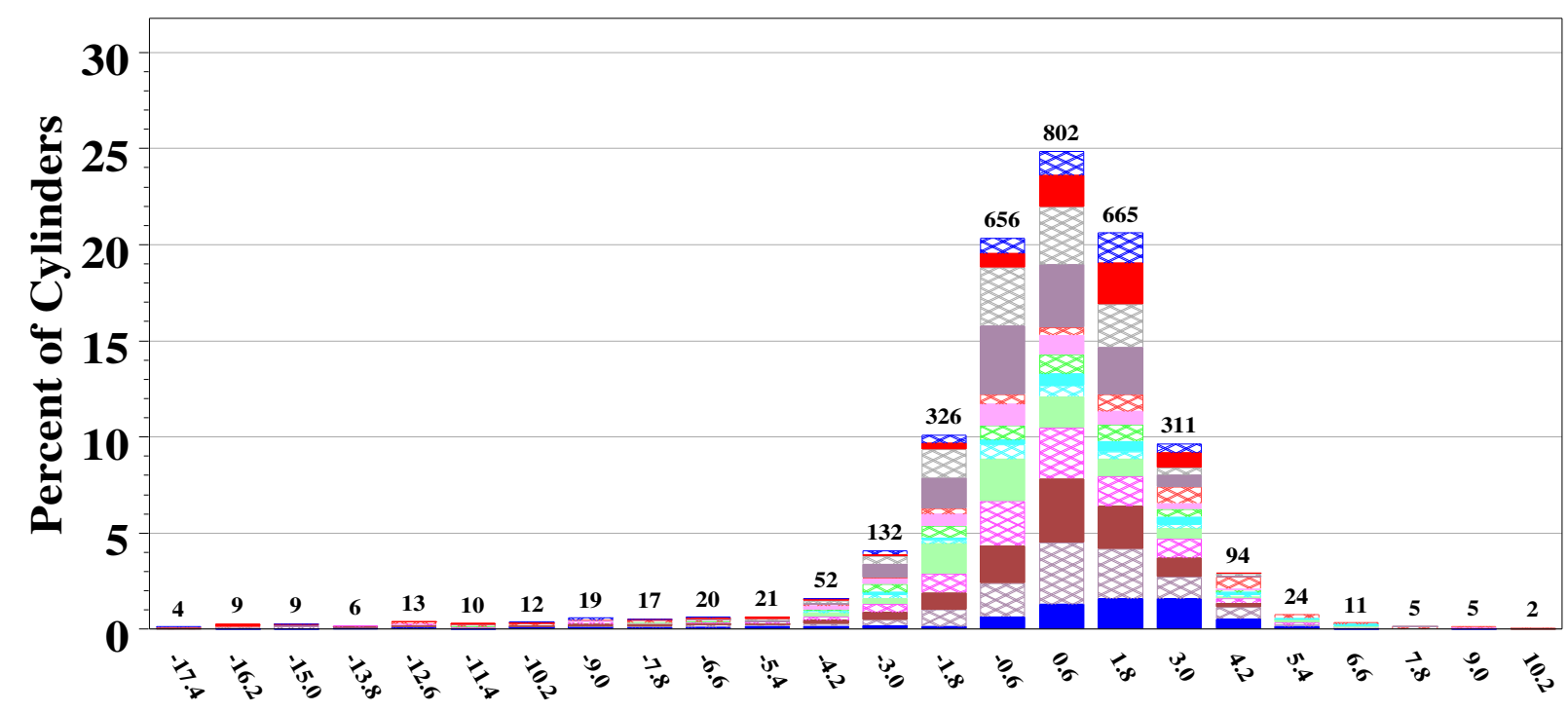

Weighted Residual Interval Midpoint (Mils)
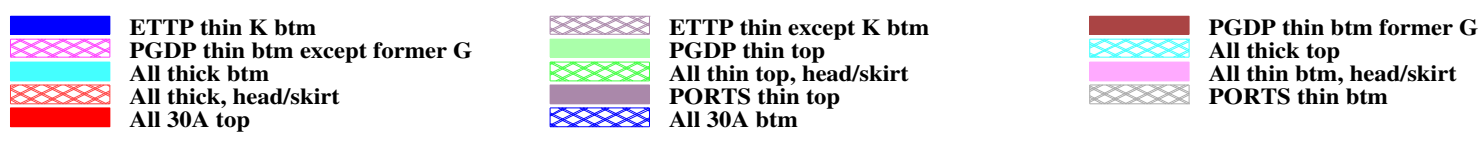

Figure 30. The distribution of the regression residuals with the nine outliers removed. Without the outliers the distribution is only slightly left skewed. The number of cylinders contributing to each bar is printed above the bar.

The other set of LCLs, which do not have the large-sample exactness property, is based on the assumption that the regression errors are normally distributed. These LCLs are included for reference because they are the usual normal-theory regression confidence limits. As Figure 30 shows, however, the somewhat left-skewed distribution of residuals (even after discarding the outliers) suggests that the regression errors are not normally distributed. Because of the left-skewed residuals, the normal-theory LCLs turn out to be higher (closer to the regression curve) than the large-sample limits. Both the largesample and normal-theory LCLs indicate that although there are slight declines over time in average minimum wall thicknesses, there is considerable uncertainty about individual cylinders, and the uncertainty about individual cylinders increases as predictions extend farther ahead in time.

In addition to outlier identification, Figure 29 can also be used for judging whether the regression errors are approximately uniform (e.g., across ages) and whether the variance-proportional-to-age weighting or some other weighting is appropriate. (A uniform distribution in the weighted residuals is an objective of the weighting because a uniform weighted error distribution is an assumption of the regression.) Figure 29 shows that, except perhaps for the nine outliers (of over 3,200 residuals), the variance of the regression residuals is approximately the same for different ages and cylinder thickness types. This suggests that the age and group weighting is appropriate. If the regression is computed without the special weighting for $30 \mathrm{~A}$ cylinders, the residual variance is not nearly as uniform. 
Table 9. Direct Model Parameter Estimates After Excluding Outliers

\begin{tabular}{|r|r|r|}
\hline Model Parameter & Estimate & $\begin{array}{c}\text { Standard } \\
\text { Error }\end{array}$ \\
\hline Nominal thickness (main body) & 1.039 & 0.007 \\
\hline Nominal thickness (H/S interface) & 1.257 & 0.006 \\
\hline Log Age for ETTP thin K btm & -5.590 & 0.668 \\
\hline Log Age for ETTP thin except K btm & -4.175 & 0.654 \\
\hline Log Age for PGDP thin btm except former G & -3.423 & 0.703 \\
\hline Log Age for PGDP thin top & -2.709 & 0.728 \\
\hline Log Age for All thick top & -3.569 & 1.253 \\
\hline Log Age for All thick btm & -3.604 & 1.273 \\
\hline Log Age for Thick/thin head/skirt & -11.919 & 0.756 \\
\hline Log Age for PORTS thin top & -0.010 & 0.730 \\
\hline Log Age for PORTS thin bottom & -0.206 & 0.749 \\
\hline Log Age for All 30As top & -14.290 & 1.434 \\
\hline Log Age for All 30As btm & -14.526 & 1.539 \\
\hline
\end{tabular}

Cylinder-to-cylinder variability is characterized by the root mean squared error for the fitted regression model. This is 2.9196 for the model with the nine outliers excluded (and 3.509 if the nine outliers are included). This is for the model with weights. The actual root mean square error depends on age:

$$
\text { Root MSE }=2.9196 \times \sqrt{\text { age }}
$$

for the thin-wall and thick-wall cylinders, and

$$
\text { Root MSE }=2.9196 \times 3.0675 \times \sqrt{\text { age }}=8.9557 \times \sqrt{\text { age }}
$$

for $30 \mathrm{~A}$ cylinders. For a 50 year-old thin or thick-wall cylinder, this is 20.6 mils, and it is 63.3 for a 50 year-old 30A cylinder. The UT instrument error is probably quite small, perhaps just a few mils (see, for example, Fowler et al 2003). The remaining error is due to cylinder-to-cylinder variability, which includes measurement error in finding the minimum thickness. The very substantial scatter in the minimum wall thicknesses can also be seen in Figures 31-44. 


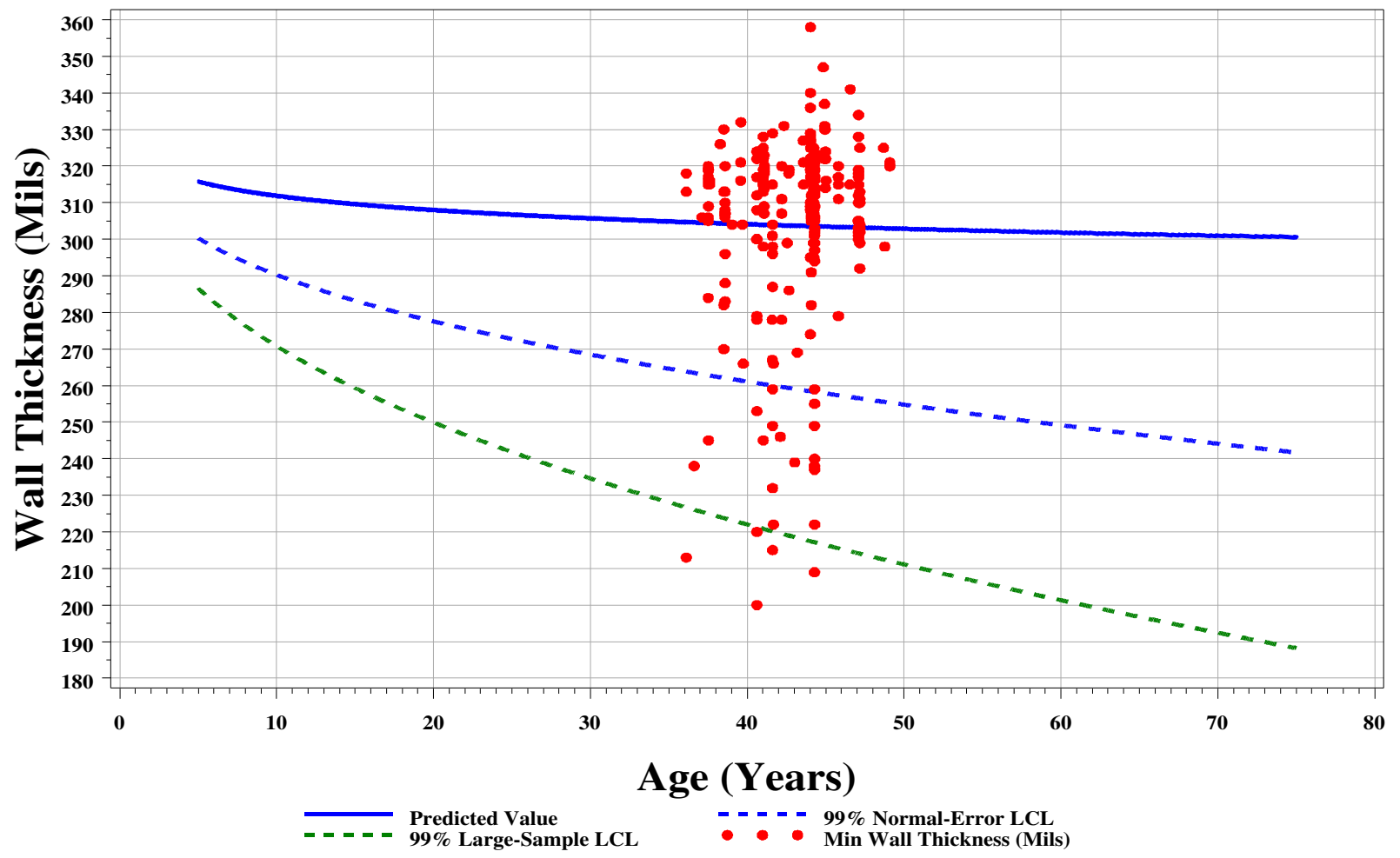

Figure 31. Direct-model predicted and observed (UT-measured) minimum wall thicknesses for ETTP thin K-yard bottom cylinders.

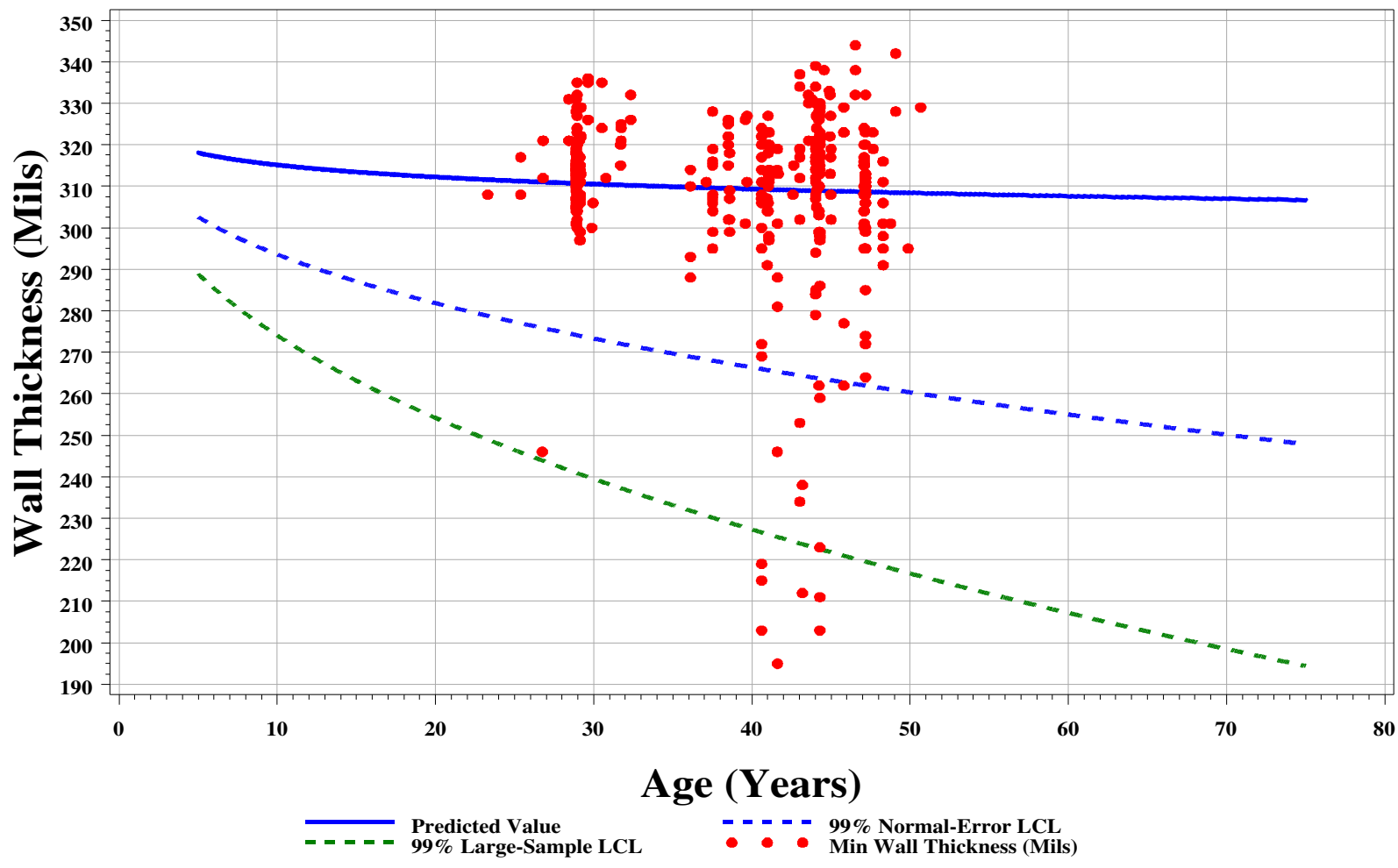

Figure 32. Direct-model predicted and observed (UT-measured) minimum wall thicknesses for ETTP thin cylinders except K-yard bottom. 


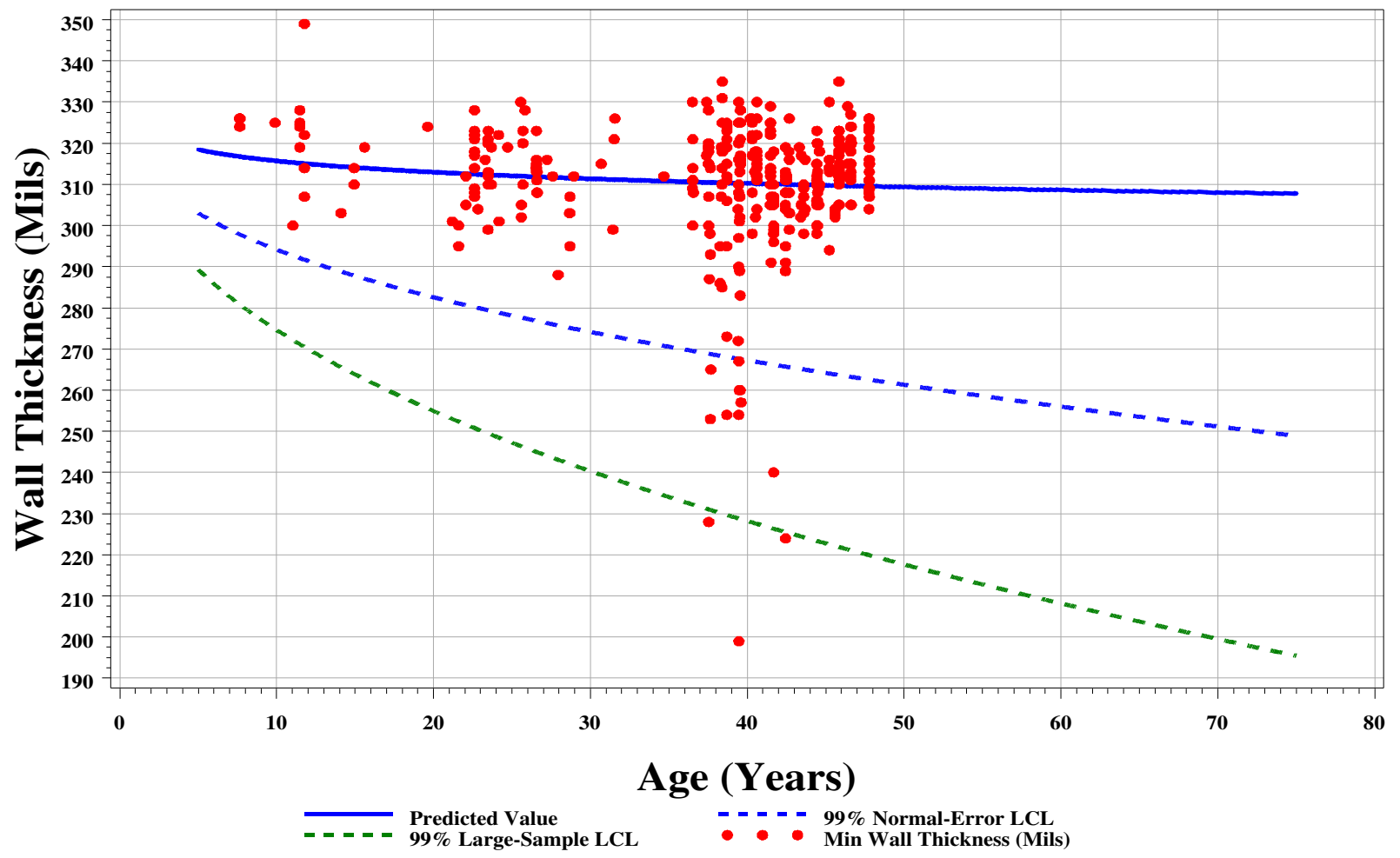

Figure 33. Direct-model predicted and observed (UT-measured) minimum wall thicknesses for PGDP thin bottom former G-yard cylinders.

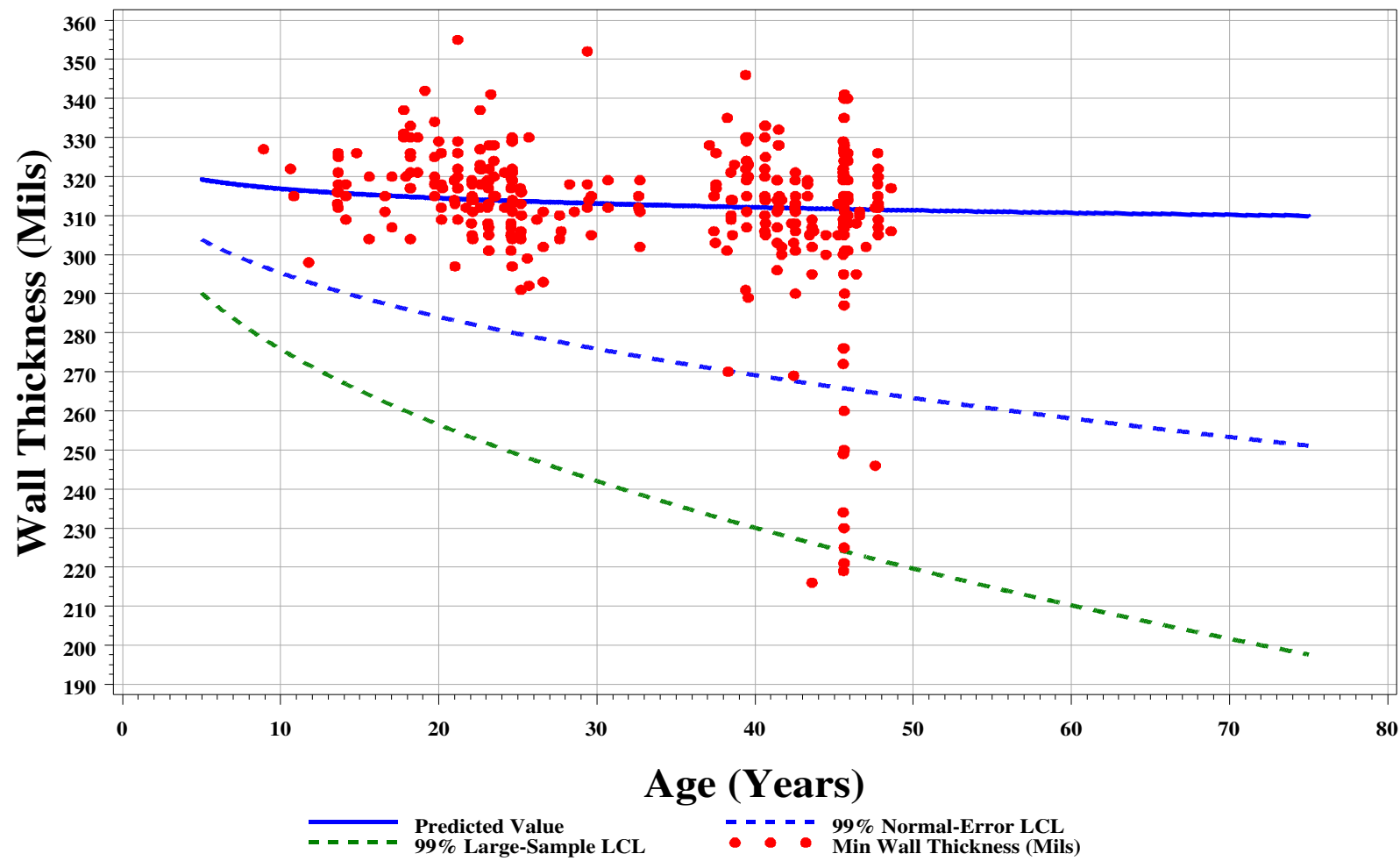

Figure 34. Direct-model predicted and observed (UT-measured) minimum wall thicknesses for PGDP thin bottom cylinders except former G-yard. 


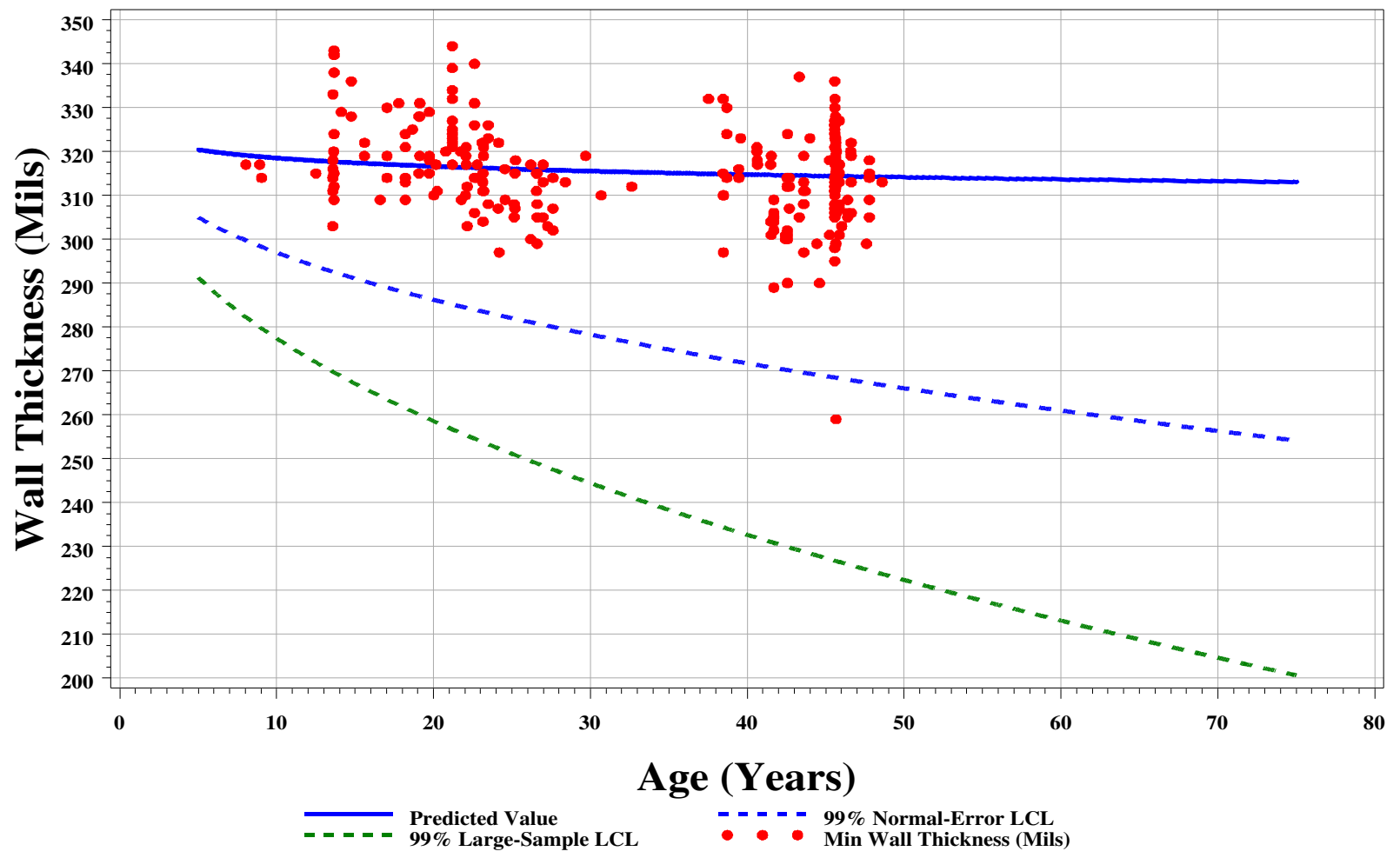

Figure 35. Direct-model predicted and observed (UT-measured) minimum wall thicknesses for PGDP thin top cylinders.

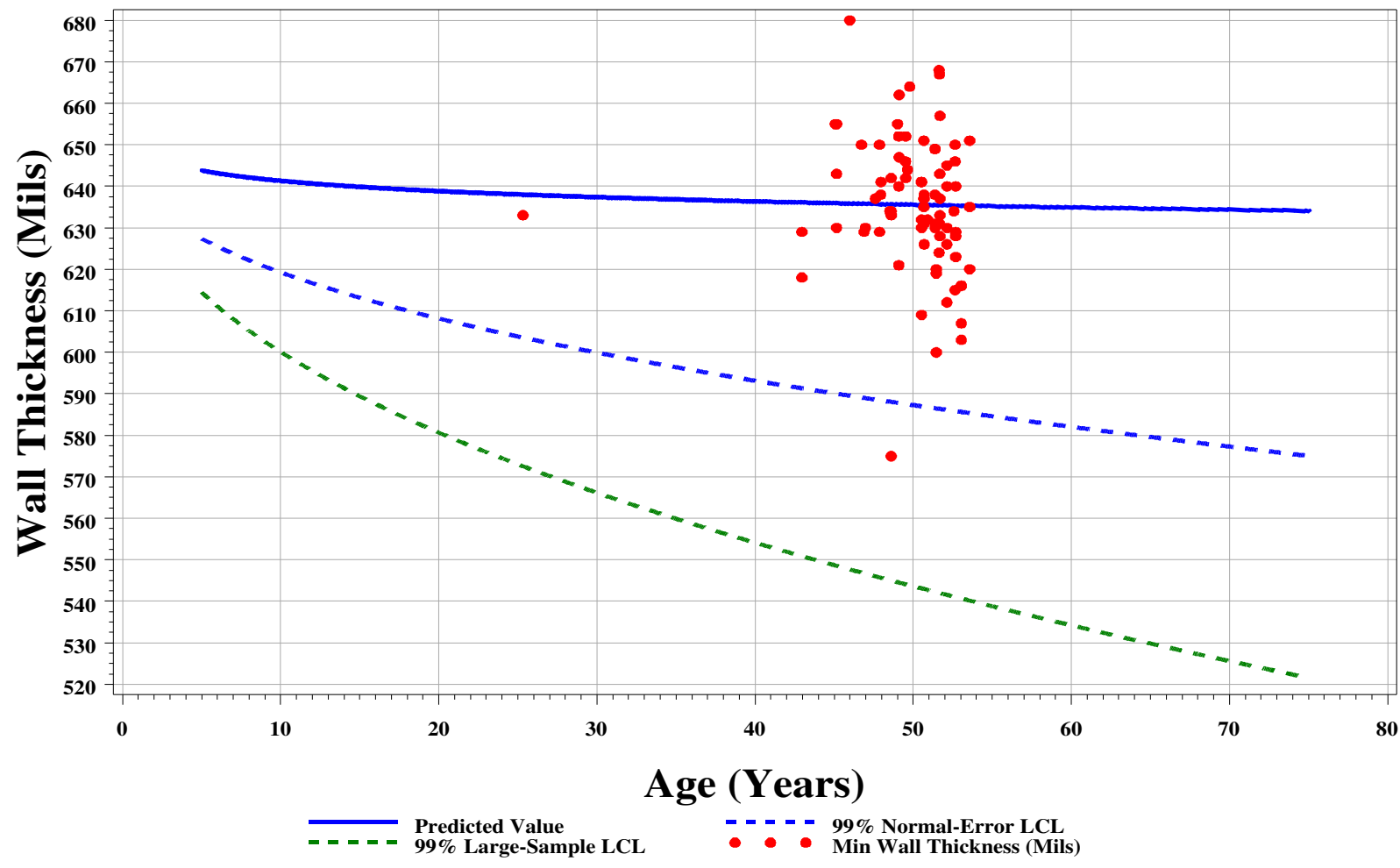

Figure 36. Direct-model predicted and observed (UT-measured) minimum wall thicknesses for all thick top cylinders. 


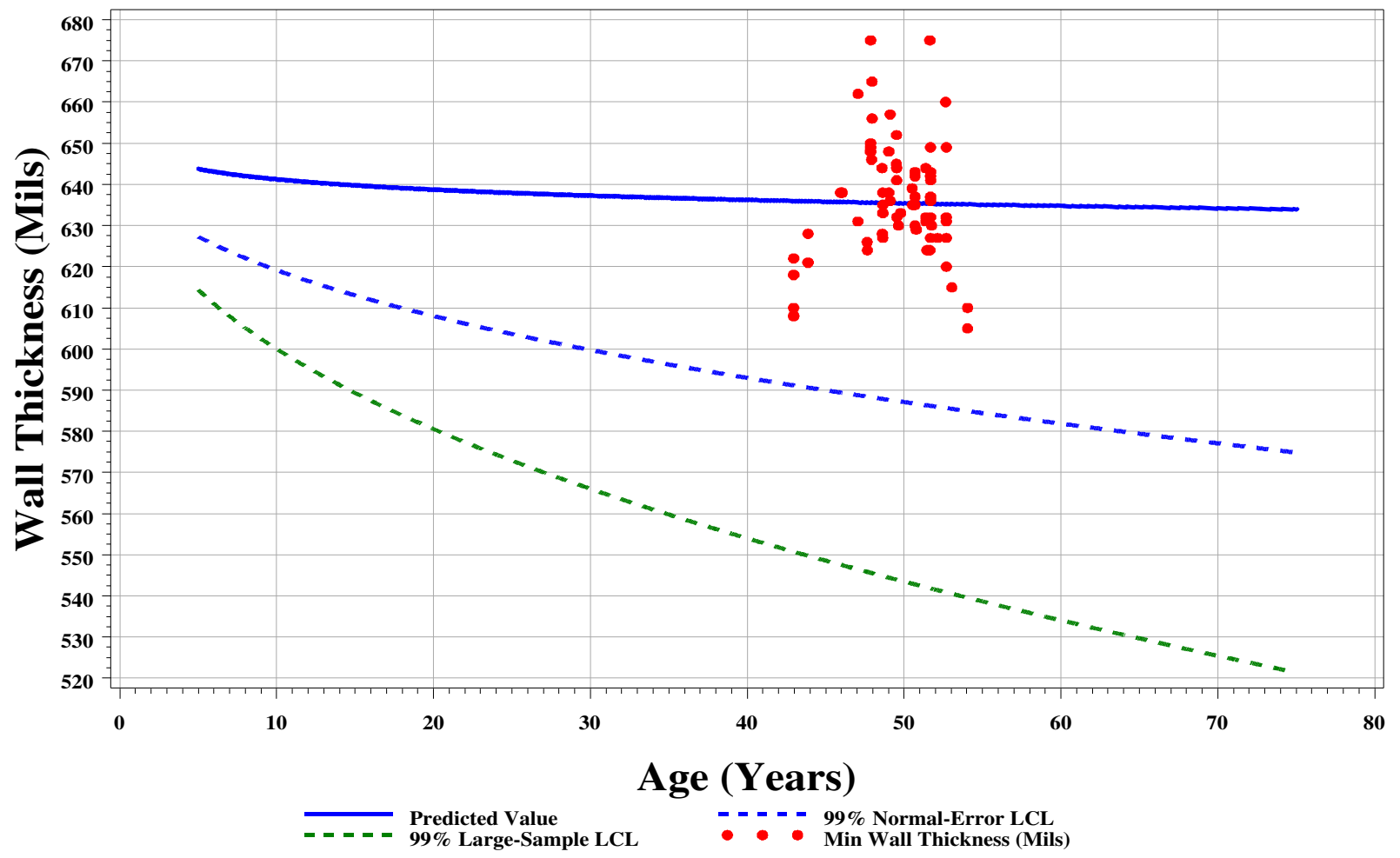

Figure 37. Direct-model predicted and observed (UT-measured) minimum wall thicknesses for all thick bottom cylinders.

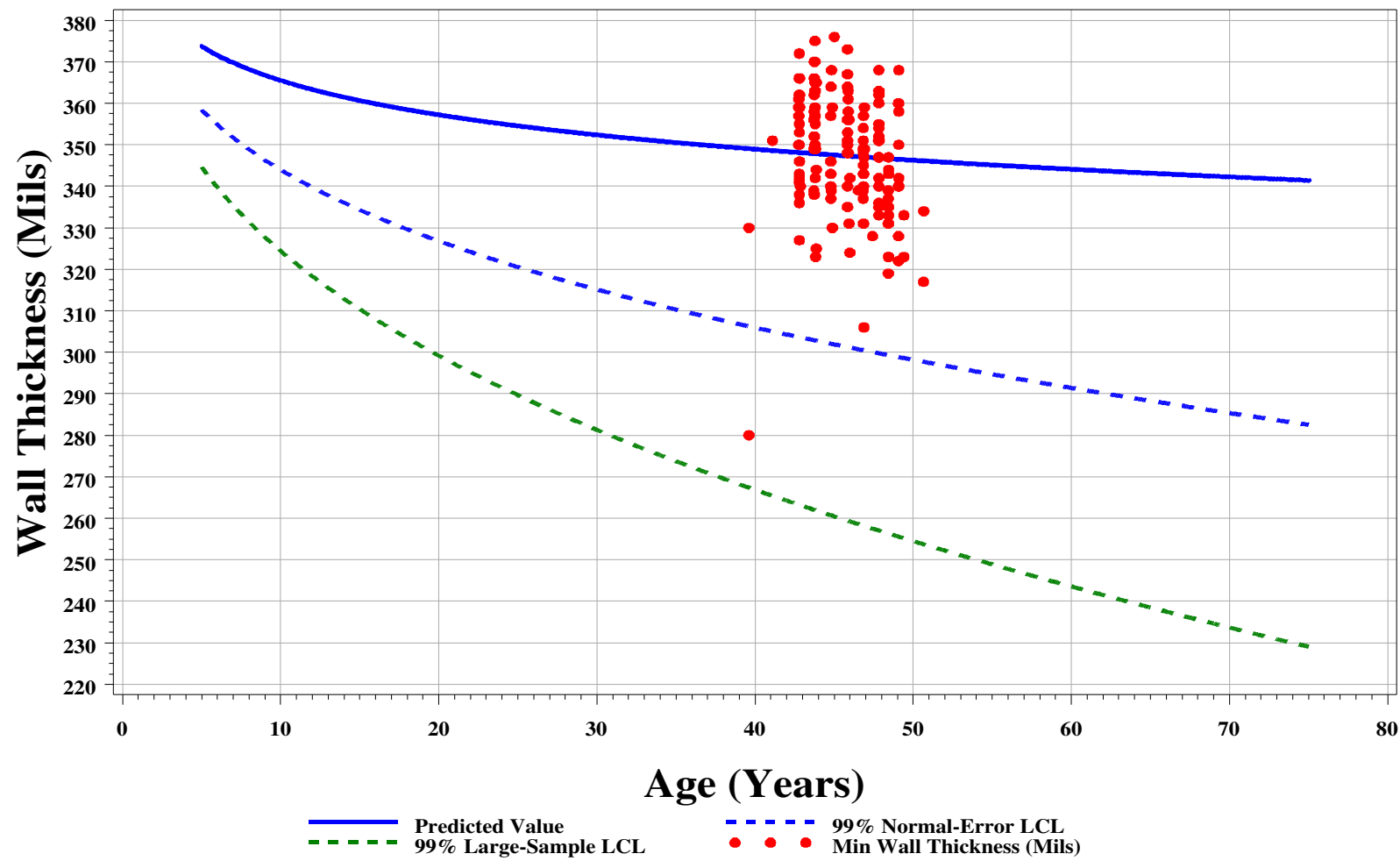

Figure 38. Direct-model predicted and observed (UT-measured) minimum wall thicknesses for all thin top cylinders, head/skirt interface. 


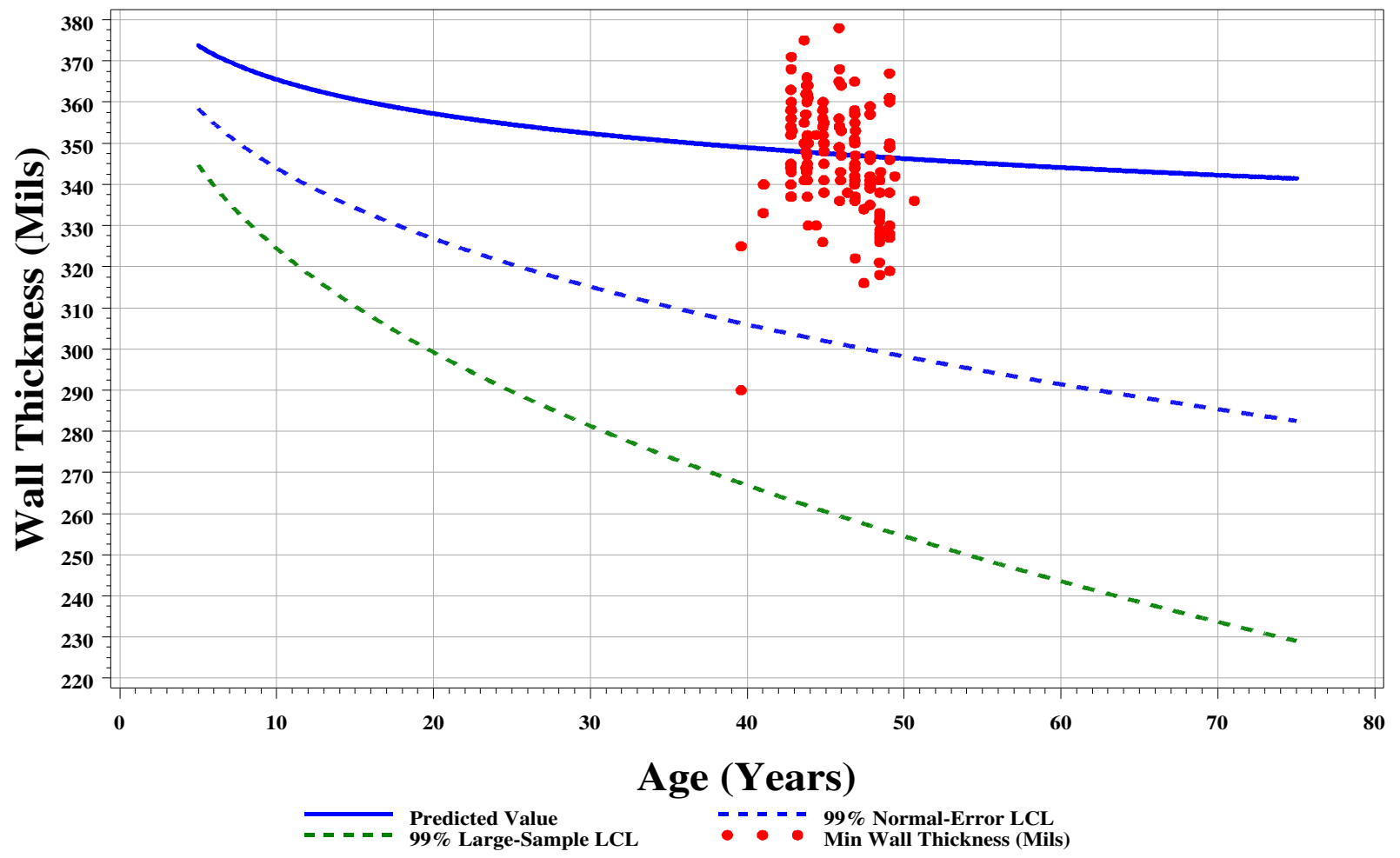

Figure 39. Direct-model predicted and observed (UT-measured) minimum wall thicknesses for all thin bottom cylinders, head/skirt interface.

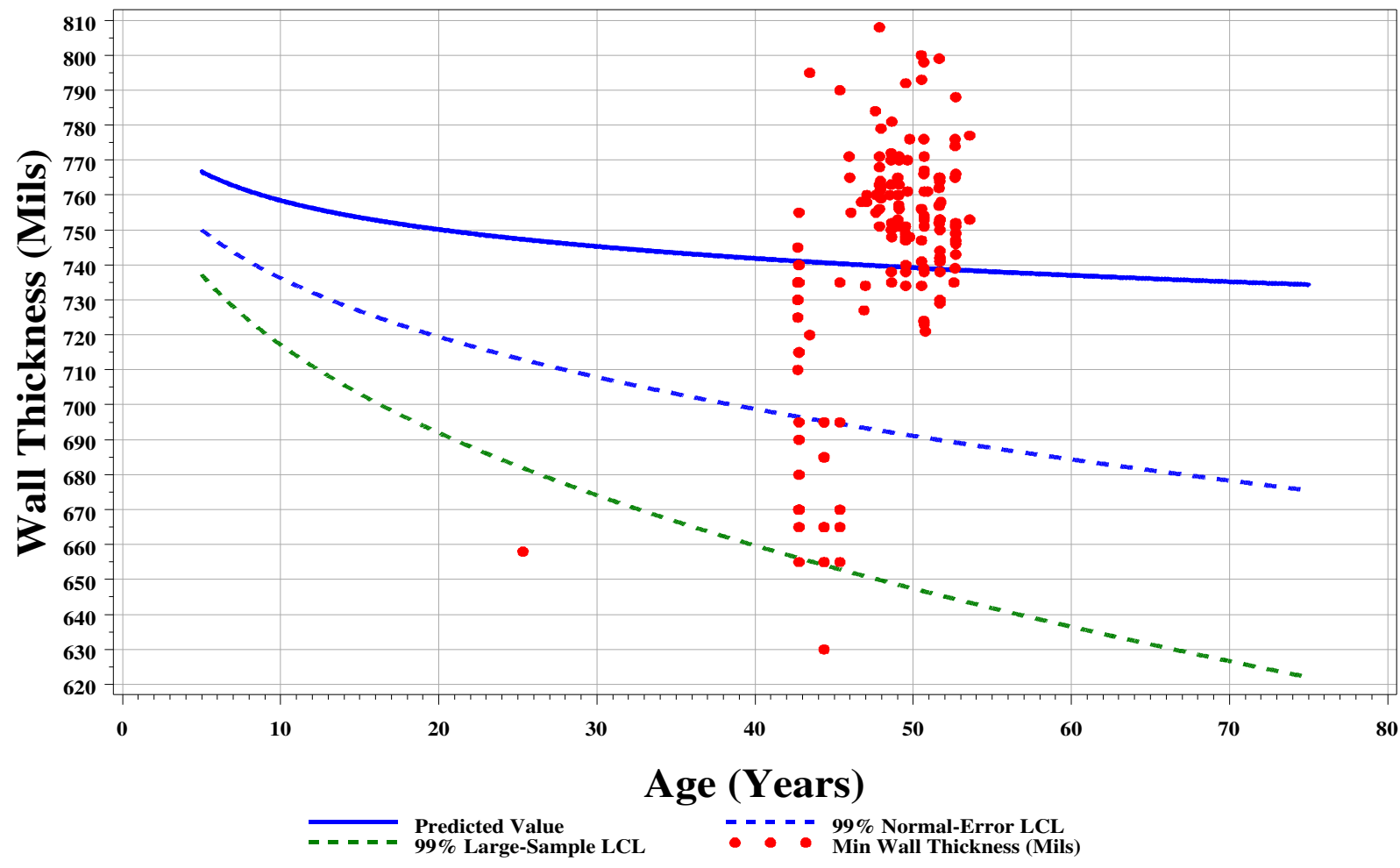

Figure 40. Direct-model predicted and observed (UT-measured) minimum wall thicknesses for all thick cylinders, head/skirt interface. 


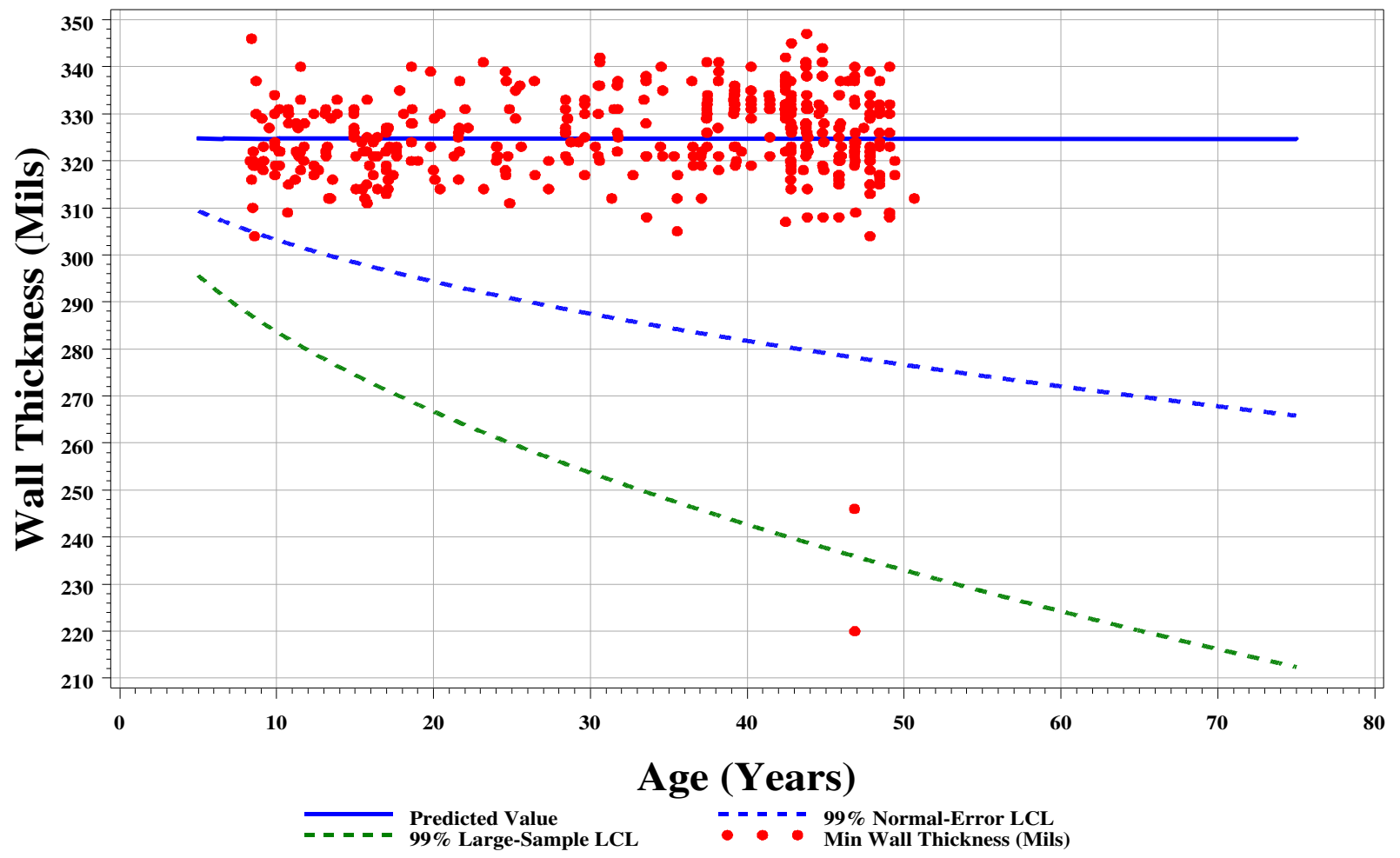

Figure 41. Direct-model predicted and observed (UT-measured) minimum wall thicknesses for Portsmouth thin top cylinders.

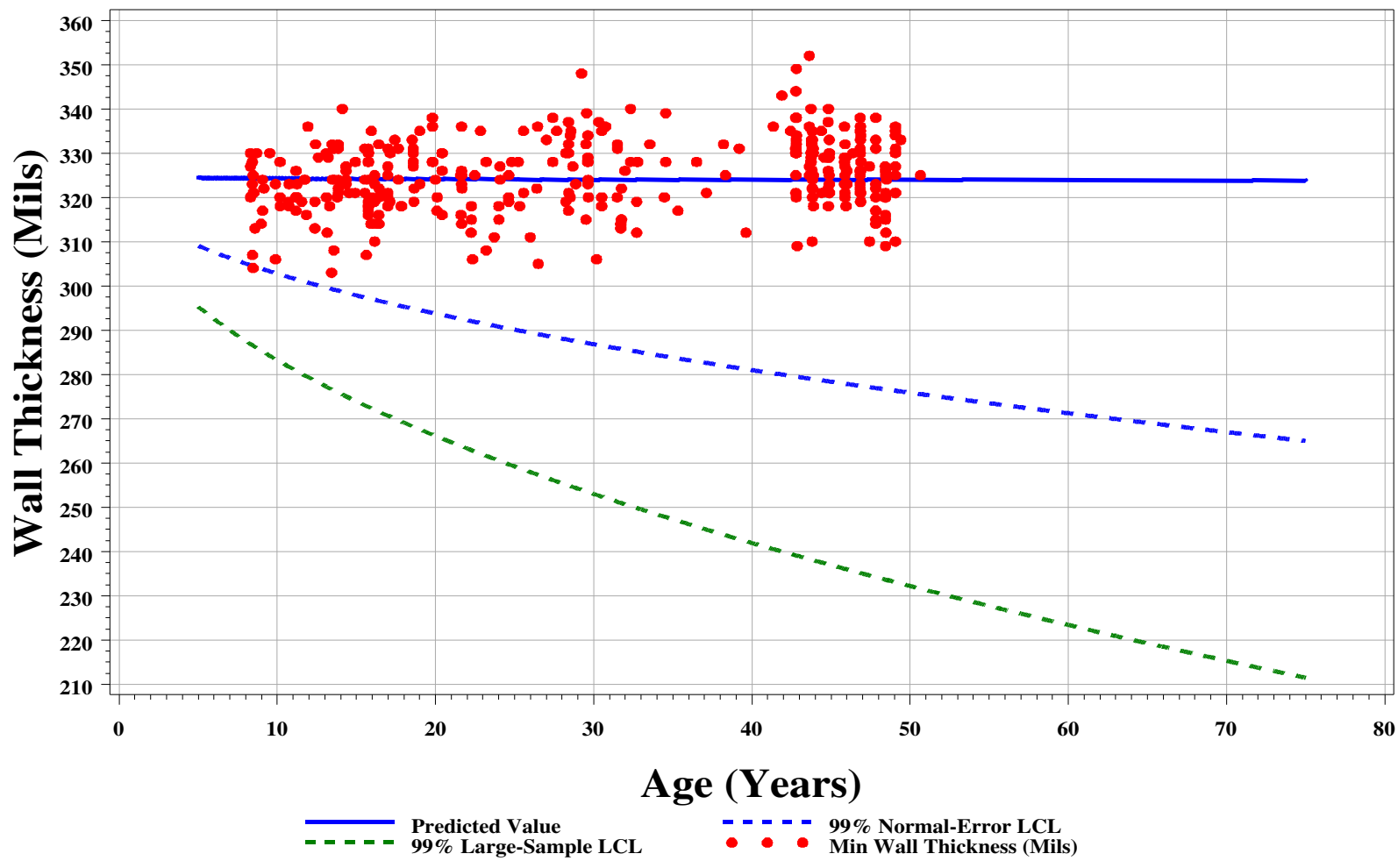

Figure 42. Direct-model predicted and observed (UT-measured) minimum wall thicknesses for Portsmouth thin bottom cylinders. 


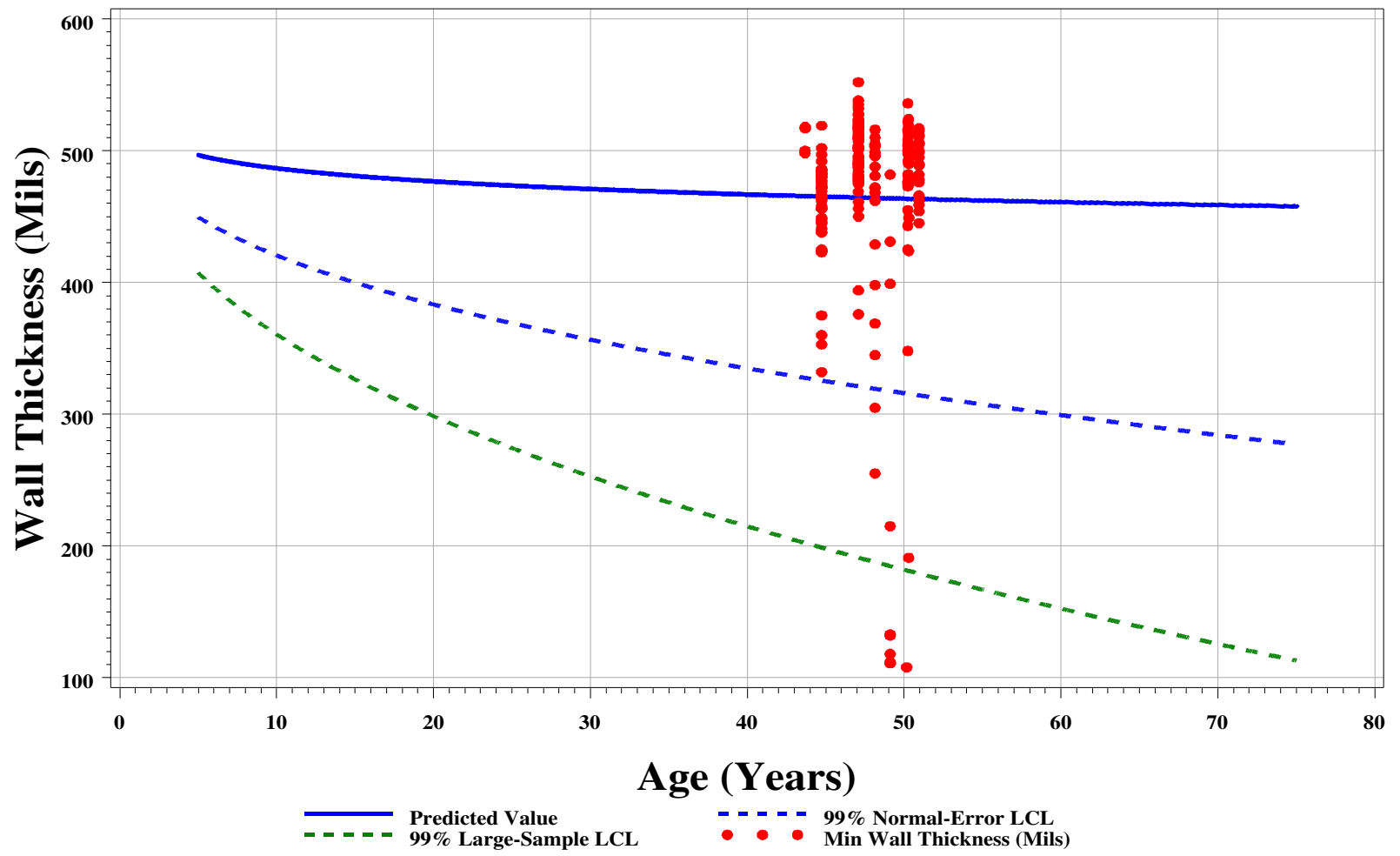

Figure 43. Direct-model predicted and observed (UT-measured) minimum wall thicknesses for all $30 \mathrm{~A}$ top cylinders.

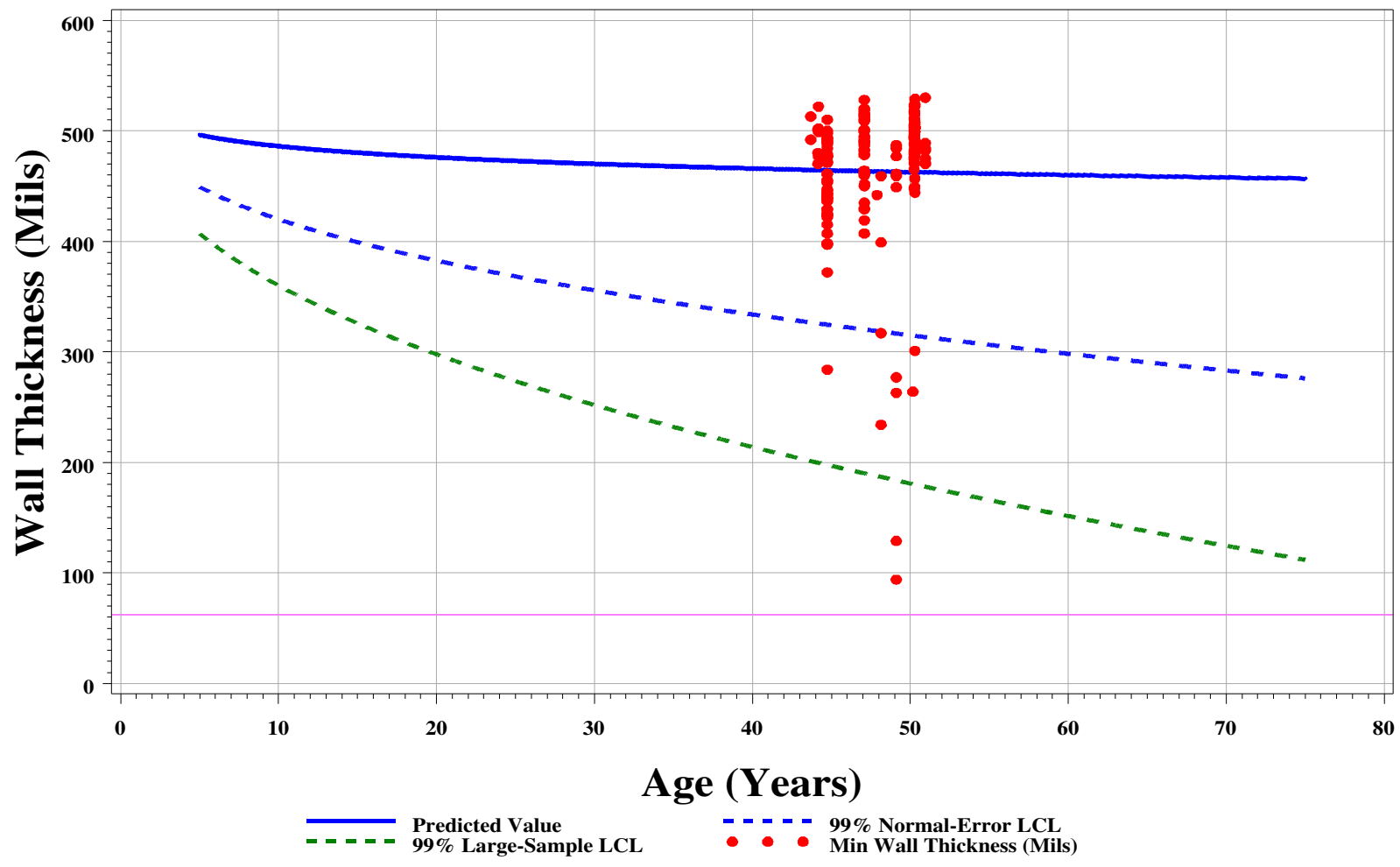

Figure 44. Direct-model predicted and observed (UT-measured) minimum wall thicknesses for all 30A bottom cylinders. 


\section{WALL THICKNESS PROJECTIONS}

In this section projections are presented of the numbers or proportions of cylinders expected to fail various thickness criteria, as a function of extended storage time. The projections are based on the direct model as developed in Section 2 and fit to the UT data in Section 4. The projections in Tables 10 and 11 are broken down by functional group. Projections in Table 10 are based on a direct-model analysis that includes the nine outliers identified in Section 4. Projections in Table 11 are based on the same analysis with the outliers excluded. Table 12 is an analog of Table 11 but with results presented as percentage risks rather than expected numbers of failures. Table 13 shows projections broken down by both functional group and age and ranked in descending order of risk.

The projections are computed for the following minimum wall thickness criteria:

1. 0 mils (i.e., a breach), which indicates a possible loss of contained material

2. 62.5 mils, below which ordinary safe handling and stacking is considered to be impaired

3. 250 mils for thin-wall cylinders and 500 mils for thick-wall cylinders, which represent applicable standards for off-site transport and contents transfer (based on ANSI 14.1, 1995).

For 30A cylinders, there are no published criteria for minimum thicknesses. However, in addition to the zero (breach) and 62.5 mil criteria, 100 mils, the minimum thickness for regular hot feeding ${ }^{11}$ is also used for $30 \mathrm{~A}$ cylinders.

These criteria are actually for an "area" of wall thinning, as opposed to a point. It might be argued that the results here are therefore conservative because the UT minimum thicknesses are for a tiny area of only about 0.01 square inches, essentially a point. What is meant by "area" in this context has not been precisely defined, however, and so treating areas as points is reasonable. Also, at least for the breach criteria, consider the following from DNFSB (1995):

A breach in a cylinder allows the external atmosphere to react slowly with the $\mathrm{UF}_{6}$. The solid reaction product tends to plug the breach; however, the HF formed releases slowly, attacks the metal cylinder, and enlarges the breach over time. The hole diameter is estimated to increase at a rate of approximately one inch per year.

Therefore, because of the interaction of $\mathrm{UF}_{6}$ with atmospheric moisture and the substrate steel, the approximation of a small-area breach with a point breach is not really conservative, because any point breach becomes an area breach almost immediately. ${ }^{12}$

Cylinder Count Projections. Table 10 shows numbers of cylinders projected on the basis of the direct model (equation 4.1) to have minimum wall thickness below the various thickness criteria. These projections are computed using cylinder counts from the CID and the direct-model estimates of the probability $\operatorname{Prob}(M(t)<l)$ for the various ages and thickness criteria. Outliers are included. Table 11 is the same as Table 10 but based on estimates with the outliers excluded.

\footnotetext{
${ }^{11}$ S. J. Pawel, ORNL Corrosion Science \& Technology Group, personal communication.

${ }^{12}$ However, note also page 4 of the SRD (LMES 1997a): "Reaction deposits formed when $\mathrm{UF}_{6}$ is exposed to the atmosphere in the presence of the mild steel containers have a self-sealing nature."
} 
Table 10. Direct-Model Projections for Various Target Years And Thickness Specs, Outlier Cylinders Included

\begin{tabular}{|c|c|c|c|c|c|c|c|}
\hline \multirow{2}{*}{\begin{tabular}{|l|} 
\\
Cylinder Population \\
\end{tabular}} & \multirow[b]{2}{*}{$\begin{array}{l}\text { Pop. } \\
\text { Total }\end{array}$} & \multirow[b]{2}{*}{$\begin{array}{c}\text { Spec } \\
\text { (mils) }\end{array}$} & \multicolumn{5}{|c|}{$\begin{array}{c}\text { Projected Number of } \\
\text { Cylinders Below Minimum } \\
\text { Thickness Spec in Year: }\end{array}$} \\
\hline & & & 2006 & 2010 & 2015 & 2020 & 2025 \\
\hline \multirow[t]{3}{*}{ ETTP thin $\mathrm{K}$ btm } & $\mid 1,491$ & 250 & 47 & 49 & 52 & 55 & 57 \\
\hline & & 62.5 & 2 & 2 & 2 & 2 & 2 \\
\hline & & 0 & {$[0-1]$} & 1 & 1 & 1 & 1 \\
\hline \multirow{3}{*}{ ETTP thin except $\mathrm{K}$ btm } & 3,262 & 250 & 77 & 83 & 92 & 99 & 105 \\
\hline & & 62.5 & 2 & 3 & 3 & 4 & 4 \\
\hline & & 0 & 2 & 2 & 2 & 2 & 2 \\
\hline \multirow[t]{3}{*}{ PGDP thin btm former $G$} & 9,106 & 250 & 180 & 202 & 228 & 249 & 267 \\
\hline & & 62.5 & 7 & 7 & 9 & 10 & 11 \\
\hline & & 0 & 4 & 4 & 5 & 5 & 6 \\
\hline & & & & & & & \\
\hline \multirow[t]{3}{*}{ PGDP thin btm except former $\mathrm{G}$} & 13,567 & 250 & 139 & 172 & 220 & 259 & 299 \\
\hline & & 62.5 & 6 & 7 & 8 & 9 & 11 \\
\hline & & 0 & 4 & 5 & 6 & 7 & 7 \\
\hline \multirow[t]{3}{*}{ PGDP thin top } & 13,231 & 250 & 120 & 150 & 194 & 233 & 267 \\
\hline & & 62.5 & 6 & 7 & 8 & 9 & 10 \\
\hline & & 0 & 4 & 4 & 5 & 6 & 7 \\
\hline & & & & & & & \\
\hline \multirow[t]{3}{*}{ All thick top } & 983 & 500 & 3 & 3 & 4 & 5 & 7 \\
\hline & & 62.5 & 0 & 0 & 0 & 0 & 0 \\
\hline & & 0 & 0 & 0 & 0 & 0 & 0 \\
\hline \multirow{4}{*}{ All thick btm } & & & & & & & \\
\hline & 989 & 500 & 4 & 5 & 6 & 7 & 8 \\
\hline & & 62.5 & 0 & 0 & 0 & 0 & 0 \\
\hline & & 0 & 0 & 0 & 0 & 0 & 0 \\
\hline & & & & & & & \\
\hline \multirow[t]{3}{*}{ All thin top, head/skirt } & 2,632 & 250 & 23 & 26 & 31 & 36 & 40 \\
\hline & & 62.5 & 2 & 2 & 2 & 2 & 3 \\
\hline & & 0 & 1 & 1 & 1 & 1 & 2 \\
\hline \multirow[t]{3}{*}{ All thin btm, head/skirt } & 2,818 & 250 & 24 & 27 & 32 & 37 & 43 \\
\hline & & 62.5 & 2 & 2 & 2 & 3 & 3 \\
\hline & & 0 & 1 & 1 & 1 & 1 & 2 \\
\hline & & & & & & & \\
\hline \multirow[t]{3}{*}{ All thick, head/skirt } & 1,972 & 500 & 3 & 3 & 3 & 3 & 3 \\
\hline & & 62.5 & 0 & 0 & 0 & 0 & 0 \\
\hline & & 0 & 0 & 0 & 0 & 0 & 0 \\
\hline
\end{tabular}




\section{Table 10. Direct-Model Projections for Various Target Years And Thickness Specs, Outlier Cylinders Included}

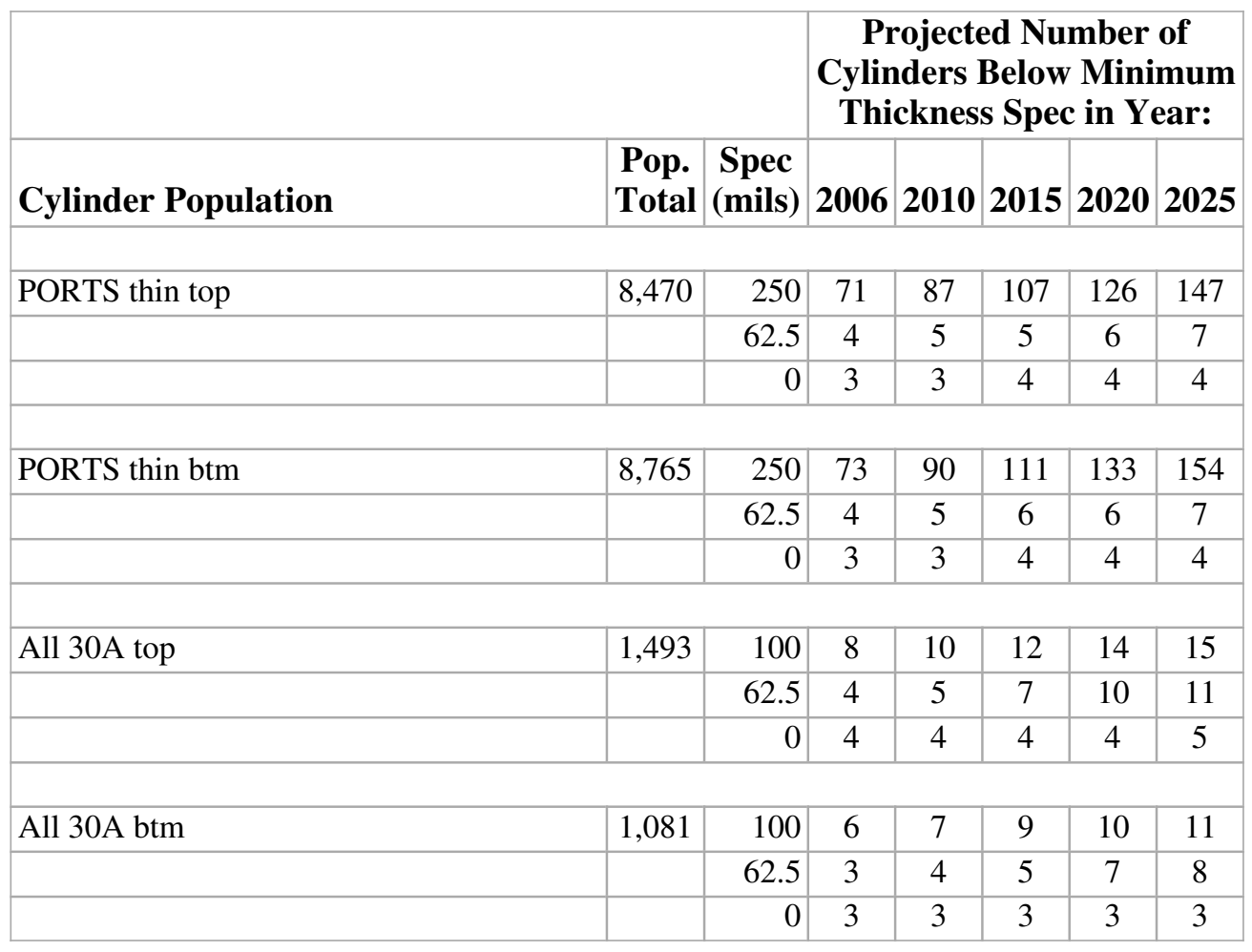

Tables 10 and 11 contain estimates of the numbers of cylinders expected to fail the various thickness criteria. They are expectations: even if the estimates of $\operatorname{Prob}(M(t)<l)$ were exact (and the estimates of the numbers of cylinders expected to fail were thus also exact), the actual numbers of cylinders observed in practice to violate the various thickness criteria would still depart randomly from the estimates. The direct-model projections in the tables are based on the same large-sample approximation that is used to derive the nonparametric LCLs plotted in Figures 31-44 for individual predicted values. They thus reflect estimation error in the direct-model regression parameters.

The probability estimates are of lower tail probabilities $(\operatorname{Prob}(M \leq l))$. A limitation of this nonparametric approach is that, because it is not premised on a distribution with functional form that is known (up to unspecified parameters), not much can be extrapolated beyond the sample about the lower (or upper) tail of the distribution. This is the problem of rare events and small sample sizes discussed in Section 2.5. An implication is that the prediction bounds are not appropriate for probabilities less than $1 /(2(n+1))$ (or perhaps $1 /(n+1))$, where $n$ is the number of observations in the regression used to compute them. A consequence of this limitation is that direct model probability estimates are never smaller than $1 /(2(n+1)$. Smaller values are in this sense below the resolution of the sample. Further details about the resolution limitation are discussed in Schmoyer (1992).

For the direct model with outliers included, there are $n=3,234$ observations. The resolution limit is $1 /(2(\mathrm{n}+1)=.000155$. Without further assumptions (e.g., that the thickness distribution is normal), the only way to reduce this limit is to increase the sample size n. For a functional group of say 2,000 cylinders, the limit translates to $.000155 \times 2,000=.31$ or, essentially, $\mathrm{N}=0$ cylinders. But for a functional group of 10,000 cylinders the limit translates to 1.55 cylinders or about $\mathrm{N}=2$ cylinders. When projections like this are at the limit of resolution of the sample, they are presented in the as bracketed ranges " $[0-\mathrm{N}]$ " in the tables to differentiate them from projections that are above this limit. Some of the entries in Table 11 are of this form. 
Table 11. Direct-Model Projections for Various Target Years And Thickness Specs, Outlier Cylinders Excluded

\begin{tabular}{|c|c|c|c|c|c|c|c|}
\hline \multirow[b]{2}{*}{ Cylinder Population } & \multirow[b]{2}{*}{$\begin{array}{l}\text { Pop. } \\
\text { Total }\end{array}$} & \multirow[b]{2}{*}{$\begin{array}{c}\text { Spec } \\
\text { (mils) }\end{array}$} & \multicolumn{5}{|c|}{$\begin{array}{c}\text { Projected Number of } \\
\text { Cylinders Below Minimum } \\
\text { Thickness Spec in Year: }\end{array}$} \\
\hline & & & 2006 & 2010 & 2015 & 2020 & 2025 \\
\hline \multirow[t]{3}{*}{ ETTP thin $\mathrm{K}$ btm } & 1,491 & 250 & 43 & 44 & 47 & 50 & 53 \\
\hline & & 62.5 & 0 & 0 & 0 & 0 & 0 \\
\hline & & 0 & 0 & 0 & 0 & 0 & 0 \\
\hline & & & & & & & \\
\hline \multirow[t]{3}{*}{ ETTP thin except $\mathrm{K}$ btm } & 3,262 & 250 & 67 & 73 & 81 & 89 & 95 \\
\hline & & 62.5 & {$[0-1]$} & {$[0-1]$} & {$[0-1]$} & {$[0-1]$} & {$[0-1]$} \\
\hline & & 0 & {$[0-1]$} & {$[0-1]$} & {$[0-1]$} & {$[0-1]$} & {$[0-1]$} \\
\hline \multirow[t]{3}{*}{ PGDP thin btm former $\mathrm{G}$} & 9,106 & 250 & $\mid 156$ & 178 & 204 & 226 & 245 \\
\hline & & 62.5 & {$[0-1]$} & {$[0-1]$} & {$[0-1]$} & {$[0-1]$} & {$[0-1]$} \\
\hline & & 0 & {$[0-1]$} & {$[0-1]$} & {$[0-1]$} & {$[0-1]$} & {$[0-1]$} \\
\hline \multirow[t]{3}{*}{ PGDP thin btm except former $G$} & 13,567 & 250 & 106 & 139 & 188 & 228 & 269 \\
\hline & & 62.5 & {$[0-2]$} & [0-2] & [0-2] & [0-2] & {$[0-2]$} \\
\hline & & 0 & {$[0-2]$} & {$[0-2]$} & {$[0-2]$} & {$[0-2]$} & {$[0-2]$} \\
\hline \multirow[t]{3}{*}{ PGDP thin top } & 13,231 & 250 & 88 & 118 & 163 & 202 & 238 \\
\hline & & 62.5 & {$[0-2]$} & {$[0-2]$} & [0-2] & {$[0-2]$} & {$[0-2]$} \\
\hline & & 0 & {$[0-2]$} & {$[0-2]$} & [0-2] & {$[0-2]$} & {$[0-2]$} \\
\hline \multirow{3}{*}{ All thick top } & 983 & 500 & 0 & 0 & 1 & 2 & 4 \\
\hline & & 62.5 & 0 & 0 & $\begin{array}{l}1 \\
0\end{array}$ & 0 & $\begin{array}{l}4 \\
0\end{array}$ \\
\hline & & 0 & 0 & 0 & 0 & 0 & 0 \\
\hline \multirow{3}{*}{ All thick btm } & 989 & 500 & 0 & {$[0-1]$} & 1 & 3 & 4 \\
\hline & & 62.5 & 0 & 0 & 0 & 0 & 0 \\
\hline & & 0 & 0 & 0 & 0 & 0 & 0 \\
\hline & & & & & & & \\
\hline \multirow[t]{3}{*}{ All thin top, head/skirt } & 2,632 & 250 & 16 & 19 & 25 & 29 & 35 \\
\hline & & 62.5 & 0 & 0 & 0 & 0 & 0 \\
\hline & & 0 & 0 & 0 & 0 & 0 & 0 \\
\hline \multirow[t]{3}{*}{ All thin btm, head/skirt } & 2,818 & 250 & 16 & 20 & 26 & 30 & 36 \\
\hline & & 62.5 & 0 & 0 & 0 & 0 & 0 \\
\hline & & 0 & 0 & 0 & 0 & 0 & 0 \\
\hline & & & & & & & \\
\hline \multirow[t]{3}{*}{ All thick, head/skirt } & 1,972 & 500 & 0 & 0 & 0 & 0 & 0 \\
\hline & & 62.5 & 0 & 0 & 0 & 0 & 0 \\
\hline & & 0 & 0 & 0 & 0 & 0 & 0 \\
\hline
\end{tabular}




\section{Table 11. Direct-Model Projections for Various Target Years And Thickness Specs, Outlier Cylinders Excluded}

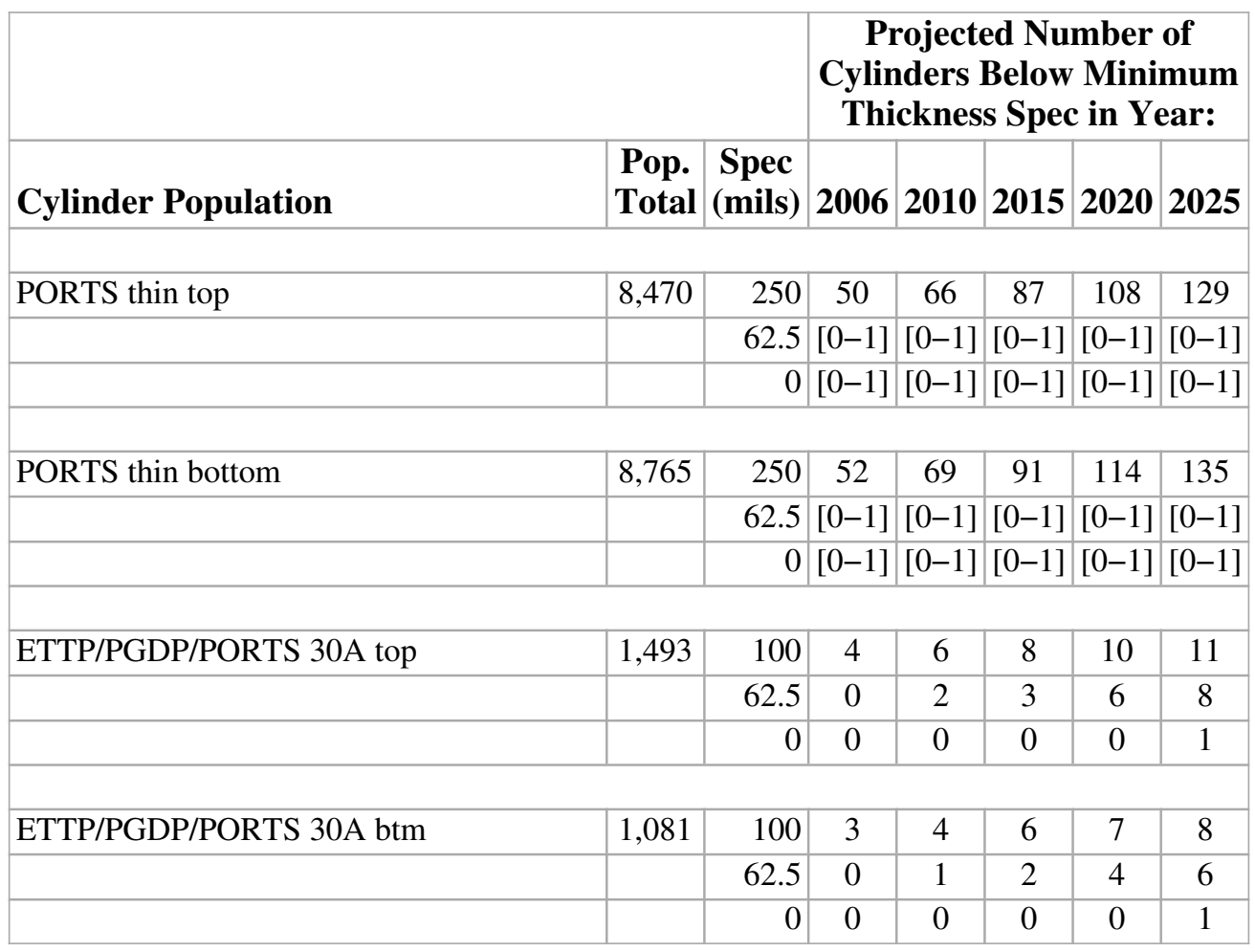

Tables 10 and 11 both show that many cylinders are projected to fail the upper (e.g., 250 or 500 mil) thickness specifications, though the proportions projected to fail are small. The validation analysis in Section 6 is consistent with these results. However, Table 10 also shows a number of breaches projected for 2006 and later years. Although breaches have occurred in the past, the numbers of breaches predicted in Table 11 seems too high - it is unlikely that breaches of this frequency would go unnoticed, even if they were not detected in the UT scanning itself. With the outliers excluded, no breaches are projected, though in some cases, because of the sample size resolution limit, breaches are not ruled out (as indicated by the "[0-N]" notation.) Because no breaches were in fact observed in FY06, this suggests that the outliers identified in Section 4 may represent bad data rather than actual minimum thicknesses. Thus the projections in Table 11 may be more reasonable that in Table 10.

Possible reasons for high projections include:

- Not all cylinders were sampled randomly (e.g., using a random number generator), but were selected "quasi-randomly" or in some cases (as is natural in inspections) with purposive focus on groups thought to be at higher risk.

- The cylinder functional groups only roughly approximate the complete storage location history of cylinders. Because cylinders are typically moved from time to time, the "locations" associated with the cylinder groupings would be better represented as combinations of locations. When cylinders are moved, they are usually moved to improved storage locations.

- Outliers. Low minimum thickness outliers have occurred in the past and can substantially effect the projections.

- Cylinders storage conditions have improved over the years, and extrapolations based on the historical record therefore tends overestimate future corrosion. 
There is no straightforward way to account for bias induced by purposive sampling or by improved storage conditions. Similarly, an accurate accounting for storage location history would be very difficult to implement. On the other hand, excluding the outliers from the analysis is at least straightforward.

Proportions Projections. The projections in Tables 10 and 11 can also be used on a relative basis, for example, to prioritize cylinder groups. Because biases tend to cancel out in comparisons, comparisons tend to be more robust than absolute estimates. For such comparisons, rather than counts of cylinders expected to fail the various thickness criteria, it is convenient to examine percentage rates of cylinders projected to fail the various thickness criteria. Table 12 is the analog of Table 11 with percentages of cylinders rather than absolute counts. Table 12 is computed with the nine outliers excluded. The table shows the cylinder groups where individual cylinders are projected to be most likely to fail either the breach or 62.5 mil criteria. According to these estimates, the 30A cylinders, both top and bottom rows, are the most likely to fail the 62.5 or breach specs, even more likely than the thin-wall cylinders. Considering in addition the $250 \mathrm{mil} \mathrm{spec}$, the functional groups with the next highest risk estimates are the thin-wall cylinders from ETTP K-yard bottom rows, followed by the other ETTP thin-wall cylinders. These conclusions hold for all years listed in the table.

Projections by Cylinder Group and Age. Because the likelihood that a cylinder will fail a particular thickness criteria depends on both the cylinder's functional group and age, and because the cylinder functional groups have different cylinder age distributions, focusing on functional groups in general can be misleading. For example, a cylinder of "average" age in a large functional group composed of many new cylinders and a few very old ones may have only a tiny chance of failing a particular criteria. Yet the oldest cylinders in that group might nevertheless be likely to fail. Therefore it is useful to examine cylinders by both functional group and age.

Table 13 lists, for each functional group and (unpainted) age in 2010, the direct-model estimates of the projected failure rate in 2010 for the 62.5 mil thickness criteria. Because these rates are very small, they are expressed as percentages. The age-functional-groups are listed in descending order of the directmodel estimates. Many of the rate estimates are the same for different ages and functional groups. That is because of the discreteness of the distribution of the 3,234 regression residuals and because the rate estimates are computed from the extreme lower tail of that distribution. Many of the estimates are in fact $100 /(2(3,234+1))=.01546$, which is the lower limit of the distribution (limit of resolution). More refined tail probability estimates are difficult because they require additional assumptions (for example, that the underlying distribution is normal), a physical basis for which is generally unknown.

Table 13 illustrates how age and functional group together affect risk. As in Table 12, the two 30A groups (top and bottom rows) have the highest 2010 risk estimates, but in Table 13 the two riskiest groups are for the oldest $30 \mathrm{~A}$ cylinders only (which happen to be nearly all of the $30 \mathrm{~A}$ cylinders). The third riskiest group consists of just one 59-year-old ETTP thin-wall cylinder not from the K-yard bottom group. As Table 12 shows, overall, the K-yard bottom group is riskier than the ETTP thin-wall cylinders not from K-yard bottom. However, as can be seen from the age distributions for these yards (see Figures 1 and 2), the K-yard bottom-row cylinders are older on average and have a tighter age distribution than the other ETTP thin-wall cylinders. (Because there is only one such, the single cylinder that is 59 years old in 2010 and 55 years old in 2006 does not show up in Figure 2.) The single 59 year old cylinder is nevertheless older (and riskier) than any cylinder in the K-yard bottom group. The fourth riskiest agefunctional-group consists of the 55 year old cylinders from ETTP K-yard bottom. Thus the overall risk of functional group may not represent the risk of certain cylinders in it. Table 13 continues with age and functional groups interleaved according to projected risk and can be used for prioritizing cylinders by both functional group and age. 


\section{Table 12. Direct-Model Failure Rate Estimates for Target Years And Thickness Specs, Outlier Cylinders Excluded}

\begin{tabular}{|c|c|c|c|c|c|c|c|}
\hline \multirow[b]{2}{*}{ Cylinder Population } & \multirow[b]{2}{*}{$\begin{array}{l}\text { Pop. } \\
\text { Total }\end{array}$} & \multirow[b]{2}{*}{$\begin{array}{l}\text { Spec } \\
\text { (mils) }\end{array}$} & \multicolumn{5}{|c|}{$\begin{array}{l}\text { Projected Percentage of Cylinders Below } \\
\text { Minimum Thickness Spec in Year: }\end{array}$} \\
\hline & & & 2006 & 2010 & 2015 & 2020 & 2025 \\
\hline \multirow{3}{*}{ ETTP thin $\mathrm{K}$ btm } & 1,491 & 250 & 2.9 & 3.0 & 3.2 & 3.4 & 3.6 \\
\hline & & 62.5 & {$[0-0.015]$} & {$[0-0.015]$} & {$[0-0.015]$} & {$[0-0.015]$} & {$[0-0.015]$} \\
\hline & & 0 & {$[0-0.015]$} & {$[0-0.015]$} & {$[0-0.015]$} & {$[0-0.015]$} & [0-0.015] \\
\hline \multirow{3}{*}{ ETTP thin except $\mathrm{K}$ btm } & 3262 & 250 & 21 & 22 & 25 & 27 & 20 \\
\hline & $J, 202$ & 62.5 & {$[0-0.015]$} & {$[0-0.015]$} & {$[0-0.015]$} & {$[0-0.015]$} & {$[0-0.015]$} \\
\hline & & 0 & {$[0-0.015]$} & {$[0-0.015]$} & {$[0-0.015]$} & {$[0-0.015]$} & {$[0-0.015]$} \\
\hline \multirow[t]{3}{*}{ PGDP thin btm former $\mathrm{G}$} & 9,106 & 250 & 1.7 & 2.0 & 2.2 & 2.5 & 2.7 \\
\hline & & 62.5 & {$[0-0.015]$} & {$[0-0.015]$} & {$[0-0.015]$} & {$[0-0.015]$} & {$[0-0.015]$} \\
\hline & & 0 & {$[0-0.015]$} & {$[0-0.015]$} & {$[0-0.015]$} & {$[0-0.015]$} & {$[0-0.015]$} \\
\hline \multirow[t]{3}{*}{ PGDP thin btm except former $\mathrm{G}$} & 13,567 & 250 & 0.8 & 1.0 & 1.4 & 1.7 & 2.0 \\
\hline & & 62.5 & {$[0-0.015]$} & {$[0-0.015]$} & {$[0-0.015]$} & {$[0-0.015]$} & {$[0-0.015]$} \\
\hline & & 0 & {$[0-0.015]$} & [0-0.015] & [0-0.015] & {$[0-0.015]$} & [0-0.015] \\
\hline \multirow[t]{3}{*}{ PGDP thin top } & 13,231 & 250 & 0.7 & 0.9 & 1.2 & 1.5 & 1.8 \\
\hline & & 62.5 & {$[0-0.015]$} & {$[0-0.015]$} & {$[0-0.015]$} & {$[0-0.015]$} & {$[0-0.015]$} \\
\hline & & 0 & [0-0.015] & {$[0-0.015]$} & {$[0-0.015]$} & {$[0-0.015]$} & {$[0-0.015]$} \\
\hline \multirow[t]{3}{*}{ All thick top } & 983 & 500 & 0.0 & 0.0 & 0.1 & 0.2 & 0.4 \\
\hline & & 62.5 & {$[0-0.015]$} & {$[0-0.015]$} & {$[0-0.015]$} & {$[0-0.015]$} & {$[0-0.015]$} \\
\hline & & 0 & {$[0-0.015]$} & {$[0-0.015]$} & {$[0-0.015]$} & {$[0-0.015]$} & {$[0-0.015]$} \\
\hline \multirow[t]{3}{*}{ All thick btm } & 989 & 500 & 0.0 & 0.1 & 0.1 & 0.3 & 0.4 \\
\hline & & 62.5 & [0-0.015] & {$[0-0.015]$} & [0-0.015] & {$[0-0.015]$} & [0-0.015] \\
\hline & & 0 & {$[0-0.015]$} & {$[0-0.015]$} & {$[0-0.015]$} & {$[0-0.015]$} & {$[0-0.015]$} \\
\hline \multirow[t]{3}{*}{ All thin top, head/skirt } & 2,632 & 250 & 0.6 & 0.7 & 0.9 & 1.1 & 1.3 \\
\hline & & 62.5 & {$[0-0.015]$} & [0-0.015] & {$[0-0.015]$} & {$[0-0.015]$} & {$[0-0.015]$} \\
\hline & & 0 & {$[0-0.015]$} & {$[0-0.015]$} & {$[0-0.015]$} & {$[0-0.015]$} & {$[0-0.015]$} \\
\hline \multirow{3}{*}{ All thin btm, head/skirt } & 2,818 & 250 & 0.6 & 0.7 & 0.9 & 1.1 & 1.3 \\
\hline & & 62.5 & {$[0-0.015]$} & {$[0-0.015]$} & {$[0-0.015]$} & {$[0-0.015]$} & {$[0-0.015]$} \\
\hline & & 0 & {$[0-0.015]$} & {$[0-0.015]$} & {$[0-0.015]$} & {$[0-0.015]$} & {$[0-0.015]$} \\
\hline \multirow[t]{3}{*}{ All thick, head/skirt } & 1,972 & 500 & {$[0-0.015]$} & {$[0-0.015]$} & {$[0-0.015]$} & {$[0-0.015]$} & {$[0-0.015]$} \\
\hline & & 62.5 & {$[0-0.015]$} & {$[0-0.015]$} & {$[0-0.015]$} & {$[0-0.015]$} & [0-0.015] \\
\hline & & 0 & {$[0-0.015]$} & [0-0.015] & {$[0-0.015]$} & {$[0-0.015]$} & [0-0.015] \\
\hline
\end{tabular}




\section{Table 12. Direct-Model Failure Rate Estimates for Target Years And Thickness Specs, Outlier Cylinders Excluded}

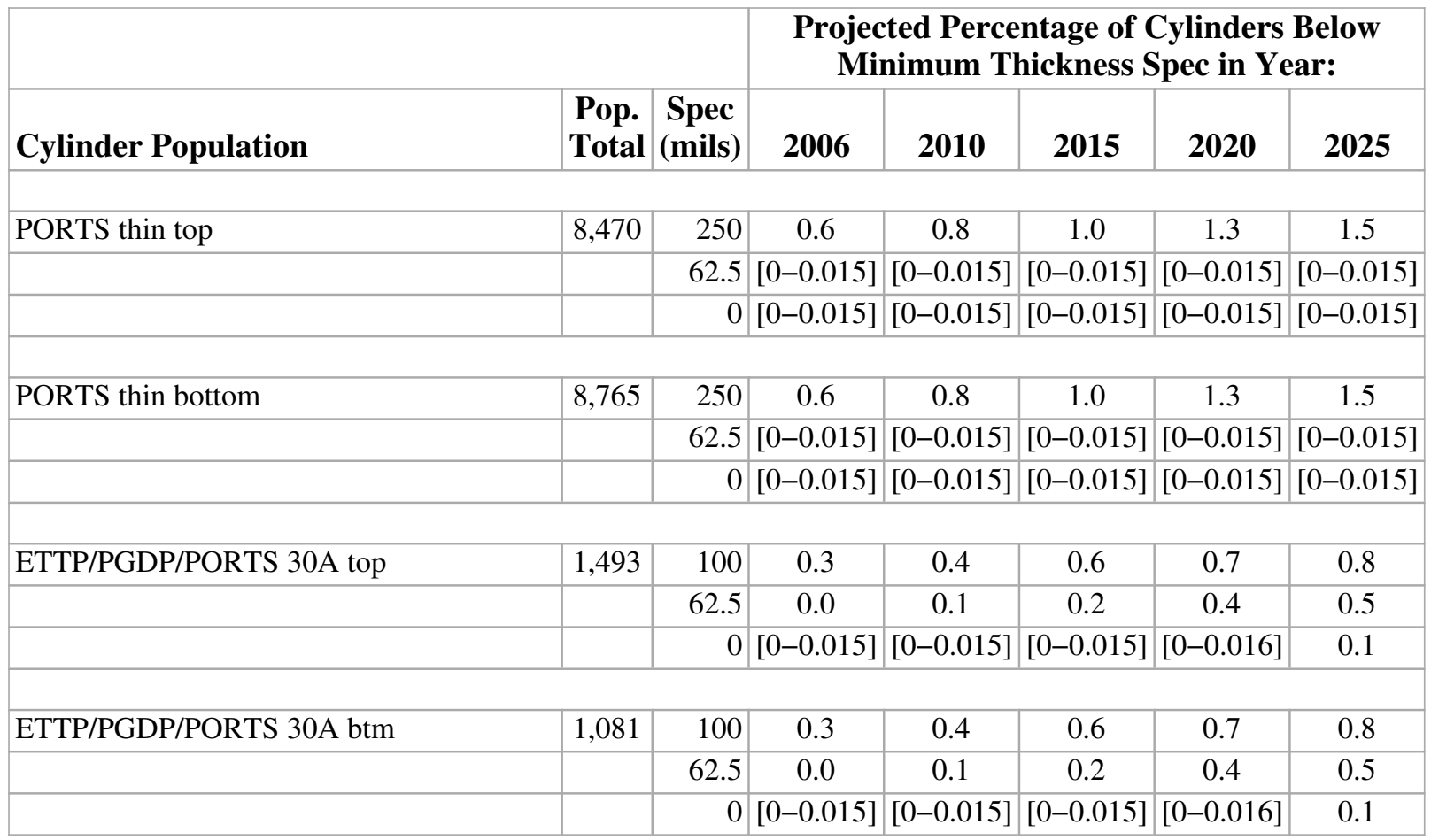


Table 13. Projections by Age and Functional Group of the 2010 Risk of Failing The 62.5 Mil Thickness Spec, By Descending Projection Estimate

\begin{tabular}{|c|c|c|c|}
\hline Functional Group & Age & $\mathbf{N}$ & $\begin{array}{c}\text { Est. } \\
\text { Percent } \\
\text { Below } \\
\text { Spec }\end{array}$ \\
\hline All 30As btm & 56 & 1,055 & 0.368 \\
\hline All 30As btm & 56 & 1,055 & 0.368 \\
\hline All 30As top & 56 & 1,474 & 0.363 \\
\hline All 30As top & 56 & 1,474 & 0.363 \\
\hline ETTP thin except $\mathrm{K}$ btm & 59 & 1 & 0.139 \\
\hline ETTP thin except $K$ btm & 59 & 1 & 0.139 \\
\hline ETTP thin $\mathrm{K}$ btm & 55 & 28 & 0.139 \\
\hline ETTP thin except $\mathrm{K}$ btm & 55 & 40 & 0.139 \\
\hline PGDP thn btm exc fmr $G$ & 55 & 283 & 0.139 \\
\hline ETTP thin $K$ btm & 55 & 28 & 0.139 \\
\hline ETTP thin except $\mathrm{K}$ btm & 55 & 40 & 0.139 \\
\hline PGDP thn btm exc fmr G & 55 & 283 & 0.139 \\
\hline ETTP thin $K$ btm & 53 & 347 & 0.139 \\
\hline ETTP thin except $\mathrm{K}$ btm & 53 & 382 & 0.139 \\
\hline ETTP thin $K$ btm & 53 & 347 & 0.139 \\
\hline ETTP thin except $K$ btm & 53 & 382 & 0.139 \\
\hline ETTP thin $K$ btm & 52 & 49 & 0.139 \\
\hline ETTP thin except $K \mathrm{btm}$ & 52 & 49 & 0.139 \\
\hline ETTP thin $K$ btm & 52 & 49 & 0.139 \\
\hline ETTP thin except $\mathrm{K}$ btm & 52 & 49 & 0.139 \\
\hline ETTP thin $\mathrm{K}$ btm & 51 & 6 & 0.139 \\
\hline ETTP thin $\mathrm{K}$ btm & 51 & 6 & 0.139 \\
\hline ETTP thin $\mathrm{K}$ btm & 50 & 32 & 0.139 \\
\hline ETTP thin $\mathrm{K}$ btm & 50 & 32 & 0.139 \\
\hline PGDP thn btm exc fmr $G$ & 54 & 1 & 0.138 \\
\hline PGDP thn btm exc fmr G & 54 & 1 & 0.138 \\
\hline PGDP thin top & 55 & 254 & 0.137 \\
\hline PGDP thin top & 55 & 254 & 0.137 \\
\hline PGDP thin btm fmr $G$ & 52 & 819 & 0.130 \\
\hline PGDP thin btm fmr $G$ & 52 & 819 & 0.130 \\
\hline ETTP thin $\mathrm{K}$ btm & 49 & 164 & 0.130 \\
\hline ETTP thin $K$ btm & 49 & 164 & 0.130 \\
\hline PGDP thn btm exc fmr G & 53 & 39 & 0.127 \\
\hline
\end{tabular}

\begin{tabular}{|c|c|c|c|}
\hline Functional Group & Age & $\mathbf{N}$ & $\begin{array}{c}\text { Est. } \\
\text { Percent } \\
\text { Below } \\
\text { Spec }\end{array}$ \\
\hline PGDP thn btm exc fmr G & 53 & 39 & 0.127 \\
\hline ETTP thin except $\mathrm{K}$ btm & 51 & 8 & 0.125 \\
\hline ETTP thin except $\mathrm{K}$ btm & 51 & 8 & 0.125 \\
\hline PGDP thin top & 54 & 2 & 0.123 \\
\hline PGDP thin top & 54 & 2 & 0.123 \\
\hline ETTP thin $\mathrm{K}$ btm & 48 & 482 & 0.112 \\
\hline ETTP thin $\mathrm{K}$ btm & 48 & 482 & 0.112 \\
\hline PGDP thin btm fmr $G$ & 51 & 620 & 0.111 \\
\hline PGDP thin btm fmr $G$ & 51 & 620 & 0.111 \\
\hline PGDP thin top & 53 & 27 & 0.110 \\
\hline PGDP thin top & 53 & 27 & 0.110 \\
\hline PGDP thn btm exc fmr G & 52 & 320 & 0.110 \\
\hline PGDP thn btm exc fmr G & 52 & 320 & 0.110 \\
\hline ETTP thin except $K \mathrm{btm}$ & 50 & 28 & 0.109 \\
\hline ETTP thin except $\mathrm{K}$ btm & 50 & 28 & 0.109 \\
\hline PORTS thin top & 55 & 152 & 0.108 \\
\hline PORTS thin bottom & 55 & 134 & 0.108 \\
\hline PORTS thin top & 55 & 152 & 0.108 \\
\hline PORTS thin bottom & 55 & 134 & 0.108 \\
\hline PORTS thin top & 53 & 911 & 0.108 \\
\hline PORTS thin bottom & 53 & 929 & 0.108 \\
\hline PORTS thin top & 53 & 911 & 0.108 \\
\hline PORTS thin bottom & 53 & 929 & 0.108 \\
\hline PGDP thin top & 52 & 331 & 0.108 \\
\hline PORTS thin top & 52 & 24 & 0.108 \\
\hline PORTS thin bottom & 52 & 17 & 0.108 \\
\hline PGDP thin top & 52 & 331 & 0.108 \\
\hline PORTS thin top & 52 & 24 & 0.108 \\
\hline PORTS thin bottom & 52 & 17 & 0.108 \\
\hline PGDP thn btm exc fmr G & 51 & 142 & 0.108 \\
\hline PGDP thin top & 51 & 136 & 0.108 \\
\hline PORTS thin top & 51 & 3 & 0.108 \\
\hline PORTS thin bottom & 51 & 4 & 0.108 \\
\hline
\end{tabular}


Table 13. Projections by Age and Functional Group of the 2010 Risk of Failing The 62.5 Mil Thickness Spec, By Descending Projection Estimate

\begin{tabular}{|c|c|c|c|}
\hline Functional Group & Age & $\mathbf{N}$ & $\begin{array}{c}\text { Est. } \\
\text { Percent } \\
\text { Below } \\
\text { Spec }\end{array}$ \\
\hline PGDP thn btm exc fmr G & 51 & 142 & 0.108 \\
\hline PGDP thin top & 51 & 136 & 0.108 \\
\hline PORTS thin top & 51 & 3 & 0.108 \\
\hline PORTS thin bottom & 51 & 4 & 0.108 \\
\hline PGDP thin btm fmr $G$ & 50 & 750 & 0.108 \\
\hline PGDP thn btm exc fmr G & 50 & 241 & 0.108 \\
\hline PGDP thin top & 50 & 275 & 0.108 \\
\hline PGDP thin btm fmr $G$ & 50 & 750 & 0.108 \\
\hline PGDP thn btm exc fmr G & 50 & 241 & 0.108 \\
\hline PGDP thin top & 50 & 275 & 0.108 \\
\hline ETTP thin except $\mathrm{K}$ btm & 49 & 172 & 0.108 \\
\hline PGDP thin btm fmr G & 49 & 602 & 0.108 \\
\hline PGDP thn btm exc fmr G & 49 & 207 & 0.108 \\
\hline PGDP thin top & 49 & 211 & 0.108 \\
\hline ETTP thin except $\mathrm{K}$ btm & 49 & 172 & 0.108 \\
\hline PGDP thin btm fmr $G$ & 49 & 602 & 0.108 \\
\hline PGDP thn btm exc fmr G & 49 & 207 & 0.108 \\
\hline PGDP thin top & 49 & 211 & 0.108 \\
\hline ETTP thin except $\mathrm{K}$ btm & 48 & 472 & 0.108 \\
\hline PGDP thin btm fmr $G$ & 48 & 278 & 0.108 \\
\hline PGDP thn btm exc fmr G & 48 & 151 & 0.108 \\
\hline PGDP thin top & 48 & 151 & 0.108 \\
\hline ETTP thin except $\mathrm{K}$ btm & 48 & 472 & 0.108 \\
\hline PGDP thin btm fmr $G$ & 48 & 278 & 0.108 \\
\hline PGDP thn btm exc fmr G & 48 & 151 & 0.108 \\
\hline PGDP thin top & 48 & 151 & 0.108 \\
\hline ETTP thin $\mathrm{K}$ btm & 47 & 69 & 0.108 \\
\hline ETTP thin except $\mathrm{K}$ btm & 47 & 58 & 0.108 \\
\hline PGDP thin btm fmr G & 47 & 17 & 0.108 \\
\hline PGDP thn btm exc fmr G & 47 & 31 & 0.108 \\
\hline PGDP thin top & 47 & 21 & 0.108 \\
\hline ETTP thin $\mathrm{K}$ btm & 47 & 69 & 0.108 \\
\hline ETTP thin except $\mathrm{K}$ btm & 47 & 58 & 0.108 \\
\hline
\end{tabular}

\begin{tabular}{|c|c|c|c|}
\hline Functional Group & Age & $\mathbf{N}$ & $\begin{array}{c}\text { Est. } \\
\text { Percent } \\
\text { Below } \\
\text { Spec }\end{array}$ \\
\hline PGDP thin btm fmr $G$ & 47 & 17 & 0.108 \\
\hline PGDP thn btm exc fmr G & 47 & 31 & 0.108 \\
\hline PGDP thin top & 47 & 21 & 0.108 \\
\hline ETTP thin $\mathrm{K}$ btm & 46 & 2 & 0.108 \\
\hline ETTP thin except $\mathrm{K}$ btm & 46 & 4 & 0.108 \\
\hline ETTP thin $\mathrm{K}$ btm & 46 & 2 & 0.108 \\
\hline ETTP thin except $\mathrm{K}$ btm & 46 & 4 & 0.108 \\
\hline ETTP thin K btm & 45 & 129 & 0.108 \\
\hline ETTP thin except $\mathrm{K}$ btm & 45 & 109 & 0.108 \\
\hline ETTP thin K btm & 45 & 129 & 0.108 \\
\hline ETTP thin except $\mathrm{K}$ btm & 45 & 109 & 0.108 \\
\hline ETTP thin K btm & 43 & 181 & 0.108 \\
\hline ETTP thin K btm & 43 & 181 & 0.108 \\
\hline PORTS thin bottom & 50 & 17 & 0.105 \\
\hline PORTS thin bottom & 50 & 17 & 0.105 \\
\hline PORTS thin top & 50 & 20 & 0.101 \\
\hline PORTS thin top & 50 & 20 & 0.101 \\
\hline ETTP thin except $\mathrm{K}$ btm & 43 & 191 & 0.086 \\
\hline ETTP thin except $\mathrm{K}$ btm & 43 & 191 & 0.086 \\
\hline PORTS thin bottom & 49 & 57 & 0.085 \\
\hline PORTS thin bottom & 49 & 57 & 0.085 \\
\hline PORTS thin top & 49 & 119 & 0.080 \\
\hline PORTS thin top & 49 & 119 & 0.080 \\
\hline All thin top, head/skirt & 55 & 439 & 0.077 \\
\hline All thin btm, head/skirt & 55 & 452 & 0.077 \\
\hline All thin top, head/skirt & 55 & 439 & 0.077 \\
\hline All thin btm, head/skirt & 55 & 452 & 0.077 \\
\hline All thin top, head/skirt & 54 & 2 & 0.077 \\
\hline All thin top, head/skirt & 54 & 2 & 0.077 \\
\hline All thin top, head/skirt & 53 & 1,307 & 0.077 \\
\hline All thin btm, head/skirt & 53 & 1,328 & 0.077 \\
\hline All thin top, head/skirt & 53 & 1,307 & 0.077 \\
\hline All thin btm, head/skirt & 53 & 1,328 & 0.077 \\
\hline
\end{tabular}


Table 13. Projections by Age and Functional Group of the 2010 Risk of Failing The 62.5 Mil Thickness Spec, By Descending Projection Estimate

\begin{tabular}{|c|c|c|c|}
\hline Functional Group & Age & $\mathbf{N}$ & $\begin{array}{c}\text { Est. } \\
\text { Percent } \\
\text { Below } \\
\text { Spec }\end{array}$ \\
\hline PORTS thin top & 48 & 48 & 0.077 \\
\hline PORTS thin bottom & 48 & 23 & 0.077 \\
\hline PORTS thin top & 48 & 48 & 0.077 \\
\hline PORTS thin bottom & 48 & 23 & 0.077 \\
\hline All thin top, head/skirt & 47 & 29 & 0.077 \\
\hline All thin btm, head/skirt & 47 & 36 & 0.077 \\
\hline PORTS thin top & 47 & 33 & 0.077 \\
\hline PORTS thin bottom & 47 & 14 & 0.077 \\
\hline All thin top, head/skirt & 47 & 29 & 0.077 \\
\hline All thin btm, head/skirt & 47 & 36 & 0.077 \\
\hline PORTS thin top & 47 & 33 & 0.077 \\
\hline PORTS thin bottom & 47 & 14 & 0.077 \\
\hline ETTP thin except $K$ btm & 42 & 11 & 0.077 \\
\hline PGDP thin btm fmr $G$ & 42 & 528 & 0.077 \\
\hline PGDP thn btm exc fmr G & 42 & 130 & 0.077 \\
\hline PGDP thin top & 42 & 72 & 0.077 \\
\hline PORTS thin top & 42 & 47 & 0.077 \\
\hline PORTS thin bottom & 42 & 11 & 0.077 \\
\hline ETTP thin except $\mathrm{K}$ btm & 42 & 11 & 0.077 \\
\hline PGDP thin btm fmr $G$ & 42 & 528 & 0.077 \\
\hline PGDP thn btm exc fmr $G$ & 42 & 130 & 0.077 \\
\hline PGDP thin top & 42 & 72 & 0.077 \\
\hline PORTS thin top & 42 & 47 & 0.077 \\
\hline PORTS thin bottom & 42 & 11 & 0.077 \\
\hline PGDP thin btm fmr $G$ & 41 & 544 & 0.077 \\
\hline PGDP thn btm exc fmr G & 41 & 27 & 0.077 \\
\hline PGDP thin top & 41 & 19 & 0.077 \\
\hline PGDP thin btm fmr $G$ & 41 & 544 & 0.077 \\
\hline PGDP thn btm exc fmr G & 41 & 27 & 0.077 \\
\hline PGDP thin top & 41 & 19 & 0.077 \\
\hline PGDP thin btm fmr $G$ & 40 & 481 & 0.077 \\
\hline PGDP thn btm exc fmr $G$ & 40 & 35 & 0.077 \\
\hline PGDP thin top & 40 & 13 & 0.077 \\
\hline
\end{tabular}

\begin{tabular}{|c|c|c|c|}
\hline Functional Group & Age & $\mathbf{N}$ & $\begin{array}{c}\text { Est. } \\
\text { Percent } \\
\text { Below } \\
\text { Spec }\end{array}$ \\
\hline PGDP thin btm fmr G & 40 & 481 & 0.077 \\
\hline PGDP thn btm exc fmr G & 40 & 35 & 0.077 \\
\hline PGDP thin top & 40 & 13 & 0.077 \\
\hline ETTP thin except $K$ btm & 39 & 10 & 0.077 \\
\hline PGDP thin btm fmr G & 39 & 459 & 0.077 \\
\hline PGDP thn btm exc fmr G & 39 & 33 & 0.077 \\
\hline PGDP thin top & 39 & 14 & 0.077 \\
\hline ETTP thin except $K$ btm & 39 & 10 & 0.077 \\
\hline PGDP thin btm fmr G & 39 & 459 & 0.077 \\
\hline PGDP thn btm exc fmr G & 39 & 33 & 0.077 \\
\hline PGDP thin top & 39 & 14 & 0.077 \\
\hline ETTP thin K btm & 38 & 1 & 0.077 \\
\hline ETTP thin except $K$ btm & 38 & 14 & 0.077 \\
\hline PGDP thin btm fmr G & 38 & 311 & 0.077 \\
\hline PGDP thn btm exc fmr G & 38 & 9 & 0.077 \\
\hline PGDP thin top & 38 & 8 & 0.077 \\
\hline ETTP thin K btm & 38 & 1 & 0.077 \\
\hline ETTP thin except $\mathrm{K}$ btm & 38 & 14 & 0.077 \\
\hline PGDP thin btm fmr G & 38 & 311 & 0.077 \\
\hline PGDP thn btm exc fmr G & 38 & 9 & 0.077 \\
\hline PGDP thin top & 38 & 8 & 0.077 \\
\hline ETTP thin except $\mathrm{K}$ btm & 37 & 6 & 0.077 \\
\hline PGDP thin btm fmr G & 37 & 302 & 0.077 \\
\hline PGDP thn btm exc fmr G & 37 & 83 & 0.077 \\
\hline PGDP thin top & 37 & 63 & 0.077 \\
\hline ETTP thin except $\mathrm{K}$ btm & 37 & 6 & 0.077 \\
\hline PGDP thin btm fmr G & 37 & 302 & 0.077 \\
\hline PGDP thn btm exc fmr G & 37 & 83 & 0.077 \\
\hline PGDP thin top & 37 & 63 & 0.077 \\
\hline ETTP thin except $\mathrm{K}$ btm & 36 & 903 & 0.077 \\
\hline PGDP thin btm fmr G & 36 & 197 & 0.077 \\
\hline PGDP thn btm exc fmr G & 36 & 9 & 0.077 \\
\hline ETTP thin except $\mathrm{K}$ btm & 36 & 903 & 0.077 \\
\hline
\end{tabular}


Table 13. Projections by Age and Functional Group of the 2010 Risk of Failing The 62.5 Mil Thickness Spec, By Descending Projection Estimate

\begin{tabular}{|c|c|c|c|}
\hline Functional Group & Age & $\mathbf{N}$ & $\begin{array}{c}\text { Est. } \\
\text { Percent } \\
\text { Below } \\
\text { Spec }\end{array}$ \\
\hline PGDP thin btm fmr $G$ & 36 & 197 & 0.077 \\
\hline PGDP thn btm exc fmr G & 36 & 9 & 0.077 \\
\hline All 30As top & 11 & 17 & 0.076 \\
\hline All 30As btm & 11 & 24 & 0.076 \\
\hline All 30As top & 11 & 17 & 0.076 \\
\hline All 30As btm & 11 & 24 & 0.076 \\
\hline PORTS thin bottom & 39 & 132 & 0.074 \\
\hline PORTS thin bottom & 39 & 132 & 0.074 \\
\hline All thin top, head/skirt & 46 & 4 & 0.071 \\
\hline All thin btm, head/skirt & 46 & 2 & 0.071 \\
\hline All thin top, head/skirt & 46 & 4 & 0.071 \\
\hline All thin btm, head/skirt & 46 & 2 & 0.071 \\
\hline PORTS thin top & 39 & 120 & 0.071 \\
\hline PORTS thin top & 39 & 120 & 0.071 \\
\hline PGDP thin top & 36 & 2 & 0.065 \\
\hline PGDP thin top & 36 & 2 & 0.065 \\
\hline ETTP thin except $\mathrm{K}$ btm & 34 & 555 & 0.059 \\
\hline ETTP thin except $K \mathrm{btm}$ & 34 & 555 & 0.059 \\
\hline All thin top, head/skirt & 45 & 107 & 0.048 \\
\hline All thin btm, head/skirt & 45 & 131 & 0.048 \\
\hline All thin top, head/skirt & 45 & 107 & 0.048 \\
\hline All thin btm, head/skirt & 45 & 131 & 0.048 \\
\hline PORTS thin bottom & 38 & 190 & 0.048 \\
\hline PORTS thin bottom & 38 & 190 & 0.048 \\
\hline PGDP thin btm fmr $G$ & 34 & 642 & 0.048 \\
\hline PGDP thin btm fmr $G$ & 34 & 642 & 0.048 \\
\hline PORTS thin top & 38 & 163 & 0.047 \\
\hline PORTS thin top & 38 & 163 & 0.047 \\
\hline All thin top, head/skirt & 43 & 183 & 0.046 \\
\hline All thin btm, head/skirt & 43 & 189 & 0.046 \\
\hline All thin top, head/skirt & 43 & 183 & 0.046 \\
\hline All thin btm, head/skirt & 43 & 189 & 0.046 \\
\hline PORTS thin top & 37 & 265 & 0.046 \\
\hline
\end{tabular}

\begin{tabular}{|c|c|c|c|}
\hline Functional Group & Age & $\mathbf{N}$ & $\begin{array}{c}\text { Est. } \\
\text { Percent } \\
\text { Below } \\
\text { Spec }\end{array}$ \\
\hline PORTS thin bottom & 37 & 334 & 0.046 \\
\hline PORTS thin top & 37 & 265 & 0.046 \\
\hline PORTS thin bottom & 37 & 334 & 0.046 \\
\hline PORTS thin top & 36 & 502 & 0.046 \\
\hline PORTS thin bottom & 36 & 510 & 0.046 \\
\hline PORTS thin top & 36 & 502 & 0.046 \\
\hline PORTS thin bottom & 36 & 510 & 0.046 \\
\hline PORTS thin top & 35 & 1 & 0.046 \\
\hline PORTS thin top & 35 & 1 & 0.046 \\
\hline PGDP thn btm exc fmr G & 34 & 1,033 & 0.046 \\
\hline PGDP thin top & 34 & 916 & 0.046 \\
\hline PORTS thin top & 34 & 808 & 0.046 \\
\hline PORTS thin bottom & 34 & 857 & 0.046 \\
\hline PGDP thn btm exc fmr G & 34 & 1,033 & 0.046 \\
\hline PGDP thin top & 34 & 916 & 0.046 \\
\hline PORTS thin top & 34 & 808 & 0.046 \\
\hline PORTS thin bottom & 34 & 857 & 0.046 \\
\hline ETTP thin e & 32 & 200 & 0.046 \\
\hline PGDP thin btm fmr G & 32 & 220 & 0.046 \\
\hline PGDP thn btm exc fmr G & 32 & 1,173 & 0.046 \\
\hline PGDP thin top & 32 & 1,125 & 0.046 \\
\hline All thin top, head/skirt & 32 & 155 & 0.046 \\
\hline All thin btm, head/skirt & 32 & 206 & 0.046 \\
\hline PORTS thin top & 32 & 253 & 0.046 \\
\hline PORTS thin bottom & 32 & 273 & 0.046 \\
\hline ETTP thin except $\mathrm{K}$ btm & 32 & 200 & 0.046 \\
\hline PGDP thin btm fmr G & 32 & 220 & 0.046 \\
\hline PGDP thn btm exc fmr G & 32 & 1,173 & 0.046 \\
\hline PGDP thin top & 32 & 1,125 & 0.046 \\
\hline All thin top, head/skirt & 32 & 155 & 0.046 \\
\hline All thin btm, head/skirt & 32 & 206 & 0.046 \\
\hline PORTS thin top & 32 & 253 & 0.046 \\
\hline PORTS thin bottom & 32 & 273 & 0.046 \\
\hline
\end{tabular}


Table 13. Projections by Age and Functional Group of the 2010 Risk of Failing The 62.5 Mil Thickness Spec, By Descending Projection Estimate

\begin{tabular}{|c|c|c|c|}
\hline Functional Group & Age & $\mathbf{N}$ & $\begin{array}{c}\text { Est. } \\
\text { Percent } \\
\text { Below } \\
\text { Spec }\end{array}$ \\
\hline ETTP thin except $\mathrm{K}$ btm & 31 & 14 & 0.046 \\
\hline PGDP thn btm exc fmr G & 31 & 6 & 0.046 \\
\hline All thin top, head/skirt & 31 & 241 & 0.046 \\
\hline All thin btm, head/skirt & 31 & 264 & 0.046 \\
\hline PORTS thin top & 31 & 236 & 0.046 \\
\hline PORTS thin bottom & 31 & 249 & 0.046 \\
\hline ETTP thin except $K$ btm & 31 & 14 & 0.046 \\
\hline PGDP thn btm exc fmr G & 31 & 6 & 0.046 \\
\hline All thin top, head/skirt & 31 & 241 & 0.046 \\
\hline All thin btm, head/skirt & 31 & 264 & 0.046 \\
\hline PORTS thin top & 31 & 236 & 0.046 \\
\hline PORTS thin bottom & 31 & 249 & 0.046 \\
\hline ETTP thin except $K$ btm & 30 & 17 & 0.046 \\
\hline PGDP thn btm exc fmr G & 30 & 324 & 0.046 \\
\hline PGDP thin top & 30 & 309 & 0.046 \\
\hline All thin top, head/skirt & 30 & 8 & 0.046 \\
\hline All thin btm, head/skirt & 30 & 5 & 0.046 \\
\hline PORTS thin top & 30 & 14 & 0.046 \\
\hline PORTS thin bottom & 30 & 19 & 0.046 \\
\hline ETTP thin except $\mathrm{K}$ btm & 30 & 17 & 0.046 \\
\hline PGDP thn btm exc fmr G & 30 & 324 & 0.046 \\
\hline PGDP thin top & 30 & 309 & 0.046 \\
\hline All thin top, head/skirt & 30 & 8 & 0.046 \\
\hline All thin btm, head/skirt & 30 & 5 & 0.046 \\
\hline PORTS thin top & 30 & 14 & 0.046 \\
\hline PORTS thin bottom & 30 & 19 & 0.046 \\
\hline ETTP thin except $\mathrm{K}$ btm & 29 & 3 & 0.046 \\
\hline PGDP thin btm fmr $G$ & 29 & 22 & 0.046 \\
\hline PGDP thn btm exc fmr G & 29 & 1,175 & 0.046 \\
\hline PGDP thin top & 29 & 1,142 & 0.046 \\
\hline PORTS thin top & 29 & 259 & 0.046 \\
\hline PORTS thin bottom & 29 & 278 & 0.046 \\
\hline ETTP thin except $\mathrm{K}$ btm & 29 & 3 & 0.046 \\
\hline
\end{tabular}

\begin{tabular}{|c|c|c|c|}
\hline Functional Group & Age & $\mathbf{N}$ & $\begin{array}{c}\text { Est. } \\
\text { Percent } \\
\text { Below } \\
\text { Spec }\end{array}$ \\
\hline PGDP thin btm fmr G & 29 & 22 & 0.046 \\
\hline PGDP thn btm exc fmr G & 29 & 1,175 & 0.046 \\
\hline PGDP thin top & 29 & 1,142 & 0.046 \\
\hline PORTS thin top & 29 & 259 & 0.046 \\
\hline PORTS thin bottom & 29 & 278 & 0.046 \\
\hline ETTP thin except $K$ btm & 28 & 12 & 0.046 \\
\hline PGDP thin btm fmr $G$ & 28 & 86 & 0.046 \\
\hline PGDP thn btm exc fmr G & 28 & 849 & 0.046 \\
\hline PGDP thin top & 28 & 797 & 0.046 \\
\hline All thin top, head/skirt & 28 & 156 & 0.046 \\
\hline All thin btm, head/skirt & 28 & 204 & 0.046 \\
\hline PORTS th & 28 & 330 & 0.046 \\
\hline PORTS thin bottom & 28 & 366 & 0.046 \\
\hline ETTP thin except $\mathrm{K}$ btm & 28 & 12 & 0.046 \\
\hline PGDP thin btm fmr G & 28 & 86 & 0.046 \\
\hline PGDP thn btm exc fmr G & 28 & 849 & 0.046 \\
\hline PGDP thin top & 28 & 797 & 0.046 \\
\hline All thin top, head/skirt & 28 & 156 & 0.046 \\
\hline All thin btm, head/skirt & 28 & 204 & 0.046 \\
\hline PORTS thin top & 28 & 330 & 0.046 \\
\hline PORTS thin bottom & 28 & 366 & 0.046 \\
\hline PGDP thin btm fmr G & 27 & 226 & 0.046 \\
\hline PGDP thn btm exc fmr G & 27 & 2 & 0.046 \\
\hline PGDP thin btm fmr G & 27 & 226 & 0.046 \\
\hline PGDP thn btm exc fmr G & 27 & 2 & 0.046 \\
\hline ETTP thin except $\mathrm{K}$ btm & 26 & 1 & 0.046 \\
\hline PGDP thin btm fmr G & 26 & 148 & 0.046 \\
\hline PGDP thn btm exc fmr G & 26 & 51 & 0.046 \\
\hline PGDP thin top & 26 & 61 & 0.046 \\
\hline PORTS thin top & 26 & 348 & 0.046 \\
\hline PORTS thin bottom & 26 & 363 & 0.046 \\
\hline ETTP thin except $K$ btm & 26 & 1 & 0.046 \\
\hline PGDP thin btm fmr G & 26 & 148 & 0.046 \\
\hline
\end{tabular}


Table 13. Projections by Age and Functional Group of the 2010 Risk of Failing The 62.5 Mil Thickness Spec, By Descending Projection Estimate

\begin{tabular}{|c|c|c|c|}
\hline Functional Group & Age & $\mathbf{N}$ & $\begin{array}{c}\text { Est. } \\
\text { Percent } \\
\text { Below } \\
\text { Spec }\end{array}$ \\
\hline PGDP thn btm exc fmr G & 26 & 51 & 0.046 \\
\hline PGDP thin top & 26 & 61 & 0.046 \\
\hline PORTS thin top & 26 & 348 & 0.046 \\
\hline PORTS thin bottom & 26 & 363 & 0.046 \\
\hline ETTP thin except $\mathrm{K}$ btm & 24 & 1 & 0.046 \\
\hline PGDP thin btm fmr $G$ & 24 & 369 & 0.046 \\
\hline PGDP thn btm exc fmr G & 24 & 350 & 0.046 \\
\hline PGDP thin top & 24 & 350 & 0.046 \\
\hline All thin top, head/skirt & 24 & 1 & 0.046 \\
\hline PORTS thin top & 24 & 230 & 0.046 \\
\hline PORTS thin bottom & 24 & 256 & 0.046 \\
\hline ETTP thin except $\mathrm{K}$ btm & 24 & 1 & 0.046 \\
\hline PGDP thin btm fmr $G$ & 24 & 369 & 0.046 \\
\hline PGDP thn btm exc fmr G & 24 & 350 & 0.046 \\
\hline PGDP thin top & 24 & 350 & 0.046 \\
\hline All thin top, head/skirt & 24 & 1 & 0.046 \\
\hline PORTS thin top & 24 & 230 & 0.046 \\
\hline PORTS thin bottom & 24 & 256 & 0.046 \\
\hline PGDP thn btm exc fmr G & 23 & 239 & 0.046 \\
\hline PGDP thin top & 23 & 236 & 0.046 \\
\hline PORTS thin top & 23 & 364 & 0.046 \\
\hline PORTS thin bottom & 23 & 356 & 0.046 \\
\hline PGDP thn btm exc fmr G & 23 & 239 & 0.046 \\
\hline PGDP thin top & 23 & 236 & 0.046 \\
\hline PORTS thin top & 23 & 364 & 0.046 \\
\hline PORTS thin bottom & 23 & 356 & 0.046 \\
\hline PGDP thin btm fmr $G$ & 22 & 609 & 0.046 \\
\hline PGDP thn btm exc fmr G & 22 & 599 & 0.046 \\
\hline PGDP thin top & 22 & 575 & 0.046 \\
\hline PORTS thin top & 22 & 397 & 0.046 \\
\hline PORTS thin bottom & 22 & 466 & 0.046 \\
\hline PGDP thin btm fmr G & 22 & 609 & 0.046 \\
\hline PGDP thn btm exc fmr G & 22 & 599 & 0.046 \\
\hline
\end{tabular}

\begin{tabular}{|c|c|c|c|}
\hline Functional Group & Age & $\mathbf{N}$ & $\begin{array}{c}\text { Est. } \\
\text { Percent } \\
\text { Below } \\
\text { Spec }\end{array}$ \\
\hline PGDP thin top & 22 & 575 & 0.046 \\
\hline PORTS thin top & 22 & 397 & 0.046 \\
\hline PORTS thin bottom & 22 & 466 & 0.046 \\
\hline PGDP thin btm fmr $G$ & 21 & 87 & 0.046 \\
\hline PGDP thn btm exc fmr G & 21 & 107 & 0.046 \\
\hline PGDP thin top & 21 & 110 & 0.046 \\
\hline PORTS thin top & 21 & 899 & 0.046 \\
\hline PORTS thin bottom & 21 & 897 & 0.046 \\
\hline PGDP thin btm fmr $G$ & 21 & 87 & 0.046 \\
\hline PGDP thn btm exc fmr G & 21 & 107 & 0.046 \\
\hline PGDP thin top & 21 & 110 & 0.046 \\
\hline PORTS thin top & 21 & 899 & 0.046 \\
\hline PORTS thin bottom & 21 & 897 & 0.046 \\
\hline PGDP thin btm fmr $G$ & 20 & 272 & 0.046 \\
\hline PGDP thn btm exc fmr G & 20 & 501 & 0.046 \\
\hline PGDP thin top & 20 & 514 & 0.046 \\
\hline PORTS thin top & 20 & 606 & 0.046 \\
\hline PORTS thin bottom & 20 & 606 & 0.046 \\
\hline PGDP thin btm fmr $G$ & 20 & 272 & 0.046 \\
\hline PGDP thn btm exc fmr G & 20 & 501 & 0.046 \\
\hline PGDP thin top & 20 & 514 & 0.046 \\
\hline PORTS thin top & 20 & 606 & 0.046 \\
\hline PORTS thin bottom & 20 & 606 & 0.046 \\
\hline ETTP thin K btm & 19 & 1 & 0.046 \\
\hline PGDP thin btm fmr G & 19 & 8 & 0.046 \\
\hline PGDP thn btm exc fmr G & 19 & 900 & 0.046 \\
\hline PGDP thin top & 19 & 821 & 0.046 \\
\hline PORTS thin top & 19 & 284 & 0.046 \\
\hline PORTS thin bottom & 19 & 260 & 0.046 \\
\hline ETTP thin K btm & 19 & 1 & 0.046 \\
\hline PGDP thin btm fmr G & 19 & 8 & 0.046 \\
\hline PGDP thn btm exc fmr G & 19 & 900 & 0.046 \\
\hline PGDP thin top & 19 & 821 & 0.046 \\
\hline
\end{tabular}


Table 13. Projections by Age and Functional Group of the 2010 Risk of Failing The 62.5 Mil Thickness Spec, By Descending Projection Estimate

\begin{tabular}{|c|c|c|c|}
\hline Functional Group & Age & $\mathbf{N}$ & $\begin{array}{c}\text { Est. } \\
\text { Percent } \\
\text { Below } \\
\text { Spec }\end{array}$ \\
\hline PORTS thin top & 19 & 284 & 0.046 \\
\hline PORTS thin bottom & 19 & 260 & 0.046 \\
\hline ETTP thin except $\mathrm{K}$ btm & 18 & 1 & 0.046 \\
\hline PGDP thin btm fmr $G$ & 18 & 508 & 0.046 \\
\hline PGDP thn btm exc fmr G & 18 & 337 & 0.046 \\
\hline PGDP thin top & 18 & 340 & 0.046 \\
\hline PORTS thin top & 18 & 26 & 0.046 \\
\hline PORTS thin bottom & 18 & 38 & 0.046 \\
\hline ETTP thin except $K$ btm & 18 & 1 & 0.046 \\
\hline PGDP thin btm fmr $G$ & 18 & 508 & 0.046 \\
\hline PGDP thn btm exc fmr G & 18 & 337 & 0.046 \\
\hline PGDP thin top & 18 & 340 & 0.046 \\
\hline PORTS thin top & 18 & 26 & 0.046 \\
\hline PORTS thin bottom & 18 & 38 & 0.046 \\
\hline PGDP thn btm exc fmr G & 17 & 601 & 0.046 \\
\hline PGDP thin top & 17 & 594 & 0.046 \\
\hline PORTS thin top & 17 & 152 & 0.046 \\
\hline PORTS thin bottom & 17 & 153 & 0.046 \\
\hline PGDP thn btm exc fmr G & 17 & 601 & 0.046 \\
\hline PGDP thin top & 17 & 594 & 0.046 \\
\hline PORTS thin top & 17 & 152 & 0.046 \\
\hline PORTS thin bottom & 17 & 153 & 0.046 \\
\hline PGDP thn btm exc fmr G & 16 & 442 & 0.046 \\
\hline PGDP thin top & 16 & 415 & 0.046 \\
\hline PORTS thin top & 16 & 398 & 0.046 \\
\hline PORTS thin bottom & 16 & 479 & 0.046 \\
\hline PGDP thn btm exc fmr G & 16 & 442 & 0.046 \\
\hline PGDP thin top & 16 & 415 & 0.046 \\
\hline PORTS thin top & 16 & 398 & 0.046 \\
\hline PORTS thin bottom & 16 & 479 & 0.046 \\
\hline PGDP thin btm fmr G & 15 & 1 & 0.046 \\
\hline PGDP thn btm exc fmr G & 15 & 1,018 & 0.046 \\
\hline PGDP thin top & 15 & 986 & 0.046 \\
\hline
\end{tabular}

\begin{tabular}{|c|c|c|c|}
\hline Functional Group & Age & $\mathbf{N}$ & $\begin{array}{c}\text { Est. } \\
\text { Percent } \\
\text { Below } \\
\text { Spec }\end{array}$ \\
\hline PORTS thin top & 15 & 107 & 0.046 \\
\hline PORTS thin bottom & 15 & 105 & 0.046 \\
\hline PGDP thin btm fmr $G$ & 15 & 1 & 0.046 \\
\hline PGDP thn btm exc fmr G & 15 & 1,018 & 0.046 \\
\hline PGDP thin top & 15 & 986 & 0.046 \\
\hline PORTS thin top & 15 & 107 & 0.046 \\
\hline PORTS thin bottom & 15 & 105 & 0.046 \\
\hline PGDP thn btm exc fmr G & 14 & 999 & 0.046 \\
\hline PGDP thn btm exc fmr G & 14 & 999 & 0.046 \\
\hline All 30As top & 10 & 2 & 0.046 \\
\hline All 30As btm & 10 & 2 & 0.046 \\
\hline All 30As top & 10 & 2 & 0.046 \\
\hline All 30As btm & 10 & 2 & 0.046 \\
\hline PGDP thin top & 14 & 983 & 0.043 \\
\hline PGDP thin top & 14 & 983 & 0.043 \\
\hline All thick top & 59 & 247 & 0.015 \\
\hline All thick btm & 59 & 233 & 0.015 \\
\hline All thick, head/skirt & 59 & 480 & 0.015 \\
\hline All thick top & 59 & 247 & 0.015 \\
\hline All thick btm & 59 & 233 & 0.015 \\
\hline All thick, head/skirt & 59 & 480 & 0.015 \\
\hline All thick top & 58 & 213 & 0.015 \\
\hline All thick btm & 58 & 260 & 0.015 \\
\hline All thick, head/skirt & 58 & 473 & 0.015 \\
\hline All thick top & 58 & 213 & 0.015 \\
\hline All thick btm & 58 & 260 & 0.015 \\
\hline All thick, head/skirt & 58 & 473 & 0.015 \\
\hline All thick top & 57 & 84 & 0.015 \\
\hline All thick btm & 57 & 78 & 0.015 \\
\hline All thick, head/skirt & 57 & 162 & 0.015 \\
\hline All thick top & 57 & 84 & 0.015 \\
\hline All thick btm & 57 & 78 & 0.015 \\
\hline All thick, head/skirt & 57 & 162 & 0.015 \\
\hline
\end{tabular}


Table 13. Projections by Age and Functional Group of the 2010 Risk of Failing The 62.5 Mil Thickness Spec, By Descending Projection Estimate

\begin{tabular}{|c|c|c|c|}
\hline Functional Group & Age & $\mathbf{N}$ & $\begin{array}{c}\text { Est. } \\
\text { Percent } \\
\text { Below } \\
\text { Spec }\end{array}$ \\
\hline All thick top & 56 & 296 & 0.015 \\
\hline All thick btm & 56 & 310 & 0.015 \\
\hline All thick, head/skirt & 56 & 606 & 0.015 \\
\hline All thick top & 56 & 296 & 0.015 \\
\hline All thick btm & 56 & 310 & 0.015 \\
\hline All thick, head/skirt & 56 & 606 & 0.015 \\
\hline All thick top & 49 & 22 & 0.015 \\
\hline All thick btm & 49 & 7 & 0.015 \\
\hline All thick, head/skirt & 49 & 29 & 0.015 \\
\hline All thick top & 49 & 22 & 0.015 \\
\hline All thick btm & 49 & 7 & 0.015 \\
\hline All thick, head/skirt & 49 & 29 & 0.015 \\
\hline All thick top & 48 & 29 & 0.015 \\
\hline All thick btm & 48 & 29 & 0.015 \\
\hline All thick, head/skirt & 48 & 58 & 0.015 \\
\hline All thick top & 48 & 29 & 0.015 \\
\hline All thick btm & 48 & 29 & 0.015 \\
\hline All thick, head/skirt & 48 & 58 & 0.015 \\
\hline All thick top & 31 & 48 & 0.015 \\
\hline All thick btm & 31 & 69 & 0.015 \\
\hline All thick, head/skirt & 31 & 117 & 0.015 \\
\hline All thick top & 31 & 48 & 0.015 \\
\hline All thick btm & 31 & 69 & 0.015 \\
\hline All thick, head/skirt & 31 & 117 & 0.015 \\
\hline All thick top & 21 & 42 & 0.015 \\
\hline All thick, head/skirt & 21 & 42 & 0.015 \\
\hline All thick top & 21 & 42 & 0.015 \\
\hline All thick, head/skirt & 21 & 42 & 0.015 \\
\hline All thick top & 17 & 2 & 0.015 \\
\hline All thick btm & 17 & 3 & 0.015 \\
\hline All thick, head/skirt & 17 & 5 & 0.015 \\
\hline All thick top & 17 & 2 & 0.015 \\
\hline All thick btm & 17 & 3 & 0.015 \\
\hline
\end{tabular}

\begin{tabular}{|c|c|c|c|}
\hline Functional Group & Age & $\mathbf{N}$ & $\begin{array}{c}\text { Est. } \\
\text { Percent } \\
\text { Below } \\
\text { Spec }\end{array}$ \\
\hline All thick, head/skirt & 17 & 5 & 0.015 \\
\hline PORTS thin top & 14 & 351 & 0.015 \\
\hline PORTS thin bottom & 14 & 372 & 0.015 \\
\hline PORTS thin top & 14 & 351 & 0.015 \\
\hline PORTS thin bottom & 14 & 372 & 0.015 \\
\hline PGDP thn btm exc fmr G & 13 & 447 & 0.015 \\
\hline PGDP thin top & 13 & 485 & 0.015 \\
\hline All thin btm, head/skirt & 13 & 1 & 0.015 \\
\hline PGDP thn btm exc fmr G & 13 & 447 & 0.015 \\
\hline PGDP thin top & 13 & 485 & 0.015 \\
\hline All thin btm, head/skirt & 13 & 1 & 0.015 \\
\hline PGDP thn btm exc fmr G & 11 & 525 & 0.015 \\
\hline PGDP thin top & 11 & 708 & 0.015 \\
\hline PGDP thn btm exc fmr G & 11 & 525 & 0.015 \\
\hline PGDP thin top & 11 & 708 & 0.015 \\
\hline PGDP thn btm exc fmr G & 9 & 148 & 0.015 \\
\hline PGDP thin top & 9 & 165 & 0.015 \\
\hline PGDP thn btm exc fmr G & 9 & 148 & 0.015 \\
\hline PGDP thin top & 9 & 165 & 0.015 \\
\hline
\end{tabular}




\section{MODEL CHECKS AND VALIDATION}

The analysis and projection estimates in the previous two sections depend on the underlying regression model. In this section, several checks are performed of the model's formulation. In Section 6.1, FY06 observed UT results are compared to results projected for FY06 using the same regression model but with UT data from prior to FY06 only. Concordance of the observed and predicted FY06 results supports use of the model. In Section 6.2, original thickness estimates based on the fitted model are compared to original thickness estimates computed from UT maximum thickness measurements and nominal thicknesses. Agreement of the new model-based and the maximum-thickness-based original thickness estimates supports the use of the nominal thicknesses in the direct model and the corresponding coefficient estimates.

The choice of functional groups is considered in Section 6.3. As noted in Section 1, various functional groupings could be used for modeling minimum thickness, any of which can lead to valid conclusions about minimum thicknesses, as long as sampling from them is (approximately) random. Of course, some functional groupings are better than others. For statistical purposes, groups should be large enough to support good estimates of the corresponding log-age coefficients, but at the same time groupings should be fine enough to resolve important differences between the groups. Group comparisons and statistical significance levels of differences between groups provides a way to assess this. Group differences that are not significant suggest that the functional grouping may be too fine to resolve with the data available. On the other hand, group differences that are highly significant suggest that groups are needed and possibly that an even finer partition should be used. In Section 6.3 such comparisons demonstrate that the current functional grouping is a good choice.

\subsection{FY06 Projected vs Observed}

Table 14 shows counts of cylinders whose actual FY06 UT measurements were below the 62.5 mil thickness specifications, and projections of those counts based on a direct model fit to pre-FY06 data. Table 14 was computed with outliers included. An analogous table computed using the same outlier exclusion algorithm employed in fitting the main model ${ }^{13}$ was used in fitting the validation model, but the numbers of cylinders projected to fail the various specs were in this case the same as in Table 14. The projected and actual counts in Table 14 suggest that the direct model fit in Section 4 is slightly conservative, but only slightly. Keeping in mind that at most general agreement, not exact agreement, should be expected between the actual and projected counts in the table, Table 14 thus supports the analysis in Section 4 and the projections in Section 5.

\subsection{Original Thickness Estimates}

In previous editions of this report, original thickness estimates computed from UT maximum thickness measurements were used as predictors in the direct model. In addition to being somewhat arbitrarily defined, the original thickness estimates were (1) subject to estimation error and (2) not statistically independent of minimum UT measurements made on the same cylinders. However, conditions (1) and (2) are required for valid regressions. Thus the use of nominal thicknesses rather than original thickness estimates as predictors in the models represents a potential improvement.

\footnotetext{
${ }^{13}$ That is, cylinders with residuals less than -18 mils were dropped in computing the table. As in the main analysis, nine cylinders were excluded from the validation analysis. Cylinder 11431000 (not excluded from the main analysis) was excluded from the validation analysis, and cylinder 00105200 (excluded from the main analysis) was not excluded from the validation analysis. Otherwise the same cylinders were excluded from the main and validation analyses.
} 
Table 14. Projections for FY06 Based Only on UT Measurements Made Before FY06, Outliers Excluded*

\begin{tabular}{|c|c|c|c|c|}
\hline Cylinder Population & $\begin{array}{c}\text { Number } \\
\text { Sampled } \\
\text { in } 2006\end{array}$ & $\begin{array}{c}\text { Spec } \\
(\text { mils })\end{array}$ & $\begin{array}{c}\text { Projected } \\
\text { Number } \\
\text { Below } \\
\text { Spec } \\
\text { in } 2006\end{array}$ & \begin{tabular}{|c} 
Actual \\
Number \\
Below \\
Spec \\
in 2006
\end{tabular} \\
\hline \multirow[t]{3}{*}{ ETTP thin $\mathrm{K}$ btm } & 9 & 250 & 0 & 0 \\
\hline & & 62.5 & 0 & 0 \\
\hline & & 0 & 0 & 0 \\
\hline \multirow[t]{3}{*}{ ETTP thin except $\mathrm{K}$ btm } & 30 & 250 & 1 & 0 \\
\hline & & 62.5 & 0 & 0 \\
\hline & & 0 & 0 & 0 \\
\hline \multirow[t]{3}{*}{ PGDP thin btm former $\mathrm{G}$} & 58 & 250 & 2 & 0 \\
\hline & & 62.5 & 0 & 0 \\
\hline & & 0 & 0 & 0 \\
\hline \multirow[t]{3}{*}{ PGDP thin btm except former G } & 23 & 250 & 1 & 0 \\
\hline & & 62.5 & 0 & 0 \\
\hline & & 0 & 0 & 0 \\
\hline \multirow[t]{3}{*}{ PGDP thin top } & 19 & 250 & 0 & 0 \\
\hline & & 62.5 & 0 & 0 \\
\hline & & 0 & 0 & 0 \\
\hline \multirow[t]{3}{*}{ All thick top } & 19 & 500 & 0 & 0 \\
\hline & & 62.5 & 0 & 0 \\
\hline & & 0 & 0 & 0 \\
\hline \multirow{3}{*}{ All thick btm } & 17 & 500 & 0 & 0 \\
\hline & & 62.5 & 0 & 0 \\
\hline & & 0 & 0 & 0 \\
\hline \multirow[t]{3}{*}{ All thin top, head/skirt } & 13 & 250 & 0 & 0 \\
\hline & & 62.5 & 0 & 0 \\
\hline & & 0 & 0 & 0 \\
\hline \multirow{3}{*}{ All thin btm, head/skirt } & 16 & 250 & 0 & 0 \\
\hline & & 62.5 & 0 & 0 \\
\hline & & 0 & 0 & 0 \\
\hline
\end{tabular}




\section{Table 14. Projections for FY06 Based Only on UT Measurements Made Before FY06, Outliers Excluded*}

\begin{tabular}{|l|r|r|r|r|}
\hline & $\begin{array}{c}\text { Number } \\
\text { Sampled } \\
\text { in 2006 }\end{array}$ & $\begin{array}{c}\text { Spec } \\
\text { (mils) }\end{array}$ & $\begin{array}{c}\text { Projected } \\
\text { Number } \\
\text { Below } \\
\text { Spec } \\
\text { in 2006 }\end{array}$ & $\begin{array}{c}\text { Actual } \\
\text { Number } \\
\text { Below } \\
\text { Spec } \\
\text { in 2006 }\end{array}$ \\
\hline \multicolumn{5}{|l|}{} \\
\hline PORTS thin top & 61 & 250 & 0 & 0 \\
\hline & & 62.5 & 0 & 0 \\
\hline & & 0 & 0 & 0 \\
\hline & & & & \\
\hline & 62 & 250 & 0 & 0 \\
\hline & & 62.5 & 0 & 0 \\
\hline & & 0 & 0 & 0 \\
\hline
\end{tabular}

*No 30A cylinders were used for the validation because none were measured in FY06.

However, fitting the direct model produces estimates of average cylinder minimal thicknesses at age one year. For each functional group, these are computed simply by multiplying the nominal thicknesses for the group by the main-body or skirted coefficient estimate, depending on whether the group is defined for main-body or head/skirt interface measurements. As a model validation check, these model-based original thickness estimates can be compared with the earlier original thickness estimates computed from UT measurement maximums.

For each of the fourteen cylinder functional groups, Table 15 shows $97.5 \%$ one-side lower and upper confidence limits (which together compose a 95\% confidence interval) for the mean maximum thickness. The confidence limits are computed from wall maximum thickness measurements for each cylinder group. The table also contains nominal lower and upper design limits, from the design sheets. The upper and lower limits, which are discussed in previous editions of this report, represent manufacturing variability about the nominal thicknesses $(312.5,625$, and 500 mils for thin-wall, thick-wall, and 30A cylinders respectively). Table 15 suggests that for estimating initial thicknesses, the design-sheet specifications for some of the functional groups might be refined.

The original thickness estimates (column E) in Table 15 are computed from the UT maximums and nominal thicknesses as follows. Except for the skirted groups and the 30A cylinders, the confidence limit ranges in the table are not far from the nominal ranges and in most cases overlap them. Because of metal forming in manufacturing, the nominal wall thickness is probably not a good measure of the original thickness of walls at the head/skirt interface. For the $30 \mathrm{~A}$ cylinders, the maximum thickness measurements are so far from the nominal that the nominal values are not reasonable. So, for the skirted and the 30A groups, the $97.5 \%$ LCL was taken as the original thickness estimate. The $97.5 \%$ LCL is the point in the $95 \%$ confidence range closest to the nominal thickness range. 


\section{Table 15. Original Thickness Estimates and Corresponding Direct Model Estimates}

(All Values in Mils)

\begin{tabular}{|c|c|c|c|c|c|c|c|}
\hline Functional Group & $\begin{array}{c}97.5 \% \\
\text { LCL } \\
\text { Mean } \\
\text { UT } \\
\text { Max } \\
\text { (A) }\end{array}$ & $\begin{array}{c}97.5 \% \\
\text { UCL } \\
\text { Mean } \\
\text { UT } \\
\text { Max } \\
\text { (B) }\end{array}$ & $\begin{array}{c}\text { Nominal } \\
\text { Lower } \\
\text { (C) }\end{array}$ & $\begin{array}{c}\text { Nominal } \\
\text { Upper } \\
\text { (D) }\end{array}$ & $\begin{array}{l}\text { Orig. } \\
\text { Thick. } \\
\text { Est. } \\
\text { From } \\
\text { (A-D) } \\
\text { (E) }\end{array}$ & $\begin{array}{c}\text { Direct } \\
\text { Model } \\
\text { Estimate } \\
\text { (F) }\end{array}$ & $\begin{array}{c}\text { Diff. } \\
(\mathbf{F})-(\mathbf{E})\end{array}$ \\
\hline ETTP thin K btm & 332.2 & 335.8 & 302.5 & 345.5 & 334.0 & 324.8 & -9.2 \\
\hline ETTP thin except $\mathrm{K}$ btm & 328.1 & 331.0 & 302.5 & 345.5 & 329.6 & 324.8 & -4.8 \\
\hline PGDP thin btm former $G$ & 325.3 & 328.3 & 302.5 & 345.5 & 326.8 & 324.8 & -2.0 \\
\hline PGDP thin btm except former $G$ & 328.4 & 331.2 & 302.5 & 345.5 & 329.8 & 324.8 & -5.0 \\
\hline PGDP thin top & 326.5 & 329.6 & 302.5 & 345.5 & 328.1 & 324.8 & -3.3 \\
\hline All thick top & 665.8 & 678.7 & 615.0 & 655.0 & 655.0 & 649.6 & -5.4 \\
\hline All thick btm & 664.7 & 676.8 & 615.0 & 655.0 & 655.0 & 649.6 & -5.4 \\
\hline All thin top, head/skirt & 361.1 & 365.7 & 302.5 & 345.5 & 361.1 & 392.9 & 31.8 \\
\hline All thin btm, head/skirt & 357.6 & 361.6 & 302.5 & 345.5 & 357.6 & 392.9 & 35.4 \\
\hline All thick, head/skirt & 777.2 & 785.1 & 615.0 & 655.0 & 777.2 & 785.9 & 8.7 \\
\hline PORTS thin top & 356.5 & 359.6 & 302.5 & 345.5 & 345.5 & 324.8 & -20.7 \\
\hline PORTS thin btm & 356.8 & 360.0 & 302.5 & 345.5 & 345.5 & 324.8 & -20.7 \\
\hline All 30A top & 512.8 & 522.0 & 343.8 & 468.8 & 512.8 & 519.7 & 6.8 \\
\hline All 30A btm & 515.4 & 527.9 & 343.8 & 468.8 & 515.4 & 519.7 & 4.3 \\
\hline
\end{tabular}

For the other cylinder groups, the confidence intervals and nominal ranges are closer. For these other groups, when the confidence and nominal ranges overlap, the original thickness estimate was taken as the midpoint of the range of overlap. When the confidence and nominal ranges do not overlap, the nominal range endpoint nearest to the confidence interval was taken as the original thickness estimate. Thus, except for skirted and 30A cylinders, the original thickness estimate is defined as follows:

If Nominal Upper $<$ LCL, then Original Estimate $=$ Nominal Upper;

Otherwise, if UCL $<$ Nominal Lower, then Original Estimate = Nominal Lower;

Otherwise, Original Estimate $=[\min ($ UCL, Nominal Upper $)+\max ($ LCL, Nominal Lower $)] / 2$.

Because a nominal range endpoint is used when the confidence and nominal ranges do not overlap, this algorithm for estimating the initial thickness favors the nominal specification. The rationale for preferring the nominal specification is that if the original thickness of a cylinder was not uniform, then the maximum thickness (at any time) is likely to be a poor estimate of the original minimum thickness of the cylinder. For the skirted groups or the $30 \mathrm{~A}$ cylinders, the discrepancy between the confidence limits and the nominal specification is so great that the nominal specification does not seem reasonable, and the confidence limit closest to the nominal range is used instead. 
Table 15 also shows the original thickness estimates computed from the direct-model regression of minimum thicknesses on nominal thicknesses and age, and the difference between the maximum thickness and regression model original thickness estimates. For most of the functional groups the two original thickness estimates are very consistent. The biggest differences occur for the thin-wall head/skirt groups, but as discussed above, the head/skirt groups are probably the most difficult to estimate original thicknesses for anyway. The consistency between the model-based and maximum thickness-based original thickness estimates supports the nominal thickness terms and estimates in the direct model.

\subsection{Statistical Assessment of the Choice of Functional Groups}

The functional grouping system used for the analysis in this report was developed over the years on the basis of engineering judgment about cylinder storage location histories and cylinder management operations and statistical considerations about data availability. In this section the functional groups are compared to assess, on a statistical basis, whether the functional grouping system is a good one. A different assessment might be made on the basis of engineering judgment, particularly with the recent cylinder transfers to and reorganization at Portsmouth.

All of the comparisons are based on log-age coefficient $\left(\beta_{\mathrm{G}}\right)$ estimates because the functional groups are used in the model to differentiate those coefficients. Note however, that nominal thickness is also a model term. After accounting for nominal thickness, the $\beta_{\mathrm{G}}$ coefficients for, say, thin-wall and thick-wall cylinders can in theory be close. In this sense UT measurement results for all functional groups are combined in the direct model analysis.

Figure 45 shows $95 \%$ confidence intervals for the 12 functional groups (where the three head/skirt interface groups have been combined). Table 16 shows comparison test results for various comparisons among the functional groups. All of the comparisons are based on t-tests. The table shows the significance level of the test and the t-statistic. With 3,211 (3,234 observations less 9 outliers less 14 estimated parameters) error degrees of freedom, under a no-difference hypothesis, a t-statistic of absolute value greater than 1.96 occurs less than one time in twenty $(\mathrm{p}<.05)$ and is generally considered significant. A t-statistic of absolute value greater than 4.90 occurs less than one time in one million $(\mathrm{p}<$ 0.000001 ) and might be thus be considered "highly" significant. ${ }^{14}$

Four "supergroups" of cylinders are suggested in Figure 45: the 30As (top and bottom rows together), the cylinders with head/skirt interface measurements (top, bottom, thick and thin), Portsmouth thin-wall cylinders (top and bottom rows), and the other cylinders (ETTP and PGDP thin-wall and all thick-wall cylinders, main-body data). Except for the "30As vs Skirted" comparison, the comparisons in Table 16 show that the supergroups are all different. That is, the "30As vs All others," "Skirted vs All others," "Thin: ETTP vs Ports," and "Thin: PGDP vs Ports" comparison are all highly significant. The "30As vs Skirted" comparison is actually not significant $(\mathrm{p}=.08)$.

\footnotetext{
${ }^{14}$ With 3,211 degrees of freedom, a t-statistic of absolute value greater than 3.90 occurs less than 1 time in ten thousand ( $\mathrm{p}<0.0001)$ and might also be considered "highly"significant.
} 


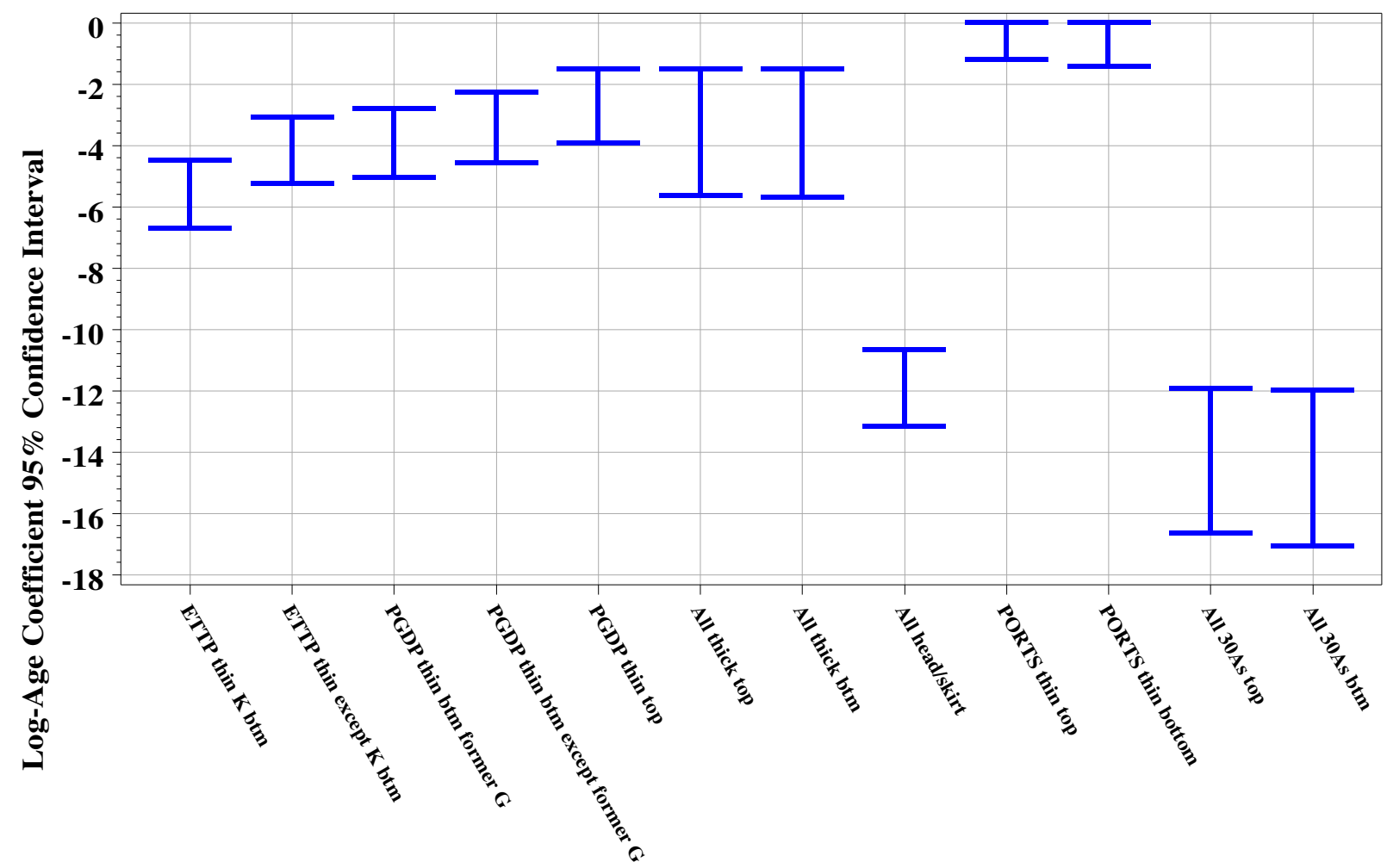

Cylinder Functional Group

Figure 45. 95\% confidence intervals for the $\beta_{\mathrm{G}}$ parameter estimates for the 12 functional groups. (The three head/skirt interface groups are combined.)

Some of the functional group comparisons within the supergroups are also significant, though not "highly" significant: "ETTP (thin): Top vs Btm" ( $\mathrm{p}=.0009)$, "PGDP (thin): Top vs Btm." (p=.007), "PORTS (all): Top vs Btm" ( $\mathrm{p}=.03$ ). One of functional group comparisons within the supergroups, "Thin: ETTP vs PGDP"comparison, is also "highly" significant. And some of the functional group comparisons within the supergroups are not significant at all: "Thick: Top vs Btm" ( $\mathrm{p}=.97)$, "Thin vs Thick”(p=.26), "PGDP G (thin): Top vs Btm” ( $\mathrm{p}=.17)$, “30As: Top vs Btm” (p=.89).

From a statistical perspective, the functional grouping system seems reasonable. Differences between several supergroups of cylinders are highly significant, and within the supergroups there are also many significant group differences. However, some group differences are not significant, which suggests that at least those groups should not be split further. Because the direct model combines to some extent results for groups anyway, there would not be much advantage, statistically, to combining them either. Of course, revisions of the grouping system might still be motivated by engineering and operational considerations. 
Table16. Functional Group and "Supergroup” Comparison Tests

\begin{tabular}{|l|r|r|r|r|}
\hline \multicolumn{1}{|c|}{ Comparison } & $\begin{array}{c}\text { Coefficient } \\
\left(\boldsymbol{\beta}_{\mathbf{G}}\right) \\
\text { Estimate }\end{array}$ & \multicolumn{1}{c|}{$\begin{array}{c}\text { Standard } \\
\text { Error }\end{array}$} & T-Value & $\begin{array}{c}\text { Significance } \\
\text { Level }\end{array}$ \\
\hline Thin: ETTP vs PGDP & 9.17 & 1.63 & 5.63 & $<.000001$ \\
\hline Thin: ETTP vs Ports & 9.55 & 0.59 & 16.30 & $<.000001$ \\
\hline Thin: PGDP vs Ports & 19.48 & 1.43 & 13.61 & $<.000001$ \\
\hline Thin vs Thick & -10.12 & 8.94 & -1.13 & 0.2576 \\
\hline 30As vs All others & -133.76 & 10.92 & -12.25 & $<.000001$ \\
\hline Skirted vs All others & -75.08 & 12.09 & -6.21 & $<.000001$ \\
\hline 30As vs Skirted & -4.98 & 2.89 & -1.73 & 0.0846 \\
\hline 30As: Top vs Btm & -0.24 & 1.68 & -0.14 & 0.8880 \\
\hline ETTP (thin): Top vs Btm & 1.41 & 0.42 & 3.33 & 0.0009 \\
\hline PGDP G (thin): Top vs Btm & 0.51 & 0.37 & 1.36 & 0.1733 \\
\hline PGDP (thin): Top vs Btm & 1.94 & 0.71 & 2.73 & 0.0065 \\
\hline PORTS (all): Top vs Btm & 1.74 & 0.79 & 2.21 & 0.0273 \\
\hline Thick: Top vs Btm & -0.03 & 0.84 & -0.04 & 0.9673 \\
\hline
\end{tabular}




\section{CONCLUSIONS, LIMITATIONS, RECOMMENDATIONS}

Conclusions. In addition to the incorporation of new FY04, FY05, and FY06 UT measurement data, this report differs from previous editions in that automatic P-Scan data is no longer used in the data analysis. This is consistent with recommendations in the 2004 report. Also new for this report is that the analysis almost entirely based on the direct modeling approach. The indirect model is fit as in the past, but as in the past, so many of its parameter estimates are inconsistent with corrosion theory (and even routine observation) that the model is not pursued further. This is also consistent with the recommendations of the 2004 report.

Also new for this report is that age is now modeled as "unpainted age," that is time spent in an unpainted state, which is defined as not having been painted for ten or more years. In previous reports painted cylinders were simply excluded from the analysis. However in making future projections it is better to represent painted cylinders as "younger" rather than to simply exclude them.

Also new for this report is that nominal thicknesses rather than original thickness estimates are used in the direct regression model. This is preferable because regression independent variables are assumed to be fixed (not random) and independent of the regression dependent variable (minimum thickness). This condition holds for the nominal thicknesses but not original thickness estimates. However, as a validation check, the original thickness estimates as previously computed are now compared to corresponding estimates based on fitted model, and the two sets of estimates do tend to agree.

As in past editions of the report, statistical outliers are identified in the analysis, and the model-based projections differ depending on whether outliers are included in or dropped from the analysis. Nine outliers are identified. As in the past, projections with the outliers included in the analysis seem too conservative. Furthermore, remeasurements in FY03 of several outlier thin-wall cylinders identified in the 2003 corrosion report suggested that did not confirm their original measurements. This suggests that the nine outlier cylinders identified in this report should be remeasured (or else explained on a case by case basis). Projections in this report are computed both with and again without the nine outliers.

According to the direct-model rate projections (Tables 10 and 11), the cylinders most likely to fail either the breach or 62.5 mil criteria are the $30 \mathrm{~A}$ cylinders, both top and bottom rows. Because of both lower (i.e., more negative) log-age coefficient estimates for the 30As and greater variability of the 30A cylinder minimum UT measurements, the risk estimates for the 30A functional groups are higher than for the thin-wall cylinders. The functional groups with the next highest risk estimates are the thin-wall cylinders from ETTP K-yard bottom rows followed by the other ETTP thin-wall cylinders. These conclusions hold for all years listed in the table.

Before excluding the nine outliers, the direct model predicts a few failures of the breach and 62.5 mil thickness criteria. After excluding the outliers, the direct model projections are at the model's limit of resolution, which is essentially the smallest number of thickness failures the direct model can predict. The direct-model projections are consistent with the hypothesis of zero breaches for all of the years 2005-2025 (in Table 11) with the exception of 2025 for the 30A cylinders (either top or bottom rows), for which, according to the model, one breach (on average) is expected. For the 62.5 mil criteria, the projections are consistent with no failures for all years and all groups except the 30As. Note also that because of the resolution limit, however, failures are not ruled out.

Relative to the variability of the UT measurements, cylinder corrosion and age are only weakly related to cylinder age. That cylinder-to-cylinder variability is substantial, even for cylinders of the same age and grouping, is obvious from Figures 31-44. Age nevertheless does have an important and statistically significant effect on the corrosion process, and the oldest cylinders are of greater concern. Tables 10 and 11 of functional-group-wide numbers of cylinders projected to fall below the various thickness criteria and the corresponding percentages in Table 12 can be misleading if attention is not also paid to the oldest 
and most vulnerable cylinders in each functional group. Thus the age and functional-group-specific risks in Table 13 should also be considered in cylinder management.

Limitations. The following limitations should be kept in mind when considering this report: (1) UT minimum thicknesses are only estimates of actual minimum thicknesses because the thinnest points on each cylinder are not necessarily found in the measurement process. (2) Storage (e.g., ground contact) conditions have improved over the years for many cylinders. (3) Implicit in the modeling approach is an assumption of age invariance - that newer or older cylinders alike tend to have similar corrosion when they are the same age. This assumption could fail because of generally improved cylinder storage conditions and could thus lead to overestimation of the effect of age on corrosion. (4) Environmental changes such as increased acid rain are not accounted for in the model. (5) Cylinder sampling was not always random. Inspection is one reason for making the cylinder UT measurements, and inspection sampling tends to focus on cylinders with poorer conditions. This would lead to a more pessimistic assessment of overall conditions of cylinders than random sampling for the express purpose of characterization. (6) Literature about the atmospheric corrosion of steel might not apply well to cylinder corrosion modeling, for example because of the thermal inertia of the cylinders. (7) Age and population-specific projections should be considered in addition to projections by populations for all ages.

Corrosion projections made in this report are based on analyses that account for cylinder functional groups, ages, and initial thicknesses. However, a myriad of other variables are not accounted for. Examples include how many use cycles the cylinders went through, how many dents and scrapes they suffered, and the nature of surface coatings, now perhaps long gone. There are variations in how the UT measurements were made. Functional group membership is often only known approximately and in a some cases (e.g., 30As) even cylinder ages are approximations. Because of these extraneous sources of variation and other approximations, corrosion physics is blurred in the statistical noise. Thickness measurements vary widely about their model-based predictions. In this context, because there is not a definitive corrosion model based on chemistry and physics, it does not make sense to try to resolve fine differences between either the deterministic or stochastic components of plausible candidate models. The choice is not going to be clear. It is better to focus on general model behavior and on data quality and quantity, so that laws-of-large numbers will allow a general corrosion signal to be resolved from the statistical noise.

The main recommendations of this report are as follows:

1. The projections in this report are based on the assumption that historical trends will continue. However, cylinder maintenance is not static. Storage yards have been improved. Cylinders have been moved and restacked. Cylinders have been painted. Although the statistical assessment in this report does not point to a need for redefining the cylinder functional grouping, an engineering assessment might. Particularly in view of the imminent conversion processing, the functional grouping used to classify cylinders should be reconsidered, in addition, from an operational perspective.

2. Nine cylinders with UT measurements identified in this report as direct-model outliers substantially influence the corrosion projections. Those cylinders should be remeasured (or explained) to confirm or correct their thickness measurements.

3. With the nine outlier cylinders excluded from the analysis, projections are consistent with the hypothesis of zero breaches for all of the years 2005-2025 with the exception of 2025 for the $30 \mathrm{~A}$ cylinders (either top or bottom rows), for which one breach (on average) is expected. For the 62.5 mil criteria, the projections are consistent with no failures for all years and all groups except the 30As. When the nine outliers are included in the analysis, the model predicts a few failures of the breach and 62.5 mil thickness criteria. 
4. Cylinder maintenance, sampling, and conversion/disposition schedules should be prioritized in terms of the risk estimates in this report. Both cylinder age and functional group differences affect projections about risk or, equivalently, years of service life. Oldest cylinders from the riskiest functional groups should be processed first.

5. Similarly, because of the dual objectives of inspection and characterization in cylinder sampling, sampling for future UT measurements should be weighted toward riskier cylinders. In the past, sampling has tended to focus more heavily on riskier functional groups, though not necessarily on older cylinders within the riskier groups. Particularly now with a clearer cylinder disposition schedule, the service lives of most cylinders need only extend for a few more years. Sampling plans can now focus on characterizing percentages of cylinders that are acceptable, rather than on determining the relationship between minimum thickness and functional group and age. Through the use of sampling weights, plans can be designed to preferentially sample riskier cylinders while still admitting (through the weights) unbiased estimates with valid confidence intervals. The analysis in this report can be used as a basis for sampling weights. 


\section{REFERENCES}

ANSI (1995). American National Standards for Nuclear Materials-Uranium Hexafluoride-Packaging for Transport, ANSI N14.1, American National Standards Institute, New York, 1995 edition.

Barber, E. J., Butler, T. R., DeVan, J. H., Googin, J. M. and Taylor, M. S., Dyer, R. H., and Russell, J. R. (1991). Investigation of Breached Depleted UF ${ }_{6}$ Cylinders. ORNL/TM-11988, Oak Ridge, Tennessee, September 1991.

Barber, E. J., Butler, T. R., DeVan, J. H., Googin, J. M. and Taylor, M. S. (1994). Investigation of Breached Depleted $U F_{6}$ Cylinders at the K-25 Site. ORNL/TM-12840, Oak Ridge, Tennessee, October 1994.

Bechtel Jacobs (1998). "Functional System Design Document DOE UF6 Cylinder Information Database (CID)," https://www-internal1.bechteljacobs.org/scripts/CID/documentation/system_doc.cfm.

Blue, S. C. (1994). Facsimile from S.C. Blue to M. Taylor, October 27, 1994.

Blue, S. C. (1995). Memorandum from S.C. Blue to A.K. Balding, September 25, 1995.

David, H. A. (1981) Order Statistics, Second Edition, John Wiley \& Sons, New York.

Draper, N., and Smith, H. (1981) Applied Regression Analysis, 2nd ed., New York, John Wiley \& Sons.

DOE (2003) Draft Environmental Impact Statement for Construction and Operation of a Depleted Uranium Hexafluoride Conversion Facility at Portsmouth, Ohio, Site. DOE/EIS-0360 (December 2003), http://tis.eh.doe.gov/nepa/docs/deis/eis0360/.

DNFSB (1995) "Integrity of Uranium Hexafluoride Cylinders," Defense Nuclear Facilities Safety Board, DNFSB/TECH-4, May 5, 1995 (http://www.dnfsb.gov/techrpts/tech-4.html).

Felieu, S., M. Morcillo and S. Felieu, Jr. (1993a). The Prediction of Atmospheric Corrosion from Meteorological and Pollution Parameters--Ii. Annual Corrosion in Corrosion Science, Vol. 34, No.3, pp.403-414.

Felieu, S., M. Morcillo and S. Felieu, Jr. (1993b). The Prediction of Atmospheric Corrosion from Meteorological and Pollution Parameters--II. Long-term Forecasts in Corrosion Science, Vol. 34, No.3, pp.415-422.

Fowler, K. A., Elfbaum, G. M., Smith, K. A, Nelligan, T. J. (2003) “Theory and Application of Precision Ultrasonic Thickness Gaging Thickness Gaging," GE Panametrics NDT Division, http://www.checkline.com/wall_thickness_gauges/ultrasonic_theory.htm.

Horton, J. B. (1964). The Composition, Structure and Growth of the Atmospheric Rust on Various Steels. Thesis Lehigh University 1964, Bethlehem, PA.

Legault, R. A. and G. Preban (1975). Corrosion-NACE, Vol. 31, p.117.

LMES (1997a). UF 6 Cylinder Project System Requirements Document (SRD). K/TSO-001, Rev.3. May 1997. Lockheed Martin Energy Systems, Inc. and U.S. Department of Energy.

LMES (1997b). UF ${ }_{6}$ Cylinder Project System Engineering Management Plan (SEMP). K/TSO-017. July 1997. Lockheed Martin Energy Systems, Inc. and U.S. Department of Energy. 
Lykins, M. L. and S. J. Pawel (1997). Evaluation of Wall Thickness in the Cylinder Head/Skirt Interface on Skirted Cylinders. Memorandum from M.L Lykins and S.J. Pawel to M.S. Taylor, ORNL/CST-SP-102297-1, October 22, 1997.

Lyon, B. F. (1995). Prediction of External Corrosion for UF ${ }_{6}$ Cylinders: Results of an Empirical Method, ORNL/TM-13012. June 1995. Oak Ridge National Laboratory, Oak Ridge, Tennessee.

Lyon, B. F. (1996). Prediction of External Corrosion for Steel Cylinders at the Paducah Gaseous Diffusion Plant: Application of an Empirical Method, ORNL/TM-13192. February 1996. Oak Ridge National Laboratory, Oak Ridge, Tennessee.

Lyon, B. F. and M. L. Lykins (1996). Ultrasonic Thickness Sampling Plan for the Depleted Uranium Hexafluoride Program, ORNL/TM-13280. July 1996. Oak Ridge National Laboratory, Oak Ridge, Tennessee.

Lyon, B. F. (1997). Prediction of External Corrosion for Steel Cylinders, ORNL/TM-13359. February 1997. Oak Ridge National Laboratory, Oak Ridge, Tennessee.

Lyon, B. F. (1998). Prediction of External Corrosion for Steel Cylinders - 1998 Report, ORNL/TM13568. February 1998. Oak Ridge National Laboratory, Oak Ridge, Tennessee.

Lyon, B. F. (2000). Prediction of External Corrosion for Steel Cylinders - 2000 Report, ORNL/TM2000/96. June 2000. Oak Ridge National Laboratory, Oak Ridge, Tennessee.

Mughabghab, S. F. and T. M. Sullivan (1989). Evaluation of the Pitting Corrosion of Carbon Steels and Other Ferrous Metals in Soil Systems. Waste Management, Vol. 9, pp. 239-251.

Philpot, H. E. (1995). Memorandum from Halen Philpot to Valerie Newman, February 17, 1995.

Pourbaix, M. (1982). The Linear Bilogarithmic Law for Atmospheric Corrosion, in Atmospheric Corrosion (W. H. Ailor, ed.). John Wiley and Sons, New York.

Romanoff, M. (1957). Underground Corrosion. NBS Circular 579, National Bureau of Standards, Washington, D.C.

Rosen, R. S. and R. E. Glaser (1996). Letter to B.F. Lyon from R.S. Rosen and R.E. Glaser, April, 10, 1996.

Schmidt, M. A., J. K. Harper, and J. A. Broders (1996). A Comparison of Wall Thickness Measurements on UF ${ }_{6}$ Cylinders using Scanning vs Hand-held Ultrasonic Probes. K/TSO-019, November 1996. Oak Ridge National Laboratory, Oak Ridge, Tennessee.

Schmoyer, R. L. (1992), "Asymptotically Valid Prediction Intervals for Linear Models," Technometrics, 34, 399-408.

Schmoyer, R. L., and Lyon, B. F. (2001). Prediction of External Corrosion for Steel Cylinders - 2001 Report, ORNL/TM-2001/164. September 2001. Oak Ridge National Laboratory, Oak Ridge, Tennessee.

Schmoyer, R. L., and Lyon, B. F. (2002). Prediction of External Corrosion for Steel Cylinders - 2002 Report, ORNL/TM-2002/143. July 2002. Oak Ridge National Laboratory, Oak Ridge, Tennessee. 
Schmoyer, R. L., and Lyon, B. F. (2003). Prediction of External Corrosion for Steel Cylinders - 2003 Report, ORNL/TM-2002/218. August 2003. Oak Ridge National Laboratory, Oak Ridge, Tennessee.

Schmoyer, R. L. (2004). Prediction of External Corrosion for Steel Cylinders - 2004 Report, ORNL/TM-2002/33. April 2004. Oak Ridge National Laboratory, Oak Ridge, Tennessee. 


\section{DISTRIBUTION}

1. ORNL Central Research Library

2. ORNL Laboratory Records-OSTI

3. Doug Adkisson (Uranium Disposition Services, LLC)

4. David Jonik (LMK Engineers)

5. Tom Marshall (Uranium Disposition Services, LLC)

6. John McCoy (Uranium Disposition Services, LLC)

7. Phil McGinnis (Oak Ridge National Laboratory)

8. Steve Pawel (Oak Ridge National Laboratory)

9. Dale Roberts (Uranium Disposition Services, LLC)

10. John Sheppard (Department of Energy)

11. John Shine (Department of Energy)

12. Richard Veazey (Uranium Disposition Services, LLC)

13. Jack Zimmerman (Department of Energy) 